NBER WORKING PAPER SERIES

\title{
RACE AND ECONOMIC OPPORTUNITY IN THE UNITED STATES: AN INTERGENERATIONAL PERSPECTIVE
}

\author{
Raj Chetty \\ Nathaniel Hendren \\ Maggie R. Jones \\ Sonya R. Porter \\ Working Paper 24441 \\ http://www.nber.org/papers/w24441
NATIONAL BUREAU OF ECONOMIC RESEARCH
1050 Massachusetts Avenue \\ Cambridge, MA 02138 \\ March 2018, Revised December 2019
}

\begin{abstract}
The views expressed are those of the authors and not necessarily those of the U.S. Census Bureau or the National Bureau of Economic Research. The statistical summaries reported in this paper have been cleared by the Census Bureau's Disclosure Review Board release authorization number CBDRB-FY18-195. We thank Rick Banks, Jennifer Eberhardt, David Ellwood, John Friedman, Roland Fryer, David Grusky, Anthony Jack, Lawrence Katz, Adam Looney, Alex Mas, Amy O'Hara, Amanda Pallais, John Powell, Sean Reardon, Jesse Shapiro, Emmanuel Saez, Robert Sampson, Isaac Sorkin, Florencia Torche, William Julius Wilson, numerous seminar participants, and anonymous referees for helpful comments and discussions. We are indebted to Michael Droste, Benjamin Goldman, Jamie Gracie, Alexandre Jenni, Martin Koenen, Sarah Merchant, Emanuel Schertz, James Stratton, Joseph Winkelmann, and our other Opportunity Insights predoctoral fellows for their outstanding contributions to this work. This research was funded by the Bill \& Melinda Gates Foundation, the Robert Wood Johnson Foundation, the Kellogg Foundation, and Harvard University.
\end{abstract}

NBER working papers are circulated for discussion and comment purposes. They have not been peer-reviewed or been subject to the review by the NBER Board of Directors that accompanies official NBER publications.

(C) 2018 by Raj Chetty, Nathaniel Hendren, Maggie R. Jones, and Sonya R. Porter. All rights reserved. Short sections of text, not to exceed two paragraphs, may be quoted without explicit permission provided that full credit, including $\odot$ notice, is given to the source. 
Race and Economic Opportunity in the United States: An Intergenerational Perspective Raj Chetty, Nathaniel Hendren, Maggie R. Jones, and Sonya R. Porter

NBER Working Paper No. 24441

March 2018, Revised December 2019

JEL No. H0,J0

\begin{abstract}
$\underline{\text { ABSTRACT }}$
We study the sources of racial disparities in income using anonymized longitudinal data covering nearly the entire U.S. population from 1989-2015. We document three results. First, black Americans and American Indians have much lower rates of upward mobility and higher rates of downward mobility than whites, leading to persistent disparities across generations. Conditional on parent income, the black-white income gap is driven by differences in wages and employment rates between black and white men; there are no such differences between black and white women. Hispanic Americans have rates of intergenerational mobility more similar to whites than blacks, leading the Hispanic-white income gap to shrink across generations. Second, differences in parental marital status, education, and wealth explain little of the black-white income gap conditional on parent income. Third, the black-white gap persists even among boys who grow up in the same neighborhood. Controlling for parental income, black boys have lower incomes in adulthood than white boys in $99 \%$ of Census tracts. The few areas with small black-white gaps tend to be low-poverty neighborhoods with low levels of racial bias among whites and high rates of father presence among blacks. Black males who move to such neighborhoods earlier in childhood have significantly better outcomes. However, fewer than $5 \%$ of black children grow up in such areas. Our findings suggest that reducing the black-white income gap will require efforts whose impacts cross neighborhood and class lines and increase upward mobility specifically for black men.
\end{abstract}

\author{
Raj Chetty \\ Department of Economics \\ Harvard University \\ Littauer 321 \\ Cambridge, MA 02138 \\ and NBER \\ chetty@fas.harvard.edu \\ Nathaniel Hendren \\ Harvard University \\ Department of Economics \\ Littauer Center Room 235 \\ Cambridge, MA 02138 \\ and NBER \\ nhendren@gmail.com
}

Maggie R. Jones

Bureau of the Census

4600 Silver Hill Rd.

Washington, DC 20233

margaret.r.jones@census.gov

Sonya R. Porter

Bureau of the Census

4600 Silver Hill Rd.

Washington, DC 20233

sonya.rastogi.porter@census.gov 


\section{Introduction}

Differences in economic outcomes by race have persisted for centuries in the United States and continue up to the present day (Myrdal 1944; Duncan 1968; Margo 2016). For example, in 2016, the median household income of black Americans was $\$ 39,500$, compared with $\$ 65,000$ for non-Hispanic white Americans (U.S. Department of Commerce, Bureau of the Census 2017). The sources of these disparities have been heavily studied and debated, with proposed explanations ranging from residential segregation (e.g., Wilson 1987; Massey and Denton 1993) and discrimination (e.g., Pager 2003; Eberhardt, Goff, Purdie and Davies 2004; Bertrand and Mullainathan 2004) to differences in family structure (e.g., McAdoo 2002; Autor et al. 2019). ${ }^{1}$

Most empirical research on racial disparities has tested competing theories using cross-sectional data on a single generation of individuals (Altonji and Blank 1999). ${ }^{2}$ In this paper, we analyze the sources of racial disparities from an intergenerational perspective, focusing on the dynamics of income across generations. ${ }^{3}$ In canonical intergenerational models of inequality (e.g., Becker and Tomes 1979), racial differences in income distributions in the long run are determined by differences by race in children's incomes conditional on parental income, which we term intergenerational gaps. For example, if black and white children have the same income distributions conditional on parental income - i.e., if there is no black-white intergenerational gap - income disparities between the two groups would vanish in the long run regardless of their initial magnitude. ${ }^{4}$ From this perspective, the critical question to understand black-white income differences in the long run is: do black children have lower incomes than white children conditional on parental income, and if so, how can

\footnotetext{
${ }^{1}$ See Online Appendix Table I for a more detailed categorization of alternative explanations and selected references.

${ }^{2}$ There are three primary exceptions to this characterization of the prior literature, each of which addresses the lack of historical data linking parents to children in different ways: (1) studies that focus on intermediate outcomes such as test scores using data from schools, which contain information on parental income and other characteristics (e.g., Jencks and Phillips 1998; Magnuson and Duncan 2006; Fryer and Levitt 2006); (2) studies that use ethnographic methods (e.g., Carter 2005; Lareau 2011); and (3) work using longitudinal survey data (Blau and Duncan 1967; Corcoran, Gordon, Laren and Solon 1992; Hertz 2005, Bhattacharya and Mazumder 2011; Mazumder 2014; Davis and Mazumder 2018). Our study contributes to this literature by (1) directly examining long-term outcomes such as earnings rather than intermediate outcomes; (2) presenting quantitative evidence that complements qualitative case studies; and (3) presenting evidence from population-level data that reveals several results that cannot be detected in survey data, such as neighborhood-level variation.

${ }^{3}$ We focus on five racial and ethnic groups - non-Hispanic whites, non-Hispanic blacks, non-Hispanic Asians, non-Hispanic American Indians and Alaskan Natives, and Hispanics - who together comprise 98.4\% of individuals with non-missing race information for the children we study. As has been noted in prior work, there is considerable heterogeneity in outcomes within these five groups, and our conclusions should not be interpreted as applying uniformly to all subgroups within each of these populations. For simplicity, we use "race" to refer to race and ethnicity; "American Indians" to refer to American Indians and Alaskan Natives; and "whites" to refer to non-Hispanic whites, "blacks" to refer to non-Hispanic blacks, etc.

${ }^{4}$ In richer models in which children's outcomes depend upon other factors beyond their parents' incomes, income disparities may not vanish, but the intergenerational gap remains a key determinant of the dynamic of income disparities. We discuss these issues further in Section II below.
} 
we reduce these intergenerational gaps?

We study this question using longitudinal data that covers virtually the entire American population from 1989-2015. Building on work by Akee, Jones and Porter (2017), we use de-identified data from the 2000 and 2010 decennial Censuses linked to data from federal income tax returns and the 2005-2015 American Community Surveys (ACS) to obtain information on income, race, parental characteristics, and other variables. We focus on children in the 1978-1983 birth cohorts who were born in the U.S. or authorized immigrants who came to the U.S. in childhood. Our primary analysis sample consists of 20 million children, approximately $94 \%$ of the total number of children in the birth cohorts we study.

We divide our empirical analysis into four parts. In the first part, we characterize intergenerational gaps by race. We measure children's incomes as their mean household income in 2014-15, when they are in their mid-thirties. We measure their parents' income as mean household income between 1994 and 2000, when their children are between the ages of 11 and 22. Following Chetty, Hendren, Kline and Saez (2014), we measure intergenerational mobility using a rank specification. We rank children based on their incomes relative to all other children in the same birth cohort. Similarly, we rank parents of these children based on their incomes relative to all other parents with children in the same birth cohort.

We find that intergenerational mobility and the persistence of disparities vary significantly across racial groups. White and Hispanic children have fairly similar rates of intergenerational mobility. For example, white children born to parents at the 25 th percentile of the income distribution reach the 45th percentile on average, while Hispanic children born to parents at the 25th percentile reach the 43rd percentile on average. Because of these modest intergenerational gaps, the income gap between Hispanic and white Americans is shrinking across generations. If mobility rates were to remain constant across generations, a model analogous to Becker and Tomes (1979) predicts that the income disparity between Hispanic and white Americans would shrink from 22 percentiles for the parents in our sample to 10 percentiles for their children (who are currently in their mid-30s) and ultimately to 6 percentiles in steady state.

Asian children with parents at the 25 th percentile reach the 56th percentile on average, well above white Americans, echoing the widespread perception of Asians as a "model minority" (e.g., Wong, Lai, Nagasawa and Lin 1998). However, the exceptional outcomes of low-income Asian children are largely driven by first-generation immigrants. Restricting the sample to Asians whose mothers were born in the U.S., we find intergenerational gaps between Asians and whites of approx- 
imately 2 percentiles on average across the parental income distribution. The changing patterns of intergenerational mobility for Asians make it more difficult to predict the trajectory of their incomes, but Asians appear likely to converge to income levels comparable to white Americans in the long run.

In contrast to Hispanics and Asians, there are large intergenerational gaps between black and American Indian children relative to white children. Both blacks and American Indians have rankrank mobility curves that are shifted down relative to whites across the entire parental income distribution by approximately 13 percentiles. This remains true even among children born to parents in the top 1 percent, implying that children born into high-income black families have substantially higher rates of downward mobility than whites across generations, consistent with Bhattacharya and Mazumder (2011). Indeed, a black child born to parents in the top quintile is roughly as likely to fall to the bottom family income quintile as he or she is to remain in the top quintile; in contrast, white children are nearly five times as likely to remain in the top quintile as they are to fall to the bottom quintile.

The large intergenerational gaps for blacks and American Indians relative to whites lead to disparities in earnings for these groups that persist across generations. If mobility rates do not change, our estimates imply a steady-state gap in family income ranks between whites and American Indians of 18 percentiles, and a white-black gap of 19 percentiles. These values are very similar to the empirically observed gaps for children in our sample, suggesting that blacks and American Indians are currently close to the steady-state income distributions that would prevail if differences in mobility rates remained constant across generations. This result shows that reducing racial disparities will require reducing intergenerational gaps - i.e., disparities in children's outcomes conditional on parental income - for blacks and American Indians. Transient programs that do not affect intergenerational mobility, such as temporary cash transfers, are insufficient to reduce disparities because income distributions will eventually revert back to their steady-states.

In light of this finding, the rest of the paper focuses on understanding the factors that drive intergenerational gaps in income, particularly between blacks and whites. One mechanical explanation for black-white intergenerational gaps in household income is that blacks marry at much lower rates than whites (Raley, Sweeney and Wondra 2015), leading to lower levels of household income simply because they tend to have one rather than two earners in their families. In the second part of the paper, we evaluate the role of marriage by measuring children's incomes at the individual rather than the household level. We find significantly smaller black-white intergenerational gaps 
in individual income, of approximately 5 percentiles instead of the 13 percentile gap in household income.

The reduction in the intergenerational gap when focusing on children's individual incomes, however, masks important heterogeneity by gender. The intergenerational gap in individual income is 10 percentiles for black men across the parental income distribution. In contrast, black women earn about 1 percentile more than white women conditional on parent income. Moreover, there is little or no gap in wage rates or hours of work between black and white women, weighing against the hypothesis that black women have comparable incomes to white women solely because they work longer hours to compensate for lower levels of spousal income. Black men, by contrast, have substantially lower employment rates and wage rates than white men, even conditional on parental income. We find analogous gender differences in other outcomes as well: black-white gaps in high school dropout rates, college attendance rates, occupation, and incarceration are all substantially larger for men than for women. Black women have higher college attendance rates than white men, conditional on parental income. For men, the gap in incarceration is particularly striking: $21 \%$ of black men born to the lowest-income families are incarcerated on a given day, as compared with $6 \%$ of white men.

Why do rates of intergenerational mobility differ so sharply for black vs. white men? In the third part of the paper, we study whether differences in other family characteristics (e.g., family structure or wealth) explain these gaps. Controlling for parental marital status reduces black-white intergenerational gaps for men only slightly, from 10 percentiles to 9.3 percentiles. Controlling for differences in parental education also does not affect the black-white intergenerational gap significantly. The black-white intergenerational gap remains substantial even after controlling for differences in parental wealth, both when controlling directly for wealth proxies such as home value observed in our ACS data as well as when adjusting for differences in total wealth using data from the Survey of Consumer Finances (SCF). Our findings are also inconsistent with the hypothesis discussed in some prior work (e.g., Rushton and Jensen 2005) that racial disparities may be due to differences in cognitive ability, as there is no biological reason that racial differences in cognitive ability would vary by gender.

In the last part of the paper, we examine environmental factors outside the family that may drive black-white intergenerational gaps (e.g., labor market conditions or the quality of schools) by studying variation across commuting zones (CZs) and neighborhoods (Census tracts or blocks) within CZs, as in prior sociological work (e.g., Sampson, Raudenbush and Earls 1997; Sharkey 
2013). CZs that have higher rates of upward mobility for whites (e.g., the Great Plains) tend to have higher rates of upward mobility for blacks as well, with the notable exception of the Southeast, where whites have especially low rates of upward mobility but blacks do not. However, there are substantial black-white gaps in nearly every commuting zone.

We continue to find large intergenerational gaps even between black and white men who grow up in the same Census tract (containing 4,256 people on average) or block (containing 50 people on average). Among children with parents at the 25th percentile, black boys have lower incomes in adulthood than white boys in $99 \%$ of Census tracts. The mean intergenerational gap in individual income ranks between black and white boys with parents at the 25th percentile remains at 7.7 percentiles with tract fixed effects and 7.0 percentiles with block fixed effects. Hence, the intergenerational gap would fall by at most $30 \%$ if black and white boys were to grow up in the same neighborhoods.

The fact that neighborhood differences explain relatively little of the black-white intergenerational gap does not mean that neighborhoods do not matter for children's outcomes. We find substantial variation across tracts within CZs in both black and white boys' outcomes. Both black and white boys have significantly higher incomes if they grow up in "good" neighborhoods - e.g., those with low poverty rates, high test scores, or a large fraction of college graduates. However, black-white gaps are larger on average for boys who grow up in such neighborhoods because the correlation between growing up in a good (e.g., low-poverty) area and income is greater for white boys than black boys.

Among low-poverty neighborhoods (those with poverty rates below 10\%), two factors are strongly associated with better outcomes for black men and smaller black-white intergenerational gaps. First, black men who grow up in tracts with less racial bias among whites - measured using tests for implicit bias or indices of explicit racial animus based on Google searches - earn more and are less likely to be incarcerated. Second, the fraction of fathers present in low-income black households in the neighborhood is associated with better outcomes among black boys, but is uncorrelated with the outcomes of black girls and white boys. Black father presence at the neighborhood level strongly predicts black boys' outcomes irrespective of whether their own father is present or not, echoing the findings of Sampson (1987). Of course, these correlations do not necessarily reflect causal effects because black father presence and racial discrimination are both associated with many unobservables, but they provide some guidance for the types of neighborhood-level factors that may warrant further study. 
Finally, using the methodology of Chetty and Hendren (2018a), we show that black boys who move to better areas (as measured by the outcomes of other black residents) earlier in their childhood have higher incomes and lower rates of incarceration in adulthood. These childhood exposure effects are race-specific: black movers' outcomes are predicted by the outcomes of other black residents, but not white residents. These findings show that environmental conditions during childhood have causal effects on racial disparities.

We conclude that neighborhoods with low poverty rates, high rates of father presence among blacks, and low levels of racial bias among whites have better outcomes for black boys and smaller racial gaps. Examples of such areas include Silver Spring in Maryland and parts of Queens in New York, where black boys growing up in low-income (25th percentile) families rise above the national median on average in adulthood. But very few black families live in such places. Less than $5 \%$ of black children currently grow up in a Census tract with a poverty rate below $10 \%$ and more than half of black fathers present. In contrast, $63 \%$ of white children live in areas with poverty rates below $10 \%$ and more than half of white fathers present. Importantly, these differences in childhood environment arise not just from neighborhood-level factors, such as poverty rates or school quality, but also factors that affect racial groups differentially within neighborhoods, such as racial bias and race-specific rates of father presence. Our findings therefore suggest that reducing the black-white income gap will require policies whose impacts cross neighborhood and class lines and increase intergenerational mobility specifically for black men.

The paper is organized as follows. Section II presents a model of intergenerational mobility and racial disparities that we use to organize our empirical analysis. Section III describes the data. In Section IV, we characterize intergenerational mobility by race. Section V examines the role of differences in marriage rates and heterogeneity by gender in black-white gaps. Section VI analyzes how family-level factors affect intergenerational gaps, while Section VII examines variation across neighborhoods. Section VIII concludes. Supplementary results and methodological details are provided in an online appendix. Statistics on children's outcomes by race, parental income, and other characteristics at the commuting zone and Census tract level can be downloaded from the Census Bureau or Opportunity Insights and visualized using the Opportunity Atlas.

\section{Conceptual Framework}

We structure our empirical analysis using a statistical model of income inequality and intergenerational mobility in the tradition of Galton (1886) and Becker and Tomes (1979). We use the model 
to identify empirically estimable parameters that control the evolution of racial disparities.

Consider a discrete-time setting in which $t$ indexes generations. For simplicity, assume that each family, indexed by $i$, consists of a single individual in each generation $t$. Let $y_{i, t}$ denote the income percentile rank of individual $i$ relative to all other individuals in the same generation $t$, and let $r(i)$ denote the race of family $i{ }^{5}$ We show in our empirical analysis that the conditional expectation of children's mean ranks given their parents' ranks is approximately linear for all races. We therefore model individual $i$ 's income as a race-specific linear function of his or her parents' income:

$$
y_{i, t}=\alpha_{r}+\beta_{r} y_{i, t-1}+\varepsilon_{i, t}
$$

where $\varepsilon_{i, t}$ denotes an idiosyncratic shock that is independent across generations and has expectation $E\left[\varepsilon_{i, t}\right]=0$. In Chetty, Hendren, Kline, and Saez's (2014) terminology, $\alpha_{r} \in[0,1]$ measures absolute rank mobility for children of the lowest-income parents: the mean rank of a child of race $r$ whose parents have income rank $y_{i, t-1}=0$. The parameter $\beta_{r} \in[0,1]$ measures the rate of relative mobility: the association between the mean percentile rank of children and their parents' income ranks for race $r$. We assume that $\alpha_{r}$ and $\beta_{r}$ do not vary across generations. Chetty et al. (2014) present evidence in support of this assumption pooling races for recent cohorts, and we present further evidence supporting this assumption by race in Online Appendix Table X.

Under the linear specification in (1), one does not need to track the evolution of the full income distribution to characterize the evolution of mean outcomes by race. The mean rank of individuals of race $r$ in generation $t$ is simply $\bar{y}_{r, t}=\alpha_{r}+\beta_{r} \bar{y}_{r, t-1}$. Iterating over generations, we can write the mean rank in generation $t+s, \bar{y}_{r, t+s}$, as a function of the mean rank in generation $t, \bar{y}_{r, t}$ :

$$
\bar{y}_{r, t+s}=\alpha_{r} \frac{1-\beta_{r}^{s}}{1-\beta_{r}}+\beta_{r}^{s} \bar{y}_{r, t} .
$$

As $s \rightarrow \infty, \beta_{r}^{s} \rightarrow 0$ if $\beta_{r}<1$. Hence, the mean rank of individuals of race $r$ converges in the long run to a steady-state in which

$$
\bar{y}_{r, t}=\bar{y}_{r, t-1}=\bar{y}_{r}^{S S}=\frac{\alpha_{r}}{1-\beta_{r}} .
$$

We now turn to the implications of (2) and (3) for the evolution of racial disparities. Let $\Delta \bar{y}_{t}=\bar{y}_{r_{1}, t}-\bar{y}_{r_{2}, t}$ denote the unconditional mean income rank gap between two races $r_{1}$ and $r_{2}$ in generation $t$. For expositional convenience, we consider a series of cases of increasing generality.

\footnotetext{
${ }^{5}$ By focusing on percentile ranks, we capture changes in the relative position of racial groups in the income distribution. As discussed in Bayer and Charles (2018) and Manduca (2018), trends in the absolute dollar magnitude of racial disparities depend upon both changes in ranks and the marginal distribution of income in each generation. We focus on ranks to separate the forces that affect racial disparities from forces that affect the income distribution more generally, such as skill-biased technical change. The rank-based estimates of mobility we report here can be translated into dollar gaps using the methods in Chetty et al. (2017).
} 
Constant Relative and Absolute Mobility. We begin with the case in which absolute and relative rates of intergenerational mobility do not vary by race: $\alpha_{r}=\alpha$ and $\beta_{r}=\beta$ for all $r$. In this case, the racial gap in mean ranks in steady state is $\Delta \bar{y}^{S S}=0$, as all races converge to the same mean rank, irrespective of their initial conditions $\bar{y}_{r, 0}$. The gap in generation $t+s$ is $\Delta \bar{y}_{t+s}=\beta^{s} \Delta \bar{y}_{t}$. As noted by Becker and Tomes (1979), the rate of convergence in incomes across racial groups is determined by the rate of relative mobility $\beta$. Chetty, Hendren, Kline and Saez (2014) estimate that $\beta \simeq 0.35$ pooling all races in the U.S. This level of relative mobility implies that racial disparities would fall to $35 \%$ of their current level after one generation and just $12 \%$ of their current level after two generations, as illustrated in Figure Ia. In the absence of differences in intergenerational mobility by race, racial disparities in income would dissipate relatively rapidly across generations given observed levels of mobility and vanish entirely in steady-state. Hence, an intergenerational model with constant relative and absolute mobility is clearly inconsistent with the persistence of income disparities by race throughout America's history (Myrdal 1944; Duncan 1968; Margo 2016).

Constant Relative Mobility. Next, consider the case where absolute mobility varies by race, but relative mobility does not: $\beta_{r}=\beta$. Let $\Delta \alpha=\alpha_{w}-\alpha_{b}$ denote the racial difference in absolute mobility, i.e. the expected gap in children's ranks conditional on parental income, which we term the intergenerational gap. In this case, the racial gap in steady-state is

$$
\Delta \bar{y}^{S S}=\frac{\Delta \alpha}{1-\beta} .
$$

The steady-state disparity is directly proportional to the size of the intergenerational gap $\Delta \alpha$, as shown in Figure Ib. Reducing racial disparities in the long run therefore requires reducing intergenerational gaps. Reducing the current gap $\Delta \bar{y}_{0}$ without changing $\Delta \alpha$ will not affect racial disparities in the long run.

The gap in generation $t+s$ is

$$
\Delta \bar{y}_{t+s}=\left(1-\beta^{s}\right) \Delta \bar{y}^{S S}+\beta^{s} \Delta \bar{y}_{t}
$$

The gap in generation $t$ is given by a weighted average of the steady-state gap and the current gap, with the weight determined by the rate of relative mobility $\beta$. As discussed above, if $\beta=0.35$ as observed empirically, convergence to the steady-state is relatively rapid and hence what matters most even after one or two generations is primarily the intergenerational gap $\Delta \alpha$.

The difference between the racial gap in the current generation and the steady state, $\Delta \bar{y}_{t}-\Delta \bar{y}^{S S}$, measures the extent to which current disparities are driven purely by intergenerational gaps $(\Delta \alpha)$ 
versus historical factors $\left(\Delta \bar{y}_{0}\right)$. If $\Delta \bar{y}_{t}-\Delta \bar{y}^{S S}$ is small, we can infer (under our assumption that rates of intergenerational mobility are stable) that most of the current disparity is due to intergenerational gaps rather than transitory factors.

General Case. We now return to the general case in which both $\alpha_{r}$ and $\beta_{r}$ vary across races. Here, steady-state disparities and rates of convergence are determined by the race-specific rates of relative and absolute mobility. As noted above, prior work has established that the average level of $\beta$ pooling all races is approximately 0.35 in the U.S., but there is less evidence on how $\beta_{r}$ varies by race (Mazumder 2014). Estimating $\beta_{r}$ by race is important because groups that have low relative mobility (high $\beta_{r}$ ) could remain stuck at lower income levels for many generations even in the absence of steady-state gaps. For example, suppose whites and blacks have the same steady-state mean rank and that whites are currently in steady-state, but blacks are not. In this case, the gap in period $t+s$ is $\Delta \bar{y}_{t+s}=\beta_{b}^{s} \Delta \bar{y}_{t}$, where $\beta_{b}$ denotes relative mobility for blacks. If $\beta_{b}=0.75$, it would take 8 generations for the black-white disparity $\Delta \bar{y}_{0}$ to fall to $10 \%$ of its current level.

To summarize, race-specific rates of relative and absolute mobility $\left(\alpha_{r}, \beta_{r}\right)$ control the persistence of racial disparities and can provide guidance on the types of interventions that may be most effective in reducing disparities. If relative mobility is high for all races (low $\beta_{r}$ ), reducing racial disparities requires policies that reduce racial gaps in children's outcomes conditional on parental income $(\Delta \alpha)$, perhaps through changes in schooling or childhood environment. Transitory interventions, such as temporary cash transfers targeted by race, will have limited long-run effects unless they change the process of intergenerational mobility itself. In contrast, if racial disparities emerge from low rates of relative mobility (high $\beta_{r}$ ) combined with large gaps due to historical or transient factors (high $\Delta \bar{y}_{t}$ ), then temporary interventions or policies that increase relative mobility would have more persistent effects.

Changes in Mobility Over Time. Our model's steady-state predictions assume that intergenerational mobility for each race is constant over time. In practice, mobility rates may change across generations. For example, Borjas (1992) proposes a model in which intergenerational gaps by race emerge from differences in "ethnic capital" (measured e.g., by the previous generation's mean income or education), which itself evolves across generations. From the perspective of a single generation, our model with heterogeneous, fixed intercepts $\alpha_{r}$ can be interpreted as a reduced-form of the Borjas model in which we do not microfound the underlying determinants of $\alpha_{r}$. Our steadystate predictions should thus be interpreted not as predictions of the actual dynamics that we expect to occur, but rather as what would happen in a (potentially counterfactual) world in which 
the differences in mobility we document below remain fixed over time. These predictions provide a useful benchmark because they tell us how mobility rates must change to achieve convergence, whether via exogenous changes in policy, endogenous changes in ethnic capital, or changes in other determinants of mobility.

More generally, richer models of intergenerational income dynamics would permit children's outcomes to depend not just upon parents' incomes but also grandparents' incomes (Long and Ferrie 2018) and allow for features such as assortative mating, endogenous fertility, and endogenous human capital investment (e.g., Becker, Kominers, Murphy and Spenkuch 2018). Although steadystate outcomes and convergence rates depend upon many additional factors in such models, rates of intergenerational income mobility $\left(\alpha_{r}, \beta_{r}\right)$ continue to play a central role and thus remain of interest.

Motivated by this framework, we focus on two sets of questions in our empirical analysis. First, how do rates of intergenerational mobility vary across racial groups? Second, what factors lead to differences in intergenerational mobility by race and produce gaps that persist across generations?

\section{Data}

We combine two sources of data housed at the Census Bureau in our primary analysis: data from the Census 2000 and 2010 short forms and data drawn from federal income tax returns in 1989, 1994, 1995, and 1998-2015. For certain supplemental analyses, we also use data from the Census 2000 long form and the 2005-2015 American Community Surveys (ACS). The Census short forms are designed to cover the entire population; the Census 2000 long form is a stratified random sample covering approximately one-sixth of households; and the ACS is a stratified random sample covering approximately $2.5 \%$ of households in each year (U.S. Department of Commerce, Bureau of the Census 2000; U.S. Department of Commerce, Bureau of the Census 2003; U.S. Department of Commerce, Bureau of the Census 2014).

These datasets are linked by a unique person identifier called a Protected Identification Key (PIK) that is assigned by Census Bureau staff using information such as Social Security Numbers (SSNs), names, addresses, and dates of birth. The Census Bureau uses the Numident, a dataset covering all SSN holders, and other administrative data to assign PIKs. All analysis in this paper is conducted using a linked dataset that contains PIKs but is stripped of personally identifiable information.

The record linkage algorithm used to assign individuals PIKs is described in Wagner and Layne 
(2014). Using datasets that have both SSNs and other identifiers, Layne, Wagner and Rothhaas (2014) show that the error rate in assigning PIKs when one does not have SSNs (as in Census surveys) is typically below $1 \%$ for government datasets. In the 2010 Census, $90.3 \%$ of individuals are successfully assigned a PIK (Wagner and Layne 2014, Table 2). Bond, Brown, Luque and Hara (2014) show that PIK rates vary slightly across population subgroups in the 2010 ACS, but exceed $85 \%$ in virtually all subgroups. We present statistics on the fraction of our target population covered by our linked dataset below.

In the rest of this section, we describe how we construct our analysis sample, define the variables we use, and present summary statistics. Further details are in Online Appendices A-C.

\section{III.A Sample Definition}

Our target sample frame consists of all children in the 1978-83 birth cohorts who were (1) born in the U.S. or are authorized immigrants who came to the U.S. in childhood and (2) whose parents were also U.S. citizens or authorized immigrants. ${ }^{6}$ We construct this sample frame in practice by identifying all children who were claimed as a child dependent on a 1040 tax form at some point between 1994-2015 by an adult who appears in the 2016 Numident file and was between the ages of 15-50 at the time of the child's birth. ${ }^{7}$ We then restrict the sample to children who were born between 1978-83, based on their record in the 2016 Numident. Note that this sample definition excludes children who are unauthorized immigrants or who are claimed as dependents by unauthorized immigrants because unauthorized immigrants do not have SSNs and therefore do not appear in the Numident file.

We define a child's "parent" as the person who first claims the child as a dependent (between 1994-2015). This person must be supporting the child to claim him or her as a dependent, but may not necessarily be the child's biological parent. ${ }^{8}$ If the child is first claimed by a single filer, the child is defined as having a single parent. For simplicity, we assign each child a parent (or parents) permanently using this algorithm, regardless of any subsequent changes in parents' marital status or dependent claiming.

\footnotetext{
${ }^{6}$ We limit our analysis to individuals who are authorized immigrants because coverage rates of tax data for unauthorized immigrants are difficult to determine.

${ }^{7}$ Dependent claiming information is not available in tax returns from 1989 . We impose the 15 -50 age restriction to limit links to grandparents or other guardians who might claim a child as a dependent.

${ }^{8}$ An alternative method of identifying parents is to use information on relationships to household members in the 2000 Census short form. We find that the tax- and Census-data based measures of parents are well aligned: for instance, among the children claimed as dependents by parents on a 1040 tax form in 2000, 93\% live with the same parents in the 2000 Census. We use the tax data to identify parents because many of the children in the oldest cohorts in our sample have left their parents' houses by the 2000 Census.
} 
If parents never file a tax return, we do not link them to their child. Although some low-income individuals do not file tax returns in a given year, almost all parents file a tax return at some point between 1994 and 2015 to obtain a tax refund on their withheld taxes and the Earned Income Tax Credit (Cilke 1998). As a result, virtually all of the children in the 1978-83 birth cohorts are linked to parents (Online Appendix Table II). We limit our analysis to children born during or after 1978 because many children begin to leave the household starting at age 17 (Chetty, Hendren, Kline and Saez 2014, Appendix Table I) and the first year in which we have dependent claiming information is 1994 .

In Online Appendix B, we assess the representativeness of our analysis sample by comparing sample counts and descriptive statistics to corresponding measures from the ACS. Our analysis sample covers approximately $94 \%$ of our target sample frame and has income distributions and demographic characteristics very similar to the ACS (Online Appendix Tables III and IV), confirming that it provides an accurate representation of our target population.

\section{III.B Variable Definitions}

In this subsection, we briefly define the variables we use in our primary analysis; details are provided in Online Appendix C. We measure all monetary variables in 2015 dollars, adjusting for inflation using the consumer price index (CPI-U).

Variable Definitions for Parents.

Income. Our primary measure of parent income is total pre-tax income at the household level, which we label parent family or household income. ${ }^{9}$ In years where a parent files a tax return, we define household income as Adjusted Gross Income; for non-filers, household income is coded as zero. We define our baseline parental income measure as the mean of parents' household income over five years: 1994, 1995, and 1998-2000, as tax records are unavailable in 1996 and 1997.

Marital Status. We identify parents' marital status based on their tax filing status in the year the child is first claimed as a dependent by parents. We say that a child has a "father present" if one of the tax filers who claims the child as a dependent in that year is male.

Educational Attainment. We obtain information on the highest level of education parents have completed from the American Community Survey and the 2000 Census long form. We define "parental education" as the mother's education if available; if not, we use the father's education.

Wealth. We proxy for parents' wealth (again, prioritizing the mother's data) using information

\footnotetext{
${ }^{9}$ We use the term "household" income for simplicity, but we do not include incomes from cohabitating partners or other household members aside from the primary tax filer's spouse.
} 
on home ownership, monthly mortgage payments, home value, and the number of vehicles from the 2000 Census long form and the ACS. We supplement these proxies using data from the Survey of Consumer Finances (SCF) to control for total wealth. Further details on the use of the SCF are provided in Online Appendix F.

Location. In each year, parents are assigned the address from which they filed their 1040 tax return. For non-filers, we use address information from information returns such as W-2s.

U.S. Native Status. Children are defined as having a "native-born" mother if their mother was surveyed in the 2000 Census long form or the ACS and reported being born in the United States in either survey.

Variable Definitions for Children.

Income. We define children's annual household income in the same way as parents' income, except that we use data from W-2 forms to impute income for non-filers (W-2 data are available only since 2005 and hence cannot be used to measure parents' incomes in our sample). We measure children's individual and household incomes as their mean annual incomes in 2014 and 2015, when children are between the ages of 31 and 37 .

Marriage. A child's marital status is measured based on whether he or she files a tax return jointly in 2015.

Race. We assign race and ethnicity to children using the information they report on the 2010 Census short form, 2000 Census short form or the ACS.

Employment. We use two measures of employment, one based on the tax data and one based on the ACS. In the tax data, children are defined as working if they have non-zero individual income in either 2014 or 2015. In the ACS, children are defined as working if they report positive weeks worked in the past year. This and all other employment-related ACS measures described below are defined only among children who receive the ACS at age 30 or later.

Hours Worked. Annual hours worked are measured in the ACS as the product of hours worked per week and weeks worked per year.

Hourly Wage. Hourly wages are measured in the ACS by dividing reported annual wage and salary income by annual hours worked. The hourly wage is coded as missing for those with zero hours worked.

Occupation. We obtain information on children's occupations from the ACS for children who have positive hours worked.

Educational Attainment. We measure children's educational attainment based on the highest 
level of education they report having completed in the ACS or the 2000 Census long form (prioritizing the ACS, since it is more recent).

Incarceration. Using data from the 2010 Census short form, we define an individual as incarcerated on the day of the Census (April 1, 2010) based on whether he or she lives in any of the following types of group quarters: federal detention center, federal prison, state prison, local jail, residential correctional facility, military jail, or juvenile correctional facility.

Location. Children's locations are measured based on the address from which they file tax returns in 2015 or the most recent year in which an address is available. For non-filers, we obtain address information from W-2 forms and other information returns.

\section{III.C Summary Statistics}

Table I and Online Appendix Tables V-IX report summary statistics for children and parents, by race and gender. There are 21.3 million children in our analysis sample, of whom $94 \%$ have non-missing information on race (Online Appendix Table II). Of those with non-missing race information, $67 \%$ are white, $14 \%$ are black, $13 \%$ are Hispanic, $3 \%$ are Asian, and $0.8 \%$ are American Indian. The median household income among children in 2014-15 (between the ages of 31-37) is $\$ 53,730$ for whites, $\$ 20,650$ for blacks, $\$ 35,180$ for Hispanics, $\$ 63,720$ for Asians, and $\$ 22,260$ for American Indians. Among parents, median household income is $\$ 70,640$ for whites, $\$ 29,200$ for blacks, $\$ 33,060$ for Hispanics, $\$ 53,010$ for Asians, and $\$ 34,850$ for American Indians. These differences in household income are partly driven by differences in marriage rates: $79.3 \%$ of white children grow up in two-parent households, compared with $32.2 \%$ of black children. Other variables vary across the groups in a similar manner. Notably, $10.3 \%$ of black men in our sample of children were incarcerated on April 1, 2010 (between ages 27-32), a far higher rate than for any of the other subgroups.

In Online Appendix B and Online Appendix Table IV, we show that income distributions measured in the tax records closely match those in the Current Population Survey and the ACS. For example, the median income in 2015 of children who appear in both our analysis sample and the 2015 ACS is $\$ 33,370$ based on the tax data, compared with $\$ 34,000$ based on the ACS data. Individuals recorded as having zero income in the tax records (because they do not file and have no $\mathrm{W}-2 \mathrm{~s}$ ) have a median income of $\$ 5,000$ in the ACS, showing that tax records do not miss substantial amounts of income for non-filers. 


\section{Intergenerational Mobility by Race}

In this section, we characterize the evolution of racial disparities across generations using the framework in Section II. We begin by estimating relative and absolute intergenerational mobility $\left(\alpha_{r}, \beta_{r}\right)$ for each racial group using the specification in (1). Following Chetty, Hendren, Kline and Saez (2014), we measure parents' and children's incomes using percentile ranks. We rank children based on their incomes relative to all other children in the same birth cohort. Similarly, we rank parents based on their incomes relative to all other parents with children in the same birth cohort. Pooling all races, we obtain an estimate of relative mobility of $\beta=0.35$ in our analysis sample (Online Appendix Figure I), very similar to the estimate of $\beta=0.34$ reported by Chetty, Hendren, Kline and Saez (2014, Figure IIa) based purely on tax records. ${ }^{10}$

Blacks vs. Whites. Figure IIa plots the mean household income rank of children versus the household income rank of their parents, for black and white children. For whites, we estimate a slope (relative mobility) of $\beta_{w}=0.32$ : a 10 percentile increase in parents' rank is associated with a 3.2 percentile increase in children's rank on average. The intercept for whites is $\alpha_{w}=36.8$; i.e., white children born to the lowest-income parents reach the 36.8 th percentile on average. The relationship between children's expected ranks and parents' ranks is linear across almost the entire parental income distribution, but is convex in the upper tail (top 5\%). Children from very highincome families have especially high incomes themselves; for instance, white children with parents at the 100th income percentile have a mean rank of 74.0.

Blacks have relative mobility comparable to whites $\left(\beta_{b}=0.28\right)$, but have uniformly lower rates of absolute mobility across the entire parental income distribution. For example, black children with parents at the 25 th percentile reach an income rank of 32.6 on average, 12.6 percentiles below white children born to parents with comparable incomes. Racial disparities persist even at the highest income levels: among children whose parents are in the top 1\% (who have incomes of $\$ 1.1$ million on average), the black-white gap remains at 12.4 percentiles. ${ }^{11}$ Hence, high levels of parental income provide no insulation against racial disparities.

The differences in mean ranks between black and white children arise from the fact that blacks both have much lower rates of upward mobility than whites and much higher levels of downward

\footnotetext{
${ }^{10}$ The estimate increases by 0.01 because we measure children's incomes at slightly older ages in this paper (ages 31-37 vs. ages 29-32), reducing the amount of lifecycle bias.

${ }^{11}$ One may be concerned that this gap is overstated because white parents have higher incomes on average within the top $1 \%$ than black parents (since the top percentile is effectively unbounded above). However, the black-white gap remains at 13.1 percentiles among children with parents in the 99th percentile, where that issue does not arise.
} 
mobility (Hertz 2005; Bhattacharya and Mazumder 2011). For example, among children with parents in the bottom quintile, $10.6 \%$ of white children rise up to the top quintile, but only $2.5 \%$ of black children do (Table I; see the Online Data Tables for quintile transition matrices by race and ethnicity). Among children with parents in the top quintile, $41.1 \%$ of white children remain in the top quintile, compared with $18.0 \%$ of black children. Perhaps most strikingly, black children starting from families in the top quintile have nearly the same chances of falling to the bottom income quintile $(16.7 \%)$ as they do of staying in the top quintile. ${ }^{12}$

Under the assumption that rates of mobility remain constant across generations, we can predict how the black-white disparity will evolve across generations using the model in Section II. Plugging our estimates of $\alpha_{w}$ and $\beta_{w}$ into (3), the predicted steady-state mean rank for whites under the model in Section II is $\bar{y}_{w}^{S S}=54.4$, illustrated by the point where the intergenerational mobility line intersects the 45 degree line on Figure IIa. The steady-state mean rank for blacks is $\bar{y}_{b}^{S S}=35.2$. Hence, the predicted (unconditional) black-white income gap in steady state given current levels of intergenerational mobility is $\Delta \bar{y}^{S S}=19.2$ percentiles.

Figure IIb plots the mean ranks of parents (circles) and children (diamonds) in our sample vs. the predicted steady-state mean ranks, by race. Both blacks and whites' mean incomes are close to their steady-state values, shown by the arrows intersecting the 45 degree line. The mean rank of black children in the 1978-83 birth cohorts is 34.8 , while the mean rank of white children is 55.7. Hence, the observed unconditional black-white gap in the current generation is 20.9 percentiles, very similar to the predicted steady-state gap of 19.2 percentiles. Interpreted using the model in Section II, this result implies that blacks and whites are in a steady-state in which the black-white income gap is due almost entirely to differences in rates of intergenerational mobility rather than transitory or historical factors.

As noted in Section II, these steady-state predictions assume that mobility rates do not change across generations. Whether this assumption will hold going forward is unclear; the key point is that if the race-specific levels of absolute mobility $\alpha_{r}$ do not change, there will be little progress in reducing black-white disparities in the U.S. To reduce black-white disparities, we must reduce intergenerational gaps $(\Delta \alpha)$ either through changes in policy or other factors (e.g., via changes in ethnic capital as in Borjas (1992)). Although the historical persistence of racial disparities suggests that reducing $\Delta \alpha$ will be challenging, one encouraging result is that interventions that reduce $\Delta \alpha$

\footnotetext{
${ }^{12}$ This result is not driven by measurement error in parental income: we average parent income over five years in our baseline analysis and find that using longer averages does not affect the results significantly.
} 
could lead to rapid reductions in racial disparities across generations because blacks have fairly high rates of relative mobility (low $\beta_{r}$ ). For example, under the assumptions of the model in Section II, if black children's mean ranks were increased by 13 percentiles at all levels of parental income, the unconditional black-white income gap would fall to just 2.7 percentiles within two generations.

American Indians, Hispanics, and Asians. Figure IIIa shows intergenerational mobility series for Hispanics, Asians, and American Indians in addition to the series for whites and blacks plotted in Figure IIa. Rates of intergenerational mobility for American Indians are very similar to those for blacks. As a result, the predicted steady-state mean rank for American Indians is 36.5, similar to that for blacks. The mean rank of American Indian children is 36.7, showing that they too are very close to their steady-state if rates of mobility do not change (Figure IIb). Hence, American Indians' low income levels are also due primarily to their low rates of upward mobility across generations.

Hispanics have rates of intergenerational mobility (among authorized immigrants and citizens) similar to those of whites, especially at the bottom of the income distribution. As a result, their predicted steady-state mean income (assuming constant mobility across generations) is 48.7, only 5.7 percentiles below the steady-state for whites. But Hispanics' current income distributions are closer to those of blacks and Americans Indians than whites (Online Appendix Figure II). Hispanic parents and children in our sample have a mean rank of 36.2 and 45.7 percentiles, respectively. Hence, unlike blacks and American Indians, Hispanics are on an upward trajectory across generations and may close most of the gap between their incomes and those of whites, as shown in Figure IIb. Their low levels of income at present thus appear to to be primarily due to transitory factors.

Asians have much higher rates of relative mobility than all other groups, with $\beta=0.18$. Asian children have have high levels of income across the parental income distribution; even Asian children born to the lowest-income parents reach the 51st percentile of the national income distribution on average. These patterns have led to a perception that Asians are a "model minority" whose success may serve as a model for other racial groups. One concern with this inference is that $81.8 \%$ of Asian parents in our sample are first-generation immigrants, who might have high levels of latent skill but low levels of observed income in the U.S., leading to unusually high rates of observed upward mobility for their children. We evaluate this hypothesis in Figures IIIb and IIIc by focusing on children whose mothers were born in the U.S. vs. outside the U.S. ${ }^{13}$ Asian children whose mothers were born in the U.S. have outcomes very similar to white children (Figure IIIb), while those whose

\footnotetext{
${ }^{13}$ These figures are based on the subsample of children whose mothers appear in the 2000 Census long form or the ACS because we only observe where the mother was born in those datasets.
} 
mothers were born outside the U.S. have much better outcomes than white children (Figure IIIc). Hence, the exceptional outcomes of Asian children are unique to the children of first-generation immigrants rather than a persistent feature of Asians who are U.S. natives. For this reason, Asian children of U.S. natives have a predicted steady state income level that is similar to whites, as shown in Figure IIb.

Asians are not exceptional in having higher rates of absolute and relative mobility among immigrants than natives. The same qualitative pattern holds among Hispanics, Blacks, and whites as well, as shown in Online Appendix Figure III, although the gap between natives and immigrants is significantly smaller for Hispanics than the other groups. ${ }^{14}$ This may be because first-generation immigrants have low levels of earnings when they come to the U.S. despite having high levels of latent skills that they transmit to their children or because immigrants choose to live in areas within the U.S. that foster greater upward mobility for their children (Abramitzky, Boustan, Jacome and Pérez 2019).

In sum, an intergenerational perspective suggests that the racial disparities that are most likely to persist are for blacks and American Indians, who appear to be in a steady-state with lower levels of income. Understanding the persistence of disparities for these groups requires an understanding of why black and American Indian children have lower incomes than white children conditional on parent income. In the rest of the paper, we test a range of potential explanations for intergenerational gaps among black children. We focus specifically on the black-white gap because many of our tests require examining small subgroups, and sample sizes for blacks are much larger than those for American Indians. ${ }^{15}$

\section{Marriage Rates and Gender Heterogeneity}

We begin our analysis of the sources of black-white intergenerational gaps by considering a simple mechanical explanation: racial differences in marriage rates. It is well known that blacks marry at much lower rates than whites (e.g. Raley, Sweeney and Wondra 2015). Differences in marriage rates could potentially explain the black-white gap in household income simply because we count two incomes for most white children but only one for most black children. In this section, we study the effects of differences in marriage rates by focusing on measures of individuals' own outcomes

\footnotetext{
${ }^{14}$ Because of this, the predicted steady-state for Hispanic natives is 47.3 percentiles, only 1.4 percentiles below the value for all Hispanics. In the interest of parsimony, we present statistics simply by race and ethnicity here, pooling immigrants from different countries; in the Online Data Tables, we report analogous statistics for second-generation immigrants by their parents' country of birth.

${ }^{15}$ For completeness, we present parallel analyses for other racial groups in the Online Appendix.
} 
and show that the results vary sharply by gender.

We first document the large intergenerational gaps in marriage rates between black and white children in our sample. Figure IVa plots marriage rates for black and white children in 2015 (between ages 32-37) by parental income percentile. Black children have substantially lower marriage rates across the parental income distribution, with a gap of 32 percentage points (pp) for children with parents at the 25 th percentile and $34 \mathrm{pp}$ at the 75 th percentile. White children at the bottom of the income distribution are as likely to be married as black children at the 97 th percentile of the parental income distribution.

To evaluate the impacts of these differences in marriage rates, we focus on children's individual incomes (excluding spousal income). Figure IVb plots children's mean individual income ranks vs. their parents' household income ranks, by race. The gap in individual income ranks is approximately 5 percentiles across the parental income distribution, substantially smaller than the approximately 13 percentile gap in household income in Figure IIa.

However, the smaller gap in children's individual incomes in Figure IVb masks substantial heterogeneity by gender. Figure V replicates Figure IVb separately for male and female children. This figure reveals that the black-white intergenerational gap in individual incomes is driven almost entirely by men. We find gaps for men of about 11 percentiles across the parental income distribution. In contrast, black women have 1 percentile higher individual income ranks than white women conditional on parental income. The finding that black-white racial gaps in individual income are substantially larger for men than women is consistent with prior literature showing that black-white wage disparities are smaller for women than men in the cross-section (Darity, Guilkey and Winfrey 1996; Neal and Johnson 1996; Altonji and Blank 1999; Bayard, Ilellerstein, Neumark and Troske 1999; Blau 2012).

Income Effects: Wage Rates and Hours of Work. One interpretation of the results in Figure $\mathrm{V}$ is that black-white gaps in labor market opportunities are small for women, but large for men. A competing explanation is that black women also have poorer labor market opportunities than white women, but this is masked by an income effect on labor supply: black women may be working harder to make up for having lower spousal income.

One way to distinguish these explanations is to compare the hours of work and wage rates of black and white women. In the simplest version of the income effect hypothesis, one would expect that black women would have higher hours than white women but lower wage rates. We measure annual hours of work and wages for children who appear in an ACS sample at or after age 30. We 
define wage rates as self-reported annual earnings divided by annual hours. We then convert hourly wages to percentile ranks by ranking individuals relative to others in the same birth cohort who received the ACS survey in the same year. Hours of work are coded as zero for those who do not work, while wages are coded as missing.

Figure VI plots mean wage ranks, hours, and employment rates by parental income percentile for women and men. Conditional on parental income, black and white women have very similar wage rates, hours of work, and employment rates. ${ }^{16}$ These results suggest that the lack of an intergenerational gap in income for females is not entirely due to an income effect. In contrast, there are very large gaps in both wage rates and hours of work for men. Conditional on parental income, black men have wages that are about 7 percentiles lower than white males, and work roughly 9 fewer hours per week on average. The gaps in employment rates for men are particularly stark, especially for children growing up in low-income families. Black men with parents at the 25th percentile are $18.9 \mathrm{pp}$ less likely to work in a given year than white men, while black men with parents at the 75 th percentile are 11.4 pp less likely to work than white men. The employment rates of black men with parents at the 75 th percentile are comparable to those of white men with parents at the 9 th percentile.

The black-white gap in wage rates may understate the true gap in potential wages if black women with lower wage opportunities are less likely to be employed (Heckman, Lyons and Todd 2000). The similarity of employment rates for black and white women rules out selection bias in which the decision to work is based purely on potential wage rates. However, as noted by Neal (2004), black women who do not work might have low potential wage rates, while white women who do not work have high potential wage rates but a high marginal cost of labor. Although there is certainly scope for selection bias of this form, differences in potential wages for non-working women are unlikely to overturn the conclusion that the intergenerational gap in labor market opportunities is significantly smaller for women than men, for two reasons.

First, even among women born to high-income parents - for whom employment rates are around

\footnotetext{
${ }^{16}$ This is true not just for means: the entire distribution of black womens' wage rates and hours of work is very similar to the corresponding distributions for whites, conditional on parent income (not reported). We also find that the occupational distributions of black and white women are similar conditional on parental income (Online Appendix Figure IV), suggesting that black women are not substituting toward occupations with lower amenities to obtain higher wages. We do find, however, that white women are less likely than black women to hold jobs that pay traditional wage earnings (reported on form W-2) and are more likely to earn income of other forms (e.g., reported on form 1099) conditional on parental income. Moreover, it remains possible that black women choose jobs that offer fewer amenities in exchange for greater compensation within a given occupation. Hence, we cannot be certain that there is no difference in labor market opportunities for black and white women conditional on parental income; however, the data do strongly suggest that the black-white gap in opportunities is much larger for men than women.
} 
$90 \%$ - wages are very similar for blacks and whites. Second, we continue to find smaller intergenerational gaps for women and large intergenerational gaps for men for outcomes that are observed for everyone, such as educational attainment. Among children with parents at the 25th percentile, the black-white gap in high school completion rates is $3.5 \mathrm{pp}$ for women vs. $8.3 \mathrm{pp}$ for men (Figure VIIa-b). The corresponding gaps in college attendance rates are $2.8 \mathrm{pp}$ for women and $6.5 \mathrm{pp}$ for men (Figure VIIc-d). ${ }^{17}$ It is particularly noteworthy that high school completion and college attendance rates are uniformly higher for black women than for white men across the parental income distribution.

The gender difference in racial disparities is perhaps most stark in incarceration (Steffensmeier, Ulmer and Kramer 1998). Figure VIIe shows that $21 \%$ of black males born to parents in the lowestincome (bottom 1\%) families were incarcerated on April 1, 2010 (when they are between ages 27-32). In contrast, $6.4 \%$ of white males born to parents with comparable income were incarcerated. As parental income rises, the incarceration rates decline for both white and black males. But there are substantial disparities even at the top of the parental income distribution. Among children with parents in the top $1 \%$, only $0.2 \%$ of white males were incarcerated, whereas $2.2 \%$ of black males were incarcerated - the same rate as for white boys who grew up in families at the 34th percentile of the parental income distribution. In contrast, incarceration rates are very low for both black and white females across the parental income distribution (Figure VIIf). These findings reinforce the view that the processes that generate racial disparities differ substantially by gender.

Although there are large differences in incarceration rates between black and white men, incarceration itself is unlikely to mechanically explain the black-white gaps in income for men documented in Figure Va. That is, the black-white intergenerational gap would be sizable even if we exclude individuals who are incarcerated at the point at which we measure their income (and hence have near-zero income). One way to see this is that the income gap remains substantial even among children in the highest-income families, for whom incarceration rates are small in absolute terms: $2.2 \%$ of black men born to parents in the top $1 \%$ are incarcerated, yet their individual earnings ranks are 10.2 percentiles below those of white men. Incarceration also cannot directly explain the sharp disparities observed in outcomes at younger ages, such as high school dropout rates. Moreover, incarcerated individuals have low levels of earnings even prior to incarceration

\footnotetext{
${ }^{17}$ We also find larger gaps for men than women when examining the association between children's education and parents' education (rather than income). See the Online Data Tables for intergenerational transition matrices of education by race and gender.
} 
(Looney and Turner 2017). ${ }^{18}$

Implications for the Evolution of Income Disparities. We conclude based on the preceding analysis that the black-white intergenerational gap in individual income is substantial for men, but quite small for women. It is important to note, however, that this finding does not imply that the unconditional black-white gap in women's individual incomes will vanish with time. This is because black women continue to have substantially lower levels of household income than white women, both because they are less likely to be married and because black men earn less than white men (Online Appendix Figure V). As a result, black girls grow up in lower-income households than white girls in each generation, leading to a persistent racial disparity in individual income for women even in the absence of an intergenerational gap in their individual incomes.

Nevertheless, the key to closing income disparities for both black and white women is to close intergenerational gaps in income between black and white men. We establish this result formally in Online Appendix E by extending the model in Section II to allow men's and women's individual income ranks to depend upon the individual income ranks of both men and women in the previous generation. The model predicts that in the absence of intergenerational gaps for women, the steady-state gap for both women and men is proportional to the intergenerational gap in individual incomes for men. We therefore focus on understanding the determinants of intergenerational gaps between black and white men in the rest of the paper.

\section{Family-Level Factors}

In this section, we ask whether other factors that vary across black and white families beyond parental income can explain intergenerational gaps in income between black and white men. We consider four family-level factors that have received attention in the previous literature, summarized in Online Appendix Table I: parental marital status, parental education, parental wealth, and differences in ability.

We study the role of parental characteristics by estimating regressions on the subsample of black and white children of the form:

$$
y_{i, c}=a+b_{p} y_{i, p}+b_{w} \text { white }_{i}+b_{w p} \text { white }_{i} \cdot y_{i, p}+c X_{i}+e_{i},
$$

\footnotetext{
${ }^{18}$ Our point here is simply that incarceration does not mechanically account for the black-white gap in earnings outcomes by taking people out of the labor force. Of course, high rates of incarceration could influence intergenerational gaps through broader channels, e.g. by changing ex-ante investment in human capital, by changing norms, or by reducing the presence of black fathers in a community.
} 
where $y_{i, c}$ is the child's individual income rank, $y_{i, p}$ is the parent's household income rank, white ${ }_{i}$ is an indicator for the child being white, and $X_{i}$ is a covariate such as parental education. In this specification, the intergenerational gap in income between blacks and whites at a given parental income rank $\bar{p}$, controlling for the effect of $X_{i}$, is $\Delta_{\bar{p} \mid X}=b_{w}+b_{w p} \bar{p}$. Our goal is to assess how $\Delta_{\bar{p} \mid X}$ changes as we control for various factors $X$.

In Figure VIII, we show how $\Delta_{\bar{p} \mid X}$ changes as we control for various factors $X$. Panel A considers the black-white gap for children growing up in low-income $(\bar{p}=25)$ families, while Panel B considers the gap for those growing up in high-income $(\bar{p}=75)$ families. As a reference, the first two bars in both panels report the unconditional difference in white and black children's mean individual income ranks, without controlling for parental income or any other covariate. This unconditional gap is 17.6 percentiles for males and 4.8 percentiles for females. The second set of bars report estimates of $\Delta_{\bar{p}}$ when no controls $X_{i}$ are included. These estimates correspond to the difference between the black and white series in Figure IVb at the 25th and 75th percentiles (under a linear approximation for both series).

The rest of the bars in Figures VIIIa-b show how these intergenerational gaps change with the introduction of additional controls, $X_{i}$. One prominent hypothesis is that black children have poorer outcomes because they are more likely to grow up in single parent families (Lundberg 2017), an effect that may be especially pronounced for boys (Autor et al. 2019). The third set of bars in Figure VIIIa-b show that controlling for parental marital status in (5) has a small effect on the intergenerational gap in income. At the 25 th percentile, the intergenerational gap for men falls from 10 to 9.3 percentiles; at the 75 th percentile, it falls 11.7 to 11.4 percentiles. $^{19}$

Next, we include indicators for parents' highest level of educational attainment in (5) (see Online Appendix C for details on how educational attainment is defined). Controlling for parental education in addition to marital status reduces the gap for men to 9.1 percentiles at $\bar{p}=25$; at $\bar{p}=75$, the gap remains unchanged at 11.4 percentiles.

Finally, we evaluate whether differences in parental wealth can explain the black-white gap in intergenerational mobility. Black families have much lower levels of wealth than white families,

\footnotetext{
${ }^{19}$ In Online Appendix Figures VIa-b, we relax the parametric assumption implicit in (5) that marital status has an additive effect on children's outcomes by replicating Figure Va separately for boys in single- and two-parent families. The black-white intergenerational gaps remain similar to the estimates obtained from (5) in both of these groups. Controlling for marital status has a larger effect when we do not control for parent income, reducing the unconditional black-white gap from 17.6 to 13.3 percentiles (Online Appendix Figure VII), consistent with Autor et al. (2019). This is because having two parents in the household is associated with a higher level of household income. We focus here on how controls affect the intergenerational gap (i.e., the gap conditional on parental income) because that is the parameter relevant for the dynamics of racial disparities across generations.
} 
even conditional on income (Oliver and Shapiro 2006). Unfortunately, we do not observe household wealth in our data; we only observe various proxies for wealth such as home ownership, monthly mortgage payments, home value, and the number of vehicles. Controlling for these proxies reduces the black-white intergenerational income gap modestly for males, from 9.1 to 8.4 percentiles at $\bar{p}=25 .^{20}$

To estimate how much further the gap would narrow if we were to control for total wealth, we use separate data from the Survey of Consumer Finances to assess how much of the black-white gap in total wealth (conditional on parental income) is captured by the proxies that we observe in the ACS. Our proxies account for about two-thirds of the black-white wealth gap: controlling for the proxies reduces the estimated black-white wealth gap by $64 \%$. In Online Appendix F, we show that we can use this estimate to infer the black-white intergenerational income gap controlling for total wealth under the assumption that children's outcomes are independent of the ACS wealth proxies conditional on total wealth (or, equivalently, that the components of wealth observed in the ACS have the same effects on children's outcomes as the unobserved components). Intuitively, we simply inflate the reduction in the observed black-white intergenerational gap when we control for the ACS wealth proxies by the portion of the wealth gap accounted for by those proxies to estimate how much the black-white gap would fall if we were to control for total wealth.

The adjustment for imperfect measurement of wealth in the ACS reduces the black-white income gap given parents at the 25 th percentile to 8.0 percentiles, a 0.4 percentile reduction relative to the estimate that controls only for the ACS wealth proxies. Intuitively, this is because low-income families hold the majority of their wealth in the illiquid assets that are captured in the ACS. The correction for imperfect measurement of wealth has a slightly larger effect at the 75 th percentile of the national income distribution, reducing the estimated black-white gap from 11 to 10.2 percentiles. We conclude based on this analysis that differences in wealth between black and white families are unlikely to explain their starkly different rates of intergenerational mobility.

Ability. The last family-level explanation we evaluate is the hypothesis that there are genetic differences in cognitive ability by race. Since we do not have measures of innate ability in our data, we cannot use the same approach as above to evaluate this hypothesis. However, two pieces of evidence suggest that differences in ability are unlikely to explain the intergenerational gaps we document. First, the prior literature suggests no ex-ante biological reason that racial differences in

\footnotetext{
${ }^{20}$ Controlling non-parametrically for wealth, e.g. by conditioning on the subset of families who do not own houses, also yields similar results (Online Appendix Figure VIc).
} 
cognitive ability would vary by gender (Rushton and Jensen 2005). Hence, our finding that blackwhite intergenerational gaps vary so sharply by gender casts doubt on ability as an explanation for the gaps we observe.

Second, most prior arguments for the ability hypothesis rest upon the large gaps observed between black and white children on standardized tests (e.g., Hernstein and Murray 1994). However, black-white test score gaps do not vary significantly by gender. Data from the National Assessment of Educational Progress show that the black-white gap in test scores at age 9 for low-income (freeor reduced-price lunch-eligible) children is 0.48 standard deviations (SD) for boys vs. $0.44 \mathrm{SD}$ for girls (Online Appendix Figure VIII). The fact that these test score gaps are not aligned with the earnings gaps across gender casts further doubt upon the view that differences in cognitive ability, as measured by test scores, explain black-white gaps in earnings outcomes. ${ }^{21}$

In summary, the family-level factors most commonly discussed in prior work explain very little of the differences in intergenerational mobility between black and white men. ${ }^{22}$

\section{Neighborhood-Level Factors}

In this section, we use variation across neighborhoods as a lens to study how environmental factors affect intergenerational mobility for black and white men. Since neighborhoods vary on many dimensions that can affect individuals' outcomes - from the quality of local schools to the availability of jobs to the degree of racial bias - studying differences in outcomes across neighborhoods is a fruitful way to learn about the effects of environmental factors (e.g., Wilson 1987; Cutler and Glaeser 1997; Sampson, Morenoff and Gannon-Rowley 2002; Sharkey and Faber 2014).

We organize our analysis into four sections. First, we characterize broad regional variation in black-white intergenerational gaps across commuting zones, which are aggregations of counties that are commonly used as a definition of local labor markets. Since blacks and whites often live in different parts of a given $\mathrm{CZ}$, we next examine variation in outcomes by race at much finer geographies, by Census tract and block. Having characterized the observational variation in outcomes across neighborhoods, in the third subsection, we study the outcomes of children whose families move across areas to determine whether the neighborhood-level differences in black-white gaps that we document are driven by causal effects of environment or sorting. Finally, we compare

\footnotetext{
${ }^{21}$ An alternative explanation of the test score gaps is that blacks under-perform on standardized tests relative to whites because of inherent biases in standardized tests or stereotype threat (Steele and Aronson 1995; Jencks and Phillips 1998).

${ }^{22}$ As with the black-white gap, we find that controlling for other family-level factors has little impact on intergenerational gaps between Hispanics, Asians, American Indians, and whites (Online Appendix Figure IX).
} 
the types of neighborhoods in which black and white children grow up to evaluate the extent to which changes in neighborhood environments could close the black-white gap.

Throughout this section, we focus on characterizing how the neighborhoods in which children grow up affect their outcomes, which may differ from the neighborhoods in which they live as adults. We focus on childhood neighborhoods because of prior evidence that rates of intergenerational mobility depend on where children grow up rather than where they live as adults (Chetty, Hendren and Katz 2016; Chetty and Hendren 2018a).

\section{VII.A Variation Across Commuting Zones}

We characterize black-white intergenerational gaps across CZs by assigning children to CZs based on where they grow up. Chetty and Hendren (2018a) show that the CZ in which one grows up has causal effects on earnings and other outcomes in adulthood until approximately age 23. We therefore assign children to CZs in proportion to the amount of time they spend below age 23 in each commuting zone over the years observed in our sample. ${ }^{23}$

We characterize the mean income ranks of children of race $r$ who grow up in CZ $c$ conditional on their parents' income ranks using the linear specification in (1). ${ }^{24}$ We regress children's individual income ranks in the national income distribution on their parent's household income ranks in the national income distribution:

$$
y_{i, c}=\alpha_{r}^{c}+\beta_{r}^{c} y_{i, p}+\epsilon_{i}
$$

weighting by the number of years that child $i$ is observed below age 23 in CZ $c$. This regression yields estimates of absolute mobility for children with parents at $p=0\left(\alpha_{r}^{c}\right)$ and relative mobility $\beta_{r}^{c}$, for each CZ, $c$. We combine these estimates to report levels of absolute mobility at two parent income levels: $p=25$ (corresponding to the outcomes of children of below-median-income parents) and $p=75$ (above-median-income parents). We focus primarily on the estimates at $p=25$ in the main text because most black children presently grow up in relatively low-income families, but we show that results are analogous at $p=75$ in the Online Appendix.

\footnotetext{
${ }^{23}$ These "exposure weighted" estimates could yield biased estimates of the mean outcomes of children who grow up in a single CZ from birth because they combine the causal effects of multiple areas into a single area's estimate. Restricting the sample to children who never move across areas yields similar results at the CZ level, but yields much less precise estimates when we zoom in to the Census tract level below because few children stay in a single tract for their entire childhood. Fortunately, Chetty et al. (2018, Section III) show that the exposure weighted estimates are likely to have a correlation above 0.95 with the mean outcomes one would observe if children did not move across areas at all, even at the Census tract level, because children who move tend to move to similar areas. We therefore interpret our estimates as good predictions of the outcomes of a child who grows up in a given area from birth.

${ }^{24}$ Chetty, Hendren, Kline and Saez (2014) show that the relationship between children's mean ranks and their parents' ranks is approximately linear in all $\mathrm{CZs}$, and we have verified that this continues to be the case when further disaggregating the data by race.
} 
Figure IX maps the mean individual rank of male children with parents at the 25th percentile of the national household income distribution, $\bar{y}_{25}^{c r}=\alpha_{r}^{c}+0.25 \beta_{r}^{c}$, for white and black men. ${ }^{25}$ The maps for both races are colored on a single scale: dark green colors represent areas with the highest levels of upward mobility (i.e., higher $\bar{y}_{25}^{c r}$ ), yellow denotes colors with average levels of upward mobility, and dark red represent areas with the lowest levels of upward mobility.

The maps reveal three lessons. First, both black and white children's rates of upward mobility vary substantially across areas. The difference between the 90th and 10th percentiles of the distribution of mean ranks across areas is about 10 percentile ranks for both white and black men, which is the same as the average black-white income gap in the U.S. as a whole.

Second, the areas in which white children have better outcomes tend to be places where black children have better outcomes as well, although the patterns are not identical. The correlation between $\bar{y}_{25}^{c r}$ for blacks and whites, weighting by total $\mathrm{CZ}$ population, is 0.5. The geographic patterns, especially for whites, largely mirror those documented in Chetty, Hendren, Kline and Saez (2014), which pool across races. For both blacks and whites, rates of upward mobility are highest for children who grow up in the Great Plains and the coasts and lowest in parts of the industrial Midwest. For example, Boston has outcomes towards the top of the within-race distribution for both white and black men, whereas Knoxville, TN has outcomes at the bottom of the distribution for both groups. One notable exception to this pattern is the Southeast, where whites have especially low rates of upward mobility relative to other areas but blacks do not. Among white men with parents at the 25th percentile of the national income distribution, those who grew up in Atlanta have a mean rank of 46.6, significantly lower than those who grew up in Chicago, who have a mean rank of 52.6. In contrast, black men who grew up in Atlanta have a mean rank of 37.7, higher than the mean rank of 36.8 of low-income black men who grew up in Chicago.

Third, there are substantial differences in black and white boys' outcomes within virtually all $\mathrm{CZs}$, for both children with parents at the 25 th and 75 th percentiles. Indeed, we find that the distributions of outcomes for blacks and whites across CZs are almost non-overlapping. At the 90th percentile of the (unweighted) CZ-level distribution, black boys have a mean income rank of 45.1, which falls at the 16th percentile of the corresponding distribution for white boys. Black boys do not have the same prospects for upward mobility as white boys in virtually any CZ.

\footnotetext{
${ }^{25}$ In Online Appendix Figures X-XIII, we present analogous maps for females, children growing up in high-income families $(p=75)$, children of Hispanic origin, and using household income ranks instead of individual income ranks. The CZ-level estimates of $\left\{\bar{y}_{p}^{c r}\right\}_{r, c, p}$ plotted in all of these maps are available in the Online Data Tables.
} 


\section{VII.B Variation Across Census Tracts}

Next, we zoom in to examine variation across neighborhoods within CZs by estimating intergenerational mobility at the Census tract level. To do so, we estimate the regression specification in (6) for each Census tract separately by race and gender. Children's outcomes vary substantially across tracts within CZs. The population-weighted interdecile (90-10) range of $\bar{y}_{25}^{c r}$ across tracts within CZs is 7.1 percentiles for black men and 8.4 percentiles for for white men, about as large as the variation between CZs discussed above. ${ }^{26}$ The tract-level estimates can be visualized using the Opportunity Atlas (Chetty et al. 2018), a searchable, interactive map that is analogous to Figure IX, but at the tract rather than CZ level. This subsection summarizes the key properties of the tract-level estimates, focusing in particular on the black-white gap in upward mobility.

Black-White Gaps Persist Within Tracts. One of the most well-known explanations for the black-white gap is residential segregation: blacks and whites may have different outcomes because they tend to live in different neighborhoods (e.g., Massey and Denton 1993). To test this hypothesis, we include Census tract fixed effects in equation (5), effectively comparing the outcomes of children raised in the same neighborhood. ${ }^{27}$ Figure VIIIa shows that including tract fixed effects reduces the black-white individual income gap among boys with parents at the 25th percentile $(p=25)$ from 10.0 percentiles to 7.7 percentiles. Indeed, even when we compare children who grow up on the same Census blocks (which contain 50 people on average) by adding block fixed effects, the intergenerational gap for boys remains at 7 percentiles at $p=25$ and 7.9 percentiles at $p=75$. In short, the vast majority of the black-white gap persists even among boys growing up in families with comparable incomes in the same neighborhood; differences in neighborhood quality explain at most $30 \%$ of the black-white intergenerational gap. ${ }^{28}$

Online Appendix Figure XIVa illustrates why this is the case by presenting a histogram of the

\footnotetext{
${ }^{26}$ To adjust for variance due to sampling error in our estimates of $\bar{y}_{25}^{c r}$ when computing this interdecile range, we first estimate the signal variance of $\bar{y}_{25}^{c r}$ as the raw variance of the tract-level estimates minus the noise variance. We estimate the noise variance as the mean of the square of the standard errors obtained from the regression in (6). We then use a Normal approximation to estimate the interdecile range by multiplying the signal SD by 2.56 .

${ }^{27}$ We use the first observed Census tract for individuals who move across tracts in childhood. Replicating the analysis on children who remain in the same tract for several years or their entire childhood yields very similar results.

${ }^{28}$ The small reduction in the intergenerational gap does not mean that neighborhoods do not matter for children's outcomes. Since neighborhood choice itself is an endogenous variable, one cannot separate the contribution of neighborhoods from parental income directly in observational data. Indeed, including Census block fixed effects without controlling for parent income reduces the unconditional black-white gap for males from 17.6 to 9.8 percentiles, similar to the effect of controlling for parental income. Intuitively, parent income itself might matter because it allows parents to buy access to better neighborhoods for their children. As discussed above, we focus on how the gap conditional on parental income changes when we control for neighborhood fixed effects because that is what matters for the evolution of racial disparities in the long run.
} 
intergenerational black-white gap in each tract for boys with parents at the 25th percentile of the income distribution, $\Delta \bar{y}_{25}^{b w}=\bar{y}_{25}^{c w}-\bar{y}_{25}^{c b}$, weighting by the number of black men who grew up in each tract. Consistent with Figure Xa, the mean gap within tracts is 7.5 percentiles. The raw standard deviation of $\Delta \bar{y}_{25}^{b w}$ is 6.6 percentiles. However, some of this variance is due to sampling variation resulting from small samples at the tract level. Subtracting the variance due to sampling error from the total variance yields an estimated signal standard deviation of the latent black-white intergenerational gap within tracts of 3.4 percentiles. This noise-corrected standard deviation implies that among children with parents at the 25th percentile $(p=25)$, white boys have higher incomes in adulthood than black boys in $98.7 \%$ of tracts. ${ }^{29}$

These results imply that reducing residential segregation alone may be insufficient to close the black-white gap, since substantial disparities persist within neighborhoods. Moreover, since lowincome children who live on the same block are likely to attend the same schools, simply enabling black and white children to attend the same schools, without creating greater racial integration within schools or making other changes that have differential effects by race, is also likely to be insufficient to close the gap.

Although black-white intergenerational gaps exist in virtually every neighborhood in the U.S., there is nevertheless substantial variation in the magnitude of these gaps across areas, as shown in Appendix Figure XIVa. In the rest of this subsection, we use this variation across tracts to understand the characteristics of places where black boys have better outcomes and where there are smaller intergenerational gaps.

Black-White Gaps Are Larger in "Good" Neighborhoods. We begin by analyzing the most commonly used measures of neighborhood quality in prior work on neighborhoods (e.g., Sampson, Morenoff and Gannon-Rowley 2002). We obtain data on a variety of proxies for neighborhood quality - such as poverty rates, test scores, educational attainment of local residents, housing costs, and family structure - at the tract level from the publicly available 2000 Census long form and other sources. Details on sources and definitions of these variables are in Online Appendix D.

Figure Xa plots the correlation between a selected subset of tract-level characteristics and the mean individual income ranks of black boys (solid circles) and white boys (open circles) with parents at the 25 th percentile $\left(\bar{y}_{25}^{c r}\right)$. All of these tract-level characteristics are defined so that the correlation between the characteristic and the outcome for white males is positive (e.g., we use the

\footnotetext{
${ }^{29}$ At $p=75$, white boys have higher incomes in adulthood than black boys in $98.1 \%$ of tracts (Online Appendix Figure XIVb). In contrast, black girls have higher incomes than white girls in $84 \%$ of tracts conditional on having parents at $p=25$ and $69 \%$ of tracts at $p=75$ (Online Appendix Figure XV).
} 
share above the poverty line rather than the poverty rate).

We find positive correlations between each of these proxies for neighborhood quality and the outcomes for both white and black men. For example, black and white boys who grow up in neighborhoods with lower poverty rates, higher test scores, higher median rents, and more twoparent households tend to have higher incomes in adulthood. These findings reinforce prior work showing that children who grow up in higher-income areas with more stable family structure and higher test scores typically have better outcomes (e.g., Chetty, Hendren and Katz 2016; Chetty and Hendren 2018b).

The correlations in Figure Xa are generally larger for whites than for blacks. As a result, "good" neighborhoods tend to have larger intergenerational gaps between blacks and whites. Figure $\mathrm{Xb}$ illustrates this point by presenting a binned scatter plot of the relationship between the black-white intergenerational gap for boys $\left(\Delta \bar{y}_{25}^{b w}=\bar{y}_{25}^{c w}-\bar{y}_{25}^{c b}\right)$ and the fraction of residents in the tract who are above the poverty line. This plot is constructed by dividing the fraction above the poverty line into 20 equal-sized bins (weighting by the number of black men) and plotting the means of the $x$ and $y$ variables within those bins. The mean intergenerational gap increases by 2.5 percentiles when moving from the highest poverty neighborhoods to the lowest poverty neighborhoods. Intuitively, both black and white boys have higher incomes in low-poverty areas, but the effect of growing up in a low-poverty area is larger for whites than blacks. As a result, black-white intergenerational gaps are larger in low-poverty neighborhoods than in high-poverty neighborhoods.

Characteristics of Neighborhoods with Smaller Intergenerational Gaps. In light of these findings, we next investigate whether there are certain neighborhoods where black boys do well and blackwhite intergenerational gaps are smaller. The tracts where black men do well are dispersed across the country rather than concentrated in one city or region. For example, black men have the highest rates of upward mobility in Silver Spring in the Washington DC Metro Area as well as parts of Queens in New York. In these areas, black men growing up in low-income $(p=25)$ families have mean income ranks in adulthood above the 50th percentile. Black men have the poorest outcomes in neighborhoods such as Englewood in the South Side of Chicago and parts of South Los Angeles, where their mean income ranks in adulthood are around the 30th percentile.

To characterize the features of areas that have good outcomes for black men, we first establish that the neighborhoods in which low-income black boys have high rates of upward mobility - which we define as a mean income rank in adulthood above the national median - are almost exclusively low-poverty neighborhoods. Online Appendix Figure XVI establishes this result by presenting a 
binned scatter plot of the fraction of tracts in which $\bar{y}_{25}^{c b}>50$ vs. the share of residents above the poverty line. The subset of neighborhoods in which the average rank of low-income black boys is above the 50 th percentile almost all have poverty rates below $10 \%$ (demarcated by the dashed line on the figure), which is approximately the median (population-weighted) poverty rate across tracts in the U.S. We therefore zoom in on areas with a poverty rate below $10 \%$ to identify places where low-income black boys do well in both absolute levels and relative to their white peers.

In Figure XI, we correlate various tract-level characteristics with the black-white gap given parents at $p=25\left(\Delta \bar{y}_{25}^{b w}\right)$ to identify the characteristics of areas with smaller intergenerational gaps. In addition to the more traditional proxies for neighborhood quality considered above, we expand the set of tract-level characteristics we consider to include a set of race-specific measures such as poverty rates for black and white families - as well as other variables that have differential effects by race, such as measures of racial bias. To isolate variables that are uniformly associated with better outcomes for black boys, we focus on the subset of characteristics whose correlations with black boys' outcomes have the same sign at both the 25 th and 75 th percentile of the parental income distribution. To simplify exposition, we define all the neighborhood characteristics so that they are positively correlated with $\bar{y}_{25}^{c b}$ (e.g., by examining the share above rather than below the poverty line). ${ }^{30}$

Mirroring the pattern documented above, most of the tract-level characteristics we examine are associated with larger black-white intergenerational gaps. That is, neighborhood characteristics associated with better outcomes for black boys are associated with larger intergenerational gaps relative to whites. However, there are a small number of variables that are associated with smaller gaps, which we now investigate in further detail.

Father Presence. Among all the characteristics in Figure XI, the fraction of low-income black fathers present is most predictive of smaller intergenerational gaps. ${ }^{31}$ We define father presence as an indicator for whether the child is claimed by a male on a tax form in the year he is matched to a parent. We regress this indicator for father presence on parental income rank for each tract using equation (6), and define black father presence among low-income families as the prediction for black children at $p=25$.

\footnotetext{
${ }^{30}$ Online Appendix Table XII provides the full set of variables and reports their correlations with the mean income ranks of low-income white and black males in low-poverty neighborhoods. Online Appendix Tables XI and XIII report analogous correlations for the full sample of tracts and for females, respectively.

${ }^{31}$ This pattern holds even when we restrict the sample to children whose parents are born in the U.S. or after controlling for the share of black immigrants at the tract level, allaying the concern that a high rate of black father presence may simply be acting as a proxy for a community with a large share of immigrant black families (who have higher rates of upward mobility than natives).
} 
Figure XII characterizes the association between father presence and children's outcomes across tracts. In Panel A, we present a binned scatter plot of low-income black and white boys' mean income ranks in adulthood, $\bar{y}_{25}^{c b}$ and $\bar{y}_{25}^{c w}$, vs. black father presence, among the subset of lowpoverty tracts. Consistent with the correlation in Figure XI, we find a strong positive association between black father presence and black males' incomes. In contrast, we find no association between black father presence and white males' outcomes. Because of this differential effect by race, the black-white intergenerational gap is 6.1 percentiles in tracts with the highest levels of black father presence, compared with 9.3 percentiles in the tracts with the lowest levels of father presence.

Panel B shows that these differences are even more stark when we focus on the extensive margin of employment: black boys' employment rates (measured as having positive income in the tax data in either 2014 or 2015) are significantly higher in tracts with higher levels of black father presence. Among low-poverty tracts with the highest levels of black father presence, the black-white gap in employment rates given parents at $p=25$ is $4 \mathrm{pp}$, as compared with $9 \mathrm{pp}$ in the nation as a whole. Panel $\mathrm{C}$ shows that black boys who grow up in areas with high father presence are also less likely to be incarcerated. Panel D replicates Panel B, comparing the employment rates of black boys and girls. Black father presence predicts boys' employment rates, but not girls' employment rates. ${ }^{32}$

We probe the robustness of these results in Table II. In Column 1, we regress the predicted income ranks of black males at $p=25\left(\bar{y}_{25}^{c b}\right)$ on low-income black father presence, weighting by the number of black boys who grow up in each tract. Children who grow up in a tract with 10 pp more low-income black fathers present have incomes that are 0.5 percentiles higher on average, consistent with Figure XIIa. Column 2 shows that the pattern is driven by the presence of low-income black fathers, not white fathers; including both variables in the regression yields a coefficient of 0.045 (s.e. $=0.0068)$ on the presence of low-income black fathers and 0.0077 (s.e. $=0.0076$ ) for white fathers. Column 3 shows that the results are very similar when we include state fixed effects.

Columns 4 and 5 show that the association between black boys' outcomes and neighborhoodlevel presence of black fathers remains strong when we condition on the child's own parents' marital status, by restricting the sample either to children raised in a single parent family (Column 4) or a two-parent family (Column 5). Hence, the association with father presence is driven by a characteristic of the neighborhood in which the child grows up, not simply a direct effect of the

\footnotetext{
${ }^{32}$ Symmetrically, the employment rates of low-income white men are predicted by the fraction of white fathers present and the employment rates of women are likewise predicted by the fraction of mothers present. But rates of father presence among whites and rates of mother presence (for both blacks and whites) are generally quite high, making this a less important factor in explaining the variance of outcomes for those subgroups than for black men.
} 
marital status of one's own parents, consistent with Sampson (1987).

Next, we investigate whether the association with father presence is driven by black fathers in particular or the presence of black men in general. To distinguish father presence from black male presence, we calculate two measures: the number of low-income black males in each tract in 2000 in the Decennial Census and the number of below-median-income black fathers in the tract in 2000. We divide both of these counts by the number of black children in our analysis sample in each tract to obtain a measure of black male presence and a comparable measure of black father presence. Column 6 shows that we continue to find a strong positive association between black father presence and black boys' earnings outcomes when we use the count-based measure of black father presence defined above from the 2000 Census. Column 7 shows that when we include both black father presence and black male presence in the regression, black father presence remains just as predictive as in Column 6, whereas black male presence is not significantly related to black boys' outcomes. Hence, what matters is the number of black men involved in raising children in a tract, not the number of black men overall.

Finally, we test the hypothesis that black boys' outcomes are associated with black father presence because they may both be affected by the same set of policies or shocks that persist over time in an area (such as high rates of arrests or incarceration). To do so, we include fixed effects for the tract in which the child lives as an adult (in 2015), thereby comparing children who grew up in different areas but currently live in the same place. To maximize precision, we use the full sample rather than the subset of low-poverty tracts for this analysis. The association between black father presence and black boys' earnings outcomes is strong whether or not we include adulthood tract fixed effects (Columns 8 vs. 9). Hence, what matters is the fraction of low-income fathers in the tract where the child grows up even holding fixed where they live as adults, ruling out the possibility that the same factors that affect black father presence directly affect black boys' outcomes.

Together, these results show that black father presence is associated with children's outcomes in a highly race-by-gender specific manner. Although we cannot make strong causal claims based on this correlational evidence, the specificity of this set of correlations rules out broad mechanisms that would affect both genders and races (such as differences in the quality of schools). Instead, it points to channels that affect black boys in particular, such as mentoring by black male role models in the community or differences in the treatment of black boys in communities with high rates of black father presence.

Racial Bias. We now turn to another set of factors associated with both better outcomes for 
black boys and a smaller black-white intergenerational gap in low-poverty tracts: lower levels of racial bias among whites. Prior work has shown that exposure to racial bias during childhood adversely affects black youth, especially black boys, in school (e.g. Simpson and Erickson 1983; Chavous et al. 2008). Here, we investigate whether these effects are associated with adverse longterm outcomes.

We consider two measures of racial bias. The first is a measure of implicit racial bias from implicit association tests (IAT), which measure the difference in a participant's ability to match positive and negative words with black vs. white faces (Greenwald, McGhee and Schwartz 1998). We obtain mean IAT racial bias scores for white and black study participants at the county level from the Race Implicit Association Database. ${ }^{33}$ The second measure we use is the Racial Animus Index constructed by Stephens-Davidowitz (2014). This is a measure of explicit racial bias, based on the frequency of Google searches for racial epithets at the media market level, which are aggregations of counties. We standardize all the racial bias measures used below so that they have mean zero and standard deviation 1 across areas (weighting by the number of black males in our sample), with higher values representing greater racial bias against blacks. ${ }^{34}$

Table III characterizes the association between measures of racial bias and upward mobility across counties and media markets. ${ }^{35}$ We restrict the sample to counties or media markets with poverty rates below $10 \%$ and weight the regressions by the number of black men in the relevant geographic unit. We begin in Column 1 by regressing the mean individual income rank of black boys raised in low-income families $\left(\bar{y}_{25}^{c b}\right)$ in each county on the (standardized) difference between whites' and blacks' mean IAT scores. In counties with a 1 SD higher level of racial bias against blacks among whites, black men grow up to have mean income ranks that are 0.8 percentiles lower. This coefficient implies that the difference in black boys' incomes between the least (bottom 5\%) and most (top 5\%) racially biased counties exceeds 4 percentiles. In Column 2, we regress black boys' mean income ranks on whites' and blacks' IAT scores separately. As one might expect, the negative correlation is driven entirely by variation in the degree of racial bias among whites.

\footnotetext{
${ }^{33}$ Participation in the IAT (an online test that has been taken by millions of users) is entirely voluntary. As a result, there may be selection biases induced by differences in who chooses to take the test across areas. Although we cannot definitively rule out such biases, the rate of participation in the IAT is not significantly correlated with the black-white intergenerational gap, providing some reassurance in using these measures as a rough proxy for average racial attitudes in an area.

${ }^{34}$ We did not include these racial bias measures in Figure XI because they are not available at the Census tract level. Nevertheless, among all the variables we consider (at both the tract level and broader geographies) that are not associated with larger black-white gaps, the racial bias measures have the strongest correlations with black boys' income ranks at both $p=25$ and $p=75$ within low-poverty areas (Online Appendix Table XII).

${ }^{35}$ Online Appendix Table XIV replicates the analysis in Table III using employment and incarceration among black males as the dependent variables, showing similar patterns.
} 
Column 3 shows that results remain similar when we include state fixed effects, showing that the pattern is not just driven by differences across regions.

Column 4 shows that, in contrast to the pattern for father presence, correlations with racial bias are not gender-specific: black females also have lower incomes in places that are more racially biased against blacks. Perhaps more surprisingly, Column 5 shows that low-income white males also have lower incomes if they grow up in areas with greater racial bias against blacks. One potential explanation for this association is that implicit racial bias is correlated with other forms of bias that adversely affect low-income white men. ${ }^{36}$

The patterns are very similar when we use the Racial Animus Index to proxy for racial bias. Black boys who grow up in low-income $(p=25)$ families in media markets with greater racial animus have lower incomes in adulthood (Column 6). As with the IAT results, these associations are not gender- or race-specific: low-income black women and white men who grow up in areas with more explicit racial animus have lower incomes (Columns 7 and 8).

\section{VII.C Causal Effects of Neighborhoods on Intergenerational Gaps}

The neighborhood-level variation in black-white intergenerational gaps documented above could be driven by two very different sources. One possibility is that neighborhoods have causal effects on children's outcomes: that is, moving a given child to a different neighborhood would change his outcomes. Another possibility is that the geographic variation is due to unobserved differences in the types of people living in each area. We assess the relative importance of these two explanations by studying how the outcomes of children who move across areas vary with the age at which they move. Chetty and Hendren (2018a) use this timing-of-move research design to establish that neighborhoods have causal effects on children's outcomes pooling all racial groups; here, we use the same design to identify the causal effects of areas on racial disparities by showing that neighborhoods have race-specific causal effects.

Empirical Specification. We study the outcomes of children who move across CZs exactly once during their childhood in our primary analysis sample, which we extend to cover the 1978-1985 cohorts in order to measure moves at earlier ages (see Online Appendix G for details). We focus on CZ-level variation (rather than finer geographies) because the larger sample sizes at the CZ level allow us to generate precise estimates of the outcomes of people who grow up in each area, which is essential for identifying race-specific causal effects.

\footnotetext{
${ }^{36}$ An alternative explanation is reverse causality: whites may be more biased in areas with lower earnings outcomes. A third possibility is that racial bias is correlated with other latent factors that drive these correlations.
} 
Let $i$ index children, $p_{i}$ denote their parental income ranks, and $r_{i}$ denote their racial groups. In the sample of one-time movers, let $m_{i}$ denote the age at which child $i$ moves from origin $\mathrm{CZ} o$ to destination CZ $d$. Let $\bar{y}_{p l s}^{r}$ denote the exposure-weighted outcome of $y_{i, c}$ for children of race $r$ in birth cohort $s$ who grew up in location $l$ with parental household income rank $p$, estimated using the specification in (6). ${ }^{37}$ Let $\Delta_{o d p s}^{r}=\bar{y}_{p d s}^{r}-\bar{y}_{\text {pos }}^{r}$ denote the predicted difference in income ranks in the destination versus origin $\mathrm{CZ}$ for children in cohort $s$.

We regress the income rank of children who move $\left(y_{i, c}\right)$ on the measures of origin and destination quality interacted with age-at-move fixed effects:

$$
\begin{aligned}
y_{i, c}= & \sum_{s=1978}^{1985} I\left(s_{i}=s\right)\left(\phi_{s}^{1}+\phi_{s}^{2} \bar{y}_{p o s}^{r}\right)+\sum_{m=6}^{28} I\left(m_{i}=m\right)\left(\zeta_{m}^{1}+\zeta_{m}^{2} y_{i, p}\right) \\
& +\sum_{m=6}^{28} b_{m} I\left(m_{i}=m\right) \Delta_{\text {odps }}^{r}+\varepsilon_{i},
\end{aligned}
$$

where $\phi_{s}^{1}$ is a cohort-specific intercept, $\phi_{s}^{2} \bar{y}_{p o s}$ is a cohort-specific control for the average exposureweighted outcome in the origin, $\zeta_{m}^{1}$ is an age-at-move fixed effect, and $\zeta_{m}^{2} p_{i}$ is an interaction of the age-at-move fixed effects with parental income rank. The key parameters of interest are the $b_{m}$ coefficients, which capture how children's outcomes vary with the age at which they move to an area with higher or lower predicted earnings.

Identification Assumption. We can interpret differences in the coefficients $b_{m}$, e.g. $b_{m}-b_{m+1}$, as the causal effect of exposure to a better area (i.e., an area with higher observed incomes) under the assumption that the potential outcomes of children who move to better vs. worse areas do not vary with the age at which they move. Chetty and Hendren (2018a) present a series of tests supporting this orthogonality condition: controlling for unobserved heterogeneity across families using sibling comparisons in models with family fixed effects, implementing a set of placebo tests exploiting heterogeneity in predicted causal effects across subgroups, and validating the results using experimental designs, e.g. from the Moving to Opportunity Experiment (Chetty, Hendren and Katz 2016). Furthermore, Chetty and Hendren (2018a) provide evidence that estimates of place effects among movers are externally valid to the broader population because they find similar results among those who self-select to move as compared to families displaced by idiosyncratic events such as hurricanes. Building on these results, we take the validity of the research design as given here and use it to explore racial heterogeneity in the causal effects of neighborhoods.

\footnotetext{
${ }^{37}$ We do not include one-time movers when constructing these exposure-weighted outcomes to ensure that a child's own outcome does not enter our definition of neighborhood quality; see Online Appendix G for details.
} 
Results. Panels A and B of Figure XIII plot the coefficients $\left\{b_{m}\right\}$ in (7) using individual income ranks at age 30 for black and white males, respectively. The $b_{m}$ coefficients decline until approximately age 23, after which the coefficients are flat. Under the identification assumption described above, this result implies that neighborhoods have causal effects on children's outcomes in proportion to childhood exposure prior to age 23. We estimate that every year of childhood a black boy grows up in a place where black boys grow up to have 1 percentile higher incomes increases his own income by 0.027 percentiles. The corresponding estimate for white males is 0.026 per year of exposure. ${ }^{38}$ Extrapolating over 20 years of childhood exposure, this estimate implies that children who move at birth to an area where we observe 1 percentile higher incomes for children of their race would pick up about $50 \%$ of that effect themselves through a causal effect of place.

Panels C and D of Figure XIII replicate Panels A and B using incarceration as the dependent variable and race-specific incarceration rates for $\bar{y}_{p l s}^{r}$ and $\Delta_{o d p s}^{r}$ in (7). Black boys are $0.033 \mathrm{pp}$ more likely to be incarcerated for every year of childhood exposure to a place with 1 pp higher incarceration rates for black males. We find a slightly smaller exposure effect of 0.025 for white males.

In Online Appendix Table XV, we present a series of regression estimates that consider alternative specifications and outcomes to assess the robustness of the results in Figure XIII. We find that the estimated exposure effects are very similar to those in our baseline specifications (see Online Appendix $\mathrm{G}$ for details). In addition, we show that places have causal effects not just on the level of outcomes but also on the gap in outcomes across races. In particular, moving one year later in childhood to an area where black boys have 1 percentile higher incomes in adulthood reduces a black boy's income rank by -0.029 (s.e. $=0.004$ ). In contrast, the corresponding coefficient on the change in predicted income ranks for white men is -0.003 (s.e. $=0.004$ ), controlling for the predicted income rank of black men. Hence, moving to an area with better outcomes for white boys has essentially no impact on a black boy's outcomes conditional on the outcomes of black boys who grow up in that area. The converse is true for white men. These results show that moving to an area with a larger observed black-white intergenerational gap at an earlier age in childhood results in larger intergenerational gaps in adulthood.

We conclude that much of the observational variation in black-white intergenerational gaps

\footnotetext{
${ }^{38}$ These estimates are slightly smaller than those reported in Chetty and Hendren (2018a) when pooling racial groups because they were only able to analyze moves after age 9 , whereas here we include moves at earlier ages. As is evident from Figure XIII, the $b_{m}$ coefficients decline more rapidly in adolescence than at earlier ages, which is why expanding the age window to earlier ages leads to a smaller average exposure effect estimate.
} 
documented above reflects the causal effects of childhood environment rather than selection. ${ }^{39}$ In establishing the importance of environmental factors, this finding rejects the hypothesis that racial gaps are driven entirely by differences in immutable traits such as innate ability. The finding that neighborhood effects on racial gaps are proportional to childhood exposure is consistent with prior evidence documenting the emergence of racial gaps in achievement in childhood (Fryer and Levitt 2004) and the importance of pre-labor-market measures in explaining racial gaps in labor market outcomes (Neal and Johnson 1996; Altonji and Blank 1999; Fryer 2010). It is also consistent with evidence from the Moving to Opportunity experiment showing that moving to a low-poverty neighborhood as a young child significantly increases income for both blacks and whites, whereas moving as an adult does not (Chetty, Hendren and Katz 2016).

\section{VII.D Summary: Environment Matters, but Good Environments are Rare}

The analysis in this section has shown that childhood environment has significant causal effects on black-white intergenerational gaps. Black boys do especially well in low-poverty neighborhoods with a large fraction of fathers at home in black families and low levels of racial bias among whites. However, very few black boys grow up in such areas. $4.2 \%$ of black children currently grow up in Census tracts with a poverty rate below 10 percent and more than half of black fathers present (Figure XIV). ${ }^{40}$ In contrast, $62.5 \%$ of white children grow up in low-poverty areas with more than half of white fathers present. These disparities in the environments in which black and white children are raised help explain why we observe significant black-white gaps in intergenerational mobility in virtually all areas of the U.S.

\section{Conclusion}

Differences in intergenerational mobility are a central driver of racial disparities in the U.S. Black and American Indian children have substantially lower rates of upward mobility and higher rates of downward mobility than white children. The gap in incomes between blacks and American Indians relative to whites is thus likely to persist indefinitely without changes in their rates of

\footnotetext{
${ }^{39}$ This is true not just on average but also in the tails of the distribution: moves earlier in childhood to the very best neighborhoods for black men (e.g., the top $10 \%$ of neighborhoods in terms of upward mobility) produce gains commensurate to what one would predict based on the average exposure effect estimates discussed above. This finding suggests that the exceptional outcomes observed in certain areas such as Silver Spring are not driven by selection but rather by the unique causal effects of such environments on black youth.

${ }^{40}$ Examples of such neighborhoods are given in Online Appendix Table XVI. We do not cut on racial bias in this analysis because of the lack of data on racial bias at the tract level; doing so would only further reduce the number of "good" neighborhoods for black children.
} 
intergenerational mobility. In contrast, Hispanics have relatively high rates of absolute upward mobility and are moving up significantly in the income distribution across generations, despite having incomes similar to blacks today.

The black-white gap - the largest gap among those we study - is driven entirely by sharp differences in the outcomes of black and white men who grow up in families with comparable incomes. Although closing this gap may appear to be a daunting challenge given its persistence, there are some encouraging signs that the problem can be solved. First, black children have rates of relative mobility comparable to whites: they are not stuck at the same income levels as their parents. Closing the gap in opportunities between black and white children at a given parental income level could therefore eliminate much of the black-white income gap within two generations. Second, the black-white intergenerational gap is significantly smaller for boys who grow up in certain neighborhoods - those with low poverty rates, low levels of racial bias among whites, and high rates of father presence among low-income blacks. Black boys who move to such areas at younger ages have significantly better outcomes, demonstrating that racial disparities can be narrowed through changes in environment.

The challenge is to replicate the conditions that lead to these smaller disparities more broadly across the country. Our findings suggest that many widely discussed proposals may be insufficient to narrow the unconditional black-white income gap in the long run. Policies focused on improving the economic outcomes of a single generation - such as cash transfer programs or minimum wage increases - can narrow the gap at a given point in time, but are less likely to have persistent effects unless they also affect intergenerational mobility. Policies that reduce residential segregation or enable black and white children to attend the same schools without achieving racial integration within neighborhoods and schools would also likely leave much of the gap in place, since the gap persists even among low-income children raised on the same block.

Instead, our results suggest that efforts that cut within neighborhoods and schools and improve environments for specific racial subgroups, such as black boys, may be more effective in reducing the black-white gap. Examples include mentoring programs for black boys, efforts to reduce racial bias among whites, or efforts to facilitate social interaction across racial groups within a given area (e.g., Devine, Forscher, Austin and Cox 2012; Heller et al. 2017). Our analysis does not offer guidance on which interventions of this type are most effective, but calls for greater focus on and evaluation of such efforts. 


\section{References}

Abramitzky, R., L. P. Boustan, E. Jacome, and S. Pérez (2019). Intergenerational Mobility of Immigrants in the US Over Two Centuries. NBER Working Paper No. 26408.

Akee, R., M. R. Jones, and S. R. Porter (2017). Race Matters: Income Shares, Income Inequality, and Income Mobility for All U.S. Races. NBER Working Paper No. 23733.

Alexander, M. (2010). The New Jim Crow: Mass Incarceration in the Age of Colorblindness. New Press, New York.

Altonji, J. G. and R. Blank (1999). Race and Gender in the Labor Market. Handbook of Labor Economics 3(48), 3143 - 3259.

Austen-Smith, D. and R. G. Fryer, Jr. (2005). An Economic Analysis of "Acting White". The Quarterly Journal of Economics 120(2), 551-583.

Autor, D., D. Figlio, K. Karbownik, J. Roth, and M. Wasserman (2019). Family Disadvantage and the Gender Gap in Behavioral and Educational Outcomes. American Economic Journal: Applied Economics 11(3), 338-381.

Bayard, K., J. Ilellerstein, D. Neumark, and K. Troske (1999). Why are Racial and Ethnic Wage Gaps Larger for Men Than for Women? Exploring the Role of Segregation Using the New WorkerEstablishment Characteristics Database. In The creation and analysis of employer-employee matched data, pp. 175-203. Emerald Group Publishing Limited.

Bayer, P. and K. K. Charles (2018). Divergent Paths: A New Perspective on Earnings Differences Between Black and White Men Since 1940. The Quarterly Journal of Economics 133(3), 1459-1501.

Becker, G. S., S. D. Kominers, K. M. Murphy, and J. L. Spenkuch (2018). A Theory of Intergenerational Mobility. Journal of Political Economy 126(S1), S7-S25.

Becker, G. S. and N. Tomes (1979). An Equilibrium Theory of the Distribution of Income and Intergenerational Mobility. Journal of Political Economy 87(6), 1153-89.

Bertrand, M. and S. Mullainathan (2004). Are Emily and Greg More Employable than Lakisha and Jamal? A Field Experiment on Labor Market Discrimination. The American Economic Review 94(4), 991-1013.

Bhattacharya, D. and B. Mazumder (2011). A Nonparametric Analysis of Black-White Differences in Intergenerational Income Mobility in the United States. Quantitative Economics 2(3), 335379.

Blau, F. (2012). Gender, Inequality, and Wages. Oxford University Press.

Blau, P. M. and O. D. Duncan (1967). The American Occupational Structure. New York: John Wiley and Sons.

Bond, B., J. D. Brown, A. Luque, and A. O. Hara (2014). The Nature of the Bias When Studying Only Linkable Person Records: Evidence from the American Community Survey. Working Paper No. CARRA-WP-2014-08. 
Borjas, G. J. (1992). Ethnic Capital and Intergenerational Mobility. The Quarterly Journal of Economics 107(1), 123-150.

Brummet, Q. (2014). Comparison of Survey, Federal, and Commercial Address Data Quality. Center for Administrative Records Research and Applications Working Paper No. 2014-06.

Card, D. and A. B. Krueger (1992). Does School Quality Matter? Returns to Education and the Characteristics of Public Schools in the United States. Journal of Political Economy 100(1), $1-40$.

Carter, P. L. (2005). Keepin' It Real: School Success Beyond Black and White. New York: Oxford University Press.

Chavous, T. M., D. Rivas-Drake, C. Smalls, T. Griffin, and C. Cogburn (2008). Gender Matters, Too: The Influences of School Racial Discrimination and Racial Identity on Academic Engagement Outcomes among African American Adolescents. Developmental psychology 44(3), 637.

Chetty, R., J. Friedman, N. Hendren, M. Jones, and S. Porter (2018). The Opportunity Atlas: Mapping the Childhood Roots of Social Mobility. NBER Working Paper No. 25147.

Chetty, R., D. Grusky, M. Hell, N. Hendren, R. Manduca, and J. Narang (2017). The Fading American Dream: Trends in Absolute Income Mobility since 1940. Science 356(6336), 398-406.

Chetty, R. and N. Hendren (2018a). The Impacts of Neighborhoods on Intergenerational Mobility I: Childhood Exposure Effects. The Quarterly Journal of Economics 133(3), 1107-1162.

Chetty, R. and N. Hendren (2018b). The Impacts of Neighborhoods on Intergenerational Mobility II: County-Level Estimates. The Quarterly Journal of Economics 113(3), 1163-1228.

Chetty, R., N. Hendren, and L. F. Katz (2016). The Effects of Exposure to Better Neighborhoods on Children: New Evidence from the Moving to Opportunity Experiment. American Economic Review 106(4), 855-902.

Chetty, R., N. Hendren, P. Kline, and E. Saez (2014). Where is the Land of Opportunity? The Geography of Intergenerational Mobility in the United States. The Quarterly Journal of Economics 129(4), 1553-1623.

Chetty, R., N. Hendren, P. Kline, E. Saez, and N. Turner (2014). Is the United States Still a Land of Opportunity? Recent Trends in Intergenerational Mobility. American Economic Review Papers and Proceedings (5), 141-147.

Cilke, J. (1998). A Profile of Non-Filers. U.S. Department of the Treasury, Office of Tax Analysis Working Paper No. 78.

Conley, D. (2010). Being Black, Living in the Red: Race, Wealth, and Social Policy in America. Berkeley, CA: University of California Press.

Corcoran, M., R. Gordon, D. Laren, and G. Solon (1992). The Association between Men's Economic Status and Their Family and Community Origins. The Journal of Human Resources 27(4), 575.

Cutler, D. M. and E. L. Glaeser (1997). Are Ghettos Good or Bad? The Quarterly Journal of Economics 112(3), 827-72. 
Darity, W. J., D. K. Guilkey, and W. Winfrey (1996). Explaining Differences in Economic Performance Among Racial and Ethnic Groups in the USA: the Data Examined. American Journal of Economics and Sociology 55(4), 411-425.

Davis, J. and B. Mazumder (2018). Racial and Ethnic Differences in the Geography of Intergenerational Mobility. Mimeo.

Devine, P. G., P. S. Forscher, A. J. Austin, and W. T. Cox (2012). Long-term Reduction in Implicit Race Bias: A Prejudice Habit-Breaking Intervention. Journal of Experimental Social Psychology 48(6), 1267-1278.

Donohue, J. and J. Heckman (1991). Continuous versus Episodic Change: The Impact of Civil Rights Policy on the Economic Status of Blacks. Journal of Economic Literature 29, 1603-1643.

Duncan, O. D. (1968). Inheritance of Poverty or Inheritance of Race? In D. Moynihan (Ed.), On Understanding Poverty: Perspectives from the Social Sciences, pp. 85-110. Basic Books.

Eberhardt, J. L., P. A. Goff, V. J. Purdie, and P. G. Davies (2004). Seeing Black: Race, Crime, and Visual Processing. Journal of Personality and Social Psychology 87(6), 876-893.

Fordham, S. and J. U. Ogbu (1986). Black Students' School Success: Coping with the "Burden of 'Acting White"'. The Urban Review 18(3), 176-206.

Fryer, R. (2010). Racial Inequality in the 21st Century: The Declining Significance of Discrimination. Handbook of Labor Economics 4B(10), 855-971.

Fryer, R. (2011). It May Not Take a Village: Increasing Achievement Among the Poor. Social Inequality and Educational Disadvantage.

Fryer, R. and S. Levitt (2004). Understanding the Black-White Test Score Gap in the First Two Years of School. The Review of Economics and Statistics 86(2), 447-464.

Fryer, Jr, R. G. and S. D. Levitt (2006). The Black-White Test Score Gap Through Third Grade. American Law and Economics Review 8(2), 249-281.

Galton, F. (1886). Regression Towards Mediocrity in Hereditary Stature. The Journal of the Anthropological Institute of Great Britain and Ireland 15, 246-263.

Glover, D., A. Pallais, and W. Pariente (2017). Discrimination as a Self-Fulfilling Prophecy: Evidence from French Grocery Stores. Quarterly Journal of Economics 132(3), 1219-1260.

Greenwald, A. G., D. E. McGhee, and J. L. Schwartz (1998). Measuring Individual Differences in Implicit Cognition: The Implicit Association Test. Journal of Personality and Social Psychology $74(6), 1464$.

Heckman, J. J. (1998). Detecting Discrimination. Journal of Economic Perspectives 12(2), 101-116.

Heckman, J. J., T. M. Lyons, and P. E. Todd (2000). Understanding Black-White Wage Differentials, 1960-1990. The American Economic Review 90(2), 344-349.

Heller, S. B., A. K. Shah, J. Guryan, J. Ludwig, S. Mullainathan, and H. A. Pollack (2017). Thinking, Fast and Slow? Some Field Experiments to Reduce Crime and Dropout in Chicago. The Quarterly Journal of Economics 132(1), 1-54. 
Hernstein, R. and C. Murray (1994). The Bell Curve: Intelligence and Class Structure in American Life. New York: Free Press.

Hertz, T. (2005). Rags, Riches, and Race: The Intergenerational Economic Mobility of Black and White Families in the United States. In S. Bowles, H. Gintins, and M. Osborne Groves (Eds.), Unequal Chances: Family Background and Economic Success, pp. 165-191. Princeton University Press.

Jencks, C. E. and M. E. Phillips (1998). The Black-White Test Score Gap. Washington, DC: Brookings Institution Press.

Lareau, A. (2011). Unequal Childhoods: Class, Race, and Family Life (2 ed.). Berkeley, CA: University of California Press.

Layne, M., D. Wagner, and C. Rothhaas (2014). Estimating Record Linkage False Match Rate for the Person Identification Validation System. Center for Administrative Records Research and Applications Working Paper No 2.

Long, J. and J. Ferrie (2018). Grandfathers Matter(ed): Occupational Mobility Across Three Generations in the US and Britain, 1850-1911. The Economic Journal 128(612), F422-F445.

Looney, A. and N. Turner (2017). Work and Opportunity Before and After Incarceration. Technical report, Economic Studies at Brookings.

Lopez, G. and J. Radford (2017). Facts on U.S. Immigrants, 2015: Statistical portrait of the foreign-born population in the United States. Pew Research Center.

Lundberg, S. (2017). Father Absence and the Educational Gender Gap. IZA Discussion Paper No. 10814.

Magnuson, K. A. and G. J. Duncan (2006). The Role of Family Socioeconomic Resources in the Black-White Test Score Gap Among Young Children. Developmental Review 26(4), 365 - 399.

Manduca, R. (2018). Income Inequality and the Persistence of Racial Economic Disparities. Sociological Science 5(8), 182-205.

Margo, R. A. (2016). Obama, Katrina, and the Persistence of Racial Inequality. The Journal of Economic History 76(2), 301-341.

Mas, A. and E. Moretti (2009). Racial Bias in the 2008 Presidential Election. American Economic Review 99(2), 323-29.

Massey, D. S. and N. A. Denton (1993). American Apartheid: Segregation and the Making of the Underclass. Cambridge, MA: Harvard University Press.

Mazumder, B. (2014). Black-White Differences in Intergenerational Economic Mobility in the United States. Economic Perspectives 38(1).

McAdoo, H. P. (2002). African American Parenting. In Handbook of Parenting: Social Conditions and Applied Parenting, Chapter 3, pp. 47-58.

Mickelson, R. A. (1990). The attitude-achievement paradox among black adolescents. Sociology of Education 63(1), 44-61. 
Myrdal, G. (1944). An American Dilemma; the Negro Problem and Modern Democracy (2 volumes). Harper \& Bros.

Neal, D. (2004). The Measured Black-White Wage Gap among Women is Too Small. Journal of political Economy 112(S1), S1-S28.

Neal, D. and W. Johnson (1996). The Role of Premarket Factors in Black-White Wage Differences. Journal of Political Economy 104(5), 869-895.

Noguera, P. A. (2003). The trouble with black boys:: The role and influence of environmental and cultural factors on the academic performance of african american males. Urban Education 38(4), $431-459$.

Oliver, M. L. and T. M. Shapiro (2006). Black Wealth, White Wealth: A New Perspective on Racial Inequality. Taylor \& Francis.

Orr, A. J. (2003). Black-White Differences in Achievement: The Importance of Wealth. Sociology of Education 76(4), 281-304.

Pager, D. (2003). The Mark of a Criminal Record. American Journal of Sociology 108(5), 937-975.

Raley, K., M. Sweeney, and D. Wondra (2015). The Growing Racial and Ethnic Divide in U.S. Marriage Patterns. The Future of Children 25(2), 89-109.

Rothstein, J. and N. Wozny (2013). Permanent Income and the Black-White Test Score Gap. Journal of Human Resources 48(3), 510-544.

Rushton, J. and A. Jensen (2005). Thirty Years of Research on Race Differences in Cognitive Ability. Psychology, Public Policy, and Law 11(2), 235.

Sampson, R. J. (1987). Urban Black Violence: The Effect of Male Joblessness and Family Disruption. American Journal of Sociology 93(2), 348-382.

Sampson, R. J., J. D. Morenoff, and T. Gannon-Rowley (2002). Assessing "Neighborhood Effects": Social Processes and New Directions in Research. Annual Review of Sociology 28(1), 443-478.

Sampson, R. J., S. W. Raudenbush, and F. Earls (1997). Neighborhoods and Violent Crime: A Multilevel Study of Collective Efficacy. Science 277(5328), 918-924.

Sampson, R. J. and W. J. Wilson (1995). Toward a Theory of Race, Crime, and Urban Inequality. Race, Crime, and Justice: A Reader 1995.

Sharkey, P. (2013). Stuck in Place: Urban Neighborhoods and the End of Progress Toward Racial Equality. Chicago, IL: University of Chicago Press.

Sharkey, P. and J. W. Faber (2014). Where, When, Why, and For Whom Do Residential Contexts Matter? Moving Away from the Dichotomous Understanding of Neighborhood Effects. Annual Review of Sociology 40, 559-79.

Simpson, A. W. and M. T. Erickson (1983). Teachers' Verbal and Nonverbal Communication Patterns as a Function of Teacher Race, Student Gender, and Student Race. American Educational Research Journal 20(2), 183-198. 
Small, M. Harding, D. and M. Lamont (2010). Reconsidering Culture and Poverty. ANNALS of the American Academy of Political and Social Science 629(1), 6-27.

Smith, J. P. and F. R. Welch (1989). Black economic progress after myrdal. Journal of Economic Literature 27(2), 519-564.

Smith, S. S. (2005). "Don't put my name on it": Social Capital Activation and Job-Finding Assistance among the Black Urban Poor. American Journal of Sociology 111(1), 1-57.

Steele, C. and J. Aronson (1995). Stereotype Threat and Intellectual Test Performance of African Americans. Journal of Personality and Social Psychology 69(5), 797-811.

Steffensmeier, D., J. Ulmer, and J. Kramer (1998). The Interaction of Race, Gender, and Age in Criminal Sentencing: The Punishment Cost of Being Young, Black, and Male. Criminology 36(4), $763-798$.

Stephens-Davidowitz, S. (2014). The Cost of Racial Animus on a Black Candidate: Evidence using Google Search Data. Journal of Public Economics 118, 26-40.

Tatum, B. D. (2004). Family Life and School Experience: Factors in the Racial Identity Development of Black Youth in White Communities. Journal of Social Issues 60(1), 117-135.

U.S. Department of Commerce, Bureau of the Census (2000). United States Census 2000: Informational Copy. https://www.census.gov/dmd/www/pdf/d-61b.pdf. Form D-61B.

U.S. Department of Commerce, Bureau of the Census (2003). Chapter 5, Sample Design and Estimation; 2000 Census of Population and Housing: Public-use Microdata Samples Technical Documentation. Technical report, U.S. Department of Commerce, Bureau of the Census.

U.S. Department of Commerce, Bureau of the Census (2014). American Community Survey Design and Methodology (January 2014); Chapter 4: Sample Design and Selection. Technical report.

U.S. Department of Commerce, Bureau of the Census (2017). Historic Income Tables: Households; Table H-5. Race and Hispanic Origin of Householder - Households by Median and Mean Income.

Wagner, D. and M. Layne (2014). The Person Identification Validation System (PVS): Applying the Center for Administrative Records Research and Applications' (CARRA) Record Linkage Software. Center for Administrative Records Research and Applications Working Paper.

Wilson, W. J. (1987). The Truly Disadvantaged: The Inner City, the Underclass, and Public Policy. University of Chicago Press.

Wong, P., C. F. Lai, R. Nagasawa, and T. Lin (1998). Asian Americans as a Model Minority: SelfPerceptions and Perceptions by other Racial Groups. Sociological Perspectives 41(1), 95-118. 


\section{ONLINE APPENDICES}

\section{A. Data Construction}

This appendix provides further details on the methods we use to construct our analysis sample and assign individuals to Census blocks.

Sample Construction. We begin with the set of children born between 1978 and 1983, based on birth dates recorded in the Numident file (22.8 million children), which contains records on all persons in the U.S. who have ever had a Social Security Number (SSN). For each child, we define the parent(s) as the first person(s) who claim the child as a dependent on a 1040 tax form. If parents are married but filing separately, we assign the child to both parents. To eliminate dependent claiming by siblings or grandparents, in the case of a potential match to married parents or single mothers, we require that the mother be $15-50$ at the birth of the child. In the case of children claimed by a single father, we require that he be between 15-50 at the birth of the child. ${ }^{41}$ If no such eligible match occurs in 1994, the first year of the data in which we have dependent claiming information, we search subsequent years through 2015 until a valid match is found.

Once we match a child to parents, we hold this definition of parents fixed regardless of subsequent dependent claims or changes in marital status. For example, a child matched to married parents in 1996 who divorce in 1997 will always be matched to the two original parents. Conversely, a child matched to a single parent in 1996 who marries in 1997 will be considered matched to a single parent, though spouse income will be included in our definition of parent income because we measure parent income at the family level in our baseline analysis.

We exclude children whose mean real or nominal parent income is zero or negative $(1.0 \%$ of children) because parents who file tax returns (as is required to link them to a child) reporting negative or zero income typically have large capital losses, which are a proxy for having significant wealth. We construct a strongly balanced sample of children by assigning incomes of zero to children who do not appear in the tax data (e.g., because they have died). We then assign children and parents income percentile ranks on the sample of children linked to parents with positive income, using the income definitions described in Section II.B. Finally, we restrict the sample to individuals who have non-missing race information to obtain our final analysis sample. Note that this ordering of operations implies that we rank children and parents relative to all individuals in the sample, not just those with non-missing race information.

Assignment of Children to Census Tracts. Addresses in the tax records are geocoded and assigned to standard Census geographic units (e.g. block, tract, and county) by Census staff in the Census Master Address File (MAF). The geocoding process involves cleaning address information so that it can be merged on to the MAF and assigned a MAFID, which is then associated with the geographic units that we use. Brummet (2014) describes this process in greater detail. Brummet also reports statistics on the match rate for addresses; for example, $92 \%$ of addresses in the 2009 American Housing Survey were successfully matched to the MAF.

We assign children to Census tracts (or other geographies) where they grew up based on the address from which their parents filed 1040 tax forms and claimed them as dependents. In particular, we identify all the Census tracts from which their parents filed tax returns (between 1989-2015)

\footnotetext{
${ }^{41}$ Children can be claimed as a dependent only if they are aged less than 19 at the end of the year (less than 24 if enrolled as a student) or are disabled. A dependent child is a biological child, step child, adopted child, foster child, brother or sister, or a descendant of one of these (for example, a grandchild or nephew). Children must be claimed by their custodial parent, i.e. the parent with whom they live for over half the year. Furthermore, the custodial parent must provide more than $50 \%$ of the support to the child. Hence, working children who support themselves for more than $50 \%$ cannot be claimed as dependents. See IRS Publication 501 for further details.
} 
during or before the year in which their child turned 23. Beginning in 2003, we use address data from information returns (e.g., W-2 forms) for non-filers. Since we search for address information in multiple years, we are able to assign $99.5 \%$ of children in our baseline sample to at least one non-missing tract during their childhood. We use an analogous process to assign children to geographies when they are adults in 2015, using their own 1040 form or, for non-filers, address data from information returns (e.g., W-2 forms).

\section{B. Comparison to Survey Datasets}

In this appendix, we assess the representativeness of our analysis sample by comparing sample counts and descriptive statistics to corresponding measures from publicly available survey datasets. We conduct three sets of analyses.

First, we assess the coverage rate of our analysis sample by comparing the number of children in our analysis sample to the number of individuals in the ACS who were born in the U.S. or came to the U.S. before age 16. Online Appendix Table II shows that the total number of children whom we link to parents is comparable to the expected number of children based on the ACS (using the ACS sampling weights). On average over the 1978-83 birth cohorts, our sample count of children linked to parents with positive income is $99.6 \%$ as large as that in the ACS. ${ }^{42}$ Information on race and ethnicity is available for $94.1 \%$ of children; we lose $6 \%$ of the sample because their records in the Census could not be assigned a PIK (i.e., linked to the Numident file) based on the information provided. The coverage rates are above $94 \%$ for all racial and ethnic subgroups except for Hispanics, for whom our sample count is $78.9 \%$ of that in the ACS. This is primarily because our sample includes only authorized immigrants, whereas the ACS covers all immigrants. ${ }^{43}$ Lopez and Radford (2017) estimate that approximately $17.7 \%$ of immigrants in the United States in 1990 were unauthorized, suggesting that our sample covers approximately $78.9 / 82.3=95.9 \%$ of Hispanics who are authorized immigrants or citizens, similar to rates of coverage for other groups.

Next, in Online Appendix Table III, we examine whether the characteristics of individuals in our analysis sample are representative of the corresponding population in the ACS. We start from individuals in the 1978-83 birth cohorts who appear in the 2015 ACS and report their mean individual income ranks and other characteristics (based on the ACS data) for three samples: all individuals who appear in the ACS (Column 1), those who appear in both the ACS and our analysis sample (Column 2), and those who appear in the ACS but not our analysis sample (Column 3). Mean income ranks differ by 1 percentile or less between our analysis sample and the full ACS sample for all groups except Hispanics, for whom there is a larger discrepancy because our sample does not include unauthorized immigrants as noted above. Mean income ranks are slightly higher for those in our analysis sample than in the complement, which is because individuals who have particularly low incomes are less likely to appear in Census and tax data and hence are less likely to be in our linked data. We find similar results for other variables such as marriage rates and college attendance.

Finally, we assess whether the income measures and other statistics we construct from the linked Census-tax records are representative of corresponding measures in publicly available survey data.

\footnotetext{
${ }^{42}$ These comparisons are not exact because there are small differences between our sample definitions and the ACS. As discussed in Section III, our sample does not include unauthorized immigrants, whereas the ACS does, a factor that reduces our counts relative to the ACS. In the other direction, (1) we retain individuals who have died by 2015 whereas the ACS does not; (2) we retain individuals who were ever in the U.S. but left by 2015, whereas the ACS does not; and (3) some children may have immigrated to the U.S. after age 16 and still be claimed as dependents by parents.

${ }^{43}$ The ACS does not ask about immigration status, preventing us from comparing counts of authorized immigrants directly.
} 
In Online Appendix Table IV, we report summary statistics on income distributions (Panel A) and demographics (Panel B) for five different samples. The first two columns use the (publicly available) 2012-2016 Current Population Survey (CPS) and 2012-2016 ACS, focusing on individuals in the 1978-83 birth cohorts who were born in the U.S. or came to the U.S. before age 16. Column 3 uses data from the 2015 ACS who appear in our analysis sample, and measures their incomes and other characteristics in the ACS data. As shown in Online Appendix Table III, the individuals in the linked analysis sample have slightly higher incomes than those in the ACS in general, with a median income of $\$ 33,860$ vs. $\$ 32,810$ in the publicly available ACS and $\$ 33,000$ in the CPS.

Column 4 uses the same sample as Column 3, but reports income data from the tax records. Income distributions measured in the tax records are very well aligned with the ACS. For example, median income is $\$ 33,340$ when measured in the tax data and $\$ 33,860$ in the ACS data holding the sample of individuals fixed. Column 5 assesses the extent to which estimates of income in tax records are biased due to non-filing. It shows statistics on income and other characteristics using ACS data for individuals who appear in both the ACS and the analysis sample, but who have zero income in the tax data in 2015 (i.e., those who have no 1040 or $\mathrm{W}-2$ forms in 2015). The median income of these individuals is $\$ 5,000$ in the ACS, showing that individuals we assign zero income based on tax records typically have very low incomes in survey data as well. Hence, the tax records do not miss substantial amounts of income for non-filers.

In sum, comparisons to nationally representative surveys show that our analysis sample provides an accurate representation of our target population in terms of overall coverage rates and sample characteristics and that the tax records provide valid measures of income.

\section{Construction of Individual-Level Variables}

In this appendix, we present comprehensive definitions of the variables we use in our primary analysis, expanding upon the brief definitions given in Section 3.2.

Variable Definitions for Parents.

Income. In years where a parent files a tax return, we define household income as Adjusted Gross Income (as reported on the 1040 tax return) plus tax-exempt interest income and the nontaxable portion of Social Security and Disability benefits. In years where a parent does not file a tax return, household income is coded as zero. ${ }^{44}$ Following Chetty, Hendren, Kline and Saez (2014), we define our baseline parental income measure as the mean of parents' household income over five years: 1994, 1995, and 1998-2000, as tax records are unavailable in 1996 and $1997 .{ }^{45}$ We exclude children whose mean parent income is zero or negative (1.0\% of children) because parents who file tax returns (as is required to link them to a child) reporting negative or zero income typically have large capital losses, which are a proxy for having significant wealth.

Marital Status. We identify parents' marital status based on their tax filing status in the year the child is first claimed as a dependent by parents. We say that a child has a "father present" if

\footnotetext{
${ }^{44}$ Prior work (e.g., Chetty, Hendren, Kline and Saez 2014) has used information from W-2 forms to measure income for non-filers. We cannot follow that approach here since income data from W-2 forms are unavailable at the Census Bureau before 2005. However, this has little impact on results; Chetty, Hendren, Kline and Saez (2014) show that in 2000, the median W-2 income among parents who were non-filers was $\$ 29$, and only $2.9 \%$ of parents do not file in a given year. Information from W-2s is more important when measuring the incomes of children in early adulthood, for whom we do have W-2 data at the Census Bureau.

${ }^{45}$ Formally, we define mean household income as the mother's individual income plus the father's individual income in each year of 1994-95 and 1998-2000 divided by 10 (or divided by 5 if we only identify a single parent). For parents who do not change marital status, this is simply mean household income over the 5 year period. For parents who are married initially and then divorce, this measure tracks the mean household incomes of the two divorced parents over time. For parents who are single initially and then get married, this measure tracks individual income prior to marriage and total household income (including the new spouse's income) after marriage.
} 
one of the tax filers who claims the child as a dependent in that year is male.

Educational Attainment. We obtain information on the highest level of education parents have completed from the American Community Survey and the 2000 Census long form, prioritizing information from the ACS (which is more recent) if both sources are available. We define "parental education" as the mother's education if available; if not, we use the father's education. We define seven categories of parental education: no school, less than a high school degree, high school degree, college with no degree, associate's degree, bachelor's degree, and post-graduate degree. Education (and all other variables obtained from the ACS or Census long form) are coded as missing for individuals who do not appear in the ACS or Census long form samples.

Location. In each year, parents are assigned an address based on the address from which they filed their 1040 tax return. For non-filers, we use address information from information returns such as W-2s, which are available beginning in 2003. ${ }^{46}$ Addresses are coded as missing in years when a parent does not file or does not have an information return. For children whose parents were married when they were first claimed as dependents, we prioritize the mother's location if marital status changes. Addresses are mapped to geographies such as Census tract or Census block using a geocoding algorithm developed by the Census Bureau (see Online Appendix A for details).

U.S. Native Status. Children are defined as having a "native-born" mother if their mother was surveyed in the 2000 Census long form or the ACS and reported being born in the United States in either survey.

Variable Definitions for Children.

Income. We define children's annual household income in the same way as parents' income except in our treatment of non-filers. Since W-2 data are available for the years in which we measure children's incomes, we define income for a child who does not file a tax return as wage earnings reported on form W-2. We define children's individual incomes as their own W-2 wage earnings plus self-employment and other non-wage income, which we define as Adjusted Gross Income minus total wages reported on form 1040 divided by the number of tax filers (thereby splitting non-wage income equally for joint filers). In years in which children have no tax return and no information returns, both individual and household income are coded as zero.

Marriage. A child's marital status is measured based on whether he or she files a tax return jointly in 2015.

Gender and Age. Gender and age are obtained from the Numident file.

Employment. We use two measures of employment, one based on the tax data and one based on the ACS. In the tax data, children are defined as working if they have non-zero individual income in either 2014 or 2015. In the ACS, children are defined as working if they report positive weeks worked in the past year. This and all other employment-related ACS measures described below are defined only among children who receive the ACS at age 30 or later.

Hours Worked. Annual hours worked are measured in the ACS as the product of hours worked per week and weeks worked per year. Individuals report weeks worked in bins; we use the midpoint of the bin to assign each individual a single value (e.g., those who choose "27 to 39 weeks" are assigned a value of 33). We convert the annual measures to average weekly hours worked by dividing annual hours worked by 51 (the midpoint of the top bin of weeks worked). Those not working in any week are coded as having zero hours of work.

Hourly Wage. Hourly wages are measured in the ACS by dividing reported annual wage and salary income by annual hours worked. The hourly wage is coded as missing for those with zero hours worked.

\footnotetext{
${ }^{46}$ Address information from W-2s starts in 2003, but income amounts are not available until 2005.
} 
Occupation. We obtain information on children's occupations from the ACS for children who have positive hours worked.

Incarceration. Using data from the 2010 Census short form, we define an individual as incarcerated on the day of the Census (April 1, 2010) based on whether he or she lives in any of the following types of group quarters: federal detention center, federal prison, state prison, local jail, residential correctional facility, military jail, or juvenile correctional facility.

Location. Children's locations are measured based on the address from which they file tax returns in 2015. For non-filers, we obtain address information from W-2 forms and other information returns. If no address information is available in 2015, we use the most recent year in which an address is available.

\section{Construction of Tract-Level Covariates}

This appendix provides definitions and sources for the covariates used in Section VII.B. Our source data are primarily at the Census tract level; all data obtained at other geographies were aggregated to the tract level (with the exception of measures of racial bias, which are only available at broader geographical levels). We use 2010 Census tract definitions throughout. For variables defined using 2000 tract boundaries, we use the 2010 Census Tract Relationship Files from the US Census Bureau to crosswalk 2000 tracts to 2010 tracts, weighting the 2000 tract-level covariates by the fraction of the 2010 tract population that lives within the 2000 tract boundaries.

We organize the covariates using the categories used in Online Appendix Table XI.

Economy. We calculate the share of individuals below the poverty line for all individuals and by race in each tract using tables NP087B and NP159B of the National Historical Geographic Information System (NHGIS) database (2000 Census long form SF3a). To estimate the mean household income for each tract, we use data on the distribution of households in 16 income bins from table NP052A of the NHGIS database (2000 Census long form SF3a). We assume that the mean household income in each bin equals the middle of the bin and impute a mean value of $\$ 300,000$ for the highest income bin $(\$ 200,000$ or more). We then calculate the mean household income for each tract using the distribution of households over income bins in the tract. We obtain employment rates by race and sex in each tract using table NP150E of the NHGIS database (2000 Census long form SF3a). We define the share working in manufacturing as the number of workers employed in the manufacturing industry over the total number of workers (in the sample of people who are 16 years and older). These data are from table NP049C of the NHGIS database (2000 Census long form SF3a).

Schools. Data for 3rd and 8th grade test scores are downloaded from the Stanford Education Data Archive (table MeanA_V1.1) and measured at the district level. We create a crosswalk from districts to tracts by weighting by the proportion of land area that a given school district covers in a tract.

Health. The share without health insurance is constructed using tract-level data from table B27001 of the American Community Survey (2008-2012) using the NHGIS database by subtracting the number of people ages 18-64 with health insurance from the total tract-level population and then dividing this number by the total tract-level population.

Family Structure. We define the share of single parents in each tract as the number of households with female heads (and no husband present) or male heads (and no wife present) with own children under 18 years old present divided by the total number of households with own children present. The data come from tables NP018E and NP018G of the NHGIS database (2000 Census short form SF1a). We calculate the share married and share divorced in each tract using the number of people who are married or divorced (in the sample of people who are 15 years and older) using data from 
the NHGIS database in table NPCT007C (2000 Census long form SF3a). We estimate the share of children born to low-income parents growing up in a household with father present by race in each tract using our own Census microdata analysis sample. We first regress an indicator variable for whether a child was matched to a father (see Online Appendix A) on a child's parent income percentile for each tract and race using our analysis sample (children in the 1978-83 birth cohorts). We then use the predicted value at the 25 th percentile of the parent income distribution as the estimate for each tract and race group to measure father presence at the 25th percentile. We estimate the share of children born to low-income parents growing up in a household with a mother present by race and tract analogously.

Demographics. The demographic variables are constructed from tract-level Census data using the NHGIS database. The share of black residents is defined as the share of non-Hispanic black residents who listed "Black" as their only race or as one of multiple races in the 2010 Census (long form SF1, table H73). The share of the population younger than 18 is defined as the number of persons under 18 in the 2000 Census divided by the total tract-level population (long form SF1a, table NP012B). The share foreign born is defined as the number of foreign born residents in the 2000 Census divided by the sum of native and foreign born residents (long form SF3a, table NP021A).

Education. The education variables are constructed from tract-level 2000 Census data using the NHGIS database (long form SF3, table NP037C). The share that have less than a high school education is calculated by dividing the number of people over 25 who did not graduate from high school by the total number of people over 25 in a tract. The share of college educated is calculated by dividing the number of people over 25 who have a bachelor's degree, master's degree, professional school degree, or doctorate degree over the total number of people over 25 in a tract.

Housing. The housing variables are constructed from tract-level Census and ACS data using the NHGIS database. Population density is calculated by dividing the total tract-level population in the 2000 Census by the land area of 2010 Census tract boundaries measured in square kilometers (long form SF1a, table NP001A). The share who own homes is calculated by dividing the number of housing units owned in the 2000 Census by the total number of housing units in a tract (long form $\mathrm{SF} 1 \mathrm{a}$, tables $\mathrm{H} 1$ and $\mathrm{H} 4)$. The median two-bedroom rent variable is constructed from tract-level ACS data (2011-2015) and is defined as the median gross rent for renter-occupied housing units with two bedrooms that pay cash rent (table AD79). The black median home value variable is defined as the median value of owner-occupied housing units for black homeowners in the 2000 Census; white median home value is defined analogously for whites (long form SF3a, tables NHCT042A and NHCT042C).

Racial Bias. We construct racial bias measures using three data sources. Implicit Association Test (IAT) scores were obtained from the Race Implicit Association Database, available at Journal of Open Psychology. The IAT score is a measure of racial bias that is constructed by measuring the difference in a participant's ability to match positive and negative words with black vs. white faces, where higher IAT scores represent more implicit bias toward black faces (Greenwald, McGhee and Schwartz 1998). We calculate mean IAT racial bias scores for white and black study participants at the county level, pooling data from 2003-2016.

The Racial Animus Index is obtained from Stephens-Davidowitz (2014). It is a measure of the frequency of racially charged Google searches at the media market level, which are aggregations of counties.

The interracial marriage attitude data are constructed by Mas and Moretti (2009) using publicly available data from the General Social Survey. They measure the fraction of white voters who support anti-interracial-marriage laws by state.

\section{E. Evolution of Racial Disparities with Gender Heterogeneity}


This appendix extends the model developed in Section II to show how racial disparities evolve when racial gaps in intergenerational mobility differ by gender.

For simplicity, we ignore marital choices and assume that each family $i$ consists of a man and a woman in each generation. We model the individual income of a person of gender $g \in\{m, f\}$ in family $i$ in generation $t$ as

$$
y_{i, t}^{g}=\alpha_{r}^{g}+\beta_{m} y_{i, t-1}^{m}+\beta_{f} y_{i, t-1}^{f}+\varepsilon_{i g t}
$$

where $y_{i, t-1}^{g}$ denotes the individual income of a parent of gender $g$, and $\varepsilon_{i g t}$ denotes an idiosyncratic shock that is independent across generations and genders and has expectation $E\left[\varepsilon_{i g t}\right]=0$. Note that we assume that relative mobility $\left(\beta_{m}, \beta_{f}\right)$ does not vary across races in this specification, consistent with our empirical findings.

In steady-state, the mean rank of each gender satisfies $\bar{y}_{i, t}^{g}=\bar{y}_{i, t-1}^{g}$. The steady state mean income rank for individuals of gender $g$ and race $r$ is given by:

$$
\bar{y}_{r}^{g}=\frac{\left(1-\beta_{-g}\right) \alpha_{r}^{g}+\beta_{-g} \alpha_{r}^{-g}}{1-\beta_{r}^{m}-\beta_{r}^{f}},
$$

where $-g$ denotes the other gender, i.e., $-g=m$ if $g=f$.

If $\Delta \alpha^{f}=\alpha_{w}^{f}-\alpha_{b}^{f}=0$, as we find empirically, then the black-white gap for women in the steady state is directly proportional to the black-white intergenerational gap for men, $\Delta \alpha^{m}$ :

$$
\Delta \bar{y}^{f}=\frac{\beta_{m}}{1-\beta_{m}-\beta_{f}} \Delta \alpha^{m} .
$$

We caution that the abstraction from marital choices in this model is not innocuous. In practice, closing intergenerational gaps in income for fathers may require both closing the gap in men's incomes and closing the gap in marital rates, if fathers' incomes matter more if they are part of the household raising the child. We cannot investigate this issue empirically because we cannot link children to their fathers if the father is not present in their household (i.e., does not claim them as a dependent). We therefore focus on understanding intergenerational gaps in income.

\section{F. Correction for Imperfect Measurement of Wealth}

This appendix describes how we adjust for the bias that arises from the fact that we only have partial measures of wealth in the ACS data by using information on total wealth from the Survey of Consumer Finances (SCF).

Estimand. We wish to estimate the following regression equation, analogous to the specification in (5):

$$
y_{i, c}=a+b_{p}\left(y_{i, p}-\bar{p}\right)+b_{w} \text { white }_{i}+b_{w p} \text { white }_{i}\left(y_{i, p}-\bar{p}\right)+c X_{i}+d \text { wealth }_{i}+e_{i},
$$

where $\bar{p}$ is the percentile of the income distribution at which we are estimating the black-white intergenerational gap (e.g., $\bar{p}=25$ ) and wealth ${ }_{i}$ is a parent's rank in the national wealth distribution for parents. The parameter of interest is $b_{w}$, which represents the black-white intergenerational gap conditional on family-level characteristics and wealth for children with parents at percentile $\bar{p}$ of the income distribution.

Missing Data Problem. In the linked ACS-Census-tax records dataset (which we refer to as the ACS dataset below for simplicity) that we use for our primary analysis, we observe race, children's outcomes, and proxies for wealth, but not total wealth itself. In the SCF data, we observe race, proxies for wealth, and total wealth, but not children's outcomes. Our goal is to combine these two 
datasets - each of which are representative samples of the U.S. population by design - to overcome these missing data problems.

Feasible Estimator. We begin by estimating the following two regressions of children's income ranks in adulthood on race, parental income, and controls in the ACS data:

$$
\begin{gathered}
y_{i, c}=\tilde{a}+\tilde{b}_{p}\left(y_{i, p}-\bar{p}\right)+\tilde{b}_{w} \text { white }_{i}+\tilde{b}_{w p} \text { white }_{i}\left(y_{i, p}-\bar{p}\right)+\tilde{c} X_{i}+\tilde{e}_{i}, \text { and } \\
y_{i, c}=\hat{a}+\hat{b}_{p}\left(y_{i, p}-\bar{p}\right)+\hat{b}_{w} \text { white }_{i}+\hat{b}_{w p} \text { white }_{i}\left(y_{i, p}-\bar{p}\right)+\hat{c} X_{i}+\hat{g} Z_{i}+\hat{e}_{i},
\end{gathered}
$$

where $Z_{i}$ is a vector of wealth proxies for parental wealth (e.g., home value, vehicle value, etc.). The parameter $\tilde{b}_{w}$ in equation (9) estimates the black-white gap without controlling for wealth. Equation (10) controls for wealth proxies, but omits the portion of wealth that is not captured by the proxy variables. To adjust for omitted variable bias in $\hat{b}_{w}$ that arises from controlling for wealth imperfectly using the SCF data, we make the following assumption.

Assumption 1 (ExClusion Restriction) Conditional on total wealth, children's outcomes are independent of the wealth proxies:

$$
y_{i, c} \Perp Z_{i} \mid y_{i, p}, \text { white }_{i}, X_{i}, \text { wealth }_{i}
$$

Intuitively, this exclusion restriction requires that the wealth proxies affect a child's income rank only when we do not condition on wealth itself. Equivalently, the exclusion restriction requires that the observed component of wealth captured by the proxies has the same effect on children's outcomes as the unobserved component. For example, an additional dollar of home equity wealth (which is observed in the ACS) must have the same effect on children's outcomes as an additional dollar of financial wealth (which is unobserved). Under this assumption, we can use the link between home equity wealth and children's outcomes that we can estimate in the ACS data to determine how controlling for total wealth would affect the black-white gap, based on the relationship between total wealth and home equity wealth estimated in the SCF.

Formally, we estimate the following two regressions of total wealth on race, income, and controls in the SCF data:

$$
\begin{aligned}
& \text { wealth }_{i}=\tilde{\mu}+\tilde{\lambda}_{y}\left(y_{i, p}-\bar{p}\right)+\tilde{\lambda}_{w} \text { white }_{i}+\tilde{\lambda}_{w y} \text { white }_{i}\left(y_{i, p}-\bar{p}\right)+\tilde{\lambda}_{X} X_{i}+\tilde{v}_{i} \text {, and } \\
& \text { wealth }_{i}=\hat{\mu}+\hat{\lambda}_{y}\left(y_{i, p}-\bar{p}\right)+\hat{\lambda}_{w} \text { white }_{i}+\hat{\lambda}_{w y} \text { white }_{i}\left(y_{i, p}-\bar{p}\right)+\hat{\lambda}_{X} X_{i}+\hat{\lambda}_{Z} Z_{i}+\hat{v}_{i} .
\end{aligned}
$$

The parameter $\tilde{\lambda}_{w}$ in equation (11) represents the black-white wealth gap conditioning on parent income and other baseline covariates. The analogous parameter $\hat{\lambda}_{w}$ in equation (12) represents the black-white wealth gap after we additionally control for the wealth proxies $Z_{i}$ observed in the ACS. If the wealth proxies perfectly capture total wealth, then $\hat{\lambda}_{w}=0$; if they capture none of the gap in wealth, then $\hat{\lambda}_{w}=\tilde{\lambda}_{w}$.

We now show how we can identify the estimand $b_{w}$ based on estimates of $\left\{\tilde{b}_{w}, \hat{b}_{w}, \tilde{\lambda}_{w}, \hat{\lambda}_{w}\right\}$. Let $\tilde{x}$ denote the value of a variable $x$ after residualizing with respect to $y_{i, p}$, white ${ }_{i} \cdot y_{i, p}, X_{i}$, and a 
constant term. Then we can write the OLS regression coefficient for $\tilde{b}_{w}$ in $(9)$ as:

$$
\begin{aligned}
& \tilde{b}_{w}=\frac{\operatorname{Cov}\left[b_{w} \text { white }_{i}+d \text { weâlth }_{i}+e_{i}, \text { white }_{i}\right]}{\operatorname{Var}\left[\text { white }_{i}\right]} \\
& =\frac{\operatorname{Cov}\left[b_{w} \text { white }_{i}+d\left(\tilde{\mu}+\tilde{\lambda_{w} \text { white }_{i}}+\tilde{v}_{i}\right)+e_{i}, \text { white }_{i}\right]}{\operatorname{Var}\left[\text { white }_{i}\right]} \\
& =b_{w}+d \tilde{\lambda}_{w}
\end{aligned}
$$

Analogously,

$$
\hat{b}_{w}=b_{w}+d \hat{\lambda}_{w} .
$$

Equations (13) and (14) form a system of two equations with two unknowns $\left(b_{w}\right.$ and $\left.d\right)$. Solving the system yields the following expression for the degree of bias in our estimate of the intergenerational gap $\hat{b}_{w}$ when controlling for wealth proxies in the ACS relative to the target parameter $b_{w}$ one would obtain when controlling for total wealth:

$$
\tilde{b}_{w}-b_{w}=\frac{\tilde{b}_{w}-\hat{b}_{w}}{\left(\tilde{\lambda}_{w}-\hat{\lambda}_{w}\right) / \tilde{\lambda}_{w}} .
$$

The denominator of this expression, $\frac{\tilde{\lambda}_{w}-\hat{\lambda}_{w}}{\tilde{\lambda}_{w}}$, measures the share of the black-white wealth gap explained by the ACS proxies, i.e. the extent to which our ACS measures capture the total blackwhite wealth gap. Equation (15) shows that the degree of bias in our estimate of $b_{w}$ can be estimated simply by inflating the observed effect of the wealth proxies on the intergenerational gap $\left(\tilde{b}_{w}-\hat{b}_{w}\right)$ in the ACS by this share.

Empirical Implementation. We implement this estimator using data from the $2001 \mathrm{SCF}$, the closest year available to 2000, when our wealth proxies are observed in the Census long form and the ACS. We restrict the SCF sample to black and white families with children and use sampling weights to obtain estimates for a representative sample of the American population. We topcode the number of vehicles at five in the SCF data to match the top-coding in the ACS data.

Appendix Table XVII shows our estimates of $\left\{\tilde{b}_{w}, \hat{b}_{w}, \tilde{\lambda}_{w}, \hat{\lambda}_{w}\right\}$ and the resulting estimate of $b_{w}$ for boys growing up in families at the 25 th and 75 th percentiles of the national income distribution. The first column considers families at the 25th percentile of the national income distribution. Controlling for the wealth proxies reduces the intergenerational income gap estimated in the ACS from $\tilde{b}_{w}=9.1$ (Row 1) to $\hat{b}_{w}=8.4$ percentiles (Row 2). In the SCF data, the raw black-white wealth gap is $\tilde{\lambda}_{w}=9.2$ ranks (Row 3 ). This gap shrinks to $\hat{\lambda}_{w}=3.3$ ranks when we control for the wealth proxies observed in the ACS (Row 4). Hence, the wealth proxies observed in the ACS capture about two-thirds of the difference in mean wealth between blacks and whites.

Putting together these four estimates, we calculate the effect of controlling fully for wealth using equation (15). We divide the observed change in the black-white income gap when accounting for the wealth proxies $(9.1-8.4=0.7)$ in the ACS by the share of the wealth gap explained by the proxies $\left(\frac{9.2-3.3}{9.2} \approx 0.64\right)$ to arrive at our final wealth-controlled estimate of the black-white gap of $b_{w}=9.1-\frac{0.7}{0.64}=8.0$ (Row 5$)$.

The adjustment for imperfect measurement of wealth in the ACS reduces the black-white gap at the 25 th percentile by only 0.4 percentiles - from 8.4 to 8.0 ranks - because the wealth proxies available in the ACS explain the majority of the racial wealth gap for parents at the 25th percentile of the national income distribution. Intuitively, low-income families hold the vast majority of their wealth in the illiquid assets that are captured in the ACS. The correction for imperfect 
measurement of wealth has a slightly larger effect at the 75 th percentile of the national income distribution (Column 2), reducing the estimated black-white gap from $\hat{b}_{w}=11.0$ to $b_{w}=10.2$ percentiles.

\section{G. Causal Effects of Neighborhoods}

In this appendix, we provide further details on the sample construction, variable definitions, and empirical specifications used in Section VII.C to estimate childhood exposure effects. We then assess the robustness of the findings shown in Figure XIII by discussing the additional regression estimates shown in Online Appendix Table XV.

Sample Construction and Variable Definitions. Our core sample and data construction are the same as that described in Section III, but we expand the sample in two directions that increase our ability to observe moves at younger ages. First, we extend our analysis sample to include the 1978-1985 cohorts. ${ }^{47}$ Second, we study income ranks measured at age 30, in addition to ranks of pooled incomes over ages 31-37 in our analysis above. Chetty, Hendren, Kline and Saez (2014) show that although children's incomes from different backgrounds continue to diverge in levels, the relationship between children's income ranks (relative to their cohort peers) and parental income stabilizes after age 30 .

Using the location of each child's parents in each year in our sample, we form a sample of one-time movers, defined as children whose parents move across CZs exactly once when they are age 28 or below. ${ }^{48}$ We define the year of the move as the tax year in which the parents report living in a different CZ relative to the previous year. In cases where we do not observe sequential years of location information (e.g. we do not have tax records for 1990-93 and 1996-97), we assign the year of move as the midpoint between the two nearest years in which different addresses are reported (e.g. if we see a new location in 1994 relative to 1989, we assign the year of move as 1992.5). In cases where this leads to a non-integer year of move, we randomly select the nearest year for the move (1992 or 1993 in the case above). We then define the child's age at the time of the move as the year of the move minus the child's cohort.

Following Chetty and Hendren (2018a), we make three additional sample restrictions. First, we restrict to moves between destinations and origins that have at least 25 observations used to calculate $\bar{y}_{p o s}$ and $\bar{y}_{p d s}$ and exclude a small number of observations where either $\bar{y}_{p o s}$ or $\bar{y}_{p d s}$ falls outside [0,1]. As shown in Online Appendix A of Chetty and Hendren (2018a), imposing such sample restrictions limits the degree of attenuation bias from sampling error in the $\bar{y}_{\text {pcs }}$ estimates. ${ }^{49}$ Second, we require that we are able to observe the parents for at least two years after the move in order to enter the sample (i.e. we only consider moves through 2013, since location is observed until 2015). Third, we require that families move at least 100 miles. This distance restriction ensures that the children's environments are actually changing and helps rule out cases where families move very short distances that happen to cross CZ boundaries.

We use the sample of children whose parents are not one-time movers, i.e. those observed in exactly one or $3+\mathrm{CZs}$, to estimate children's predicted outcomes $\bar{y}_{\text {pcs }}$. In the one-time movers sample, we have roughly 150,000 black male children and 884,000 white male children for whom we observe income at age 30 .

Empirical Specification for Figure XIII. Using the sample of one-time movers, we consider

\footnotetext{
${ }^{47}$ We also include the 1986 cohort in our analysis of incarceration.

${ }^{48}$ When constructing the sample, we observe location up to age 30 . But, as discussed below, we follow Chetty and Hendren (2018a) and require that we observe the parents in the destination for at least two years. Therefore, the oldest age of move for the parents is 28 .

${ }^{49}$ Chetty and Hendren (2018a) use population restrictions of 250,000 in the 2000 Census. We instead use count restrictions on $\bar{y}_{p c s}$ because many of our specifications focus on small subsamples, such as black males.
} 
the outcomes of child $i$ with parental income rank $p_{i}$ who moved at age $m_{i}$ from origin $\mathrm{CZ}, o$, to destination $\mathrm{CZ}, d$. We estimate childhood exposure effects on a given outcome $y_{i}$ using a specification analogous to that developed in Chetty and Hendren (2018a), estimated separately for a given subgroup (e.g., black males or white females). Let $\bar{y}_{p c s}$ denote the exposure-weighted outcome of $y_{i}$ for children who grew up in $\mathrm{CZ} c$ with parental income rank $p=p_{i}$, estimated using equation (6). Let $\Delta_{o d p s}=\bar{y}_{p d s}-\bar{y}_{p o s}$ denote the difference in the income rank of exposure-weighted residents in the destination versus origin for children in cohort $s$ with parental income rank $p$. We run a regression of the form described in the text:

$$
\begin{aligned}
y_{i, c}= & \sum_{s=1978}^{1985} I\left(s_{i}=s\right)\left(\phi_{s}^{1}+\phi_{s}^{2} \bar{y}_{p o s}\right)+\sum_{m=6}^{28} I\left(m_{i}=m\right)\left(\zeta_{m}^{1}+\zeta_{m}^{2} y_{i, p}\right) \\
& +\sum_{m=6}^{28} b_{m} I\left(m_{i}=m\right) \Delta_{o d p s}+\varepsilon_{1 i},
\end{aligned}
$$

where $\phi_{s}^{1}$ is a cohort-specific intercept and $\phi_{s}^{2} \bar{y}_{p o s}$ is a control for the average exposure-weighted outcome in the origin in which the coefficient is allowed to vary by cohort. These terms control for selection effects in the origin $\mathrm{CZ}$ that children are coming from. Next, $\zeta_{m}^{1}$ is an intercept and $\zeta_{m}^{2} y_{i, p}$ is an interaction with parental income rank that vary with the child's age at the time of the move, $m$. These terms control for heterogeneous disruption or selection effects that may occur with moves at different ages and vary with parental income. Finally, the key coefficients of interest, $b_{m}$, provide estimates of childhood exposure effects and are plotted in Figure XIII. The exposure effect at age $m$, given by $b_{m}-b_{m+1}$, can be interpreted as the causal effect of moving at age $m$ instead of $m+1$ to a $\mathrm{CZ}$ in which children have 1-unit higher outcomes under our identification assumption. ${ }^{50}$

Empirical Specifications for Online Appendix Table XV. In Columns 1-6 of Online Appendix Table XV, we estimate parametric models that use linear splines over the age ranges above and below 23 to estimate average exposure effects. These specifications replace the non-parametric $\sum_{m=6}^{28} b_{m} I\left(m_{i}=m\right) \Delta_{\text {odps }}$ term with a linear spline and have the form:

$$
\begin{aligned}
y_{i, c}= & \sum_{s=1978}^{1985} I\left(s_{i}=s\right)\left(\phi_{s}^{1}+\phi_{s}^{2} \bar{y}_{p c s}+\phi_{s}^{3} \bar{y}_{p c s}^{\sim r}\right)+\sum_{m=6}^{28} I\left(m_{i}=m\right)\left(\zeta_{m}^{1}+\zeta_{m}^{2} y_{i, p}\right) \\
& +1\left\{m_{i} \leq 23\right\}\left(\delta_{\leq 23}+m \gamma_{\leq 23}\right) \Delta_{\text {odps }}+1\left\{m_{i}>23\right\}\left(\delta_{>23}+m \gamma_{>23}\right) \Delta_{o d p s}+\epsilon_{2 i},
\end{aligned}
$$

The under-23 own-race coefficient reported in Online Appendix Table XV is $\gamma_{\leq 23}$, while the over-23 own-race placebo is $\gamma_{>23}$ in this specification.

To test whether the race-specific differences in observed outcomes across areas reflect the causal effect of childhood exposure, we add the outcomes of the other race to the regression in equation

\footnotetext{
${ }^{50}$ Equation (16) is identical to the baseline specification in equation (6) of Chetty and Hendren (2018), with the exception that we do not include a cohort-varying intercept term, $\sum_{s=1978}^{1985} \kappa_{s}^{d} \Delta_{\text {odps }}$. We make this modification because below we use the specification here in much smaller subsamples (e.g., black males). With few observations in some cohorts, including these terms introduces additional noise in the estimates. Chetty and Hendren (2018) verify that the exclusion of these interactions does not meaningfully affect their results.
} 
(17) in Columns 7-12 of Online Appendix Table XV:

$$
\begin{aligned}
y_{i, c}= & \sum_{s=1978}^{1985} I\left(s_{i}=s\right)\left(\phi_{s}^{1}+\phi_{s}^{2} \bar{y}_{p c s}+\phi_{s}^{3} \bar{y}_{p c s}^{\sim r}\right)+\sum_{m=6}^{28} I\left(m_{i}=m\right)\left(\zeta_{m}^{1}+\zeta_{m}^{2} y_{i, p}\right) \\
& +1\left\{m_{i} \leq 23\right\}\left(\delta_{\leq 23}+m \gamma_{\leq 23}\right) \Delta_{\text {odps }}+1\left\{m_{i}>23\right\}\left(\delta_{>23}+m \gamma_{>23}\right) \Delta_{\text {odps }}, \\
& +1\left\{m_{i} \leq 23\right\}\left(\delta_{\leq 23}^{\sim r}+m \gamma_{\leq 23}^{\sim r}\right) \Delta_{\text {odps }}^{\sim r}+1\left\{m_{i}>23\right\}\left(\delta_{>23}^{\sim r}+m \gamma_{>23}^{\sim r}\right) \Delta_{\text {odps }}^{\sim r}+\varepsilon_{3 i}
\end{aligned}
$$

where $\bar{y}_{p c s}^{\sim r}$ and $\Delta_{\text {odps }}^{\sim r}$ are the outcomes of white (black) children when running a regression on the sample of black (white) children. Here, $\gamma_{\leq 23}^{\sim r}$ is the under-23 other-race placebo reported in Online Appendix Table XV, while $\gamma_{>23}^{\sim r}$ is the over-23 other-race placebo.

Results. Online Appendix Table XV presents estimates of average annual exposure effects by replacing the age-at-move fixed effects $\left\{b_{m}\right\}$ with a linear parametrization of age at move, separately for childhood $(m \leq 23)$ and adulthood $(m>23)$. Columns 1-4 show that this specification yields estimates of annual childhood exposure effects - the impact of moving to a $\mathrm{CZ}$ with 1 unit better outcomes one year earlier in childhood - similar to those reported in Figure XIII for income and incarceration. For example, the estimate in Column 1 implies that moving one year later in childhood to an area where black boys have 1 percentile higher incomes in adulthood $\left(\Delta_{\text {odps }}^{b}=1\right)$ reduces a black boy's income rank by -0.027 . That is, an additional year of exposure to an area with 1 percentile better outcomes increases a child's own income rank by 0.027 . Columns 5 and 6 report analogous estimates of annual exposure effects for marriage rates. Every year of exposure to a $\mathrm{CZ}$ in which black males are $1 \mathrm{pp}$ more likely to be married at age 30 increases a black boy's likelihood of being married at age 30 by $0.023 \mathrm{pp}$. We find a nearly identical effect of $0.023 \mathrm{pp}$ for white males.

These results show that places have causal effects on the levels of children's outcomes in adulthood; but do they have causal effects on the gap in outcomes across races? That is, if a black and white boy both spend an additional year of childhood in a place where we observe a larger black-white gap, do we find differential effects on their outcomes? We estimate causal effects on racial gaps in Columns 7-12 of Online Appendix Table XV using an expanded specification that predicts the outcomes of black movers using not only the mean outcomes of black boys $\left(\bar{y}_{\text {pls }}^{b}\right)$ but also the outcomes of white boys $\left(\bar{y}_{p l s}^{w}\right)$ who grow up in the origin and destination CZs (and vice versa for white movers).

In Column 7, we regress the income ranks of black movers on predicted outcomes for black and white men. Moving one year later in childhood to an area where black boys have 1 percentile higher incomes in adulthood reduces a black boy's income rank by -0.029 (s.e. $=0.004$ ), similar to the baseline estimate in Column 1. In contrast, the corresponding coefficient on the change in predicted income ranks for white men $\left(\Delta_{\text {odps }}^{w}\right)$ is -0.003 (s.e. $=0.004$ ). Hence, moving to an area with better outcomes for white boys has essentially no impact on a black boy's outcomes conditional on the outcomes of black boys who grow up in that area.

Column 8 shows that the converse is true for white men. Here, we estimate an age-at-move slope of -0.023 (s.e. $=0.002$ ) on the predicted income ranks of white males $\left(\Delta_{\text {odps }}^{w}\right)$, but a coefficient of only -0.004 (s.e. $=0.001$ ) on the predicted income ranks of black males $\left(\Delta_{\text {odps }}^{b}\right)$. Together, Columns 7 and 8 show that moving to an area with a larger observed black-white gap at an earlier age in childhood results in larger intergenerational gaps in adulthood. Columns 9-12 show analogous patterns for incarceration and marriage. 
Table I

Summary Statistics on Income Disparities and Intergenerational Mobility by Race

\begin{tabular}{ccccccc}
\hline \hline & White & Black & Asian & Hispanic American Indian \\
& $(1)$ & $(2)$ & (3) & (4) & (5) \\
\hline
\end{tabular}

A. Children's Individual Income in Adulthood

\begin{tabular}{lccccc}
\hline Median Income (\$) & 33,620 & 19,550 & 43,690 & 27,140 & 16,610 \\
Mean Percentile Rank & 53.3 & 42.0 & 60.3 & 48.1 & 39.6 \\
P(Child in Q1 | Parent in Q1) & $28.1 \%$ & $28.7 \%$ & $17.5 \%$ & $23.2 \%$ & $37.8 \%$ \\
P(Child in Q5 | Parent in Q1) & $11.1 \%$ & $6.3 \%$ & $26.8 \%$ & $10.8 \%$ & $5.3 \%$ \\
P(Child in Q1 | Parent in Q5) & $11.7 \%$ & $13.8 \%$ & $11.3 \%$ & $13.3 \%$ & $18.2 \%$ \\
P(Child in Q5 | Parent in Q5) & $36.9 \%$ & $26.2 \%$ & $49.9 \%$ & $31.4 \%$ & $24.1 \%$
\end{tabular}

B. Children's Household Income in Adulthood

\begin{tabular}{|c|c|c|c|c|c|}
\hline Median Income (\$) & 53,730 & 20,650 & 63,720 & 35,180 & 22,260 \\
\hline Mean Percentile Rank & 55.7 & 34.8 & 60.7 & 45.6 & 36.7 \\
\hline $\mathrm{P}($ Child in Q1 | Parent in Q1) & $29.0 \%$ & $37.3 \%$ & $16.7 \%$ & $24.8 \%$ & $45.5 \%$ \\
\hline $\mathrm{P}($ Child in Q5 | Parent in Q1) & $10.6 \%$ & $2.5 \%$ & $25.5 \%$ & $7.1 \%$ & $3.3 \%$ \\
\hline $\mathrm{P}$ (Child in Q1 | Parent in Q5) & $8.7 \%$ & $16.7 \%$ & $9.9 \%$ & $12.0 \%$ & $18.8 \%$ \\
\hline $\mathrm{P}$ (Child in Q5 | Parent in Q5) & $41.1 \%$ & $18.0 \%$ & $48.9 \%$ & $30.6 \%$ & $23.0 \%$ \\
\hline \multicolumn{6}{|l|}{ C. Parents' Incomes } \\
\hline Median Parent Household Income (\$) & 70,640 & 29,200 & 53,010 & 33,060 & 34,850 \\
\hline Mean Parent Household Income Rank & 57.9 & 32.7 & 49.2 & 36.2 & 36.8 \\
\hline Steady-State Household Income Rank & 54.4 & 35.2 & 62.9 & 48.7 & 36.5 \\
\hline Number of children (1000's) & 13,490 & 2,750 & 685 & 2,615 & 165 \\
\hline
\end{tabular}

Notes: This table presents summary statistics on income and intergenerational mobility by race/ethnicity; see Online Appendix Table $V$ for analogous statistics broken down by gender. All racial groups except Hispanics exclude individuals of Hispanic ethnicity. Panels A and B present descriptive statistics on children's individual and household incomes in adulthood, respectively, while Panel C presents summary statistics on parents' household incomes. All statistics are based on the primary analysis sample (children in the 1978-83 birth cohorts). Child income is the mean of 2014-2015 individual or household income (when the child is between 31-37 years old), while parent income is mean household income from 1994-1995 and 1998-2000. Children are assigned percentile ranks relative to all other children in their birth cohort, while parents are ranked relative to all parents with children in the same birth cohort. Q1 and Q5 refer to the first and fifth quintiles of the relevant income distribution. All monetary values are measured in 2015 dollars. The steady-state household income rank is a prediction based on the model in Section II given observed rates of intergenerational mobility. All values in this and all subsequent tables and figures have been rounded to four significant digits as part of the disclosure avoidance protocol. Counts are rounded in the following manner: numbers between 10,000 and 99,999 are rounded to the nearest 500; between 100,000 and 9,999,999 to the nearest 1,000; and above 10,000,000 to the nearest 10,000. Sources for this and all subsequent tables and figures: authors' calculations based on Census 2000 and 2010, tax returns, and American Community Surveys 20052015. All statistics cleared under Census DRB release authorization CBDRB-FY18-195. 
Table II

Association Between Black Father Presence and Black Men's Upward Mobility Across Census Tracts: OLS Regression Estimates

Dependent Variable: Mean Individual Income Rank for Black Men Raised in Low-Income ( $p=25)$ Families

\begin{tabular}{|c|c|c|c|c|c|c|c|c|c|}
\hline & $\begin{array}{c}\text { Baseline } \\
\text { (1) } \\
\end{array}$ & $\begin{array}{l}\text { Black vs. } \\
\text { White Father } \\
\text { Presence } \\
(2)\end{array}$ & $\begin{array}{c}\text { State FE } \\
\text { (3) }\end{array}$ & $\begin{array}{c}\text { Children with } \\
\text { Fathers } \\
\text { Absent } \\
\text { (4) }\end{array}$ & $\begin{array}{l}\text { Children with } \\
\text { Two Parents } \\
\text { (5) }\end{array}$ & $\begin{array}{c}\text { Black Fathers } \\
\text { per Child } \\
\text { (6) }\end{array}$ & (7) & (8) & $\begin{array}{c}\text { Adulthood } \\
\text { Tract FE } \\
\text { (9) } \\
\end{array}$ \\
\hline Low-Income Black Father Presence & $\begin{array}{c}0.0492 \\
(0.0062)\end{array}$ & $\begin{array}{c}0.0450 \\
(0.0068)\end{array}$ & $\begin{array}{c}0.0501 \\
(0.0066)\end{array}$ & $\begin{array}{c}0.0279 \\
(0.0108)\end{array}$ & $\begin{array}{c}0.0461 \\
(0.0128)\end{array}$ & & & $\begin{array}{c}0.0806 \\
(0.0036)\end{array}$ & $\begin{array}{c}0.1052 \\
(0.0079)\end{array}$ \\
\hline Low-Income White Father Presence & & $\begin{array}{c}0.0077 \\
(0.0076)\end{array}$ & & & & & & & \\
\hline Low-Income Black Father Presence in 2000 & & & & & & $\begin{array}{c}0.0382 \\
(0.0043)\end{array}$ & $\begin{array}{c}0.0387 \\
(0.0043)\end{array}$ & & \\
\hline Low-Income Black Male Filers Per Child & & & & & & & $\begin{array}{c}-0.0011 \\
(0.0011)\end{array}$ & & \\
\hline Low Poverty Tracts & $\mathrm{x}$ & $\mathrm{x}$ & $\mathrm{x}$ & $\mathrm{x}$ & $\mathrm{x}$ & $\mathrm{x}$ & $\mathrm{x}$ & & \\
\hline State FE's & & & $\mathrm{x}$ & & & & & & \\
\hline Current Tract FE's & & & & & & & & & $\mathrm{x}$ \\
\hline Number of Tracts & 10,582 & 10,444 & 10,582 & 5,159 & 5,280 & 10,177 & 10,177 & 28,850 & \\
\hline Number of Individual Obs. & & & & & & & & & 193,000 \\
\hline
\end{tabular}

Notes: This table presents coefficients from OLS regressions run at the Census tract level, with standard errors reported in parentheses. The dependent variable in all columns is upward mobility for black males who grow up in a given Census tract. To construct upward mobility in a given tract c, we regress children's individual income ranks on parent income rank, weighting by the number of years that each child is observed below age 23 in tract c. We then define upward mobility as the predicted value from this regression at the 25th percentile of the parental income distribution. The key independent variable in Columns 1-5 is low-income black father presence. We define father presence as an indicator for whether a child is claimed by a male on a tax form in the year he is matched to a parent. We regress this indicator for father presence on parental income rank for each tract using equation (6), and define black father presence among low-income families as the prediction for black children at $\mathrm{p}=\mathbf{2 5}$. In Column 1, we regress upward mobility for black men on the fraction of low-income black fathers present, weighting by the number of black boys who grow up in each tract and restricting the sample to tracts with a poverty rate below $10 \%$ in the 2000 Census. The coefficient of 0.0492 implies that black boys who grow up in a tract with $10 \mathrm{pp}$ more low-income black fathers present have 0.5 percentile higher income ranks on average. Column 2 replicates Column 1 , including a control for low-income white father presence, which is defined analogously to black father presence. Column 3 adds state fixed effects to the baseline specification in Column 1. In Column 4, we replicate Column 1, but measure upward mobility only among black boys raised in families without a father present; Column 5 conversely measures upward mobility only among black boys raised in two-parent families. Column 6 replicates Column 1, replacing the independent variable with the number of below-median-income black fathers in the Census tract in 2000 divided by the number of children in our analysis sample, an alternative measure of father presence. Column 7 replicates Column 6 , adding the total number of low-income black males (not just fathers) per child as an additional regressor. Column 8 replicates the baseline specification in Column 1, but includes all available tracts instead of just low-poverty census tracts. Finally, Column 9 is analogous to Column 8 , but includes fixed effects for the tract in which children reside as adults (in 2015). In order to include these fixed effects, we estimate this specification at the individual level (unweighted). We restrict the sample to children who grew up in families with parents between the 20th and 30th percentiles of the parental income distribution and use their individual income rank as the dependent variable. All statistics cleared under Census DRB release authorization CBDRB-FY18-195. 
Table III

Association Between Racial Bias and Upward Mobility Across Counties and Media Markets: OLS Regression Estimates

Dep. Var.: Mean Individual Income Rank for Black Men Raised in Low-Income $(p=25)$ Families

Sample: $\quad$ Black Male Black Male Black Male $\quad \begin{gathered}\text { Black } \\ \text { Female }\end{gathered}$ White Male Black Male $\begin{gathered}\text { Black } \\ \text { Female White Male }\end{gathered}$

(1)

(2)

(3)

(4)

(5)

(6)

(7)

(8)

$\begin{array}{lcc}\text { Difference in IAT } & -0.0081 & \\ & (0.0024) & \\ \text { IAT Score for Whites } & -0.0080 \\ & & (0.0023) \\ \text { IAT Score for Blacks } & 0.0047 \\ & (0.0023)\end{array}$

Racial Animus Index

$\begin{array}{lll}-0.0060 & -0.0082 & -0.0097 \\ (0.0019) & (0.0029) & (0.0025)\end{array}$

$(0.0023)$

(0.0023)

$-0.0263-0.0191$

$-0.0203$

$\begin{array}{lll}(0.0056) & (0.0080) \quad(0.0042)\end{array}$

State FE's

$X$

$\begin{array}{lcccccccc}\text { Unit of Analysis } & \text { Counties } & \text { Counties } & \text { Counties } & \text { Counties } & \text { Counties } & \begin{array}{c}\text { Media } \\ \text { Markets }\end{array} & \begin{array}{c}\text { Media } \\ \text { Markets }\end{array} & \begin{array}{c}\text { Media } \\ \text { Markets }\end{array} \\ \begin{array}{l}\text { Number of Counties/Media } \\ \text { Markets }\end{array} & 340 & 340 & 340 & 325 & 340 & 28 & 27 & 28\end{array}$

Notes: This table presents coefficients from OLS regressions with standard errors reported in parentheses. Columns 1-5 examine the association between measures of implicit racial bias and children's income ranks in adulthood across counties. The implicit racial bias measures are based on mean scores on implicit association tests (IAT) for white and black study participants by county, obtained from the Race Implicit Association Database. All racial bias measures used in this table are standardized so that they have mean zero and standard deviation 1 across areas (weighting by the number of black males in our sample), with higher values representing greater racial bias against blacks. The dependent variable in Columns 1-3 is the predicted income rank for black men who grew up in low-income (25th percentile) families in a given county, constructed by taking a populationweighted average of the tract-level estimates of upward mobility described in the notes to Table II. Column 1 regresses this measure on the standardized difference in IAT scores for white vs. black respondents (whites' IAT minus blacks' IAT). Column 2 includes separate regressors for black and white respondents' IAT scores. Column 3 adds state fixed effects to the specification in Column 1. Column 4 replaces the dependent variable with the predicted individual income rank for black females with parents at the 25th percentile instead of black males. Column 5 replaces the dependent variable with the predicted individual income rank for white males at the 25 th percentile. Columns 6-8 present estimates from regressions using a standardized version of the Racial Animus measure constructed by Stephens-Davidowitz (2014) at the media market level as the independent variable. These columns use the same dependent variables as Columns 3-5 aggregated to the media market level. We limit the sample to counties or media markets with poverty rates below $10 \%$ in the 2000 Census in all specifications and weight the regressions by the number of black men in the relevant geographic unit. All statistics cleared under Census DRB release authorization CBDRB-FY18-195. 


\section{A. Family-Level Factors}

$\begin{array}{ll}\text { Parental Income } & \text { Magnuson \& Duncan 2006; Rothstein \& Wozny } 2013 \\ \text { Parental Human Capital \& Wealth } & \text { Oliver \& Shapiro 1995; Orr 2003; Conley } 2010 \\ \text { Family Structure and Stability } & \text { McAdoo 2002; Burchinal et al. } 2011 \\ \text { Ability at Birth } & \text { Hernstein \& Murray 1994 and Rushton \& Jensen } 2005 \text { vs. Fryer \& Levitt } 2006\end{array}$

\section{B. Structural Features of Environment}

Segregation, Neighborhoods

School Quality

Discrimination in the Labor Market

Discrimination in Criminal Justice Social Alienation, Stereotype Threat
Wilson 1987; Massey \& Denton 1993; Sampson \& Wilson 1995; Sampson, Morenoff \& GannonRowley 2002; Smith 2005; Small, Harding \& Lamont 2010

Smith \& Welch 1989; Card \& Krueger 1992; Jencks \& Phillips 1998; Dobbie \& Fryer 2011

Donohue \& Heckman 1991; Heckman 1998; Atonji \& Blank 1999; Pager 2003; Bertrand \& Mullainathan 2004; Fryer 2010

Steffensmeier, Ulmer \& Kramer 1998; Eberhardt et al. 2004; Alexander 2010 Steele \& Aaronson 1995; Tatum 2004; Glover, Pallais \& Pariente 2017

\section{Cultural Factors and Social Norms} Identity and Oppositional Norms Aspirations or Role Models

Fordham \& Ogbu 1986; Noguera 2003; Carter 2005; Austen-Smith \& Fryer 2005 Mickelson 1990; Small, Harding, \& Lamont 2010

Notes: In this table, we organize theories of racial disparities into three broad categories and provide selected references to prior work discussing each of these theories. 
Online Appendix Table II

Sample Sizes and Coverage Rates by Birth Cohort and Race

\begin{tabular}{|c|c|c|c|c|c|}
\hline \multicolumn{6}{|l|}{ A. Coverage Rates by Child's Birth Cohort } \\
\hline Cohort & $\begin{array}{c}2015 \text { ACS: Born in U.S. } \\
\text { or Arrived Before Age } \\
16(1,000 s) \\
(1)\end{array}$ & $\begin{array}{l}\text { Percent Matched to } \\
\text { Parents with Positive } \\
\text { Income } \\
\text { (2) }\end{array}$ & $\begin{array}{l}\text { And with Non- } \\
\text { missing Race } \\
\text { (3) }\end{array}$ & $\begin{array}{l}\text { And at Least } \\
\text { one Childhood } \\
\text { Tract } \\
\text { (4) }\end{array}$ & $\begin{array}{c}\text { And Appear in ACS at } \\
\text { Some Point between } \\
2005-2015 \\
\text { (5) }\end{array}$ \\
\hline 1978 & 3,334 & $94.5 \%$ & $88.6 \%$ & $88.1 \%$ & $12.3 \%$ \\
\hline 1979 & 3,594 & $92.9 \%$ & $88.3 \%$ & $87.8 \%$ & $12.1 \%$ \\
\hline 1980 & 3,715 & $95.1 \%$ & $90.9 \%$ & $90.4 \%$ & $12.2 \%$ \\
\hline 1981 & 3,580 & $105.7 \%$ & $97.1 \%$ & $96.6 \%$ & $12.8 \%$ \\
\hline 1982 & 3,660 & $104.1 \%$ & $98.5 \%$ & $98.0 \%$ & $12.7 \%$ \\
\hline 1983 & 3,678 & $104.9 \%$ & $97.9 \%$ & $97.4 \%$ & $12.5 \%$ \\
\hline Average: Cohorts 78-83 & 21,561 & $99.6 \%$ & $93.6 \%$ & $93.1 \%$ & $12.4 \%$ \\
\hline \multicolumn{6}{|l|}{ B. Coverage Rates by Race and Ethnicity } \\
\hline & $\begin{array}{l}\text { White } \\
\text { (6) }\end{array}$ & $\begin{array}{c}\text { Black } \\
(7)\end{array}$ & $\begin{array}{l}\text { Asian } \\
(8)\end{array}$ & $\begin{array}{l}\text { Hispanic } \\
\text { (9) }\end{array}$ & $\begin{array}{l}\text { American Indian } \\
\text { (10) }\end{array}$ \\
\hline Count in 2015 ACS & $13,890,000$ & $2,927,000$ & 678,000 & $3,341,000$ & 151,000 \\
\hline Share of 2015 ACS Total in Analysis Sample & $97.1 \%$ & $94.0 \%$ & $101.0 \%$ & $78.3 \%$ & $109.3 \%$ \\
\hline \multicolumn{6}{|c|}{$\begin{array}{l}\text { Notes: This table describes the coverage rates of our sample relative to the target population. Panel A presents statistics on coverage rates by birth cohort. } \\
\text { All observation counts shown are rounded as described in the notes to Table I. Column } 1 \text { presents estimates of the size of the target population (in } 1,000 \text { 's), } \\
\text { based on the number of people who were born in the U.S. or who moved to the U.S. before age } 16 \text { in the } 2015 \text { American Community Survey. We use the } \\
\text { ACS person weights to estimate total counts from the ACS sample. Column } 2 \text { shows the number of children in the tax data who are linked to parents with } \\
\text { positive income, measured as a percentage relative to the totals in Column } 1 \text {. Column } 3 \text { reports the number of children in our linked sample for whom we } \\
\text { have information on race, again as a percentage of the counts in Column } 1 \text {. In Column } 4 \text {, we further require that children are assigned to at least one census } \\
\text { tract prior to age } 23 \text {. In Column } 5 \text {, we report the fraction of the resulting children whom we ever observe in the ACS. Panel B shows the coverage rate of } \\
\text { each racial and ethnic group in our analysis sample (children matched to parents with positive income and non-missing race) relative to the counts of these } \\
\text { groups in the } 2015 \mathrm{ACS} \text {, pooling the } 1978-83 \text { birth cohorts. See Appendix B for further details. All statistics cleared under Census DRB release authorization }\end{array}$} \\
\hline
\end{tabular}

CBDRB-FY18-195. 
Online Appendix Table III

Characteristics of Matched vs. Unmatched Children

\begin{tabular}{|c|c|c|c|c|}
\hline & & $\begin{array}{l}2015 \text { ACS (1978- } \\
83 \text { cohorts, born } \\
\text { in US or came } \\
\text { before } 16) \\
\text { (1) }\end{array}$ & $\begin{array}{l}\text { In } 2015 \text { ACS and } \\
\text { appears in our } \\
\text { analysis sample } \\
\text { (2) }\end{array}$ & $\begin{array}{c}\text { In } 2015 \text { ACS but } \\
\text { does not appear } \\
\text { in our analysis } \\
\text { sample } \\
\text { (3) }\end{array}$ \\
\hline \multicolumn{5}{|c|}{ A. Individual Income Ranks in ACS Data by Race and Ethnicity } \\
\hline Pooled & Rank & 49.99 & 52.10 & 42.01 \\
\hline \multirow[t]{2}{*}{ White } & Rank & 53.02 & 54.19 & 46.27 \\
\hline & $\%$ of Sample & $64.4 \%$ & $69.4 \%$ & $45.6 \%$ \\
\hline \multirow[t]{2}{*}{ Black } & Rank & 41.36 & 43.09 & 36.60 \\
\hline & $\%$ of Sample & $13.6 \%$ & $12.6 \%$ & $17.2 \%$ \\
\hline \multirow[t]{2}{*}{ Asian } & Rank & 60.02 & 62.63 & 52.72 \\
\hline & $\%$ of Sample & $3.1 \%$ & $2.9 \%$ & $3.9 \%$ \\
\hline \multirow[t]{2}{*}{ Hispanic } & Rank & 43.54 & 47.69 & 37.12 \\
\hline & $\%$ of Sample & $15.5 \%$ & $12.3 \%$ & $30.3 \%$ \\
\hline \multirow[t]{2}{*}{ American Indian } & Rank & 37.29 & 37.46 & 36.97 \\
\hline & $\%$ of Sample & $0.7 \%$ & $0.6 \%$ & $1.2 \%$ \\
\hline \multirow[t]{2}{*}{ "Other" } & Rank & 49.67 & 51.61 & 43.44 \\
\hline & $\%$ of Sample & $2.7 \%$ & $2.6 \%$ & $3.1 \%$ \\
\hline \multicolumn{5}{|l|}{ B. Other Outcomes } \\
\hline Marriage Rate & & $51.9 \%$ & $54.1 \%$ & $43.5 \%$ \\
\hline College Attendance Rate & & $67.5 \%$ & $71.2 \%$ & $53.6 \%$ \\
\hline Incarceration Rate & & $1.9 \%$ & $1.1 \%$ & $4.7 \%$ \\
\hline
\end{tabular}

Notes: This table compares the characteristics of children who appear in our linked analysis sample vs. those who do not appear in the sample using data from the 2015 ACS. Panel A presents mean individual income ranks and sample shares by race. Panel B presents statistics on other outcomes measured in the ACS, pooling across races. In Column 1 we present statistics using the 2015 ACS, restricting to those who were born in the years 1978-1983, were born in the US, or moved to the U.S. before age 16 . We estimate the total counts and individual income ranks using the ACS person weights in this column. The income ranks are calculated using ACS income and are computed by ranking children within their birth cohort. In Column 2, we restrict the sample in 1 to children in our analysis sample i.e. those whom we can match to parents with positive income and for whom we have race information. In Column 3 we present statistics on those who appear in Column 1 but not in Column 2, i.e. children excluded from our analysis sample but part of the target sample. In all columns, all statistics are estimated using the 2015 ACS (not the tax data), so that differences between the columns are driven purely by sample selection. See Section III.B for definitions of the variables in this table. All statistics cleared under Census DRB release authorization CBDRBFY18-195. 
Online Appendix Table IV

Comparison of Tax Data Income Measures and Characteristics to CPS and ACS Data

\begin{tabular}{|c|c|c|c|c|c|}
\hline & \multirow[b]{2}{*}{$\begin{array}{c}\text { Publicly } \\
\text { Available CPS } \\
\text { 2012-2016 } \\
\text { (1) }\end{array}$} & \multirow[b]{2}{*}{$\begin{array}{c}\text { Publicly } \\
\text { Available ACS } \\
\text { 2012-2016 } \\
(2)\end{array}$} & \multicolumn{3}{|c|}{ Analysis Sample in 2015 ACS } \\
\hline & & & $\begin{array}{c}\text { Characteristics } \\
\text { in ACS } \\
\text { (3) }\end{array}$ & $\begin{array}{c}\text { Incomes in Tax } \\
\text { Records } \\
\text { (4) }\end{array}$ & $\begin{array}{l}\text { Subsample with } 0 \\
\text { Income in Tax } \\
\text { Records: Chars. in } \\
\text { ACS } \\
\text { (5) }\end{array}$ \\
\hline \multicolumn{6}{|l|}{ A. Income Statistics } \\
\hline \% Zero Income & $8.1 \%$ & $10.4 \%$ & $9.5 \%$ & $10.1 \%$ & $37.5 \%$ \\
\hline$\%$ Negative Income & $0.1 \%$ & $0.1 \%$ & $0.1 \%$ & $2.1 \%$ & $0.1 \%$ \\
\hline Mean & 42,550 & 43,760 & 42,890 & 44,990 & 12,240 \\
\hline Standard Deviation & 56,180 & 52,630 & 51,200 & 117,700 & 27,500 \\
\hline p10 & 160 & 0 & 300 & 0 & 0 \\
\hline p25 & 14,000 & 12,170 & 13,400 & 11,150 & 0 \\
\hline p50 & 33,000 & 32,810 & 34,000 & 33,370 & 5,000 \\
\hline p75 & 55,200 & 57,700 & 57,010 & 58,440 & 13,970 \\
\hline p90 & 85,250 & 91,140 & 89,000 & 92,330 & 34,000 \\
\hline p99 & 200,580 & 255,000 & 210,000 & 250,400 & 100,000 \\
\hline \multicolumn{6}{|c|}{ B. Demographic Characteristics } \\
\hline \% Married & $55.6 \%$ & $55.6 \%$ & $54.0 \%$ & - & $28.0 \%$ \\
\hline$\%$ Female & $50.8 \%$ & $49.9 \%$ & $50.3 \%$ & - & $48.2 \%$ \\
\hline \% Live in South & $37.8 \%$ & $38.1 \%$ & $37.8 \%$ & - & $44.5 \%$ \\
\hline$\%$ White & $66.2 \%$ & $64.9 \%$ & $67.3 \%$ & - & $58.2 \%$ \\
\hline$\%$ Black & $13.0 \%$ & $13.5 \%$ & $12.7 \%$ & - & $19.3 \%$ \\
\hline$\%$ Asian & $3.9 \%$ & $3.6 \%$ & $3.5 \%$ & - & $2.2 \%$ \\
\hline \% Hispanic & $14.4 \%$ & $15.1 \%$ & $13.2 \%$ & - & $15.9 \%$ \\
\hline$\%$ American Indian & $0.8 \%$ & $0.8 \%$ & $0.6 \%$ & - & $1.2 \%$ \\
\hline$\%$ Attend College & $67.4 \%$ & $61.0 \%$ & $70.2 \%$ & - & $41.9 \%$ \\
\hline
\end{tabular}

Notes: This table presents summary statistics on income distributions (Panel A) and demographics (Panel B) for five different samples. The first two columns use the (publicly available) 2012-2016 Current Population Survey (CPS) and 2012-2016 ACS, focusing on individuals in the 1978-83 birth cohorts who were born in the U.S. or came to the U.S. before age 16 . Column 3 uses data from the 2015 ACS who appear in our analysis sample, and measures their incomes and other characteristics in the ACS data. Column 4 uses the same sample as Column 3, but uses income data from the tax records. Note that the demographic characteristics of the sample in Column 4 are identical to those in Column 3 by construction since demographic information is not obtained from the tax records. Column 5 shows statistics on income and other characteristics using ACS data for individuals who appear in both the ACS and the analysis sample, but who have zero income in the tax data in 2015 (i.e., those who have no 1040 or W-2 forms in 2015). All statistics cleared under Census DRB release authorization CBDRBFY18-195. 
Online Appendix Table V

Summary Statistics on Income Disparities and Intergenerational Mobility by Race and Gender

\begin{tabular}{|c|c|c|c|c|c|c|c|c|c|c|}
\hline & \multicolumn{2}{|c|}{ White } & \multicolumn{2}{|c|}{ Black } & \multicolumn{2}{|c|}{ Asian } & \multicolumn{2}{|c|}{ Hispanic } & \multicolumn{2}{|c|}{ American Indian } \\
\hline & $\begin{array}{l}\text { Male } \\
(1)\end{array}$ & $\begin{array}{c}\text { Female } \\
(2)\end{array}$ & $\begin{array}{c}\text { Male } \\
(3)\end{array}$ & $\begin{array}{c}\text { Female } \\
\text { (4) }\end{array}$ & $\begin{array}{c}\text { Male } \\
(5)\end{array}$ & $\begin{array}{c}\text { Female } \\
(6)\end{array}$ & $\begin{array}{c}\text { Male } \\
(7)\end{array}$ & $\begin{array}{c}\text { Female } \\
\text { (8) }\end{array}$ & $\begin{array}{c}\text { Male } \\
(9)\end{array}$ & $\begin{array}{c}\text { Female } \\
(10)\end{array}$ \\
\hline \multicolumn{11}{|c|}{ A. Children's Individual Income in Adulthood } \\
\hline Median Income (\$) & 40,710 & 26,580 & 18,220 & 20,400 & 45,550 & 41,730 & 32,250 & 22,930 & 19,030 & 14,870 \\
\hline Mean Percentile Rank & 58.4 & 47.9 & 40.8 & 43.1 & 61.5 & 59.0 & 51.7 & 44.5 & 42.0 & 37.3 \\
\hline $\mathrm{P}$ (Child in Q1 | Parent in Q1) & $26.0 \%$ & $30.3 \%$ & $37.5 \%$ & $20.5 \%$ & $17.0 \%$ & $18.0 \%$ & $23.5 \%$ & $22.8 \%$ & $39.0 \%$ & $36.6 \%$ \\
\hline $\mathrm{P}$ (Child in Q5 | Parent in Q1) & $14.8 \%$ & $7.2 \%$ & $7.4 \%$ & $5.2 \%$ & $28.0 \%$ & $25.6 \%$ & $14.8 \%$ & $6.7 \%$ & $7.4 \%$ & $3.3 \%$ \\
\hline $\mathrm{P}($ Child in Q1 | Parent in Q5) & $8.7 \%$ & $14.9 \%$ & $16.4 \%$ & $11.0 \%$ & $10.8 \%$ & $11.9 \%$ & $11.6 \%$ & $15.1 \%$ & $16.2 \%$ & $20.3 \%$ \\
\hline $\mathrm{P}($ Child in Q5 | Parent in Q5) & $45.2 \%$ & $28.2 \%$ & $27.0 \%$ & $25.4 \%$ & $52.8 \%$ & $46.9 \%$ & $37.5 \%$ & $25.4 \%$ & $28.7 \%$ & $19.1 \%$ \\
\hline \multicolumn{11}{|c|}{ B. Children's Household Income in Adulthood } \\
\hline Median Income (\$) & 51,960 & 55,740 & 17,730 & 22,690 & 56,580 & 71,880 & 35,280 & 35,080 & 20,890 & 23,450 \\
\hline Mean Percentile Rank & 54.5 & 56.8 & 32.6 & 36.8 & 57.5 & 63.9 & 44.6 & 46.7 & 35.7 & 37.8 \\
\hline $\mathrm{P}($ Child in Q1 | Parent in Q1) & $31.3 \%$ & $26.7 \%$ & $48.5 \%$ & $26.8 \%$ & $19.9 \%$ & $13.2 \%$ & $29.1 \%$ & $20.4 \%$ & $49.3 \%$ & $41.7 \%$ \\
\hline $\mathrm{P}($ Child in Q5 | Parent in Q1) & $9.7 \%$ & $11.5 \%$ & $2.5 \%$ & $2.6 \%$ & $21.2 \%$ & $30.1 \%$ & $6.6 \%$ & $7.6 \%$ & $3.1 \%$ & $3.5 \%$ \\
\hline P(Child in Q1 | Parent in Q5) & $10.0 \%$ & $7.3 \%$ & $21.5 \%$ & $11.8 \%$ & $11.9 \%$ & $8.0 \%$ & $14.0 \%$ & $10.0 \%$ & $20.9 \%$ & $16.6 \%$ \\
\hline $\mathrm{P}$ (Child in Q5 | Parent in Q5) & $39.3 \%$ & $43.0 \%$ & $17.4 \%$ & $18.6 \%$ & $45.6 \%$ & $52.2 \%$ & $28.8 \%$ & $32.4 \%$ & $21.5 \%$ & $24.6 \%$ \\
\hline Number of children (1000's) & 6,891 & 6,599 & 1,348 & 1,402 & 350 & 335 & 1,312 & 1,303 & 84 & 82 \\
\hline
\end{tabular}

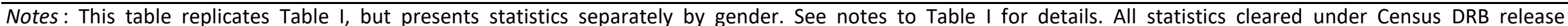
authorization CBDRB-FY18-195. 
Online Appendix Table VI

Summary Statistics on Children's Outcomes by Race

\begin{tabular}{|c|c|c|c|c|c|c|}
\hline Race & $\begin{array}{c}\text { Pooled } \\
(1)\end{array}$ & $\begin{array}{l}\text { White } \\
(2)\end{array}$ & $\begin{array}{c}\text { Black } \\
(3) \\
\end{array}$ & $\begin{array}{c}\text { Asian } \\
(4) \\
\end{array}$ & $\begin{array}{c}\text { Hispanic } \\
(5)\end{array}$ & $\begin{array}{c}\text { American Indian } \\
(6) \\
\end{array}$ \\
\hline \multicolumn{7}{|l|}{ Household Income } \\
\hline Median (\$) & 42,030 & 53,730 & 20,650 & 63,720 & 35,180 & 22,260 \\
\hline Mean (\$) & 63,530 & 74,740 & 31,160 & 100,900 & 48,600 & 35,510 \\
\hline Mean Percentile Rank & 50.00 & 55.65 & 34.76 & 60.65 & 45.65 & 36.73 \\
\hline \multicolumn{7}{|l|}{ Individual Income } \\
\hline Median (\$) & 29,210 & 33,620 & 19,550 & 43,690 & 27,140 & 16,610 \\
\hline Mean $(\$)$ & 40,700 & 45,340 & 27,450 & 63,620 & 34,590 & 25,780 \\
\hline Mean Percentile Rank & 50.00 & 53.28 & 42.01 & 60.31 & 48.10 & 39.65 \\
\hline \multicolumn{7}{|l|}{ Employment } \\
\hline Employed in Tax Data & $85.3 \%$ & $88.9 \%$ & $80.7 \%$ & $90.6 \%$ & $84.9 \%$ & $76.8 \%$ \\
\hline Employed in ACS & $84.7 \%$ & $86.5 \%$ & $74.9 \%$ & $88.2 \%$ & $81.5 \%$ & $72.8 \%$ \\
\hline Hours of Work per Week & 31.82 & 32.96 & 25.99 & 34.12 & 29.72 & 24.38 \\
\hline \multicolumn{7}{|l|}{ Wage Rate } \\
\hline Median (\$/hour) & 18.11 & 18.79 & 14.67 & 23.94 & 16.19 & 13.76 \\
\hline Mean (\$/hour) & 22.42 & 22.97 & 18.12 & 30.08 & 20.09 & 17.27 \\
\hline Mean Rank & 50.00 & 51.32 & 40.98 & 61.17 & 45.48 & 38.83 \\
\hline \multicolumn{7}{|l|}{ Other Outcomes } \\
\hline Marriage Rate & $45.0 \%$ & $54.7 \%$ & $16.3 \%$ & $50.0 \%$ & $37.4 \%$ & $30.9 \%$ \\
\hline HS Dropout Rate & $13.9 \%$ & $11.4 \%$ & $22.2 \%$ & $8.6 \%$ & $23.2 \%$ & $23.2 \%$ \\
\hline College Attendance Rate & $63.6 \%$ & $67.2 \%$ & $50.1 \%$ & $79.0 \%$ & $50.5 \%$ & $44.7 \%$ \\
\hline Incarceration Rate & $1.5 \%$ & $0.9 \%$ & $5.1 \%$ & $0.3 \%$ & $1.5 \%$ & $2.9 \%$ \\
\hline Sample Size & $21,310,000$ & $13,490,000$ & $2,750,000$ & 685,000 & $2,615,000$ & 165,000 \\
\hline Sample Size for ACS Outcomes & $4,169,000$ & $2,986,000$ & 456,000 & 131,000 & 464,000 & 40,000 \\
\hline
\end{tabular}

Notes: This table presents summary statistics on children's incomes in adulthood and other outcomes by race using our primary analysis sample (children in the 1978-1983 birth cohorts). Column 1 shows statistics for all children we link to parents with positive income, including those with missing race information; this is the sample on which children are assigned income ranks. Columns 2-6 present statistics for children with non-missing race information, based on their race and ethnicity. See Section III.B for variable definitions and data sources. We report sample sizes both for variables measured in the full sample and those measured using 2005-2015 ACS data. All statistics cleared under Census DRB release authorization CBDRB-FY18-195. 
Online Appendix Table VII

Summary Statistics on Children's Outcomes by Race for those with Mothers Born in the US

\begin{tabular}{|c|c|c|c|c|c|c|}
\hline Race & $\begin{array}{c}\text { Pooled } \\
(1) \\
\end{array}$ & $\begin{array}{l}\text { White } \\
(2)\end{array}$ & $\begin{array}{c}\text { Black } \\
(3) \\
\end{array}$ & $\begin{array}{c}\text { Asian } \\
(4) \\
\end{array}$ & $\begin{array}{c}\text { Hispanic } \\
(5) \\
\end{array}$ & $\begin{array}{c}\text { American Indian } \\
\text { (6) } \\
\end{array}$ \\
\hline \multicolumn{7}{|l|}{ Household Income } \\
\hline Median (\$) & 48,070 & 56,390 & 21,670 & 57,540 & 36,740 & 23,350 \\
\hline Mean (\$) & 68,240 & 76,020 & 32,030 & 84,980 & 53,520 & 36,240 \\
\hline Mean Percentile Rank & 52.99 & 56.91 & 35.45 & 58.11 & 46.91 & 37.45 \\
\hline \multicolumn{7}{|l|}{ Individual Income } \\
\hline Median (\$) & 31,670 & 34,710 & 20,540 & 38,760 & 27,450 & 17,520 \\
\hline Mean (\$) & 42,570 & 45,790 & 28,140 & 52,460 & 37,170 & 26,170 \\
\hline Mean Percentile Rank & 51.81 & 54.10 & 42.77 & 57.40 & 48.49 & 40.30 \\
\hline \multicolumn{7}{|l|}{ Employment } \\
\hline Employed in Tax Data & $87.9 \%$ & $90.0 \%$ & $81.7 \%$ & $90.5 \%$ & $85.7 \%$ & $78.0 \%$ \\
\hline Employed in ACS & $83.8 \%$ & $85.5 \%$ & $73.9 \%$ & $85.0 \%$ & $79.0 \%$ & $71.7 \%$ \\
\hline Hours of Work per Week & 30.93 & 32.00 & 24.74 & 31.39 & 27.84 & 23.33 \\
\hline \multicolumn{7}{|l|}{ Wage Rate } \\
\hline Median (\$/hour) & 17.18 & 17.67 & 13.95 & 19.63 & 15.42 & 13.56 \\
\hline Mean (\$/hour) & 21.05 & 21.56 & 17.37 & 24.78 & 19.16 & 16.86 \\
\hline Mean Rank & 47.68 & 48.87 & 39.31 & 53.62 & 43.54 & 38.01 \\
\hline \multicolumn{7}{|l|}{ Other Outcomes } \\
\hline Marriage Rate & $50.3 \%$ & $57.0 \%$ & $17.2 \%$ & $48.4 \%$ & $39.3 \%$ & $32.2 \%$ \\
\hline HS Dropout Rate & $15.8 \%$ & $14.2 \%$ & $23.7 \%$ & $14.5 \%$ & $22.0 \%$ & $24.0 \%$ \\
\hline College Attendance Rate & $61.4 \%$ & $64.2 \%$ & $48.2 \%$ & $68.9 \%$ & $50.9 \%$ & $42.9 \%$ \\
\hline Incarceration Rate & $1.2 \%$ & $0.7 \%$ & $4.6 \%$ & $0.4 \%$ & $1.5 \%$ & $2.6 \%$ \\
\hline Sample Size & $4,783,000$ & $3,716,000$ & 499,000 & 28,500 & 270,000 & 47,000 \\
\hline Sample Size for ACS Outcomes & $1,699,000$ & $1,364,000$ & 177,000 & 10,500 & 97,500 & 19,500 \\
\hline
\end{tabular}

Notes: This table presents statistics that are analogous to those in Online Appendix Table VI, but restricting the sample to children whose mothers were born in the United States. We measure mother's place of birth in the ACS or 2000 Long Form. The sample sizes are smaller than those in Online Appendix Table VI because we limit the sample to children whose mothers appear in the ACS or Long Form and also were born in the United States. See notes to Online Appendix Table VI for further details. All statistics cleared under Census DRB release authorization CBDRB-FY18-195. 
Online Appendix Table VIII

Summary Statistics on Children's Outcomes by Race and Gender

\begin{tabular}{|c|c|c|c|c|c|c|c|c|c|c|c|c|}
\hline & \multicolumn{2}{|c|}{ Pooled } & \multicolumn{2}{|c|}{ White } & \multicolumn{2}{|c|}{ Black } & \multicolumn{2}{|c|}{ Asian } & \multicolumn{2}{|c|}{ Hispanic } & \multicolumn{2}{|c|}{ American Indian } \\
\hline & $\begin{array}{c}\text { Male } \\
\text { (1) }\end{array}$ & $\begin{array}{c}\text { Female } \\
\text { (2) }\end{array}$ & $\begin{array}{c}\text { Male } \\
\text { (3) }\end{array}$ & $\begin{array}{c}\text { Female } \\
(4)\end{array}$ & $\begin{array}{c}\text { Male } \\
(5) \\
\end{array}$ & $\begin{array}{c}\text { Female } \\
(6)\end{array}$ & $\begin{array}{c}\text { Male } \\
(7) \\
\end{array}$ & $\begin{array}{c}\text { Female } \\
(8)\end{array}$ & $\begin{array}{c}\text { Male } \\
(9) \\
\end{array}$ & $\begin{array}{c}\text { Female } \\
(10)\end{array}$ & $\begin{array}{l}\text { Male } \\
(11)\end{array}$ & $\begin{array}{c}\text { Female } \\
(12)\end{array}$ \\
\hline \multicolumn{13}{|l|}{ Household Income } \\
\hline Median (\$) & 40,960 & 43,200 & 51,960 & 55,740 & 17,730 & 22,690 & 56,580 & 71,880 & 35,280 & 35,080 & 20,890 & 23,450 \\
\hline Mean (\$) & 60,490 & 66,700 & 71,610 & 78,000 & 29,270 & 32,980 & 89,990 & 112,300 & 46,310 & 50,900 & 34,140 & 36,920 \\
\hline Mean Percentile Rank & 48.67 & 51.39 & 54.54 & 56.80 & 32.60 & 36.83 & 57.50 & 63.94 & 44.64 & 46.66 & 35.69 & 37.82 \\
\hline \multicolumn{13}{|l|}{ Individual Income } \\
\hline Median (\$) & 34,910 & 24,170 & 40,710 & 26,580 & 18,220 & 20,400 & 45,550 & 41,730 & 32,250 & 22,930 & 19,030 & 14,870 \\
\hline Mean (\$) & 46,970 & 34,170 & 53,700 & 36,610 & 27,650 & 27,260 & 68,230 & 58,820 & 39,410 & 29,750 & 29,140 & 22,300 \\
\hline Mean Percentile Rank & 53.66 & 46.18 & 58.43 & 47.90 & 40.85 & 43.12 & 61.52 & 59.04 & 51.66 & 44.52 & 41.98 & 37.25 \\
\hline \multicolumn{13}{|l|}{ Employment } \\
\hline Employed in Tax Data & $83.7 \%$ & $87.0 \%$ & $88.4 \%$ & $89.3 \%$ & $74.1 \%$ & $87.0 \%$ & $89.2 \%$ & $92.0 \%$ & $83.2 \%$ & $86.6 \%$ & $74.7 \%$ & $79.0 \%$ \\
\hline Employed in ACS & $88.5 \%$ & $80.9 \%$ & $91.5 \%$ & $81.5 \%$ & $70.0 \%$ & $79.4 \%$ & $90.5 \%$ & $85.8 \%$ & $85.5 \%$ & $77.7 \%$ & $75.7 \%$ & $69.9 \%$ \\
\hline Hours of Work per Week & 35.71 & 28.02 & 37.66 & 28.29 & 24.87 & 27.01 & 36.31 & 31.92 & 33.05 & 26.56 & 26.25 & 22.51 \\
\hline \multicolumn{13}{|l|}{ Wage Rate } \\
\hline Median (\$/hour) & 19.18 & 17.18 & 19.63 & 17.67 & 14.72 & 14.46 & 23.53 & 24.38 & 16.84 & 15.69 & 14.46 & 13.12 \\
\hline Mean (\$/hour) & 23.48 & 21.29 & 24.13 & 21.68 & 18.32 & 17.96 & 30.12 & 30.04 & 20.79 & 19.36 & 18.00 & 16.48 \\
\hline Mean Rank & 52.10 & 47.76 & 53.63 & 48.75 & 41.35 & 40.69 & 60.63 & 61.74 & 46.97 & 43.93 & 40.65 & 36.88 \\
\hline \multicolumn{13}{|l|}{ Other Outcomes } \\
\hline Marriage Rate & $42.5 \%$ & $47.7 \%$ & $51.5 \%$ & $58.1 \%$ & $16.8 \%$ & $15.8 \%$ & $45.4 \%$ & $54.7 \%$ & $35.1 \%$ & $39.7 \%$ & $29.0 \%$ & $32.9 \%$ \\
\hline HS Dropout Rate & $16.4 \%$ & $11.5 \%$ & $13.4 \%$ & $9.3 \%$ & $27.2 \%$ & $17.6 \%$ & $10.0 \%$ & $7.2 \%$ & $26.7 \%$ & $19.8 \%$ & $26.2 \%$ & $20.2 \%$ \\
\hline College Attendance Rate & $57.8 \%$ & $69.3 \%$ & $61.6 \%$ & $72.8 \%$ & $41.5 \%$ & $57.9 \%$ & $75.7 \%$ & $82.5 \%$ & $44.5 \%$ & $56.3 \%$ & $38.1 \%$ & $51.5 \%$ \\
\hline Incarceration Rate & $2.7 \%$ & $0.3 \%$ & $1.6 \%$ & $0.2 \%$ & $10.3 \%$ & $0.6 \%$ & $0.5 \%$ & $0.0 \%$ & $2.9 \%$ & $0.2 \%$ & $5.1 \%$ & $0.8 \%$ \\
\hline Sample Size & $10,870,000$ & $10,430,000$ & $6,891,000$ & $6,599,000$ & $1,348,000$ & $1,402,000$ & 350,000 & 335,000 & $1,312,000$ & $1,303,000$ & 84,000 & 81,500 \\
\hline Sample Size for ACS Outcomes & $2,075,000$ & $2,095,000$ & $1,495,000$ & $1,490,000$ & 218,000 & 238,000 & 66,000 & 64,500 & 230,000 & 234,000 & 20,000 & 20,000 \\
\hline
\end{tabular}

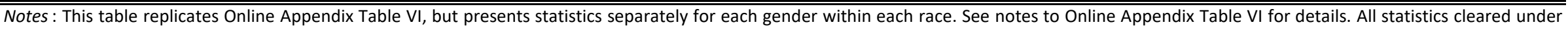

Census DRB release authorization CBDRB-FY18-195. 
Online Appendix Table IX

Summary Statistics on Parents' Incomes and Characteristics by Race

\begin{tabular}{|c|c|c|c|c|c|c|}
\hline & $\begin{array}{c}\text { Pooled } \\
(1) \\
\end{array}$ & $\begin{array}{c}\text { White } \\
(2)\end{array}$ & $\begin{array}{c}\text { Black } \\
(3) \\
\end{array}$ & $\begin{array}{c}\text { Asian } \\
(4)\end{array}$ & $\begin{array}{c}\text { Hispanic } \\
\text { (5) }\end{array}$ & $\begin{array}{c}\text { American Indian } \\
(6) \\
\end{array}$ \\
\hline \multicolumn{7}{|l|}{ Household Income } \\
\hline 25th percentile (\$) & 27,010 & 39,830 & 16,070 & 23,650 & 17,920 & 17,940 \\
\hline Median (\$) & 55,810 & 70,640 & 29,200 & 53,010 & 33,060 & 34,850 \\
\hline 75th percentile (\$) & 94,260 & 107,900 & 52,890 & 99,660 & 60,260 & 62,890 \\
\hline 99th percentile (\$) & 466,300 & 566,500 & 168,900 & 533,500 & 213,300 & 190,500 \\
\hline Mean (\$) & 79,550 & 96,680 & 40,590 & 82,670 & 47,240 & 46,990 \\
\hline Mean Percentile Rank & 50.00 & 57.86 & 32.72 & 49.20 & 36.17 & 36.76 \\
\hline \multicolumn{7}{|l|}{ Family Structure } \\
\hline Two Parent & $68.34 \%$ & $79.35 \%$ & $32.16 \%$ & $80.44 \%$ & $57.03 \%$ & $57.94 \%$ \\
\hline Father Present & $78.86 \%$ & $86.09 \%$ & $49.54 \%$ & $88.41 \%$ & $73.82 \%$ & $70.17 \%$ \\
\hline Mother Present & $89.48 \%$ & $93.26 \%$ & $82.62 \%$ & $92.02 \%$ & $83.21 \%$ & $87.76 \%$ \\
\hline \multicolumn{7}{|l|}{ Education } \\
\hline Mom HS Dropout & $12.32 \%$ & $7.38 \%$ & $17.07 \%$ & $21.90 \%$ & $37.44 \%$ & $18.22 \%$ \\
\hline Dad HS Dropout & $13.65 \%$ & $8.90 \%$ & $20.18 \%$ & $17.09 \%$ & $41.38 \%$ & $20.94 \%$ \\
\hline Mom Attended College & $55.75 \%$ & $59.35 \%$ & $50.66 \%$ & $59.15 \%$ & $36.04 \%$ & $49.29 \%$ \\
\hline Dad Attended College & $56.92 \%$ & $60.55 \%$ & $46.73 \%$ & $66.38 \%$ & $35.75 \%$ & $43.59 \%$ \\
\hline \multicolumn{7}{|l|}{ Wealth } \\
\hline Home Ownership Rate & $75.58 \%$ & $81.59 \%$ & $56.79 \%$ & $70.62 \%$ & $62.41 \%$ & $67.66 \%$ \\
\hline Median Monthly Mortgage Payment (\$) & 502 & 570 & 0 & 827 & 289 & 0 \\
\hline Mean Monthly Mortgage Payment (\$) & 704 & 742 & 490 & 1067 & 633 & 319 \\
\hline Median Number of Cars & 2 & 2 & 2 & 2 & 2 & 2 \\
\hline Mean Number of Cars & 2.30 & 2.44 & 1.73 & 2.39 & 2.14 & 2.01 \\
\hline \multicolumn{7}{|l|}{ Place of Birth } \\
\hline Foreign Born Mother & $12.26 \%$ & $4.41 \%$ & $8.37 \%$ & $81.76 \%$ & $49.07 \%$ & $3.80 \%$ \\
\hline Foreign Born Father & $12.85 \%$ & $4.29 \%$ & $10.82 \%$ & $79.96 \%$ & $54.08 \%$ & $4.22 \%$ \\
\hline \multicolumn{7}{|l|}{ Tract-Level Characteristics } \\
\hline Mean Parent Income Rank & 51.62 & 56.70 & 38.96 & 53.39 & 41.46 & 44.39 \\
\hline Single Parent Share (2000) & $30.20 \%$ & $23.06 \%$ & $53.84 \%$ & $29.23 \%$ & $38.85 \%$ & $32.17 \%$ \\
\hline Own-Race Single Parent Share (2000) & $30.12 \%$ & $19.09 \%$ & $66.70 \%$ & $18.71 \%$ & $41.05 \%$ & $38.97 \%$ \\
\hline Share White (2000) & $66.84 \%$ & $81.87 \%$ & $32.78 \%$ & $50.78 \%$ & $37.21 \%$ & $55.90 \%$ \\
\hline Sample Size & $21,310,000$ & $13,490,000$ & $2,750,000$ & 685,000 & $2,615,000$ & 165,000 \\
\hline Sample Size for ACS/Census Long Form Vars. & $5,451,000$ & $3,887,000$ & 544,000 & 157,000 & 530,000 & 49,000 \\
\hline
\end{tabular}

Notes: This table presents summary statistics on income and other characteristics of the parents of the children in our primary analysis sample (1978-83 birth cohorts). All statistics are estimated using a sample with one observation per child (rather than parent). Column 1 shows statistics on all parents, including those with missing race information; this is the sample on which parents are assigned income ranks. Columns 2-6 present statistics for parents of children with non-missing race information, based on their race and ethnicity. Statistics on mother's and father's education and place of birth are reported only for the subset of children for whom the mother or father is present. Tractlevel characteristics are calculated based on the first non-missing parental tract. Poverty rate and share white are calculated using publicly available Census 2000 data at the tract level. All other tract-level characteristics are calculated in the Census microdata. We report sample sizes both for variables measured in the full sample and those measured using the 2005-2015 ACS or Census 2000 Long Form data. See Section III.B and Online Appendices C-D for variable definitions and data sources. All statistics cleared under Census DRB release authorization CBDRB-FY18-195. 
Online Appendix Table $X$

Relative Mobility by Race and Birth Cohort

\begin{tabular}{cccccc}
\hline \hline $\begin{array}{c}\text { Child Birth } \\
\text { Cohort }\end{array}$ & White & Black & Asian & Hispanic & American Indian \\
$(1)$ & $(2)$ & $(3)$ & 0.249 & 0.289 \\
1978 & 0.322 & 0.254 & 0.198 & 0.250 & 0.280 \\
1979 & 0.326 & 0.256 & 0.193 & 0.247 & 0.291 \\
1980 & 0.327 & 0.255 & 0.189 & 0.244 & 0.307 \\
1981 & 0.328 & 0.259 & 0.187 & 0.240 & 0.303 \\
1982 & 0.328 & 0.254 & 0.180 & 0.240 & 0.316 \\
1983 & 0.329 & 0.252 & 0.174 & &
\end{tabular}

Notes: This table presents estimates of relative mobility $\left(\beta_{r}\right)$ by race, separately for each birth cohort of children in our primary analysis sample. We estimate these slopes using OLS regressions of children's household income ranks on their parents' household income ranks, separately by cohort-race cell, and report the coefficient on parent rank in each regression. All statistics cleared under Census DRB release authorization CBDRB-FY18-195. 
Online Appendix Table XI

Correlations between Predicted Individual Income Ranks of Black vs. White Males and Neighborhood Characteristics, by Parent Income

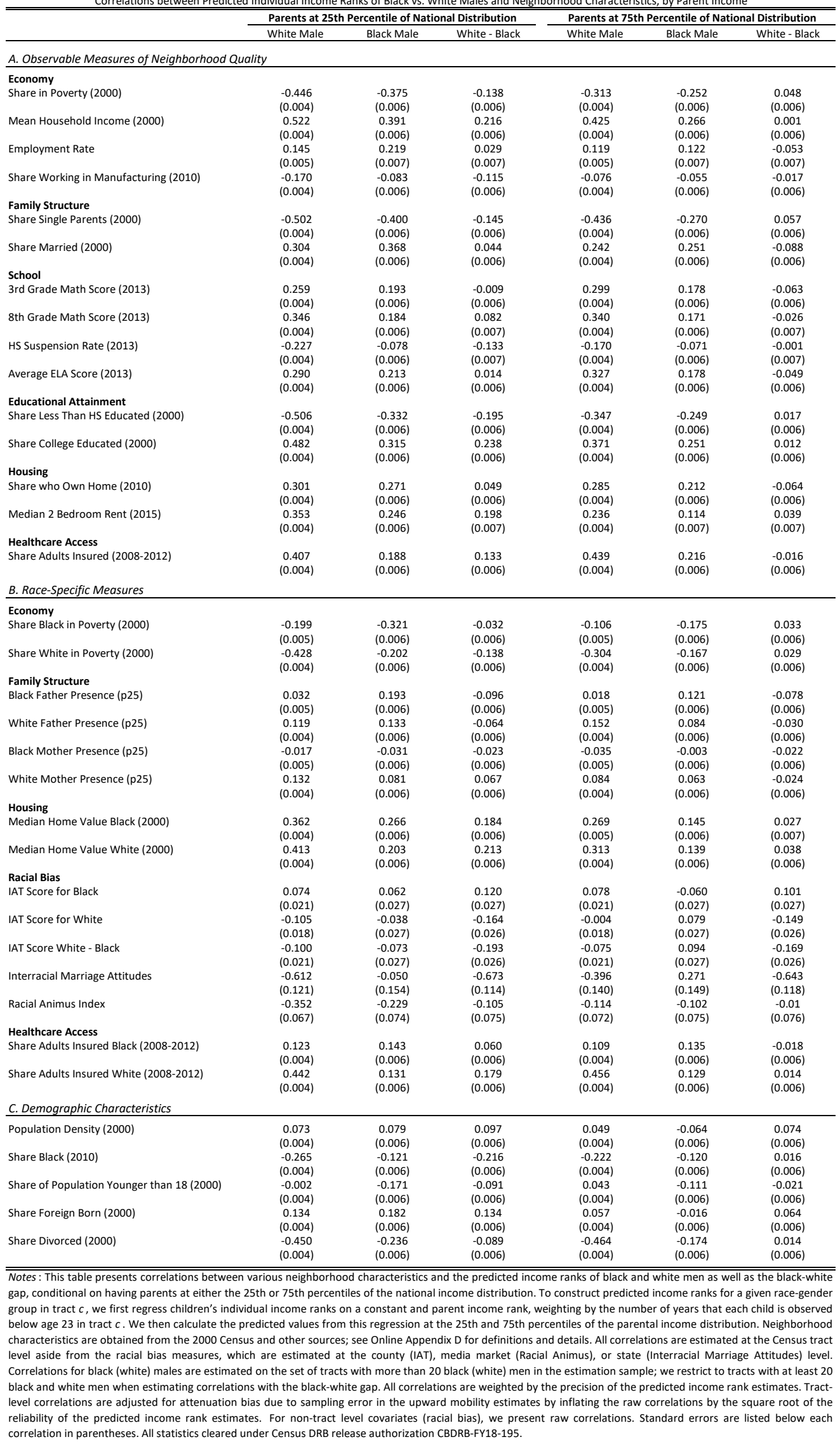


Online Appendix Table XII

Correlations between Predicted Individual Income Ranks of Black vs. White Males and Neighborhood Characteristics, Among Low-Poverty Areas

\begin{tabular}{|c|c|c|c|c|c|c|}
\hline \multirow{2}{*}{ Covariate } & \multicolumn{3}{|c|}{ Parents at 25th Percentile of National Distribution } & \multicolumn{3}{|c|}{ Parents at 75th Percentile of National Distribution } \\
\hline & White Male & Black Male & White - Black & White Male & Black Male & White - Black \\
\hline A. Observable Measures of Neighborhoo & & & & & & \\
\hline Economy & & & & & & \\
\hline Share in Poverty (2000) & -0.362 & -0.216 & -0.072 & -0.324 & -0.177 & 0.019 \\
\hline & $(0.005)$ & $(0.010)$ & $(0.010)$ & $(0.005)$ & $(0.010)$ & $(0.010)$ \\
\hline Mean Household Income (2000) & 0.461 & 0.237 & 0.170 & 0.435 & 0.196 & 0.039 \\
\hline & $(0.005)$ & $(0.010)$ & $(0.010)$ & $(0.005)$ & $(0.010)$ & $(0.010)$ \\
\hline Employment Rate & 0.026 & 0.008 & -0.002 & 0.091 & 0.014 & -0.022 \\
\hline & $(0.006)$ & $(0.012)$ & $(0.012)$ & $(0.006)$ & $(0.012)$ & $(0.012)$ \\
\hline Share Working in Manufacturing (2010) & -0.148 & -0.172 & -0.009 & -0.066 & -0.080 & 0.005 \\
\hline & $(0.005)$ & $(0.010)$ & $(0.010)$ & $(0.005)$ & $(0.010)$ & $(0.010)$ \\
\hline Family Structure & & & & & & \\
\hline Share Single Parents (2000) & -0.407 & -0.156 & -0.045 & -0.439 & -0.173 & 0.034 \\
\hline & $(0.005)$ & $(0.010)$ & $(0.010)$ & $(0.005)$ & $(0.010)$ & $(0.010)$ \\
\hline Share Married (2000) & 0.123 & 0.090 & -0.063 & 0.169 & 0.145 & -0.084 \\
\hline & $(0.005)$ & $(0.010)$ & $(0.010)$ & $(0.005)$ & $(0.010)$ & $(0.010)$ \\
\hline School & & & & & & \\
\hline 3rd Grade Math Score (2013) & 0.219 & 0.087 & -0.008 & 0.309 & 0.144 & -0.049 \\
\hline & $(0.005)$ & $(0.010)$ & $(0.010)$ & $(0.005)$ & $(0.010)$ & $(0.010)$ \\
\hline 8th Grade Math Score (2013) & 0.300 & 0.104 & 0.072 & 0.352 & 0.141 & -0.008 \\
\hline & $(0.005)$ & $(0.010)$ & $(0.010)$ & $(0.005)$ & $(0.010)$ & $(0.010)$ \\
\hline HS Suspension Rate (2013) & -0.188 & -0.047 & -0.099 & -0.154 & -0.082 & 0.016 \\
\hline & $(0.006)$ & $(0.010)$ & $(0.010)$ & $(0.006)$ & $(0.010)$ & $(0.010)$ \\
\hline Average ELA Score (2013) & 0.246 & 0.120 & 0.010 & 0.344 & 0.145 & -0.036 \\
\hline & $(0.005)$ & $(0.010)$ & $(0.010)$ & $(0.005)$ & $(0.010)$ & $(0.010)$ \\
\hline Educational Attainment & & & & & & \\
\hline Share Less Than HS Educated (2000) & -0.427 & -0.173 & -0.132 & -0.312 & -0.146 & -0.008 \\
\hline & $(0.005)$ & $(0.010)$ & $(0.010)$ & $(0.005)$ & $(0.010)$ & $(0.010)$ \\
\hline Share College Educated (2000) & 0.434 & 0.183 & 0.181 & 0.373 & 0.176 & 0.04 \\
\hline & $(0.005)$ & $(0.010)$ & $(0.010)$ & $(0.005)$ & $(0.010)$ & $(0.010)$ \\
\hline Housing & & & & & & \\
\hline Share who Own Home (2010) & 0.166 & 0.039 & 0.025 & 0.239 & 0.094 & -0.028 \\
\hline & $(0.005)$ & $(0.010)$ & $(0.010)$ & $(0.005)$ & $(0.010)$ & $(0.010)$ \\
\hline Median 2 Bedroom Rent (2015) & 0.341 & 0.284 & 0.111 & 0.253 & 0.102 & 0.046 \\
\hline & $(0.006)$ & $(0.011)$ & $(0.011)$ & $(0.006)$ & $(0.011)$ & $(0.011)$ \\
\hline Healthcare Access & & & & & & \\
\hline Share Adults Insured (2008-2012) & 0.368 & 0.104 & 0.110 & 0.465 & 0.178 & -0.013 \\
\hline & $(0.005)$ & $(0.010)$ & $(0.010)$ & $(0.005)$ & $(0.010)$ & $(0.010)$ \\
\hline B. Race-Specific & & & & & & \\
\hline Economy & & & & & & \\
\hline Share White in Poverty (2000) & -0.314 & -0.056 & -0.117 & -0.264 & -0.074 & -0.022 \\
\hline & $(0.005)$ & $(0.010)$ & $(0.010)$ & $(0.005)$ & $(0.010)$ & $(0.010)$ \\
\hline Share Black in Poverty (2000) & -0.075 & -0.161 & 0.037 & -0.051 & -0.056 & 0.011 \\
\hline & $(0.006)$ & $(0.010)$ & $(0.010)$ & $(0.006)$ & $(0.010)$ & $(0.010)$ \\
\hline Family Structure & & & & & & \\
\hline Black Father Presence $(\mathrm{p} 25)$ & -0.015 & 0.103 & -0.134 & -0.009 & 0.094 & -0.087 \\
\hline & $(0.008)$ & $(0.010)$ & $(0.010)$ & $(0.008)$ & $(0.010)$ & $(0.010)$ \\
\hline White Father Presence (p25) & 0.116 & 0.036 & -0.082 & 0.151 & 0.041 & -0.015 \\
\hline & $(0.005)$ & $(0.010)$ & $(0.010)$ & $(0.005)$ & $(0.010)$ & $(0.010)$ \\
\hline Black Mother Presence (p25) & -0.027 & -0.003 & -0.061 & -0.040 & -0.016 & -0.019 \\
\hline & $(0.008)$ & $(0.010)$ & $(0.010)$ & $(0.008)$ & $(0.010)$ & $(0.010)$ \\
\hline White Mother Presence (p25) & 0.102 & 0.045 & -0.001 & 0.078 & 0.025 & -0.021 \\
\hline & $(0.005)$ & $(0.010)$ & $(0.010)$ & $(0.005)$ & $(0.010)$ & $(0.010)$ \\
\hline Housing & & & & & & \\
\hline Median Home Value Black (2000) & 0.323 & 0.175 & 0.133 & 0.270 & 0.120 & 0.035 \\
\hline & $(0.006)$ & $(0.010)$ & $(0.010)$ & $(0.006)$ & $(0.010)$ & $(0.010)$ \\
\hline Median Home Value White (2000) & 0.379 & 0.140 & 0.165 & 0.327 & 0.118 & 0.054 \\
\hline & $(0.005)$ & $(0.010)$ & $(0.010)$ & $(0.005)$ & $(0.010)$ & $(0.010)$ \\
\hline Racial Bias & & & & & & \\
\hline IAT Score for Black & 0.073 & 0.090 & 0.084 & 0.094 & 0.022 & 0.101 \\
\hline & $(0.039)$ & $(0.054)$ & $(0.054)$ & $(0.039)$ & $(0.054)$ & $(0.054)$ \\
\hline IAT Score for White & -0.092 & -0.172 & 0.063 & 0.012 & -0.134 & 0.071 \\
\hline & $(0.034)$ & $(0.054)$ & $(0.054)$ & $(0.034)$ & $(0.054)$ & $(0.054)$ \\
\hline IAT Score White - Black & -0.093 & -0.181 & -0.035 & -0.084 & -0.100 & -0.045 \\
\hline & $(0.039)$ & $(0.053)$ & $(0.054)$ & (0.039) & $(0.054)$ & $(0.054)$ \\
\hline Interracial Marriage Attitudes & -0.428 & -0.329 & 0.214 & -0.298 & -0.472 & 0.353 \\
\hline & $(0.251)$ & $(0.273)$ & $(0.282)$ & $(0.265)$ & $(0.254)$ & $(0.270)$ \\
\hline Racial Animus Index & -0.718 & -0.679 & 0.209 & -0.469 & -0.520 & 0.400 \\
\hline & $(0.132)$ & $(0.144)$ & $(0.192)$ & $(0.167)$ & $(0.167)$ & $(0.180)$ \\
\hline Healthcare Access & & & & & & \\
\hline Share Adults Insured Black (2008-2012) & 0.088 & 0.125 & 0.013 & 0.093 & 0.113 & -0.027 \\
\hline & $(0.006)$ & $(0.010)$ & $(0.010)$ & $(0.006)$ & $(0.010)$ & $(0.010)$ \\
\hline Share Adults Insured White (2008-2012) & 0.410 & 0.116 & 0.130 & 0.486 & 0.130 & 0.019 \\
\hline & $(0.005)$ & $(0.010)$ & $(0.010)$ & $(0.005)$ & $(0.010)$ & $(0.010)$ \\
\hline C. Demographic Characteristics & & & & & & \\
\hline Population Density (2000) & 0.169 & 0.131 & 0.106 & 0.095 & -0.022 & 0.076 \\
\hline & $(0.005)$ & $(0.010)$ & $(0.010)$ & $(0.005)$ & $(0.010)$ & $(0.010)$ \\
\hline Share Black (2010) & -0.169 & 0.044 & -0.151 & -0.211 & -0.107 & 0.065 \\
\hline & $(0.005)$ & $(0.010)$ & $(0.010)$ & $(0.005)$ & $(0.010)$ & $(0.010)$ \\
\hline Share of Population Younger than $18(2000)$ & 0.105 & 0.073 & -0.096 & 0.073 & 0.023 & -0.051 \\
\hline & $(0.005)$ & $(0.010)$ & $(0.010)$ & $(0.005)$ & $(0.010)$ & $(0.010)$ \\
\hline Share Foreign Born (2000) & 0.239 & 0.236 & 0.099 & 0.141 & 0.032 & 0.067 \\
\hline & $(0.005)$ & $(0.010)$ & $(0.010)$ & $(0.005)$ & $(0.010)$ & $(0.010)$ \\
\hline Share Divorced (2000) & -0.392 & -0.186 & -0.027 & -0.473 & -0.187 & 0.020 \\
\hline & $(0.005)$ & $(0.010)$ & $(0.010)$ & $(0.005)$ & $(0.010)$ & $(0.010)$ \\
\hline
\end{tabular}


Online Appendix Table XIII

Correlations between Predicted Individual Income Ranks of Black vs. White Females and Neighborhood Characteristics, by Parent Income

\begin{tabular}{|c|c|c|c|c|c|c|}
\hline \multirow[b]{2}{*}{ Covariate } & \multicolumn{3}{|c|}{ Parents at 25th Percentile of National Distribution } & \multicolumn{3}{|c|}{ Parents at 75th Percentile of National Distribution } \\
\hline & White Female & Black Female & White - Black & White Female & Black Female & White - Black \\
\hline \multicolumn{7}{|c|}{ A. Observable Measures of Neighborhood Quality } \\
\hline \multicolumn{7}{|l|}{ Economy } \\
\hline Share in Poverty (2000) & $\begin{array}{c}-0.427 \\
(0.004)\end{array}$ & $\begin{array}{c}-0.377 \\
(0.006)\end{array}$ & $\begin{array}{c}-0.101 \\
(0.006)\end{array}$ & $\begin{array}{c}-0.321 \\
(0.004)\end{array}$ & $\begin{array}{c}-0.263 \\
(0.006)\end{array}$ & $\begin{array}{c}0.070 \\
(0.006)\end{array}$ \\
\hline Mean Household Income (2000) & $\begin{array}{c}0.581 \\
(0.003)\end{array}$ & $\begin{array}{c}0.474 \\
(0.005)\end{array}$ & $\begin{array}{c}0.196 \\
(0.006)\end{array}$ & $\begin{array}{c}0.493 \\
(0.004)\end{array}$ & $\begin{array}{c}0.360 \\
(0.006)\end{array}$ & $\begin{array}{l}-0.051 \\
(0.006)\end{array}$ \\
\hline Employment Rate & $\begin{array}{c}0.060 \\
(0.005)\end{array}$ & $\begin{array}{c}0.130 \\
(0.007)\end{array}$ & $\begin{array}{c}0.074 \\
(0.007)\end{array}$ & $\begin{array}{c}0.041 \\
(0.005)\end{array}$ & $\begin{array}{c}0.081 \\
(0.007)\end{array}$ & $\begin{array}{c}0.007 \\
(0.007)\end{array}$ \\
\hline Share Working in Manufacturing (2010) & $\begin{array}{c}-0.242 \\
(0.004)\end{array}$ & $\begin{array}{c}-0.270 \\
(0.006)\end{array}$ & $\begin{array}{c}-0.089 \\
(0.006)\end{array}$ & $\begin{array}{c}-0.172 \\
(0.004)\end{array}$ & $\begin{array}{c}-0.210 \\
(0.006)\end{array}$ & $\begin{array}{c}0.059 \\
(0.006)\end{array}$ \\
\hline \multicolumn{7}{|l|}{ Family Structure } \\
\hline Share Single Parents (2000) & $\begin{array}{c}-0.326 \\
(0.004)\end{array}$ & $\begin{array}{c}-0.207 \\
(0.006)\end{array}$ & $\begin{array}{c}-0.116 \\
(0.006)\end{array}$ & $\begin{array}{c}-0.286 \\
(0.004)\end{array}$ & $\begin{array}{c}-0.218 \\
(0.006)\end{array}$ & $\begin{array}{c}0.070 \\
(0.006)\end{array}$ \\
\hline Share Married (2000) & $\begin{array}{c}0.097 \\
(0.004)\end{array}$ & $\begin{array}{c}0.134 \\
(0.006)\end{array}$ & $\begin{array}{c}-0.004 \\
(0.006)\end{array}$ & $\begin{array}{c}0.063 \\
(0.004)\end{array}$ & $\begin{array}{c}0.158 \\
(0.006)\end{array}$ & $\begin{array}{c}-0.095 \\
(0.006)\end{array}$ \\
\hline \multicolumn{7}{|l|}{ School } \\
\hline 3rd Grade Math Score (2013) & $\begin{array}{c}0.236 \\
(0.004)\end{array}$ & $\begin{array}{c}0.141 \\
(0.006)\end{array}$ & $\begin{array}{c}0.056 \\
(0.006)\end{array}$ & $\begin{array}{c}0.294 \\
(0.004)\end{array}$ & $\begin{array}{c}0.178 \\
(0.006)\end{array}$ & $\begin{array}{c}-0.051 \\
(0.006)\end{array}$ \\
\hline 8th Grade Math Score (2013) & $\begin{array}{c}0.324 \\
(0.004)\end{array}$ & $\begin{array}{c}0.170 \\
(0.006)\end{array}$ & $\begin{array}{c}0.110 \\
(0.007)\end{array}$ & $\begin{array}{c}0.333 \\
(0.004)\end{array}$ & $\begin{array}{c}0.185 \\
(0.006)\end{array}$ & $\begin{array}{l}-0.053 \\
(0.007)\end{array}$ \\
\hline HS Suspension Rate (2013) & $\begin{array}{l}-0.189 \\
(0.004)\end{array}$ & $\begin{array}{c}-0.079 \\
(0.006)\end{array}$ & $\begin{array}{c}-0.129 \\
(0.007)\end{array}$ & $\begin{array}{c}-0.132 \\
(0.004)\end{array}$ & $\begin{array}{c}-0.069 \\
(0.006)\end{array}$ & $\begin{array}{c}-0.009 \\
(0.007)\end{array}$ \\
\hline Average ELA Score (2013) & $\begin{array}{c}0.297 \\
(0.004)\end{array}$ & $\begin{array}{c}0.160 \\
(0.006)\end{array}$ & $\begin{array}{c}0.083 \\
(0.006)\end{array}$ & $\begin{array}{c}0.361 \\
(0.004)\end{array}$ & $\begin{array}{c}0.189 \\
(0.006)\end{array}$ & $\begin{array}{c}-0.042 \\
(0.006)\end{array}$ \\
\hline \multicolumn{7}{|l|}{ Educational Attainment } \\
\hline Share Less Than HS Educated (2000) & $\begin{array}{c}-0.510 \\
(0.004)\end{array}$ & $\begin{array}{c}-0.351 \\
(0.006)\end{array}$ & $\begin{array}{c}-0.155 \\
(0.006)\end{array}$ & $\begin{array}{c}-0.382 \\
(0.004)\end{array}$ & $\begin{array}{c}-0.269 \\
(0.006)\end{array}$ & $\begin{array}{c}0.053 \\
(0.006)\end{array}$ \\
\hline Share College Educated (2000) & $\begin{array}{c}0.608 \\
(0.003)\end{array}$ & $\begin{array}{c}0.369 \\
(0.006)\end{array}$ & $\begin{array}{c}0.292 \\
(0.006)\end{array}$ & $\begin{array}{c}0.527 \\
(0.003)\end{array}$ & $\begin{array}{c}0.341 \\
(0.006)\end{array}$ & $\begin{array}{c}-0.004 \\
(0.006)\end{array}$ \\
\hline Housing & & & & & & \\
\hline Share who Own Home (2010) & $\begin{array}{c}0.149 \\
(0.004)\end{array}$ & $\begin{array}{c}0.108 \\
(0.006)\end{array}$ & $\begin{array}{c}-0.016 \\
(0.006)\end{array}$ & $\begin{array}{c}0.168 \\
(0.004)\end{array}$ & $\begin{array}{c}0.164 \\
(0.006)\end{array}$ & $\begin{array}{c}-0.060 \\
(0.006)\end{array}$ \\
\hline Median 2 Bedroom Rent (2015) & $\begin{array}{c}0.551 \\
(0.004)\end{array}$ & $\begin{array}{c}0.533 \\
(0.006)\end{array}$ & $\begin{array}{c}0.206 \\
(0.007)\end{array}$ & $\begin{array}{c}0.436 \\
(0.004)\end{array}$ & $\begin{array}{c}0.302 \\
(0.006)\end{array}$ & $\begin{array}{c}-0.006 \\
(0.007)\end{array}$ \\
\hline Healthcare Access & & & & & & \\
\hline Share Adults Insured (2008-2012) & $\begin{array}{c}0.388 \\
(0.004)\end{array}$ & $\begin{array}{c}0.238 \\
(0.006)\end{array}$ & $\begin{array}{c}0.081 \\
(0.006)\end{array}$ & $\begin{array}{c}0.475 \\
(0.004)\end{array}$ & $\begin{array}{c}0.230 \\
(0.006)\end{array}$ & $\begin{array}{c}0.008 \\
(0.006)\end{array}$ \\
\hline B. Race-Specific Measures & & & & & & \\
\hline Economy & & & & & & \\
\hline Share Black in Poverty (2000) & $\begin{array}{c}-0.222 \\
(0.004)\end{array}$ & $\begin{array}{c}-0.449 \\
(0.006)\end{array}$ & $\begin{array}{c}0.005 \\
(0.006)\end{array}$ & $\begin{array}{c}-0.143 \\
(0.005)\end{array}$ & $\begin{array}{c}-0.274 \\
(0.006)\end{array}$ & $\begin{array}{c}0.102 \\
(0.006)\end{array}$ \\
\hline Share White in Poverty (2000) & $\begin{array}{c}-0.422 \\
(0.004)\end{array}$ & $\begin{array}{c}-0.128 \\
(0.006)\end{array}$ & $\begin{array}{c}-0.118 \\
(0.006)\end{array}$ & $\begin{array}{c}-0.352 \\
(0.004)\end{array}$ & $\begin{array}{c}-0.141 \\
(0.006)\end{array}$ & $\begin{array}{c}0.027 \\
(0.006)\end{array}$ \\
\hline Family Structure & & & & & & \\
\hline Black Father Presence (p25) & $\begin{array}{c}-0.121 \\
(0.005)\end{array}$ & $\begin{array}{c}-0.190 \\
(0.006)\end{array}$ & $\begin{array}{c}-0.037 \\
(0.006)\end{array}$ & $\begin{array}{c}-0.072 \\
(0.005)\end{array}$ & $\begin{array}{c}-0.023 \\
(0.006)\end{array}$ & $\begin{array}{c}-0.024 \\
(0.006)\end{array}$ \\
\hline White Father Presence (p25) & $\begin{array}{c}-0.129 \\
(0.004)\end{array}$ & $\begin{array}{c}-0.134 \\
(0.006)\end{array}$ & $\begin{array}{l}-0.105 \\
(0.006)\end{array}$ & $\begin{array}{l}-0.110 \\
(0.004)\end{array}$ & $\begin{array}{l}-0.007 \\
(0.006)\end{array}$ & $\begin{array}{l}-0.020 \\
(0.006)\end{array}$ \\
\hline Black Mother Presence (p25) & $\begin{array}{c}0.028 \\
(0.005)\end{array}$ & $\begin{array}{c}0.126 \\
(0.006)\end{array}$ & $\begin{array}{c}-0.064 \\
(0.006)\end{array}$ & $\begin{array}{c}-0.015 \\
(0.005)\end{array}$ & $\begin{array}{c}0.025 \\
(0.006)\end{array}$ & $\begin{array}{c}-0.058 \\
(0.006)\end{array}$ \\
\hline White Mother Presence (p25) & $\begin{array}{c}0.020 \\
(0.004)\end{array}$ & $\begin{array}{c}-0.010 \\
(0.006)\end{array}$ & $\begin{array}{c}0.026 \\
(0.006)\end{array}$ & $\begin{array}{c}-0.030 \\
(0.004)\end{array}$ & $\begin{array}{c}0.003 \\
(0.006)\end{array}$ & $\begin{array}{c}-0.026 \\
(0.006)\end{array}$ \\
\hline Housing & & & & & & \\
\hline Median Home Value Black (2000) & $\begin{array}{c}0.456 \\
(0.004)\end{array}$ & $\begin{array}{c}0.481 \\
(0.006)\end{array}$ & $\begin{array}{c}0.186 \\
(0.006)\end{array}$ & $\begin{array}{c}0.350 \\
(0.004)\end{array}$ & $\begin{array}{c}0.320 \\
(0.006)\end{array}$ & $\begin{array}{c}-0.031 \\
(0.007)\end{array}$ \\
\hline Median Home Value White (2000) & $\begin{array}{c}0.540 \\
(0.003)\end{array}$ & $\begin{array}{c}0.345 \\
(0.006)\end{array}$ & $\begin{array}{c}0.254 \\
(0.006)\end{array}$ & $\begin{array}{c}0.433 \\
(0.004)\end{array}$ & $\begin{array}{c}0.260 \\
(0.006)\end{array}$ & $\begin{array}{c}0.026 \\
(0.006)\end{array}$ \\
\hline Racial Bias & & & & & & \\
\hline IAT Score for Black & $\begin{array}{c}0.061 \\
(0.021)\end{array}$ & $\begin{array}{c}0.223 \\
(0.026)\end{array}$ & $\begin{array}{c}0.174 \\
(0.026)\end{array}$ & $\begin{array}{c}0.060 \\
(0.021)\end{array}$ & $\begin{array}{c}0.101 \\
(0.027)\end{array}$ & $\begin{array}{c}0.119 \\
(0.027)\end{array}$ \\
\hline IAT Score for White & $\begin{array}{c}-0.055 \\
(0.018)\end{array}$ & $\begin{array}{c}-0.283 \\
(0.026)\end{array}$ & $\begin{array}{c}-0.161 \\
(0.026)\end{array}$ & $\begin{array}{c}0.062 \\
(0.018)\end{array}$ & $\begin{array}{l}-0.203 \\
(0.026)\end{array}$ & $\begin{array}{c}-0.054 \\
(0.027)\end{array}$ \\
\hline IAT Score White - Black & $\begin{array}{c}-0.074 \\
(0.021)\end{array}$ & $\begin{array}{c}-0.346 \\
(0.025)\end{array}$ & $\begin{array}{l}-0.235 \\
(0.026)\end{array}$ & $\begin{array}{c}-0.038 \\
(0.021)\end{array}$ & $\begin{array}{c}-0.202 \\
(0.026)\end{array}$ & $\begin{array}{l}-0.127 \\
(0.027)\end{array}$ \\
\hline Interracial Marriage Attitudes & $\begin{array}{c}-0.604 \\
(0.122)\end{array}$ & $\begin{array}{c}-0.584 \\
(0.125)\end{array}$ & $\begin{array}{l}-0.577 \\
(0.126)\end{array}$ & $\begin{array}{l}-0.306 \\
(0.145)\end{array}$ & $\begin{array}{l}-0.366 \\
(0.144)\end{array}$ & $\begin{array}{l}-0.480 \\
(0.135)\end{array}$ \\
\hline Racial Animus Index & $\begin{array}{c}-0.206 \\
(0.070)\end{array}$ & $\begin{array}{c}-0.373 \\
(0.071)\end{array}$ & $\begin{array}{c}-0.062 \\
(0.076)\end{array}$ & $\begin{array}{c}0.075 \\
(0.072)\end{array}$ & $\begin{array}{l}-0.367 \\
(0.071)\end{array}$ & $\begin{array}{c}0.181 \\
(0.075)\end{array}$ \\
\hline Healthcare Access & & & & & & \\
\hline Share Adults Insured Black (2008-2012) & $\begin{array}{c}0.126 \\
(0.004)\end{array}$ & $\begin{array}{c}0.241 \\
(0.006)\end{array}$ & $\begin{array}{c}0.008 \\
(0.006)\end{array}$ & $\begin{array}{c}0.133 \\
(0.004)\end{array}$ & $\begin{array}{c}0.175 \\
(0.006)\end{array}$ & $\begin{array}{c}-0.031 \\
(0.006)\end{array}$ \\
\hline Share Adults Insured White (2008-2012) & $\begin{array}{c}0.450 \\
(0.004)\end{array}$ & $\begin{array}{c}0.168 \\
(0.006)\end{array}$ & $\begin{array}{c}0.162 \\
(0.006)\end{array}$ & $\begin{array}{c}0.502 \\
(0.004)\end{array}$ & $\begin{array}{c}0.161 \\
(0.006)\end{array}$ & $\begin{array}{c}0.024 \\
(0.006)\end{array}$ \\
\hline C. Demographic Characteristics & & & & & & \\
\hline Population Density (2000) & $\begin{array}{c}0.231 \\
(0.004)\end{array}$ & $\begin{array}{c}0.301 \\
(0.006)\end{array}$ & $\begin{array}{c}0.158 \\
(0.006)\end{array}$ & $\begin{array}{c}0.160 \\
(0.004)\end{array}$ & $\begin{array}{c}0.070 \\
(0.006)\end{array}$ & $\begin{array}{c}0.065 \\
(0.006)\end{array}$ \\
\hline Share Black (2010) & $\begin{array}{l}-0.185 \\
(0.004)\end{array}$ & $\begin{array}{c}-0.008 \\
(0.006)\end{array}$ & $\begin{array}{l}-0.242 \\
(0.006)\end{array}$ & $\begin{array}{l}-0.135 \\
(0.004)\end{array}$ & $\begin{array}{l}-0.047 \\
(0.006)\end{array}$ & $\begin{array}{l}-0.039 \\
(0.006)\end{array}$ \\
\hline Share of Population Younger than 18 (2000) & $\begin{array}{c}-0.189 \\
(0.004)\end{array}$ & $\begin{array}{c}-0.119 \\
(0.006)\end{array}$ & $\begin{array}{c}-0.195 \\
(0.006)\end{array}$ & $\begin{array}{c}-0.263 \\
(0.004)\end{array}$ & $\begin{array}{c}-0.111 \\
(0.006)\end{array}$ & $\begin{array}{c}-0.120 \\
(0.006)\end{array}$ \\
\hline Share Foreign Born (2000) & $\begin{array}{c}0.337 \\
(0.004)\end{array}$ & $\begin{array}{c}0.383 \\
(0.006)\end{array}$ & $\begin{array}{c}0.198 \\
(0.006)\end{array}$ & $\begin{array}{c}0.215 \\
(0.004)\end{array}$ & $\begin{array}{c}0.171 \\
(0.006)\end{array}$ & $\begin{array}{c}0.013 \\
(0.006)\end{array}$ \\
\hline Share Divorced (2000) & $\begin{array}{c}-0.314 \\
(0.004)\end{array}$ & $\begin{array}{c}-0.187 \\
(0.006)\end{array}$ & $\begin{array}{c}-0.087 \\
(0.006)\end{array}$ & $\begin{array}{l}-0.326 \\
(0.004)\end{array}$ & $\begin{array}{c}-0.213 \\
(0.006)\end{array}$ & $\begin{array}{c}0.020 \\
(0.006)\end{array}$ \\
\hline
\end{tabular}

Notes : This table replicates Online Appendix Table XI for female children instead of male children. See notes to Online Appendix Table XI for details. All statistics cleared under Census DRB release authorization CBDRB-FY18-195. 
Online Appendix Table XIV

Association Between Racial Bias and Black Men's Employment and Incarceration Rates: OLS Regression Estimates

\begin{tabular}{lcccc}
\hline \hline Dependent Variable: & Employment & Incarceration & Employment & Incarceration \\
& $(1)$ & $(2)$ & $(3)$ & $(4)$ \\
\hline Difference in IAT & -0.0052 & 0.0039 & & \\
Racial Animus Index & $(0.0022)$ & $(0.0032)$ & & \\
& & & -0.0138 & 0.0278 \\
& & & $(0.0057)$ & $(0.0092)$ \\
Unit of Analysis & Counties & Counties & Media & Media \\
Number of Counties/Media & \multirow{2}{*}{340} & & Markets & Markets \\
Markets & & & 28 & 26 \\
\hline
\end{tabular}

Notes: This table replicates Table III, using employment and incarceration rates for black men with parents at the 25th percentile as the dependent variable. Columns 1 and 2 replicate Column 1 of Table III, replacing the dependent variable with predicted employment and incarceration rates given parents at the 25th percentile instead of individual income ranks. Columns 3 and 4 use the same dependent variables (aggregated to the media market level) as columns 1 and 2. See notes to Table III for further details. All statistics cleared under Census DRB release authorization CBDRB-FY18-195. 
Online Appendix Table XV

Quasi-Experimental Estimates of Childhood Exposure Effects for Black vs. White Men

\begin{tabular}{|c|c|c|c|c|c|c|c|c|c|c|c|c|}
\hline \multirow{3}{*}{$\begin{array}{l}\text { Outcome: } \\
\text { Sample: }\end{array}$} & \multicolumn{6}{|c|}{ Exposure Effects Using Baseline Specification } & \multicolumn{6}{|c|}{ Exposure Effects Using Other Race Placebos } \\
\hline & \multicolumn{2}{|c|}{ Individual Income at 30} & \multicolumn{2}{|c|}{ Incarcerated in 2010} & \multicolumn{2}{|c|}{ Married at Age 30} & \multicolumn{2}{|c|}{ Individual Income at 30} & \multicolumn{2}{|c|}{ Incarcerated in 2010} & \multicolumn{2}{|c|}{ Married at Age 30} \\
\hline & $\begin{array}{c}\text { Black } \\
\text { Males } \\
(1) \\
\end{array}$ & $\begin{array}{c}\text { White } \\
\text { Males } \\
(2) \\
\end{array}$ & $\begin{array}{c}\text { Black } \\
\text { Males } \\
(3) \\
\end{array}$ & $\begin{array}{c}\text { White } \\
\text { Males } \\
(4)\end{array}$ & $\begin{array}{c}\text { Black } \\
\text { Males } \\
(5) \\
\end{array}$ & $\begin{array}{c}\text { White } \\
\text { Males } \\
(6) \\
\end{array}$ & $\begin{array}{c}\text { Black } \\
\text { Males } \\
(7) \\
\end{array}$ & $\begin{array}{c}\text { White } \\
\text { Males } \\
(8) \\
\end{array}$ & $\begin{array}{c}\text { Black } \\
\text { Males } \\
(9) \\
\end{array}$ & $\begin{array}{c}\text { White } \\
\text { Males } \\
(10) \\
\end{array}$ & $\begin{array}{c}\text { Black } \\
\text { Males } \\
(11) \\
\end{array}$ & $\begin{array}{c}\text { White } \\
\text { Males } \\
(12) \\
\end{array}$ \\
\hline $\begin{array}{l}\text { Under-23 Own-Race Coeff. } \\
\text { (Annual Exposure Effect) }\end{array}$ & $\begin{array}{l}-0.027 \\
(0.004)\end{array}$ & $\begin{array}{l}-0.027 \\
(0.002)\end{array}$ & $\begin{array}{l}-0.034 \\
(0.004)\end{array}$ & $\begin{array}{l}-0.027 \\
(0.003)\end{array}$ & $\begin{array}{l}-0.023 \\
(0.004)\end{array}$ & $\begin{array}{l}-0.022 \\
(0.001)\end{array}$ & $\begin{array}{l}-0.029 \\
(0.004)\end{array}$ & $\begin{array}{l}-0.023 \\
(0.002)\end{array}$ & $\begin{array}{l}-0.032 \\
(0.004)\end{array}$ & $\begin{array}{l}-0.031 \\
(0.004)\end{array}$ & $\begin{array}{l}-0.017 \\
(0.004)\end{array}$ & $\begin{array}{l}-0.021 \\
(0.002)\end{array}$ \\
\hline \multicolumn{13}{|l|}{ Placebos: } \\
\hline Under-23 Other-Race Placebo & & & & & & & $\begin{array}{c}0.003 \\
(0.004)\end{array}$ & $\begin{array}{l}-0.004 \\
(0.001)\end{array}$ & $\begin{array}{l}-0.018 \\
(0.014)\end{array}$ & $\begin{array}{c}0.001 \\
(0.001)\end{array}$ & $\begin{array}{l}-0.015 \\
(0.003)\end{array}$ & $\begin{array}{l}-0.002 \\
(0.002)\end{array}$ \\
\hline Over-23 Own-Race Placebo & $\begin{array}{c}0.008 \\
(0.025)\end{array}$ & $\begin{array}{l}-0.016 \\
(0.011)\end{array}$ & $\begin{array}{l}-0.030 \\
(0.027)\end{array}$ & $\begin{array}{l}-0.010 \\
(0.023)\end{array}$ & $\begin{array}{c}0.018 \\
(0.029)\end{array}$ & $\begin{array}{c}0.004 \\
(0.010)\end{array}$ & $\begin{array}{c}0.015 \\
(0.029)\end{array}$ & $\begin{array}{l}-0.025 \\
(0.015)\end{array}$ & $\begin{array}{l}-0.032 \\
(0.030)\end{array}$ & $\begin{array}{c}0.020 \\
(0.033)\end{array}$ & $\begin{array}{c}0.005 \\
(0.030)\end{array}$ & $\begin{array}{l}-0.005 \\
(0.015)\end{array}$ \\
\hline Over-23 Other-Race Placebo & & & & & & & $\begin{array}{l}-0.013 \\
(0.028)\end{array}$ & $\begin{array}{c}0.005 \\
(0.010)\end{array}$ & $\begin{array}{c}0.012 \\
(0.099)\end{array}$ & $\begin{array}{c}0.004 \\
(0.007)\end{array}$ & $\begin{array}{c}0.034 \\
(0.023)\end{array}$ & $\begin{array}{l}-0.007 \\
(0.011)\end{array}$ \\
\hline Num. of Obs. & 150,000 & 884,000 & 123,000 & 712,000 & 150,000 & 884,000 & 150,000 & 668,000 & 122,000 & 460,000 & 150,000 & 666,000 \\
\hline
\end{tabular}

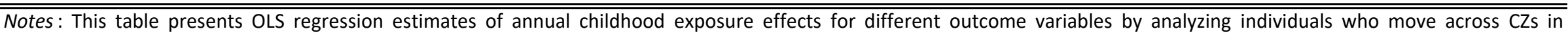

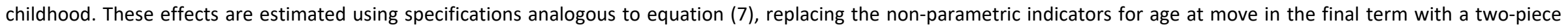

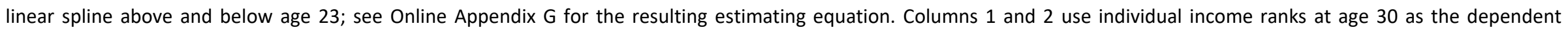

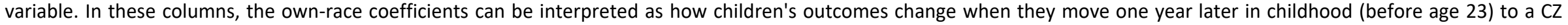

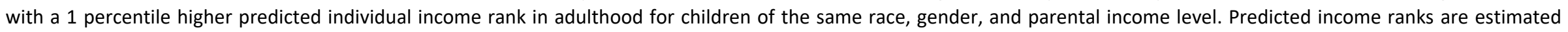

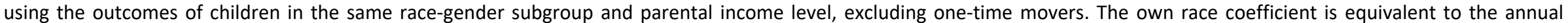

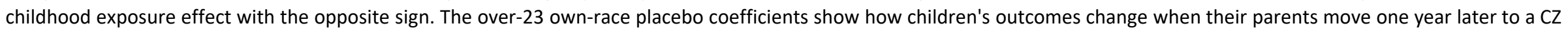

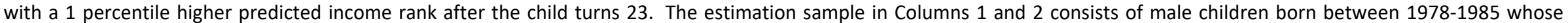

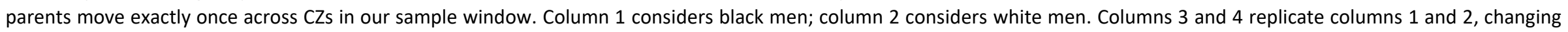

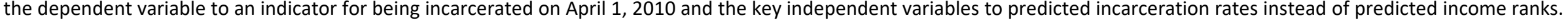

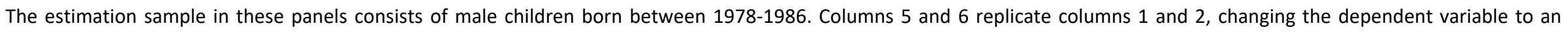

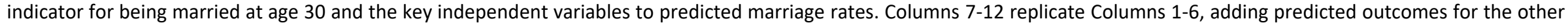

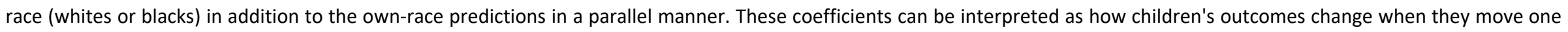

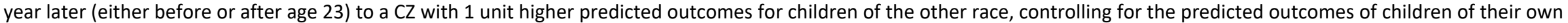

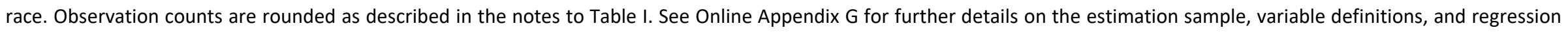
specifications. All statistics cleared under Census DRB release authorization CBDRB-FY18-195. 
Online Appendix Table XVI

Tracts With Highest, Average, and Lowest Rates of Upward Mobility for Black Men: Illustrative Examples

Tract FIPS code CZ Name Neighborhood Name
Predicted Rank of Fraction of Fathers Poverty Rate in Black Men with Present in Tract Tract

A. Highest Upward Mobility Places

\begin{tabular}{|c|c|c|c|c|c|}
\hline 36047083800 & New York & East Flatbush, Kings County & 46.1 & $51.3 \%$ & $6.1 \%$ \\
\hline 36081064600 & New York & Laurelton, Queens County & 46.7 & $53.9 \%$ & $4.4 \%$ \\
\hline 36081054200 & New York & Queens Village, Queens County & 55.4 & $56.2 \%$ & $8.1 \%$ \\
\hline 51510200102 & Washington DC & Alexandria West, Alexandria City County & 45.0 & $53.4 \%$ & $7.3 \%$ \\
\hline 24031704000 & Washington DC & Silver Spring, Montgomery County & 50.1 & $63.2 \%$ & $4.7 \%$ \\
\hline \multicolumn{6}{|c|}{ B. Average Places } \\
\hline 13121006500 & Atlanta & Capitol View, Fulton County & 38.1 & $33.9 \%$ & $24.5 \%$ \\
\hline 37119001400 & Charlotte & North Charlotte, Mecklenburg County & 39.1 & $37.8 \%$ & $22.2 \%$ \\
\hline 48201231600 & Houston & East Little York/Homestead, Harris County & 37.6 & $34.9 \%$ & $23.3 \%$ \\
\hline 48201331300 & Houston & Sunnyside, Harris County & 37.3 & $36.7 \%$ & $20.7 \%$ \\
\hline 42101029000 & Philadelphia & Olney, Philadelphia County & 38.4 & $36.9 \%$ & $19.8 \%$ \\
\hline \multicolumn{6}{|c|}{ C. Lowest Upward Mobility Places } \\
\hline 17031680600 & Chicago & Englewood, Cook County & 32.3 & $23.9 \%$ & $48.4 \%$ \\
\hline 17031350400 & Chicago & South Loop, Cook County & 26.6 & $19.8 \%$ & $76.0 \%$ \\
\hline 39061026400 & Cincinnati & West End, Hamilton County & 31.6 & $20.5 \%$ & $62.2 \%$ \\
\hline 26163512400 & Detroit & Chandler Park, Wayne County & 30.5 & $15.9 \%$ & $41.3 \%$ \\
\hline 6037237101 & Los Angeles & South Los Angeles, Los Angeles County & 32.5 & $24.7 \%$ & $42.1 \%$ \\
\hline
\end{tabular}

Notes: This table provides selected examples of the best, average, and worst Census tracts in terms of upward mobility and its key tract-level correlates for black boys growing up in low-income $(p=25)$ families using tract-level data reported in the Opportunity Atlas (www.opportunityatlas.org). The highest upward mobility tracts listed in Panel A satisfy three criteria: (1) they are above the 90th percentile in predicted individual income ranks for black boys with parents at $p=25$ (across all tracts with at least 50 black boys in the tract whose parents have income below the national median, weighting by black population); (2) have a poverty rate below $10 \%$ in the 2000 Census; and ( 3 ) have more than $50 \%$ of black boys in families at $\mathrm{p}=25$ who are raised with a father present (defined as in the notes to Table II). The poverty rate threshold corresponds to approximately the 15th percentile of poverty rates across tracts with at least 50 black boys (weighting by black population); the father presence threshold corresponds to around the 90th percentile of father presence for low-income black boys across the same set of tracts. "Average" tracts in Panel B are between the 40th and 60th percentile in predicted income ranks, poverty rates, and father presence. The lowest upward mobility tracts listed in Panel $\mathrm{C}$ are those with predicted income ranks below the 10th percentile, rates of father presence below the 10 th percentile, and poverty rates above the 85th percentile. There are many more tracts than the examples listed here that fall into each of these three groups; a comprehensive list can be obtained from the tract-level Online Data Tables for the Opportunity Atlas at www.opportunityinsights.org/data. 
Online Appendix Table XVII

Correction for Imperfect Measurement of Wealth Using Data from the Survey of Consumer Finances

\begin{tabular}{|c|c|c|}
\hline & $\begin{array}{c}\text { Men with Parents at 25th } \\
\text { Percentile } \\
\text { (1) }\end{array}$ & $\begin{array}{c}\text { Men with Parents at 75th } \\
\text { Percentile } \\
\text { (2) }\end{array}$ \\
\hline \multicolumn{3}{|l|}{ A. Estimated Black-white gaps in income ranks and wealth } \\
\hline Black-white gap in child individual income rank $\left(\tilde{b}_{w}\right)$ & 9.1 & 11.4 \\
\hline Black-white gap in child individual income rank $\left(\hat{b}_{w}\right)$ & 8.4 & 11.0 \\
\hline Black-white gap in household wealth, no wealth proxies $\left(\tilde{\lambda}_{w}\right)$ & 9.2 & 15.2 \\
\hline Black-white gap in household wealth, wealth controls $\left(\hat{\lambda}_{w}\right)$ & 3.3 & 10.1 \\
\hline \multicolumn{3}{|l|}{ B. Black-white intergenerational income gap, controlling for total wealth } \\
\hline Black-white gap in child individual income rank $\left(b_{w}\right)$ & 8.0 & 10.2 \\
\hline \multicolumn{3}{|c|}{$\begin{array}{l}\text { Notes: This table reports estimates of black-white intergenerational gaps for men controlling for total wealth rather than just the wealth proxies } \\
\text { observed in the ACS. To do so, we combine data from the SCF with the Census-tax-ACS data we use for our primary analysis, following the method } \\
\text { described in Online Appendix F. Panel A shows the black-white gap in household wealth (estimated using SCF data) and the black-white gap in } \\
\text { child individual income rank (estimated using Census and ACS data), the key inputs needed to compute the total-wealth-controlled estimates of } \\
\text { the intergenerational gap. The black-white gap is computed based on an OLS regression of an outcome variable (income or wealth rank) on the } \\
\text { indicator variable for being white, parental income, an interaction of the white indicator and parental income, and various additional controls. We } \\
\text { report the estimated black-white gap given a parental income rank of } p=25 \text { in Column } 1 \text { and } p=75 \text { in Column } 2 \text {. The first row shows the black- } \\
\text { white gap in child individual income rank after controlling for parental education and marital status in addition to income. The second row } \\
\text { replicates the first, adding controls for the wealth proxies observed in the ACS-Census-tax records dataset: home ownership, monthly mortgage } \\
\text { payments, home value, and number of vehicles. The third row shows the black-white wealth gap, in ranks, among families with children in the SCF } \\
\text { data after controlling for education, marital status, income, and the interaction of an indicator variable for being white and income. The fourth } \\
\text { row replicates the third, adding controls for the proxies for wealth observed in the ACS-Census-tax records dataset. Panel B shows the wealth- } \\
\text { adjusted black-white gap that we obtain using these inputs by applying the formula in equation (15), which are the values plotted in the sixth set } \\
\text { of bars in Figure VIII. }\end{array}$} \\
\hline
\end{tabular}




\section{FIGURE I: Intergenerational Mobility and the Evolution of Racial Disparities}

A. Constant Relative and Absolute Mobility

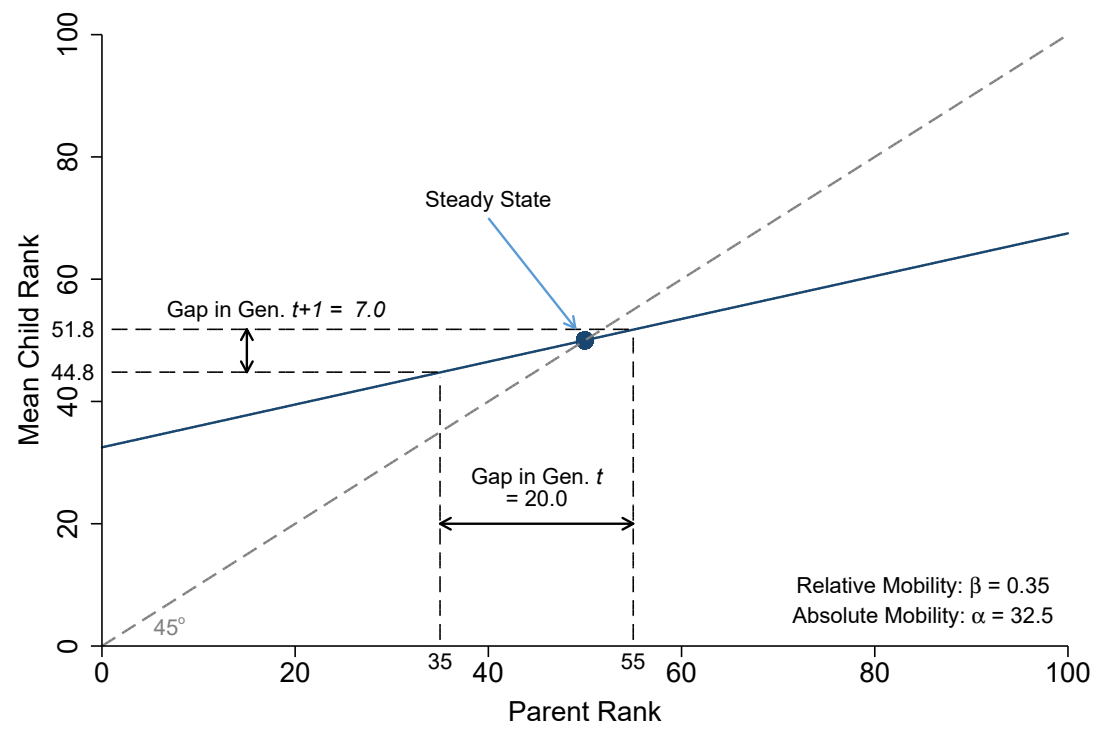

B. Constant Relative Mobility, Racial Differences in Absolute Mobility

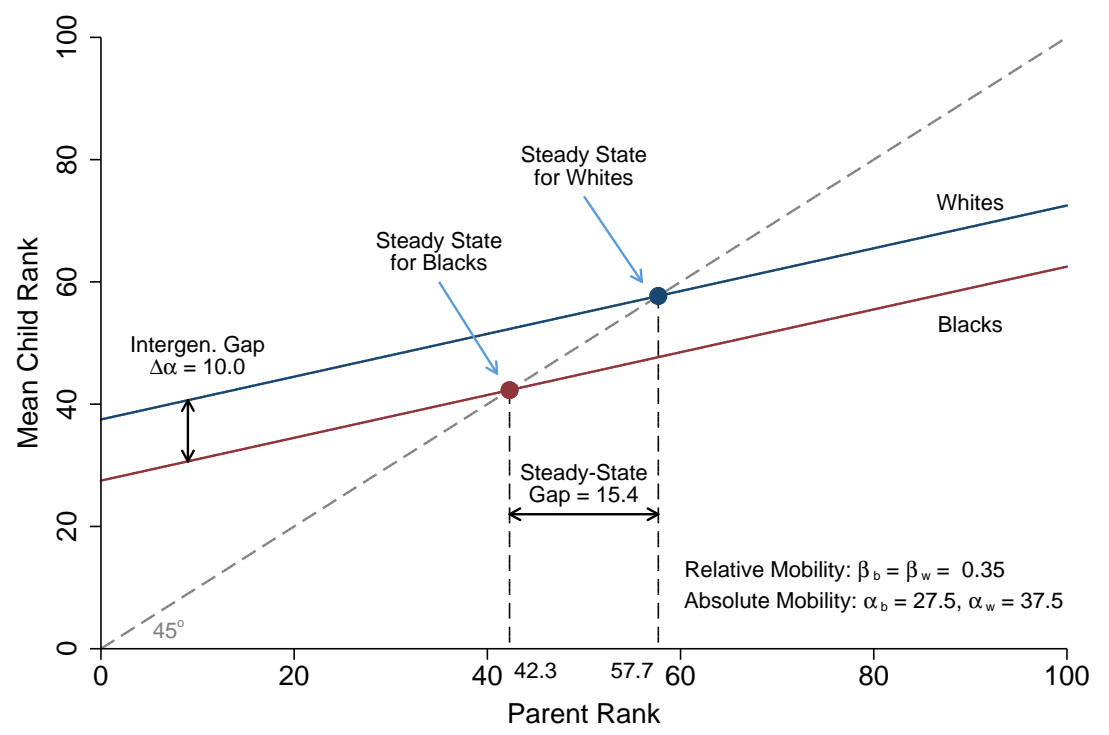

Notes: These figures show how rates of intergenerational mobility determine the evolution of racial disparities under the model in Section II. In Panel A, we assume that both black and white children have the same rates of relative and absolute intergenerational mobility. The solid line plots children's expected ranks conditional on their parents' ranks. We assume this line has a slope of 0.35, consistent with evidence from Chetty, Hendren, Kline, and Saez (2014). Since mean ranks are 50 (by definition) for both parents and children, this line must pass through $(50,50)$. The steady-state mean income rank for both blacks and whites, depicted by the point where the solid line crosses the dashed 45 degree line, is therefore 50 . The figure illustrates convergence to this steady-state given mean ranks of 35 percentiles for black parents and 55 percentiles for white parents in the initial generation, depicted by the vertical lines. In this case, white children have a mean rank of 51.8 percentiles and black children have a mean rank of 44.8 percentiles in the next generation, depicted by the horizontal lines. The gap therefore falls from 20 percentiles to 7 percentiles in one generation. In Panel B, we assume that blacks and whites have the same rates of relative mobility $(\beta=0.35)$, but absolute mobility is 10 percentiles lower for blacks than whites $\left(\alpha_{w}-\alpha_{b}=10\right)$. Here, the steady-state for blacks is 42.3 percentiles, while the steady-state for whites is 57.7 percentiles; hence the intergenerational gap of $\Delta \alpha=10$ leads to a steady-state racial disparity of 15.4 percentiles. 


\section{FIGURE II: Empirical Estimates of Intergenerational Mobility and Racial Disparities}

\section{A. Intergenerational Mobility and Steady States for Blacks vs. Whites}

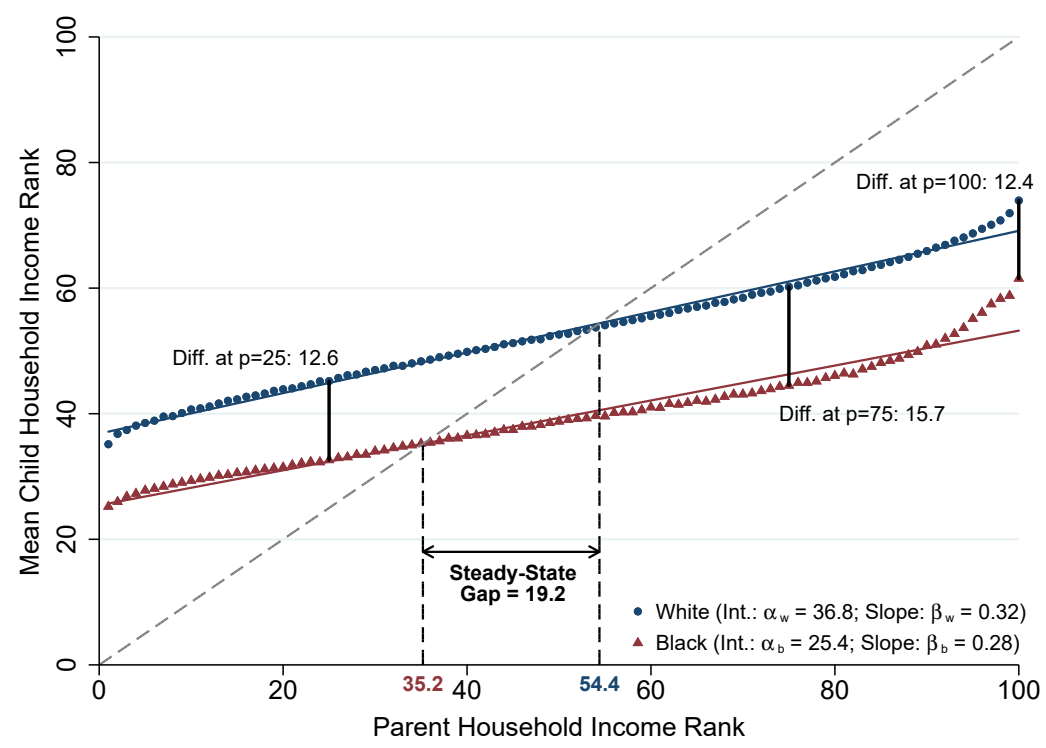

B. Current Mean Ranks vs. Predicted Ranks in Steady State, by Race

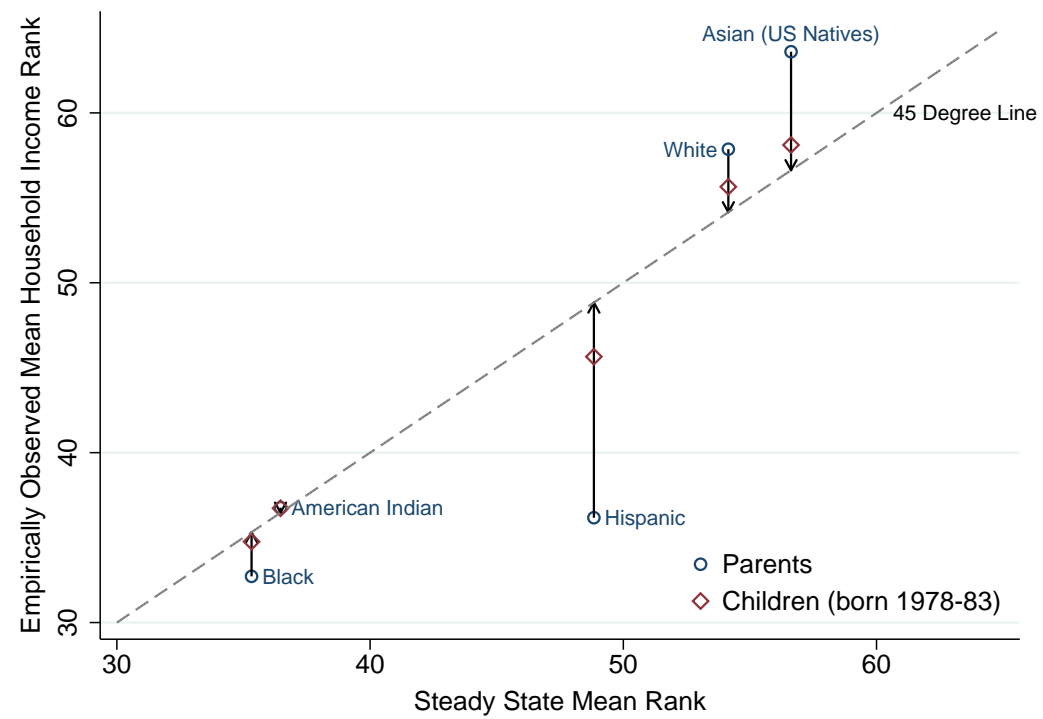

Notes: These figures show how empirical estimates of intergenerational mobility by race (Panel A) relate to the evolution of racial disparities (Panel B) using the model in Section II. These figures use the primary analysis sample (children in the 1978-83 birth cohorts). Child income is the mean of 2014-2015 household income (when the child is between 31-37 years old), while parent income is mean household income from 1994-1995 and 1998-2000. Children are assigned percentile ranks relative to all other children in their birth cohort, while parents are ranked relative to all parents with children in the same birth cohort. Panel A plots the mean household income rank of children by parent household income rank for black and white children. The best-fit lines are estimated using an OLS regression on the binned series; the slopes $\left(\beta_{r}\right)$ and intercepts $\left(\alpha_{r}\right)$ from these regressions are reported for each race. We also report white-black differences in mean child individual income rank at the 25th, 75th, and 100th percentiles of the parent income distribution. Plugging the estimates of $\alpha_{r}$ and $\beta_{r}$ into equation (3) from our model, the steady-state mean rank for blacks is $\frac{\alpha_{b}}{1-\beta_{b}}=35.2$ percentiles, while the steady-state for whites is $\frac{\alpha_{w}}{1-\beta_{w}}=54.4$ percentiles, resulting in a 19.2 percentile black-white gap in steady state. Panel B plots the empirically observed mean parent and child household ranks by race against the predicted steady-state mean ranks for blacks, whites, and other racial groups. Estimates for Asians are based on the subsample of children whose mothers were born in the United States, as in Figure IIIb below. The circles show the unconditional mean income ranks for parents, while the diamonds show mean ranks for children in our analysis sample. 


\section{FIGURE III: Intergenerational Mobility by Race}

A. All Children

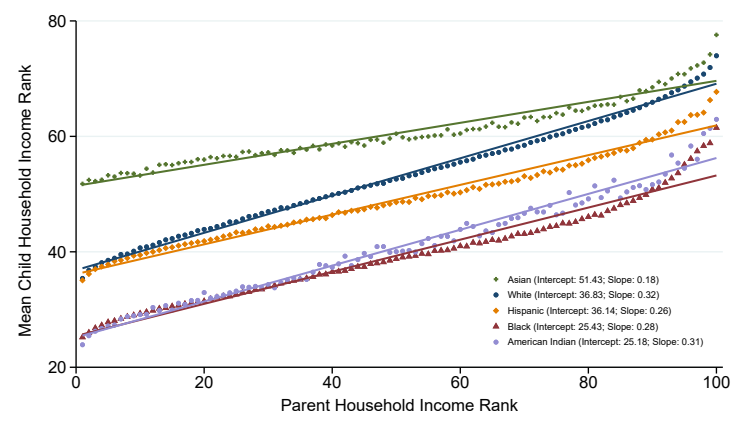

B. Children with Mothers Born in the U.S.

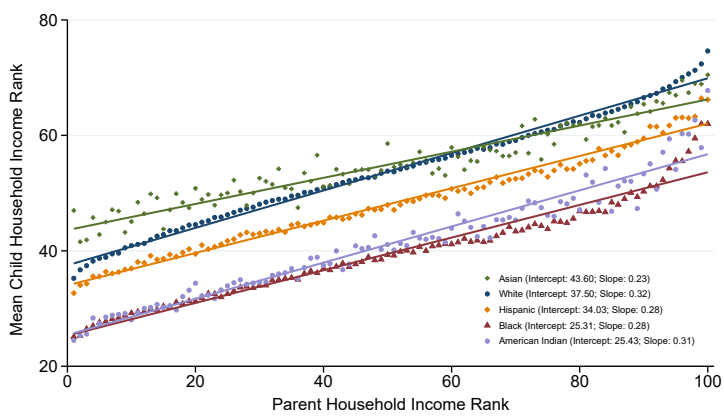

C. Children with Mothers Born Outside the U.S.

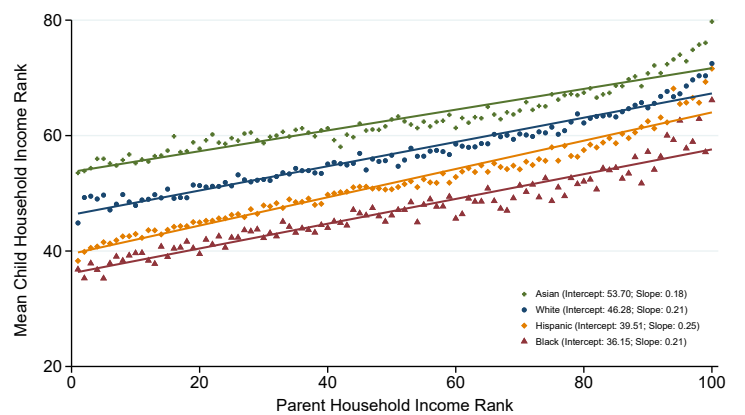

Notes: Panel A replicates Figure IIa, including series for Hispanics, Asians, and American Indians. Panel B replicates Panel A for children whose mothers were born in the United States. Panel C replicates Panel A for children whose mothers were born outside the United States. Panels B and C are based on the subsample of children whose mothers appear in the 2000 Census long form or the 2005-2015 American Community Survey because information on parental birthplace is available only for those individuals. Panel $\mathrm{C}$ excludes American Indians because of the small sample size of American Indian children with mothers born outside the U.S. See notes to Figure II for further details. 


\section{FIGURE IV: Black-White Gaps in Marriage Rates and Individual Income}

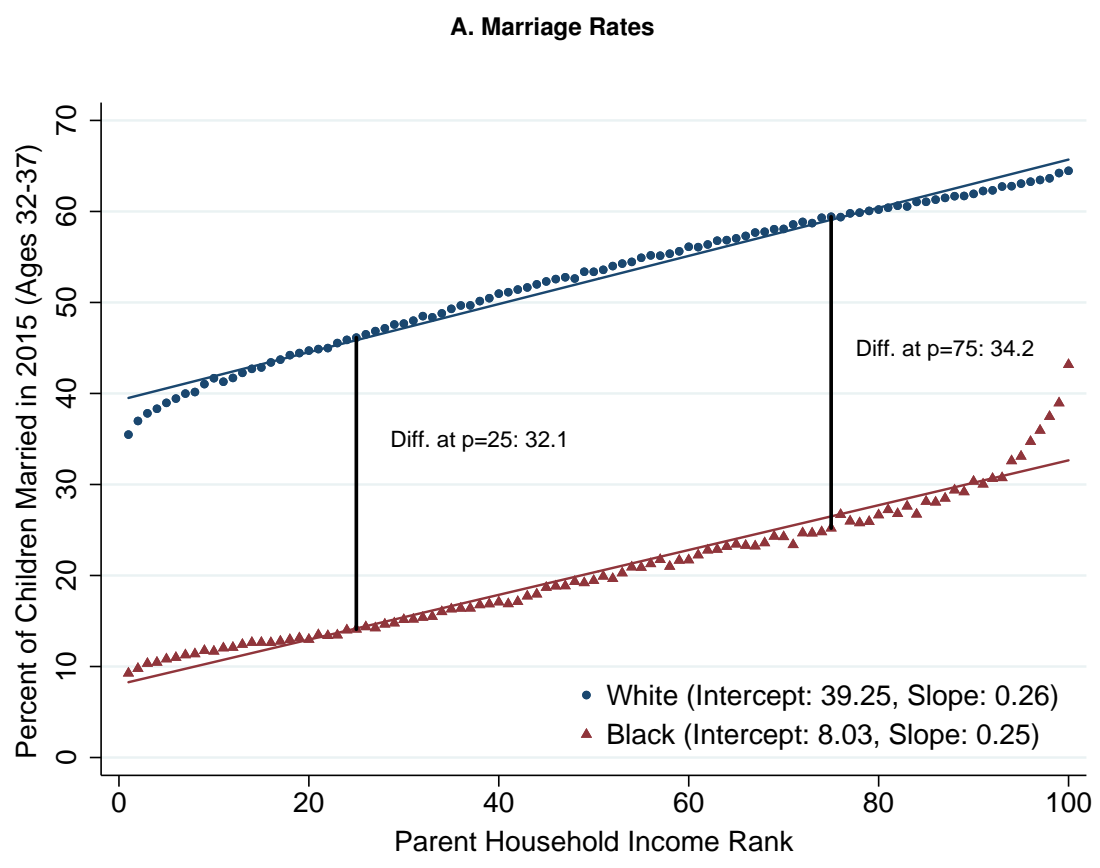

B. Individual Income

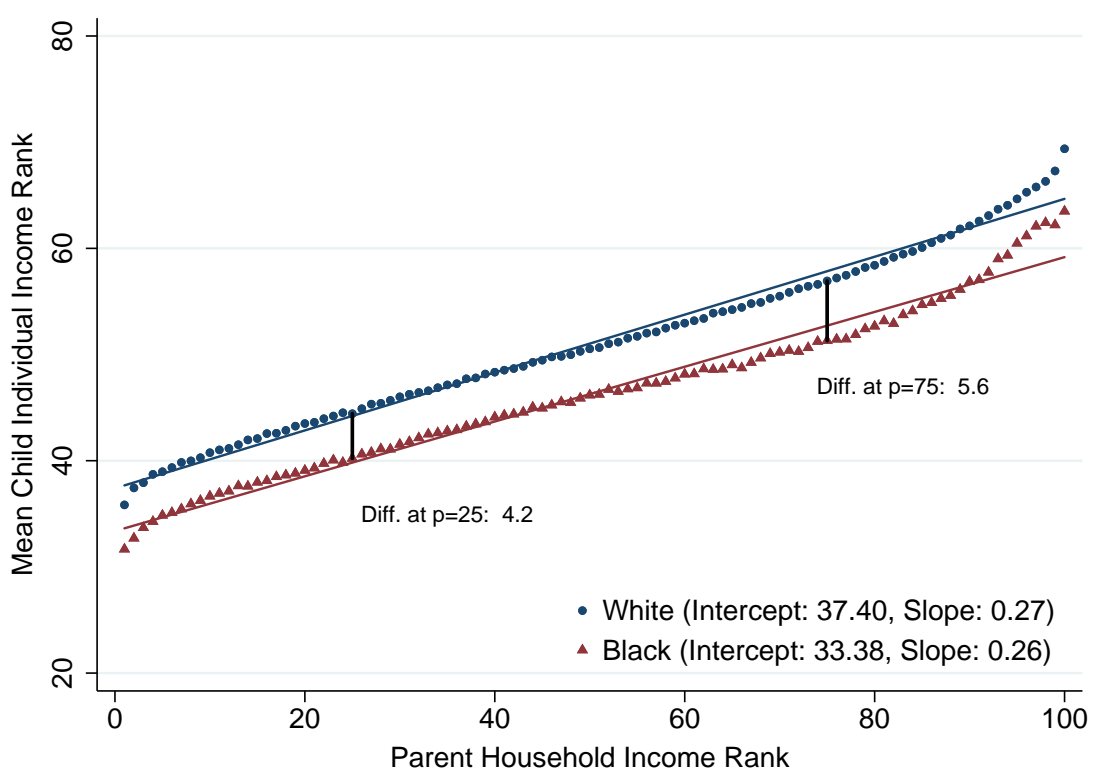

Notes: Panel A plots children's marriage rates by parent income percentile for black and white children. A child's marital status is defined based on the marital status used when filing his or her 2015 tax return. Children in our sample are between the ages of 32-37 at that point. Panel B plots the mean individual income rank of children vs. their parents' household income rank for black and white children. Individual income is defined as own W-2 wage earnings plus self-employment and other non-wage income, which is Adjusted Gross Income minus total wages reported on form 1040 divided by the number of tax filers (thereby splitting non-wage income equally for joint filers). We measure children's individual incomes as their mean annual incomes in 2014 and 2015. The intercepts, slopes, and best-fit lines are estimated using OLS regressions on the binned series. We also report the white-black differences in outcomes at the 25 th and 75 th parent income percentiles. See notes to Figure II for further details on sample and variable definitions. 
FIGURE V: Black-White Gaps in Individual Income, by Gender

A. Males

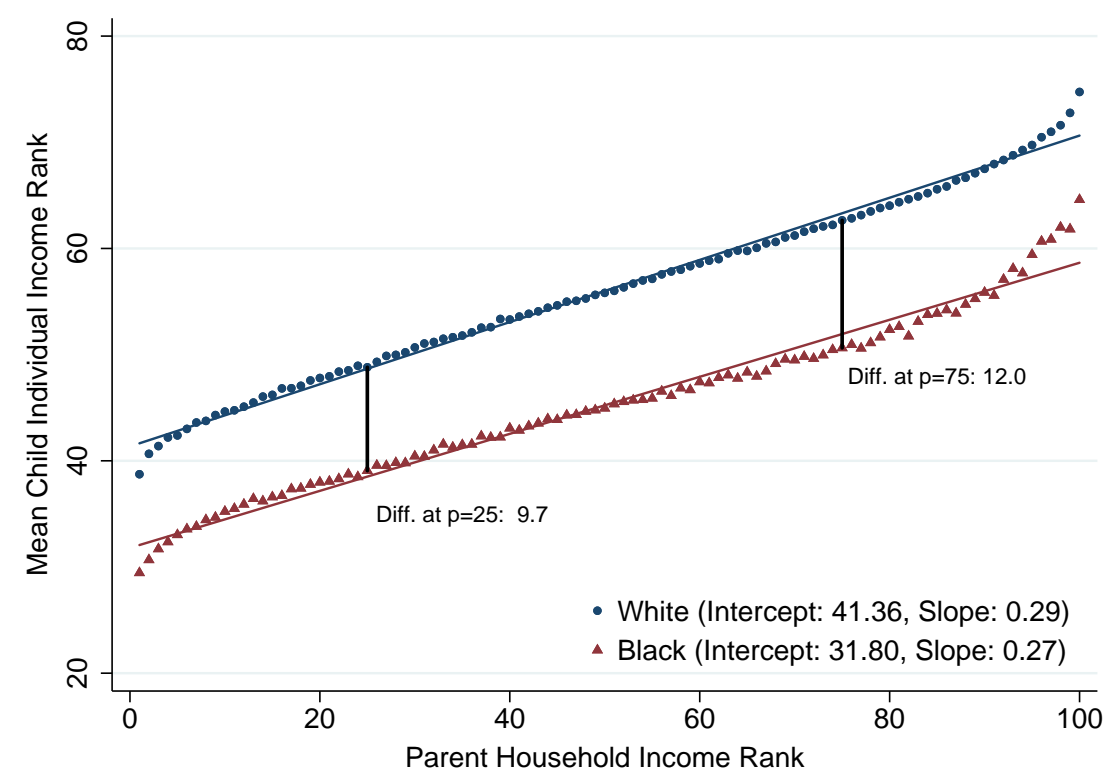

B. Females

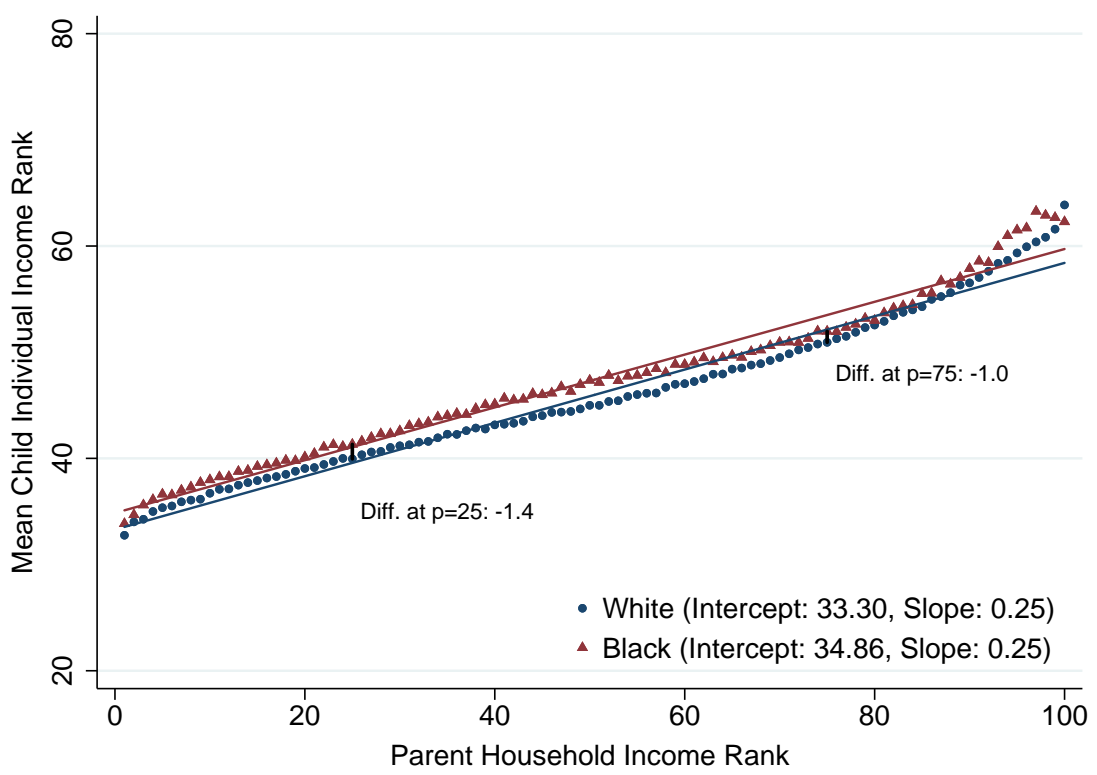

Notes: These figures replicate Figure IVb separately for male (Panel A) and female children (Panel B). Individual income ranks are computed within a child's cohort pooling across race and gender. See notes to Figure IV for further details. 


\section{FIGURE VI: Black-White Gaps in Wage Rates, Hours, and Employment, by Gender}

A. Wage Rank, Females

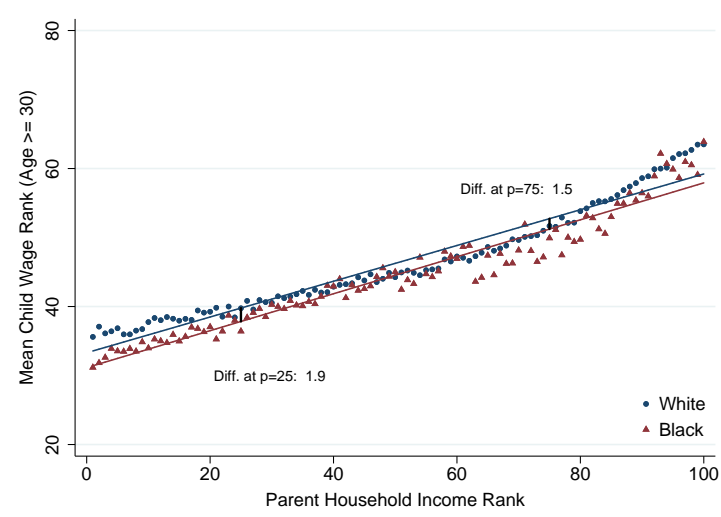

C. Hours Worked, Females

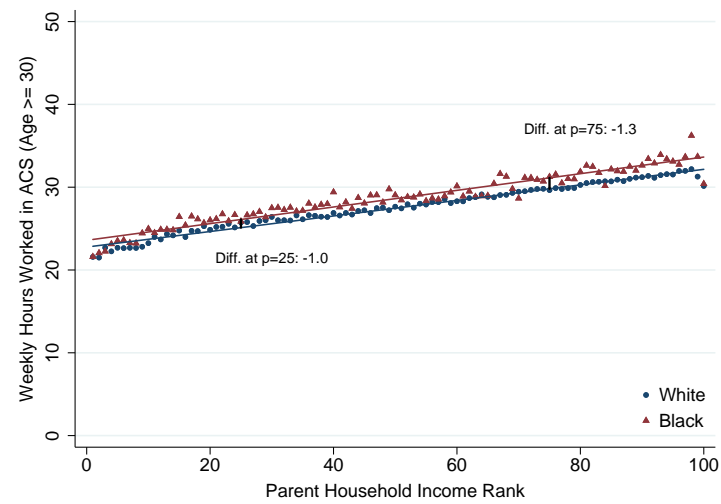

E. Employment Rates, Females

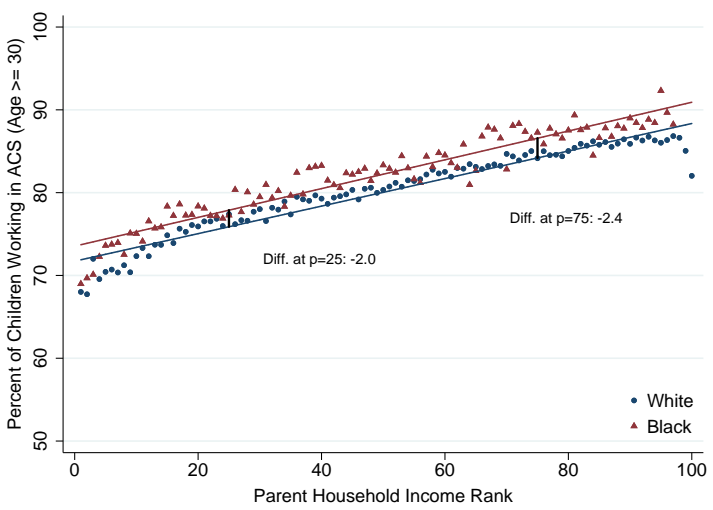

B. Wage Rank, Males

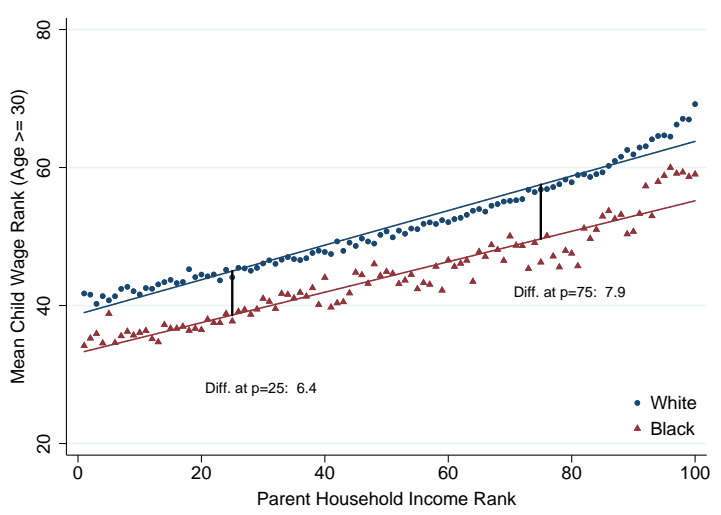

D. Hours Worked, Males

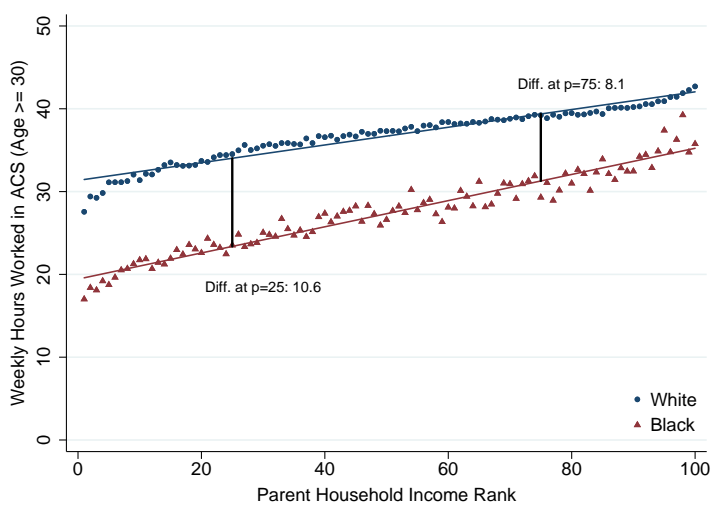

F. Employment Rates, Males

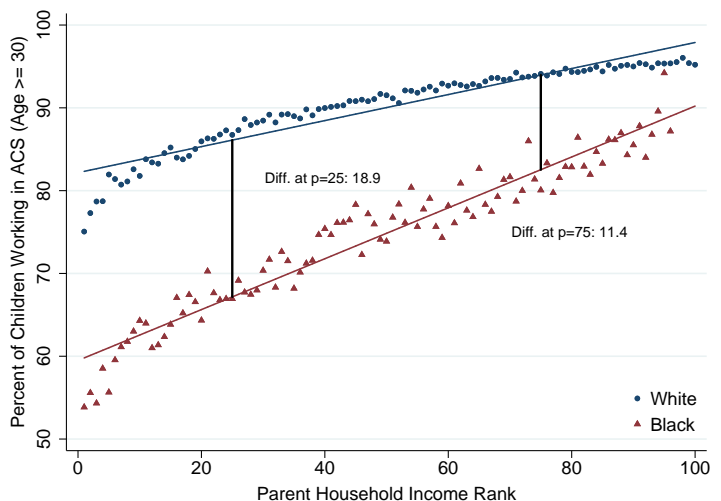

Notes: This figure shows the relationship between children's employment outcomes and their parents' household income, by race and gender. All children's outcomes in this figure are obtained from the American Community Survey and all panels include only children observed in the 2005-15 ACS at age 30 or older. Panels A and B plot mean wage ranks vs. parental household income percentile, by race and gender. Panels C and D replicate A and B using mean weekly hours of work as the outcome, while Panels E and F use annual employment rates as the outcome. Wages are computed as self-reported annual earnings divided by total hours of work; they are missing for those who do not work. We convert wages to percentile ranks by ranking individuals relative to others in the same birth cohort who received the ACS survey in the same year. Hours of work are defined as total annual hours of work divided by 51 and are coded as zero for those who do not work. Employment is defined as having positive hours of work in the past 12 months. To protect confidentiality, bins in which there are fewer than 10 children who are employed or not employed are suppressed in Panels E and F. In each figure, the best-fit lines are estimated using OLS regressions on the binned series. We report white-black differences based on the best-fit lines at the 25 th and 75 th parent income percentiles. 
FIGURE VII: Black-White Gaps in Educational Attainment and Incarceration, by Gender

A. High School Completion Rates, Females

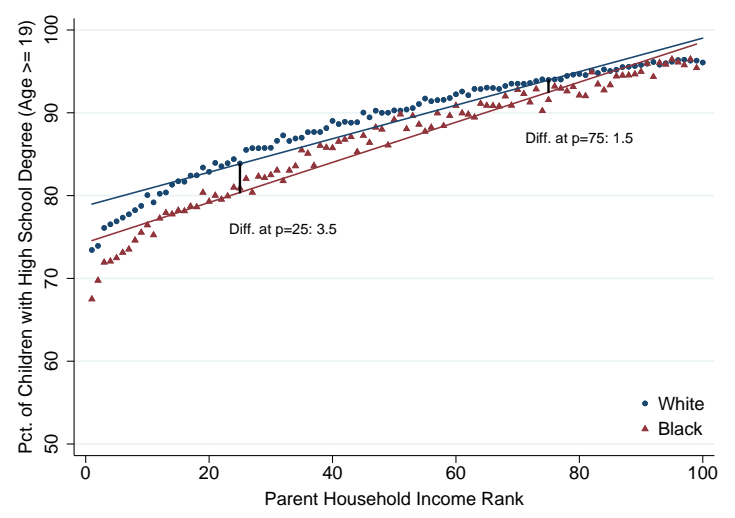

C. College Attendance Rates, Females

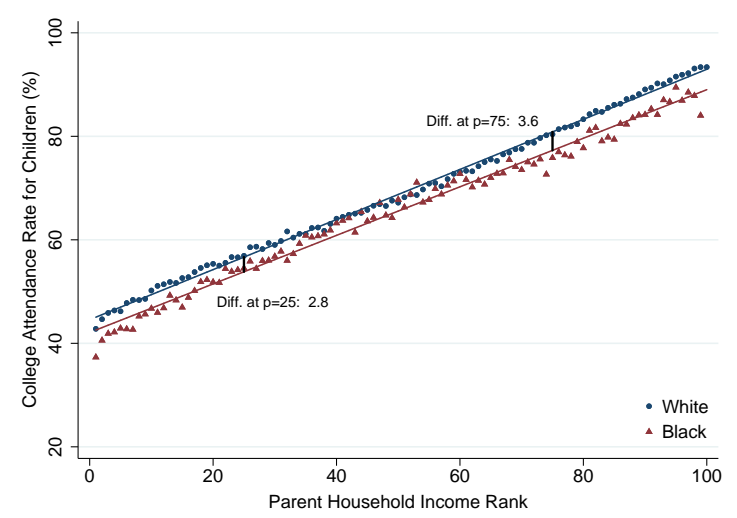

E. Incarceration, Females

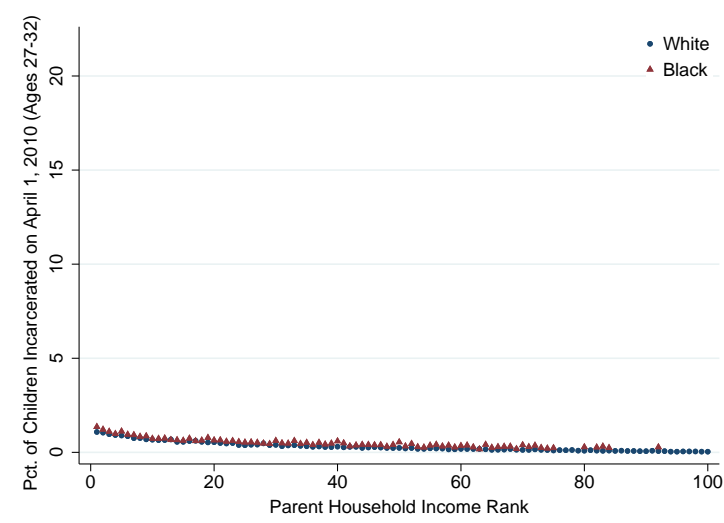

B. High School Completion Rates, Males

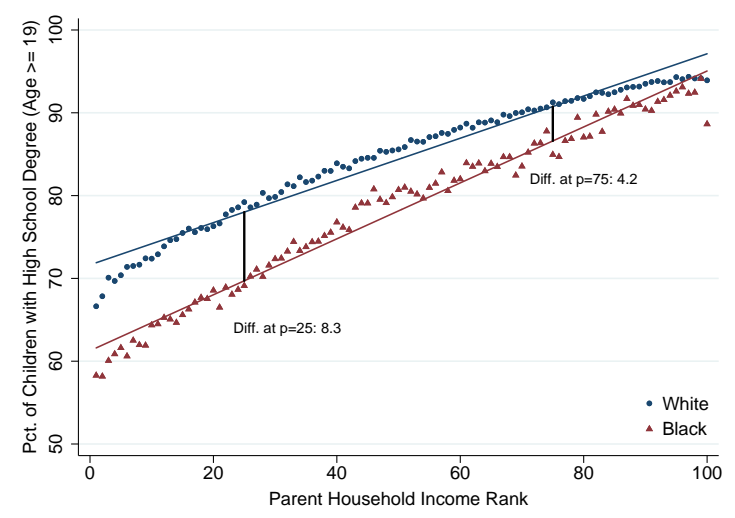

D. College Attendance Rates, Males

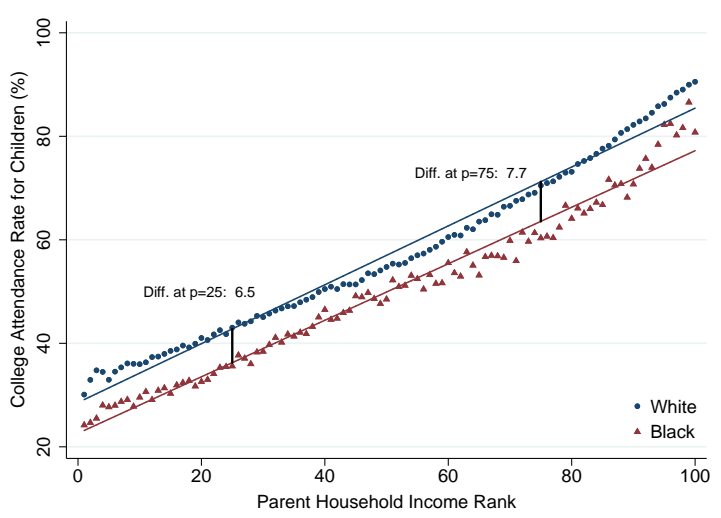

F. Incarceration, Males

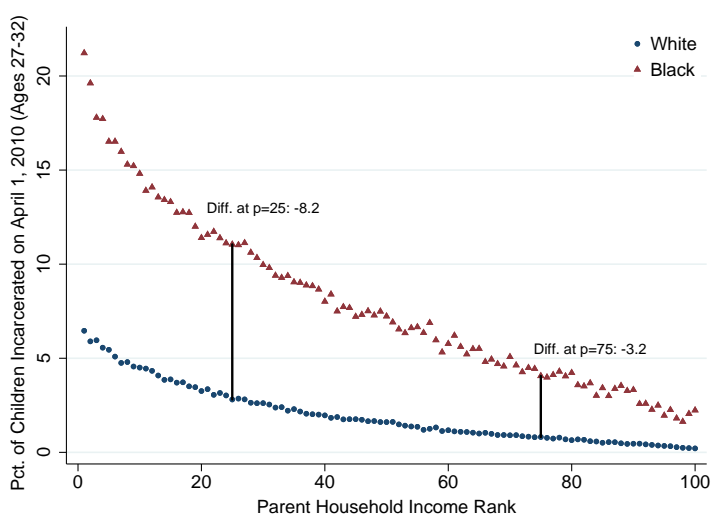

Notes: Panels A-D show the relationship between children's educational attainment and their parents' household income, by race and gender. Data on educational attainment is obtained from the American Community Survey. Panels A and B plot the fraction of children who complete high school by parental income percentile, by race and gender. Panels $\mathrm{C}$ and $\mathrm{D}$ replicate Panels A and B using college attendance as the outcome. Panels A-B include only children observed in the 2005-15 ACS at age 19 or older, while Panels C-D include those observed at age 20 or older. High school completion is defined as having a high school diploma or GED. College attendance is defined as having obtained "at least some college credit." Panels E and $\mathrm{F}$ plot incarceration rates vs. parent income percentile, by race and gender. Incarceration is defined as being incarcerated on April 1, 2010 using data from the 2010 Census short form. The children in our sample are between the ages of 27-32 at that point. The best-fit lines in Panels A-D are estimated using OLS regressions on the binned series. We report white-black differences based on the best-fit lines (in Panels A-D) and based directly on the non-parametric estimates (in Panel F) at the 25th and 75th parent income percentiles. To protect confidentiality, bins in which there are fewer than 10 children who either exhibit the outcome (e.g., college attendance) or do not exhibit the outcome are suppressed. 


\section{FIGURE VIII: Effects of Family- and Neighborhood-Level Factors on the Black-White Income Gap}

\section{A. Children with Parents at 25th Percentile}

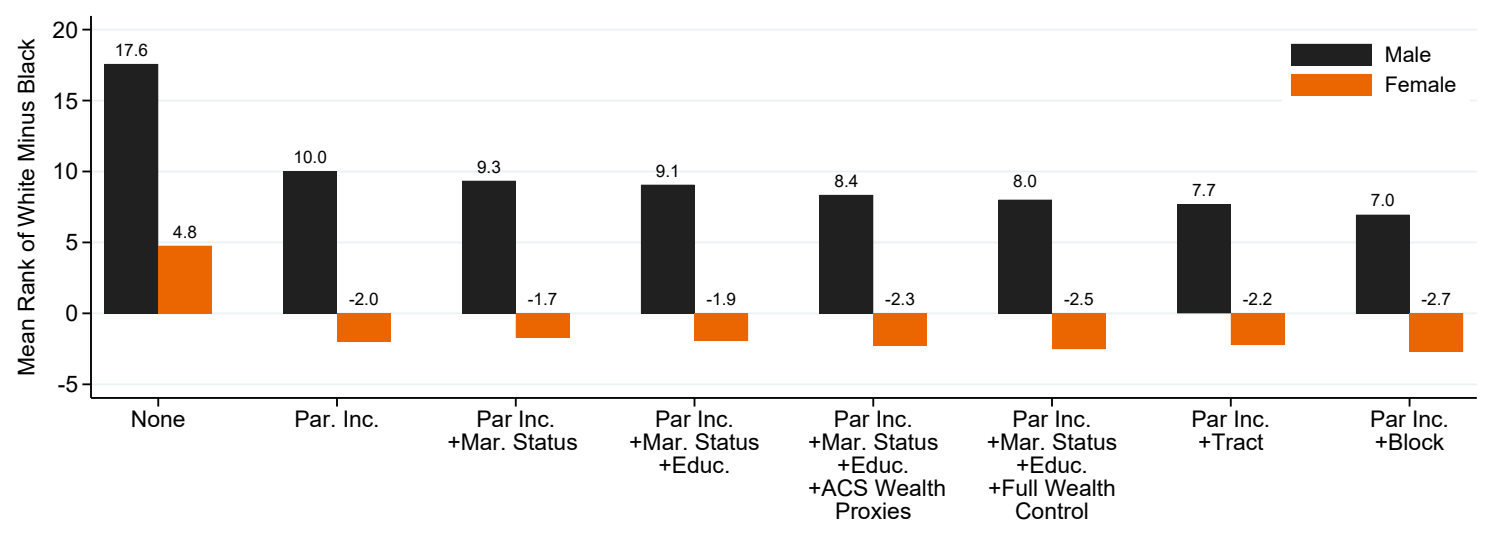

B. Children with Parents at 75th Percentile

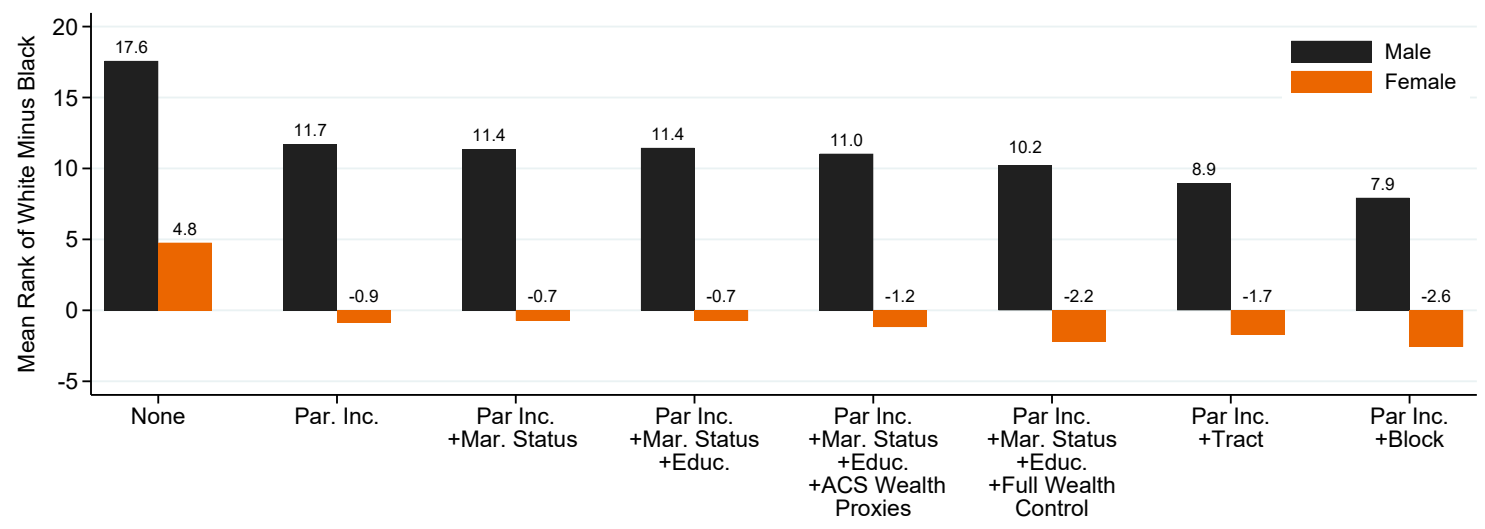

Notes: These figures show how the black-white gap in children's individual income ranks changes as we control for familyand neighborhood-level factors. The bars on the left in each pair report the black-white gap in individual income ranks for boys, while the bars on the right report the same statistics for girls. The first set of bars shows the unconditional black-white gap in mean individual income ranks. The second set of bars reports $\Delta_{\bar{p}}$, the intergenerational gap in mean income ranks at percentile $\bar{p}$ of the parental income distribution, estimated by regressing children's income ranks on their parents' ranks, an indicator for being white, and the interaction of these two variables. Panel A reports estimates for $\bar{p}=25$, while Panel B reports estimates for $\bar{p}=75$. The next three sets of bars report estimates of $\Delta_{\bar{p}}$ as we include additional family-level controls in the regression: parental marital status, education, and wealth proxies. Parental marital status is measured based on whether the primary tax filer who first claims the child as a dependent is married. We control for parental education using indicator variables for the highest level of education parents have completed using data from the ACS and the 2000 Census long form, prioritizing information from the ACS if both sources are available. We define seven categories of parental education: no school, less than high school, high school degree, college no degree, associate degree, bachelor degree and graduate degree. We use the mother's education if available; if not, we use the father's education. We use indicators for home ownership and the number of vehicles owned and linear controls for monthly mortgage payments and home value as wealth proxies. These variables are also obtained from the 2000 Census long form and ACS, again prioritizing the mother's data. The sixth set of bars controls for total wealth (including the component not captured by the Census/ACS wealth proxies) by using information from the SCF, following the method described in Online Appendix F. The seventh set of bars includes fixed effects for the tract in which the child grew up (defined as the first non-missing tract of their parents). The eighth set of bars replicates the seventh, replacing the Census tract fixed effects with Census block fixed effects. The estimates reported in the fourth, fifth and sixth pairs of bars use the subsample for which the relevant controls are available from the 2000 Census and ACS, while the other estimates use the full analysis sample. 


\section{A. White Males with Parents at 25th Percentile}

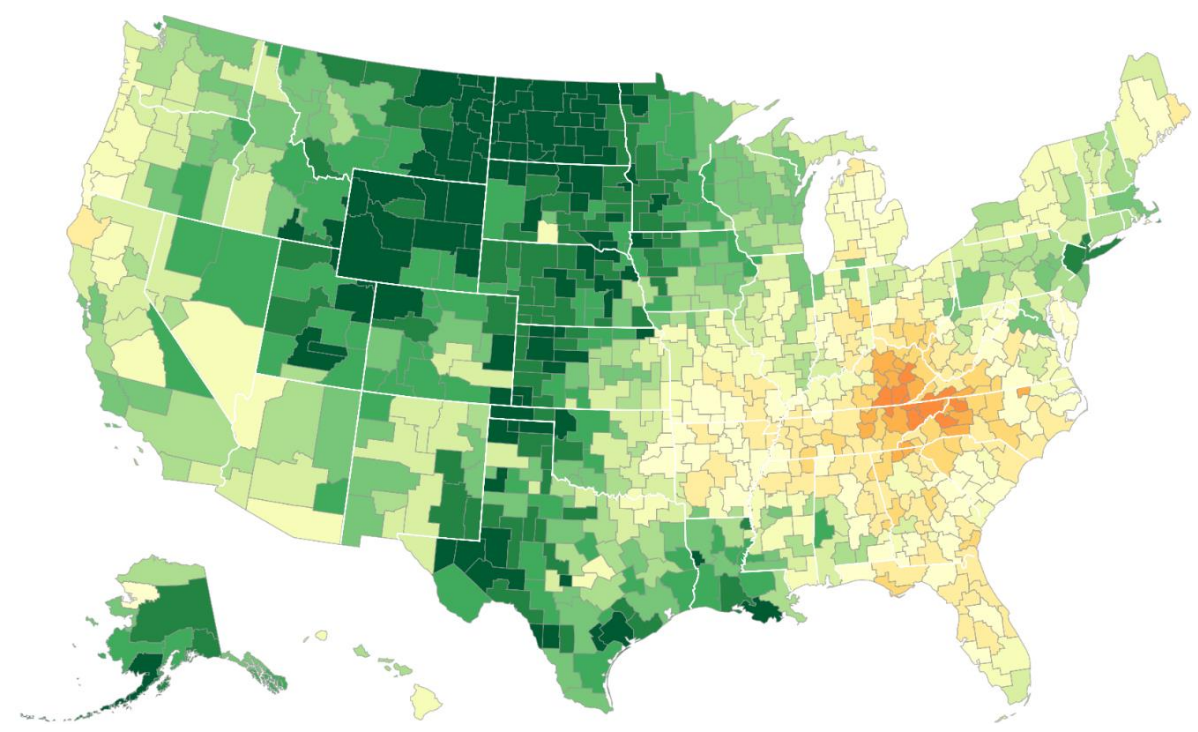

Mean Individual Income Rank

$56.9(\$ 35 k)$

54.6

52.8

50.9

49.4

B. Black Males with Parents at 25th Percentile

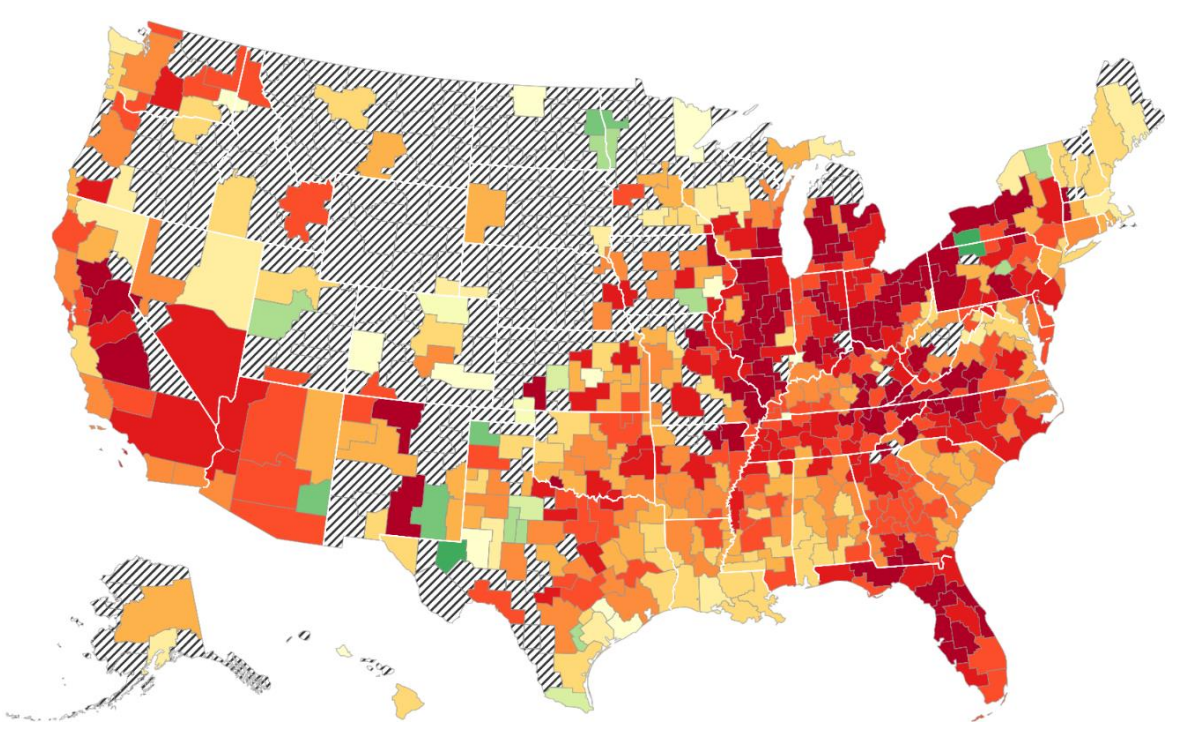

48.1

46.5

45.1 ( $\$ 25 k)$

43.6

41.6

40.3

39.2

37.8

$36.5(\$ 17 \mathrm{k})$

Insufficient

Data

These maps must be printed in color to be interpretable.

Notes: These figures present maps of upward mobility by commuting zone (CZ) for white male children (Panel A) and black male children (Panel B). All figures are based on the same sample and income definitions as in Figure III. To construct upward mobility for a given race-gender group in CZ $c$, we first regress children's individual income ranks on a constant and parent income rank, weighting by the number of years that each child is observed below age 23 in CZ $c$. We then define upward mobility as the predicted value from this regression at the 25 th percentile of the parental income distribution. The maps are constructed by grouping the CZ-by-race observations into fifteen quantiles and coloring the areas so that green colors represent higher levels of upward mobility, while red colors correspond to lower mobility. The two maps are on a single color scale to permit comparisons across racial groups. Estimates for areas with fewer than 20 children in our analysis sample or fewer than 500 residents of the children's racial group in the 2000 Census are omitted and are shaded with the cross-hatch pattern. The dollar amounts shown in the legend represent the mean income (in 2015 dollars) corresponding to the relevant percentile for children in the analysis sample in 2014-15, when they are between ages 31-37. 


\section{FIGURE X: Correlations Between Upward Mobility and Tract-Level Characteristics}

\section{A. Correlations between Tract-Level Characteristics and Upward Mobility for Black vs. White Males}

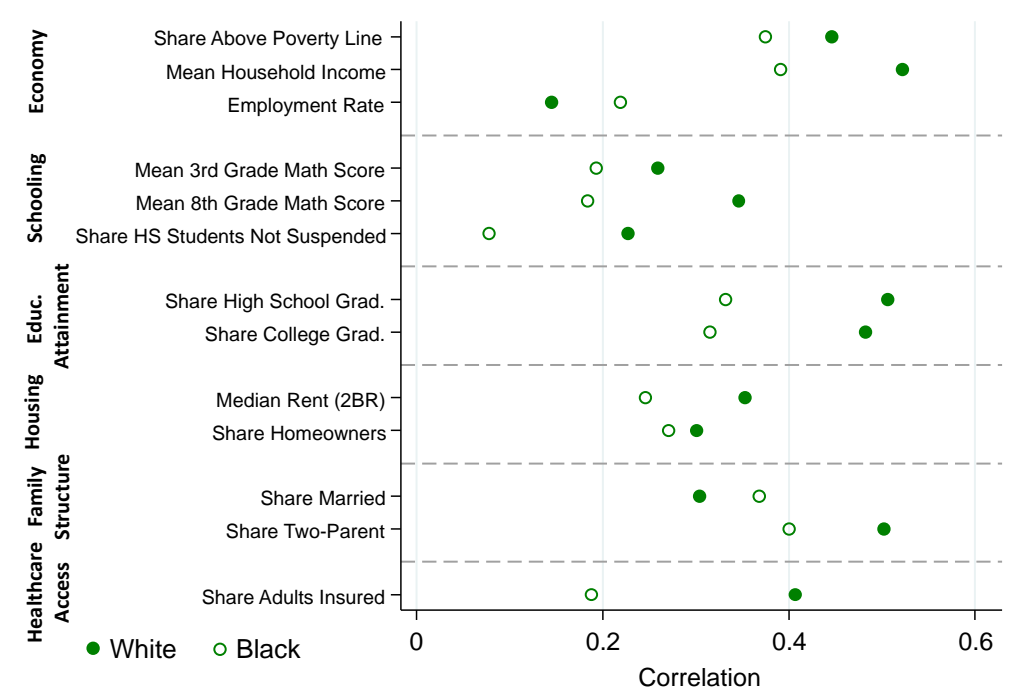

B. Black-White Intergenerational Gap for Men vs. Share Above Poverty Line

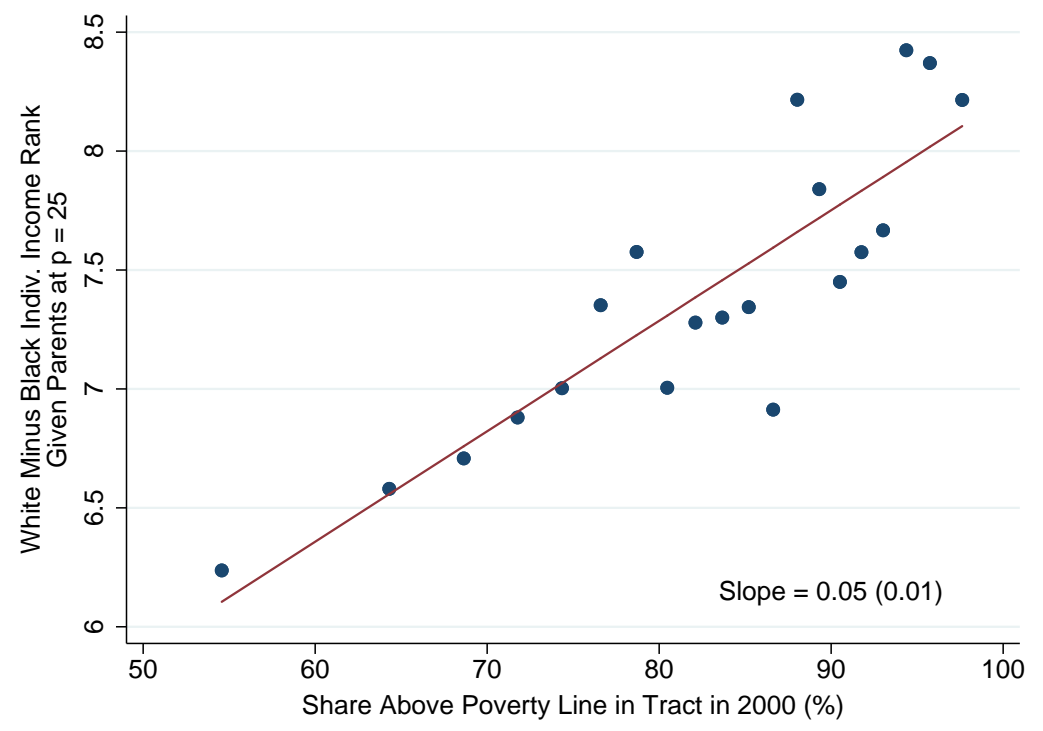

Notes: Panel A presents tract-level correlations between various characteristics and upward mobility for black men (hollow circles) and white men (solid circles) with parents at the 25 th percentile of the national income distribution. To construct upward mobility for a given race-gender group in tract $c$, we first regress children's individual income ranks on a constant and parent income rank, weighting by the number of years that each child is observed below age 23 in tract $c$. We then define upward mobility as the predicted value from this regression at the 25th percentile of the parental income distribution. Tract-level characteristics are obtained from the 2000 Census and other sources; see Online Appendix D for definitions and details. All characteristics are defined such that correlations with upward mobility are positive. Correlations for black (white) males are estimated on the set of tracts with more than 20 black (white) men in the estimation sample and are weighted by the precision of the upward mobility estimates. Correlations are adjusted for attenuation bias due to sampling error in the upward mobility estimates by inflating the raw correlations by the square root of the reliability of the upward mobility estimates. Panel B presents a binned scatter plot of the black-white gap in upward mobility (white minus black) for men with parents at the 25 th percentile vs. the share of residents in the tract in which they grew up who were above the poverty line in the 2000 Census. To construct this figure, we first bin tracts into ventiles (20 groups) based on poverty rates, weighting each tract by the number of black men in the analysis sample. We then plot the mean black-white gap vs. the mean share above the poverty line within each bin. The sample for Panel B consists of all tracts with at least 20 white males and 20 black males in our analysis sample. 


\section{FIGURE XI: Correlations Between Black-White Gap for Men and Tract-Level Characteristics}

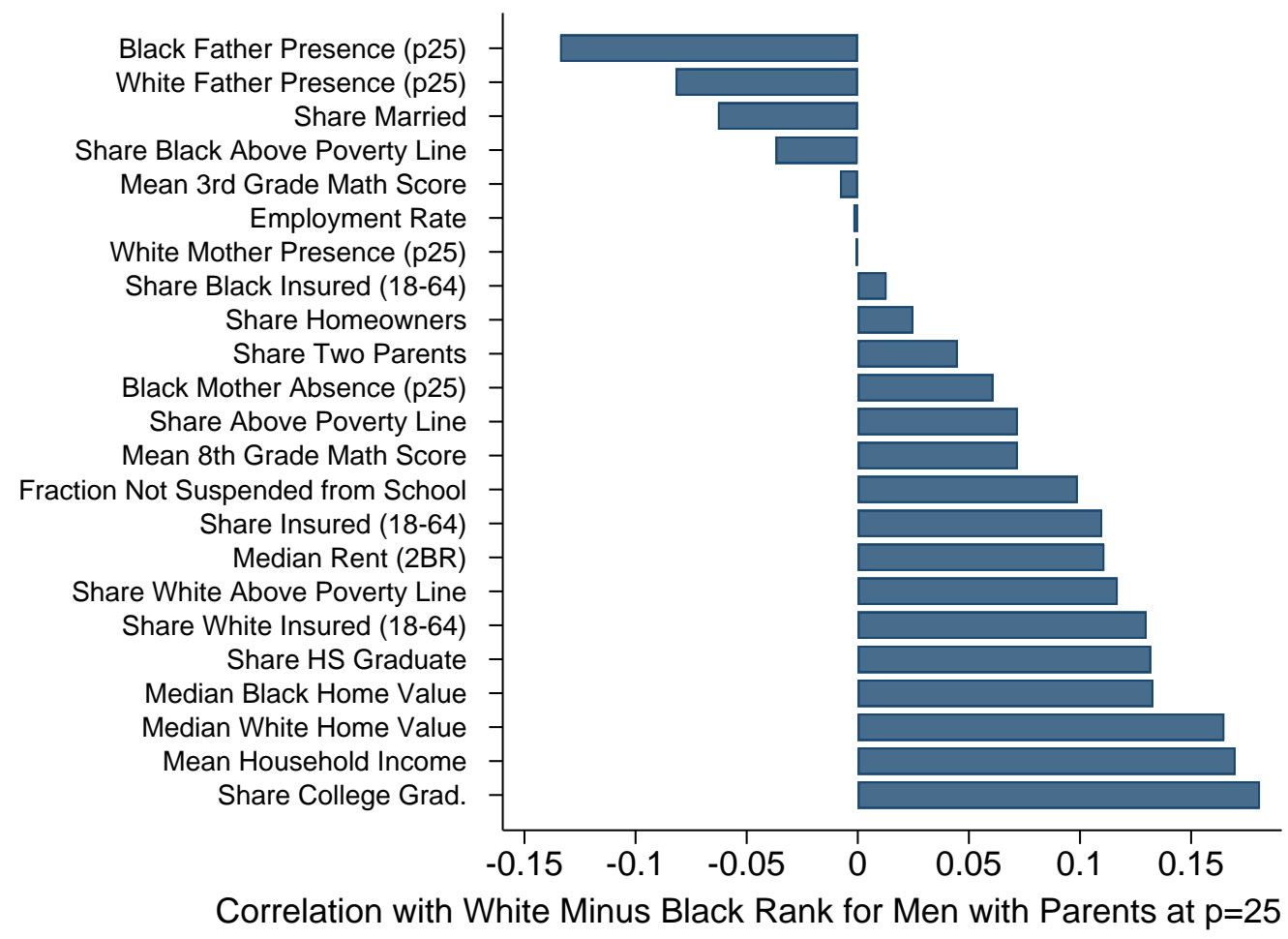

Notes: This figure shows correlations between selected tract-level characteristics and the black-white gap in upward mobility (white minus black) for men with parents at $p=25$, limiting the sample to Census tracts with poverty rates below $10 \%$ in the 2000 Census. Upward mobility is estimated as described in the notes to Figure X. Tract-level characteristics are obtained from the 2000 Census and other sources; see Online Appendix C for definitions and details. All characteristics are defined such that their correlation with the level of incomes for black men is positive. We include only characteristics whose correlations with black men's incomes have the same sign at both the 25 th and 75 th percentile of the parental income distribution ( $p=25$ and $p=75$ ). Correlations are weighted by the precision of the estimated intergenerational gaps and are adjusted for attenuation bias due to sampling error in the upward mobility estimates by inflating the raw correlations by the square root of the reliability of the estimated intergenerational gaps. Negative correlations correspond to smaller magnitudes of intergenerational gaps between blacks and whites. 


\section{FIGURE XII: Black-White Gaps vs. Father Presence by Census Tract}

A. Individual Income Ranks for Black vs. White Males

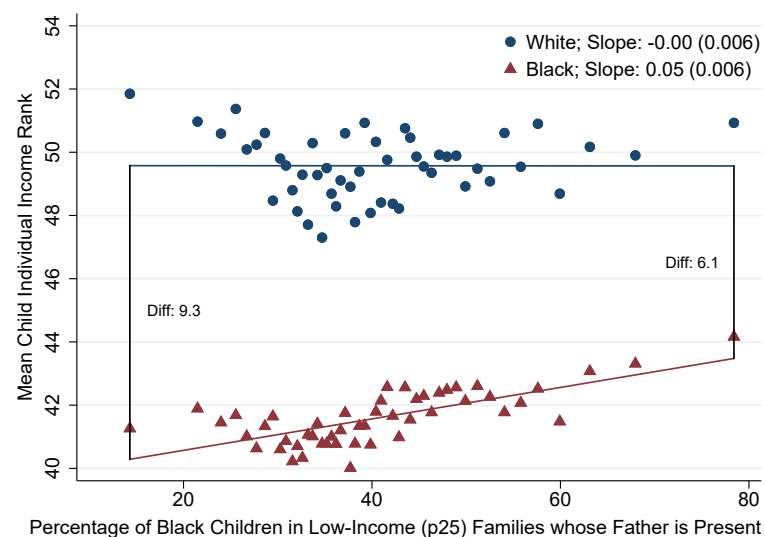

C. Incarceration Rates for Black vs. White Males

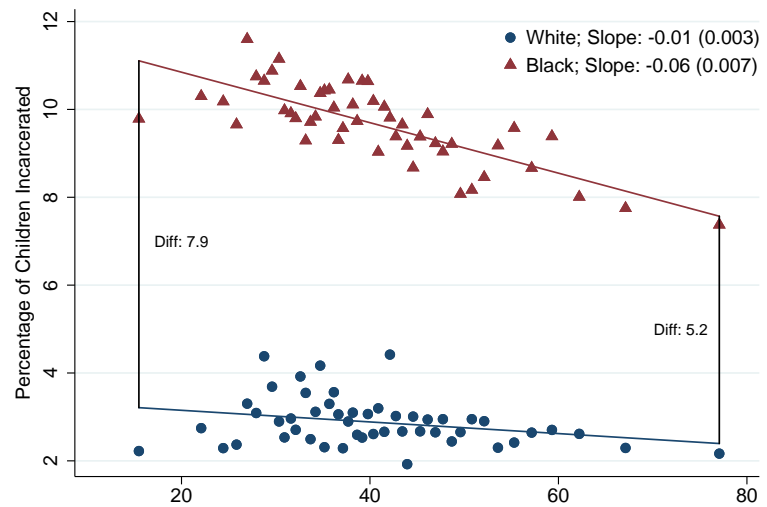

Percentage of Black Children in Low-Income (p25) Families whose Father is Present
B. Employment Rates for Black vs. White Males

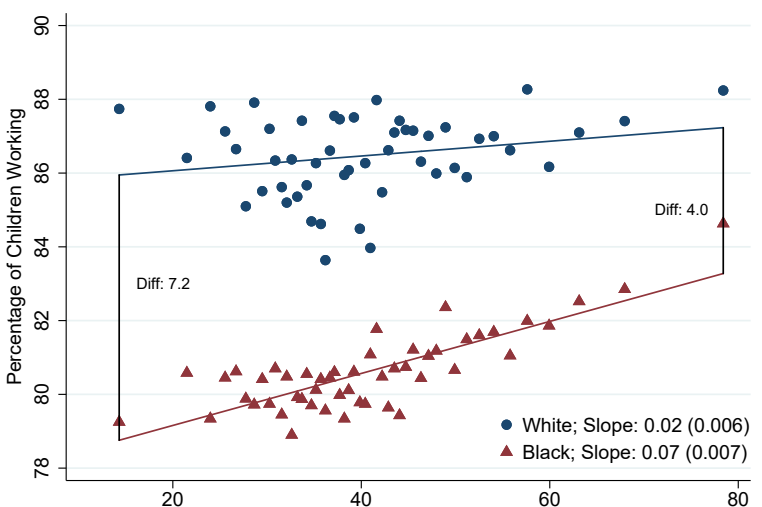

Percentage of Black Children in Low-Income (p25) Families whose Father is Present

D. Employment Rates for Black Males vs. Females

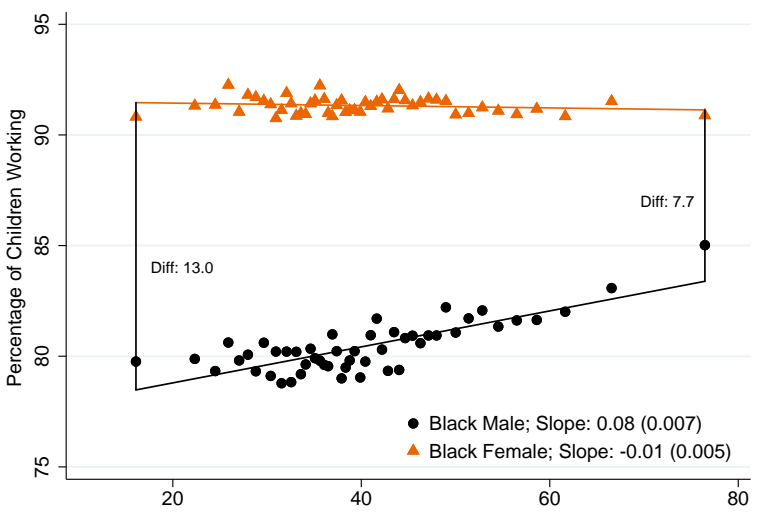

Percentage of Black Children in Low-Income (p25) Families whose Father is Present

Notes: These figures present binned scatter plots of various outcomes in adulthood vs. the percentage of black children raised in low-income families whose fathers are present in their household, by Census tract. We define father presence as an indicator for whether a child is claimed by a male on a tax form in the year he or she is matched to a parent. We regress this indicator for father presence on parental income rank for each tract using equation (6), and define black father presence among low-income families as the prediction for black children at $p=25$. Each figure is constructed by dividing the $x$ variable (father presence) into 50 equal-sized bins and plotting the mean of the $y$ and $x$ variables in each bin, separately for various subgroups. In Panel A, the $y$ variable is upward mobility, the predicted individual income rank in adulthood conditional on having parents at the 25th percentile, estimated as described in the notes to Figure X. In Panels B and D, the $y$ variable is an indicator for working, where working is defined as having non-zero individual income in either 2014 or 2015 . In Panel C, the $y$ variable is an indicator for being incarcerated on April 1, 2010. In all panels, we restrict the sample to tracts with a poverty rate below $10 \%$ in the 2000 Census. We also limit the sample to tracts with at least 20 observations for both white and black males in Panels A, B, and C, and 20 observations for both black males and females in Panel D. We estimate best fit lines on the plotted points using OLS and report the differences in the predicted values from these regressions in the 1st and 50th quantile. We also report the slope coefficients and standard errors (in parentheses). 


\section{FIGURE XIII: Childhood Exposure Effects on Income and Incarceration in Adulthood}

A. Income Rank at Age 30, Black Males

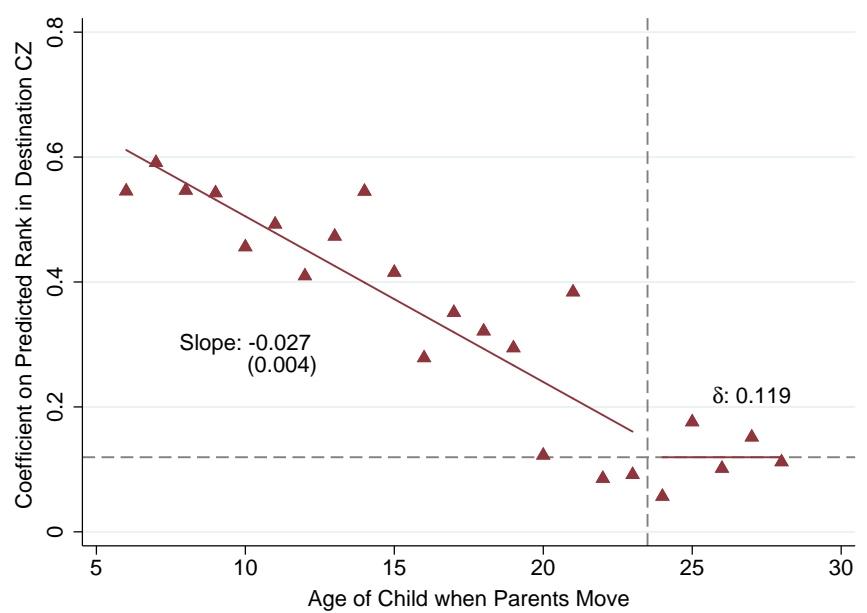

C. Incarceration Rates in 2010, Black Males

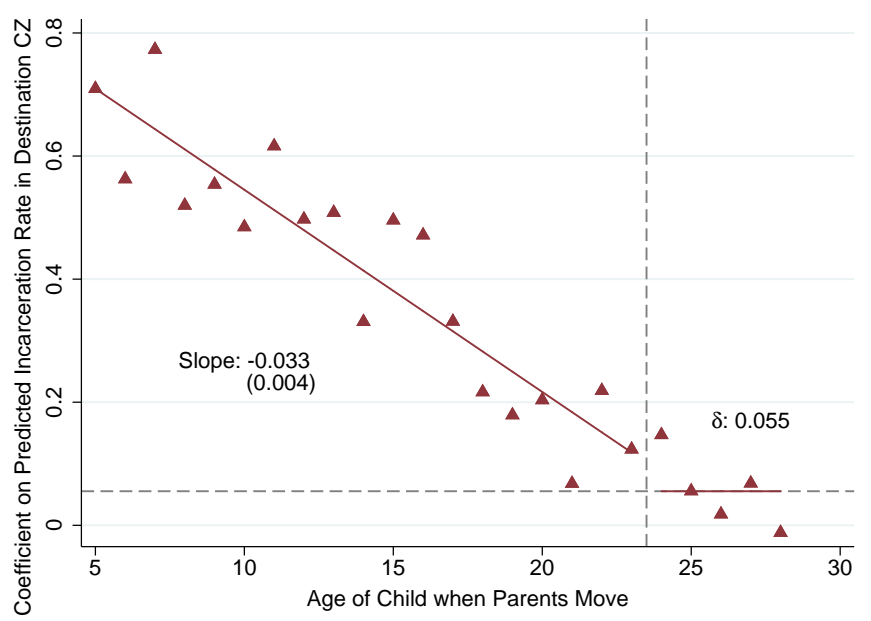

B. Income Rank at Age 30, White Males

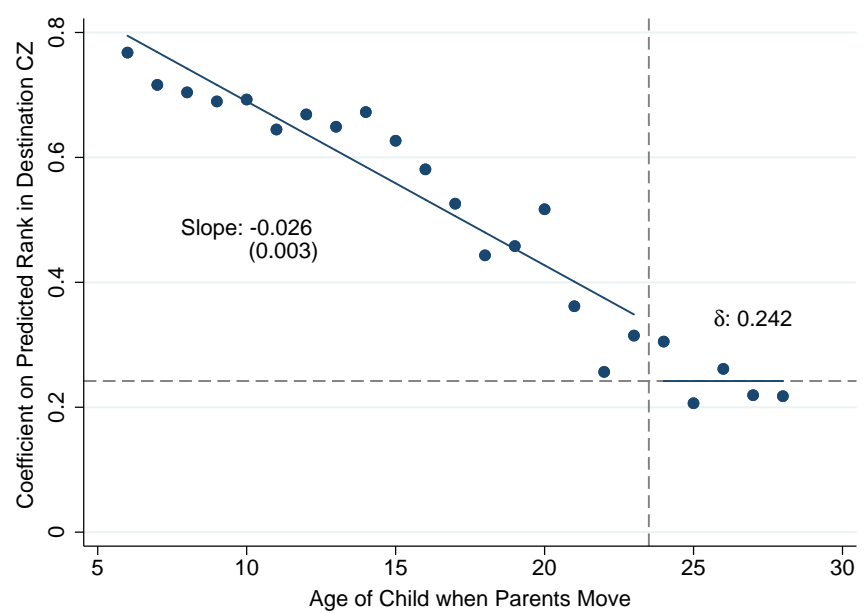

D. Incarceration Rates in 2010, White Males

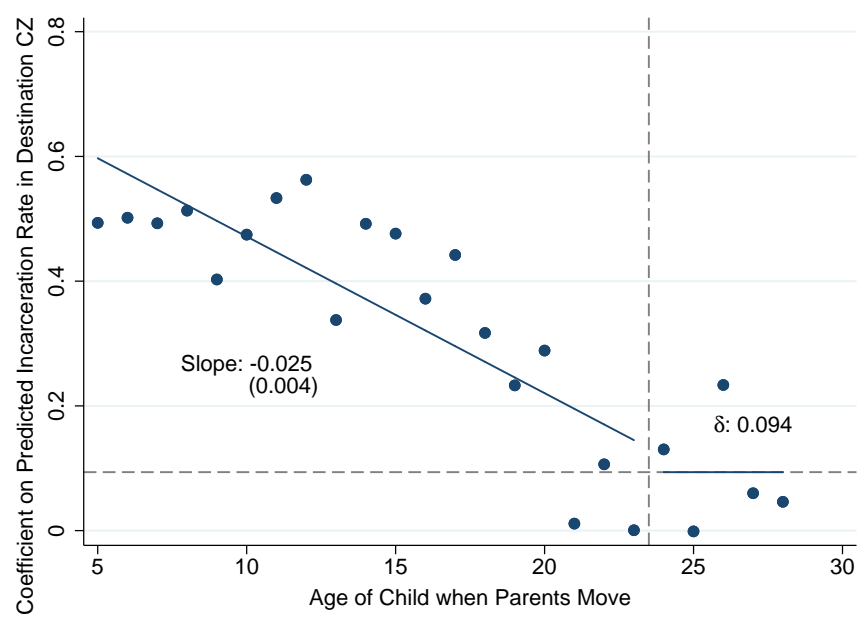

Notes: These figures show estimates of childhood exposure effects on income and incarceration in adulthood. Panels A and B plot estimates of the coefficients $\left\{b_{m}\right\}$ vs. the child's age when his parents move $(m)$ using the regression specification in equation (7) with individual income rank at age 30 as the dependent variable. The coefficients $b_{m}$ can be interpreted as how children's outcomes change when they move at age $m$ to a $\mathrm{CZ}$ with a 1 percentile higher predicted individual income rank in adulthood for children of the same race, gender, and parental income level. Predicted income ranks are estimated using the outcomes of children in the same race-gender subgroup and parental income level, excluding one-time movers. The estimation sample in Panels A and B consists of male children born between 1978-1985 whose parents move exactly once across CZs in our sample window. Panel A considers black men; Panel B considers white men. Panels C and D replicate A and B, changing the dependent variable to an indicator for being incarcerated on April 1, 2010 and the key independent variables to predicted incarceration rates instead of predicted income ranks. The estimation sample in these panels consists of male children born between 1978-1986. The dashed vertical lines separate the data into two groups: age at move $m \leq 23$ and $m>23$. Best-fit lines are estimated using unweighted OLS regressions of the $\left\{b_{m}\right\}$ coefficients on $m$ separately for $m \leq 23$ and $m>23$. The slopes of these regression lines are reported along with standard errors (in parentheses) on the left side of each panel for $m \leq 23$ and on the right side for $m>23$. The magnitudes of the slopes for $m \leq 23$ represent estimates of annual childhood exposure effects. The slopes reported differ slightly from Online Appendix Table XV because they are estimated from a regression on the coefficients, $b_{m}$, rather than a linear parametrization in the individual-level data. 
FIGURE XIV: Father Presence and Poverty Rates by Tract for Black vs. White Children

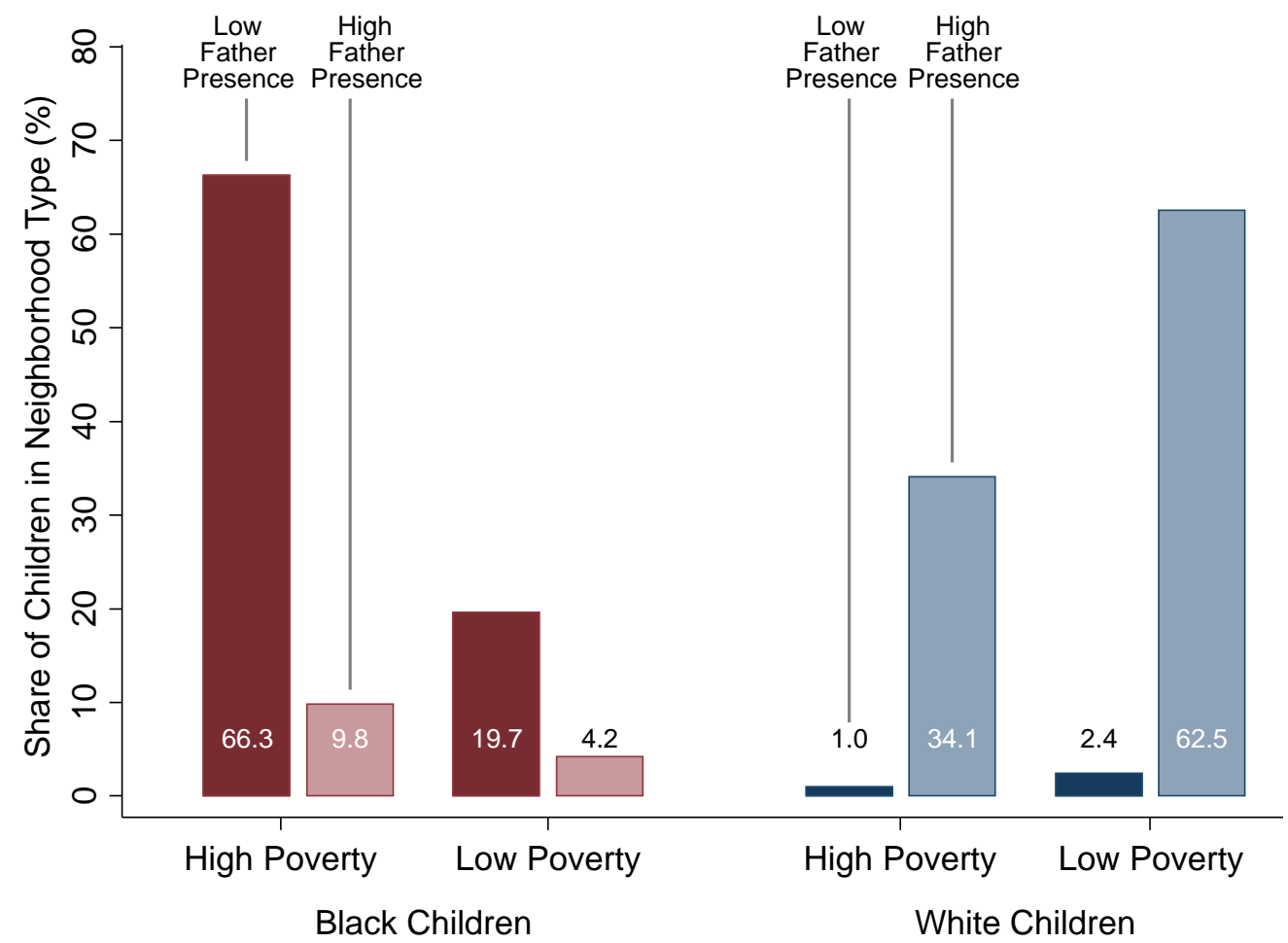

Notes: This figure plots the share of black and white children who grow up in four types of Census tracts: high poverty, low father presence; high poverty, high father presence; low poverty, low father presence; and low poverty, high father presence. We define Census tracts as "low poverty" if they have an overall poverty rate below $10 \%$ in the 2000 Census; we define tracts as having "high father presence" if more than $50 \%$ of fathers are present in families among children of the same race. 
ONLINE APPENDIX FIGURE I: Intergenerational Mobility in the Full Population

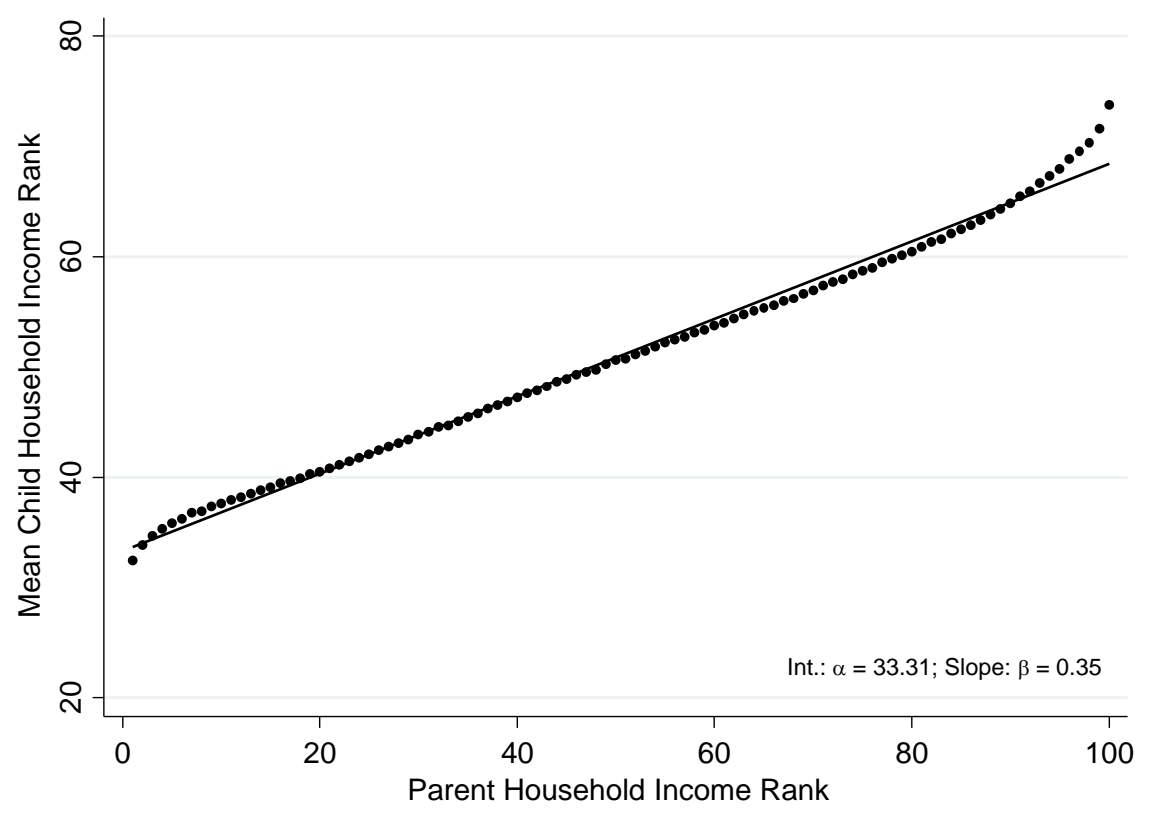

Notes: This figure plots the mean household income rank of children vs. parent household income rank in our primary analysis sample (1978-83 birth cohorts). This figure is constructed in exactly the same way as Figure IIa, except that here we pool races and genders. The best-fit line and slope are estimated using an OLS regression on the plotted points. See notes to Figure II for details on variable and sample definitions. 
ONLINE APPENDIX FIGURE II: Parental Income Distributions by Race

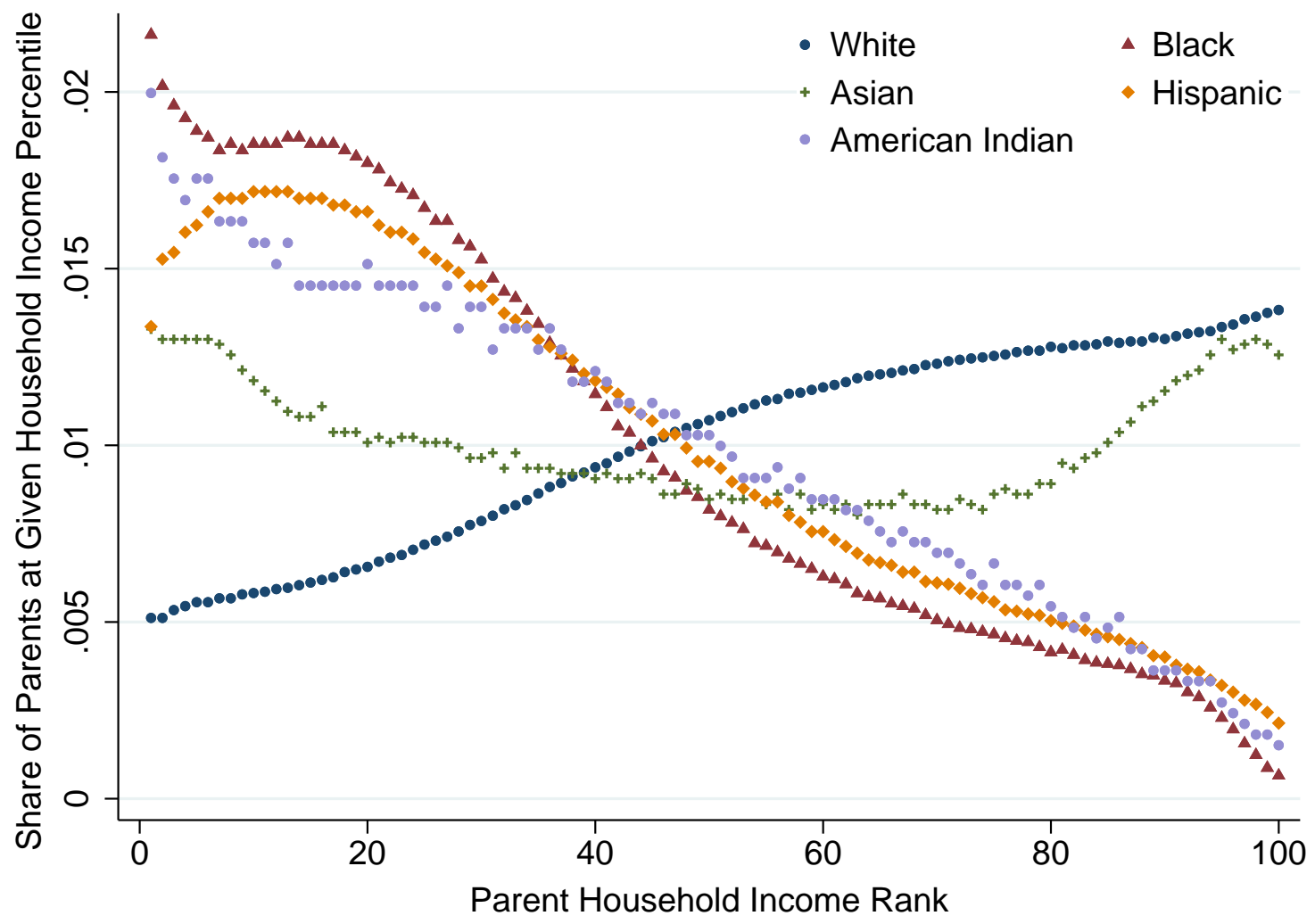

Notes: This figure plots the empirical distribution of parental income by race and ethnicity in our primary analysis sample. Each curve shows the fraction of children whose parents fall in each of the 100 percentiles of the national parental income distribution using our baseline definition of parental household income. This distribution is uniform (with a value of 0.01 ) by construction when pooling all races. See notes to Figure II for details on variable and sample definitions. 
ONLINE APPENDIX FIGURE III: Intergenerational Mobility by Race for Children with Immigrant vs. Non-Immigrant Mothers

A. White Children

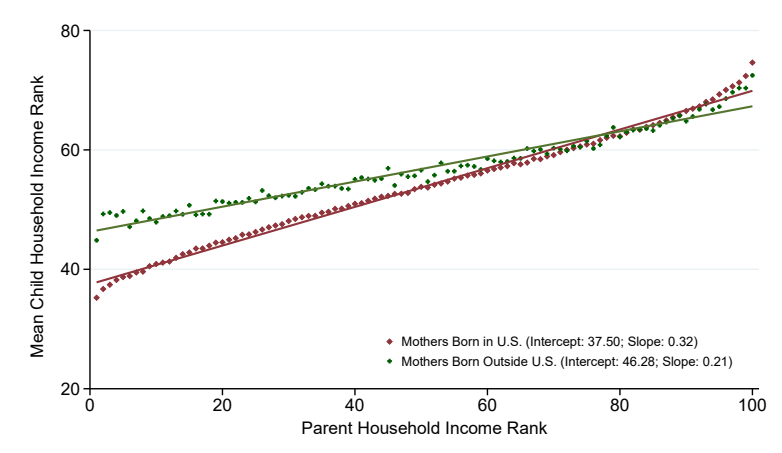

C. Hispanic Children

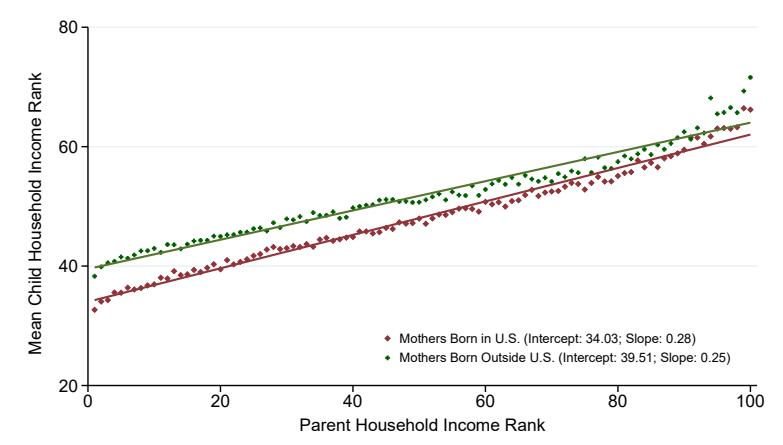

B. Black Children

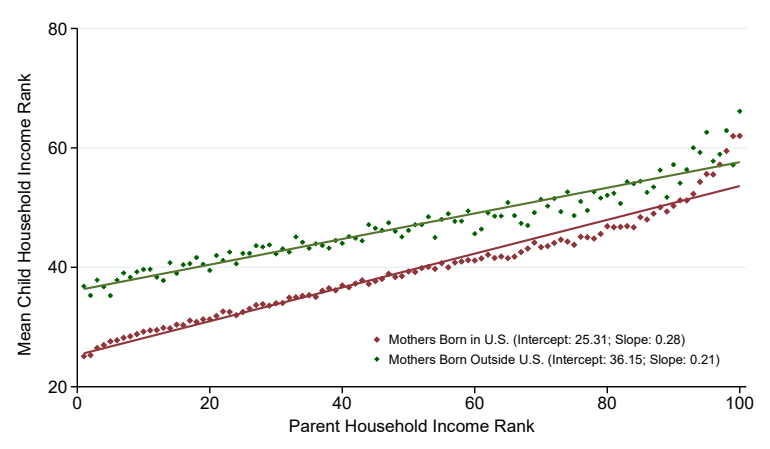

D. Asian Children

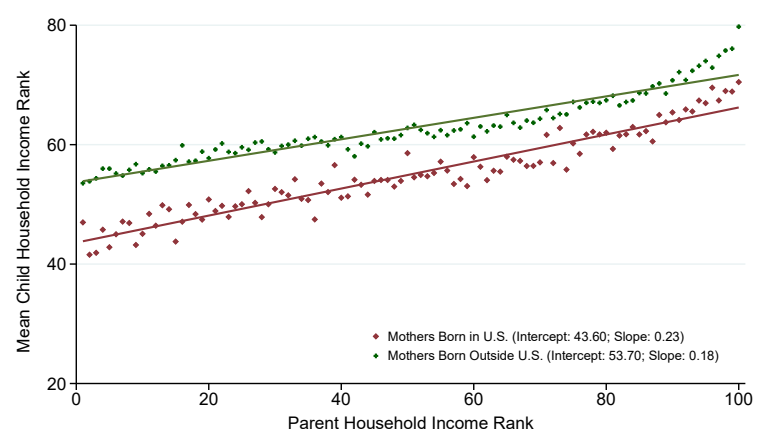

Notes: This figure replicates the series shown in Panels B and C of Figure III, but showing estimates for children whose mothers were born in the U.S. vs. outside the U.S. on the same scale for each race to facilitate comparison between the outcomes of natives and immigrants. The figure excludes American Indians because of the small sample size of American Indian children with mothers born outside the U.S. See notes to Figure III for details. 


\section{ONLINE APPENDIX FIGURE IV: Occupational Distributions by Race and Gender}

\section{A. Parents in 3rd Income Decile}

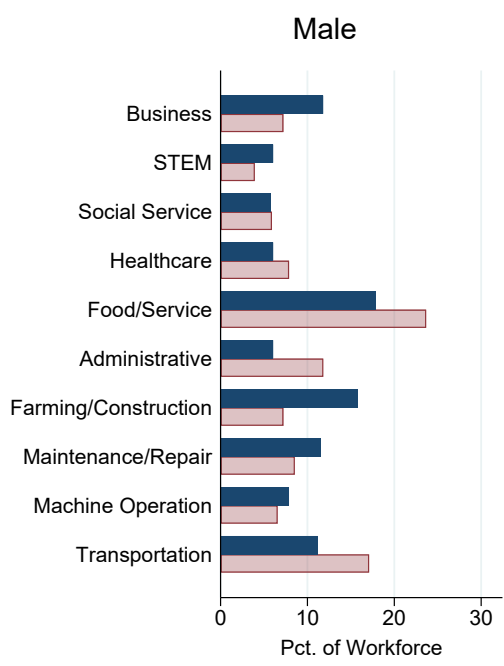

Mismatch Fraction $=19.5 \%$

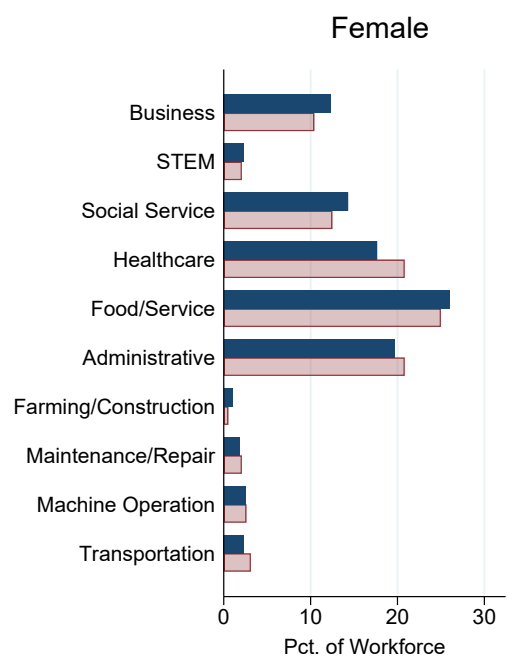

Mismatch Fraction $=5.5 \%$

White

Black

\section{B. Parents in 8th Income Decile}

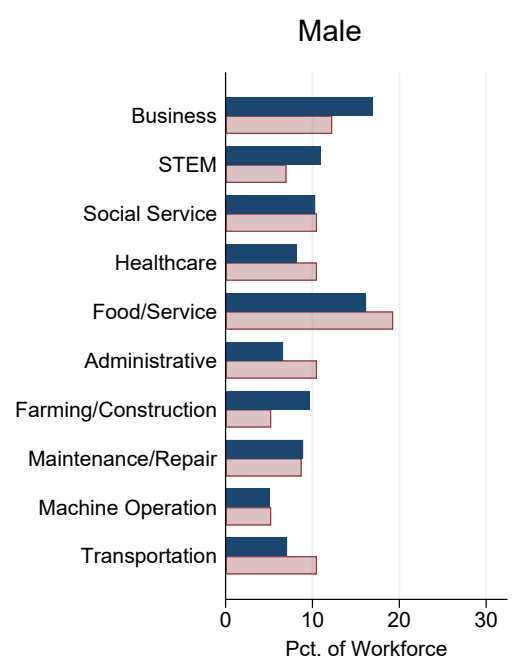

Mismatch Fraction $=13.2 \%$

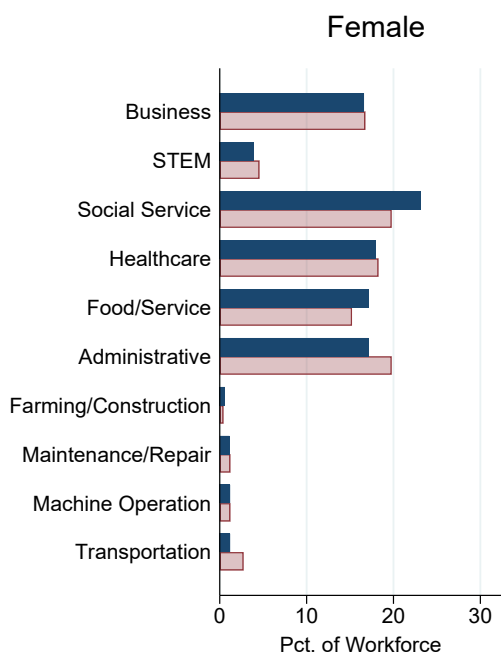

Mismatch Fraction $=5.4 \%$

White

Black

Notes: This figure plots the empirical distribution of children's occupations in adulthood conditional on parental income, by race and gender. The sample consists of children in our primary analysis sample whom we observe in the ACS at age 30 or older and who report working in the previous year in the ACS. Occupations are grouped using one-digit ACS occupation codes. In Panel A, we focus on children with parents in the third decile of the household income distribution; in Panel B, we focus on children with parents in the 8 th decile. We use our baseline definition of parent household income ranks in this analysis. For each parent income decile and race, we also report a measure of the mismatch between the two distributions, defined as the minimum fraction of black workers who would have to be allocated a different occupation to match the occupational distribution of white workers. 
ONLINE APPENDIX FIGURE V: Intergenerational Gaps in Household and Spousal Income, by Gender

\section{A. Household Income Rank, Females}

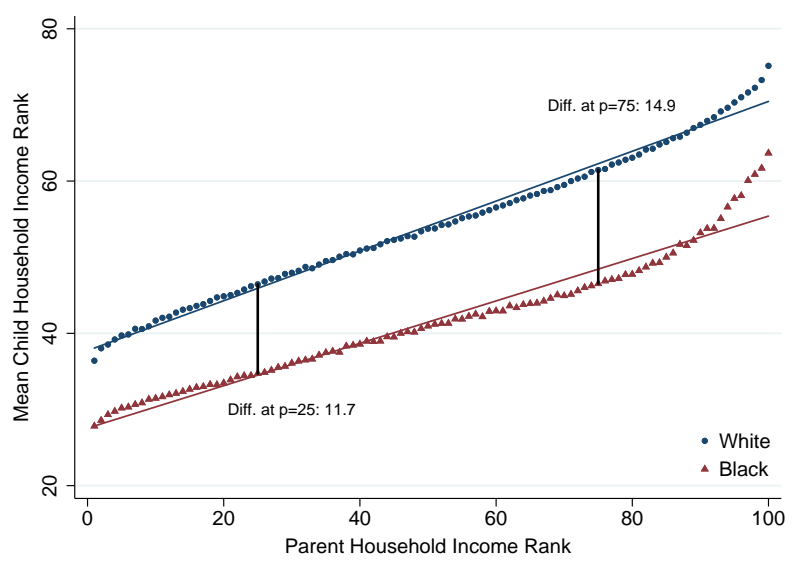

C. Spouse Income Rank, Females

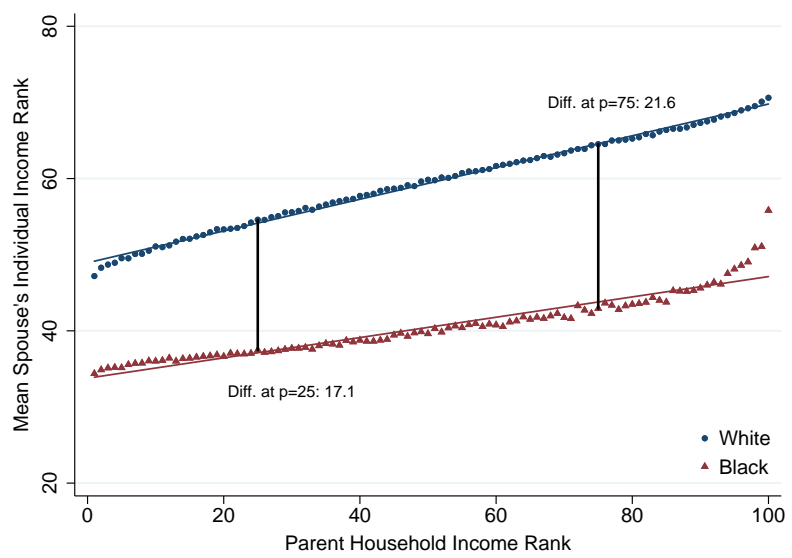

B. Household Income Rank, Males

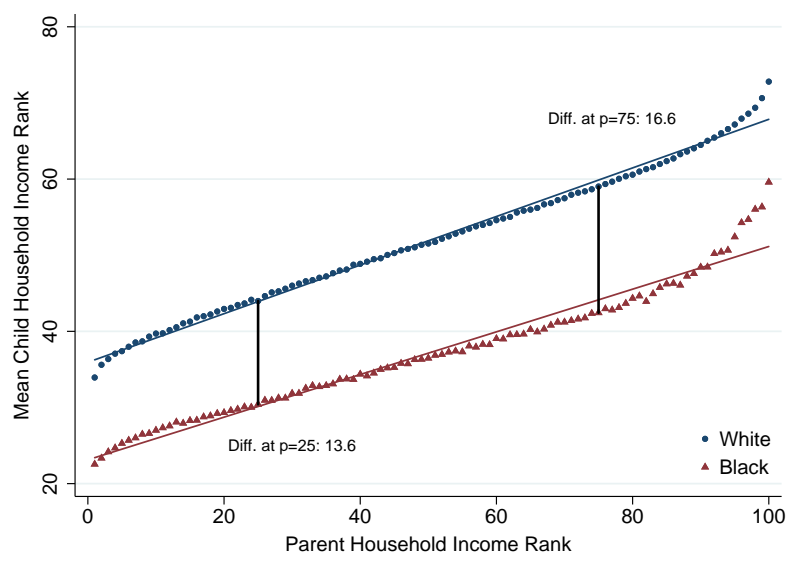

D Spouse Income Rank, Males

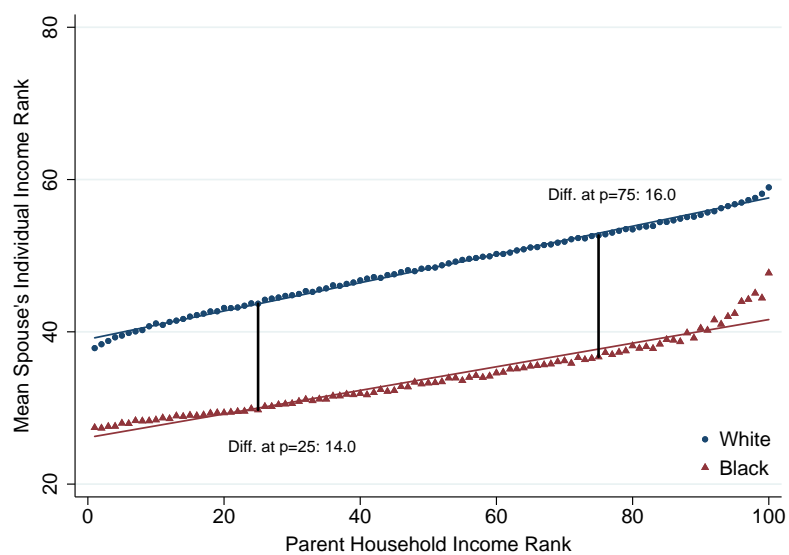

Notes: This figure replicates Figure V using children's household income ranks (Panels A and B) and spousal income ranks (Panels C and D) instead of individual income ranks as the y variable. Spousal income is defined as household income minus individual income; children who are not married are assigned spousal income of 0 and are included in the figures. See notes to Figure $\mathrm{V}$ for further details. 
ONLINE APPENDIX FIGURE VI: Black-White Intergenerational Gaps, Controlling for Parental Marital Status and Wealth

A. Male Children in Single-Parent Families

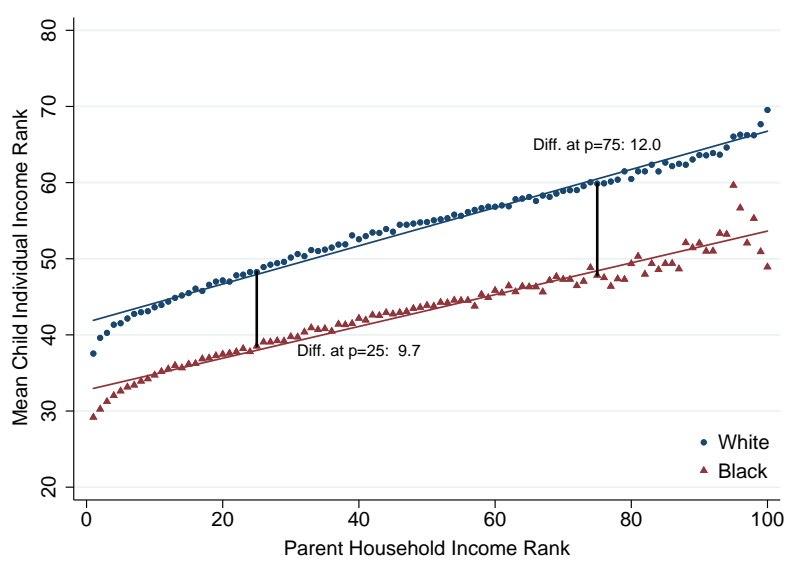

B. Male Children in Two-Parent Families

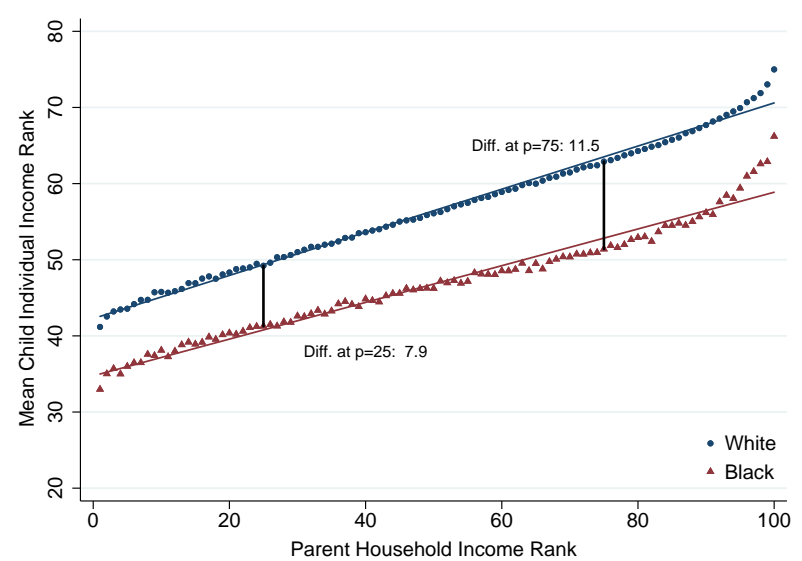

C. Male Children, Parents Do Not Own Home

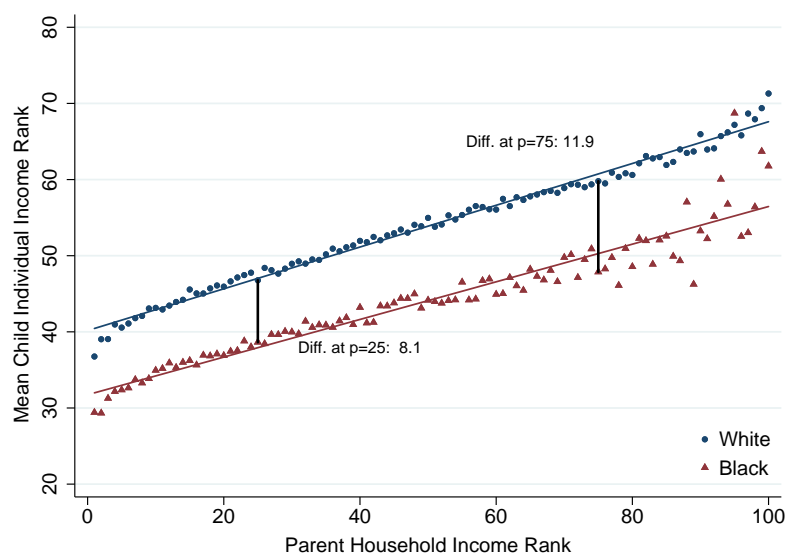

Notes: These figures replicate Figure Va for male children in single-parent families (Panel A), two-parent families (Panel B), and among parents who do not own a home (Panel C). See notes to Figure V for further details and Section III for definitions of parental marital status and home ownership. 
ONLINE APPENDIX FIGURE VII: Effects of Family-Level Factors on the Unconditional Black-White Gap

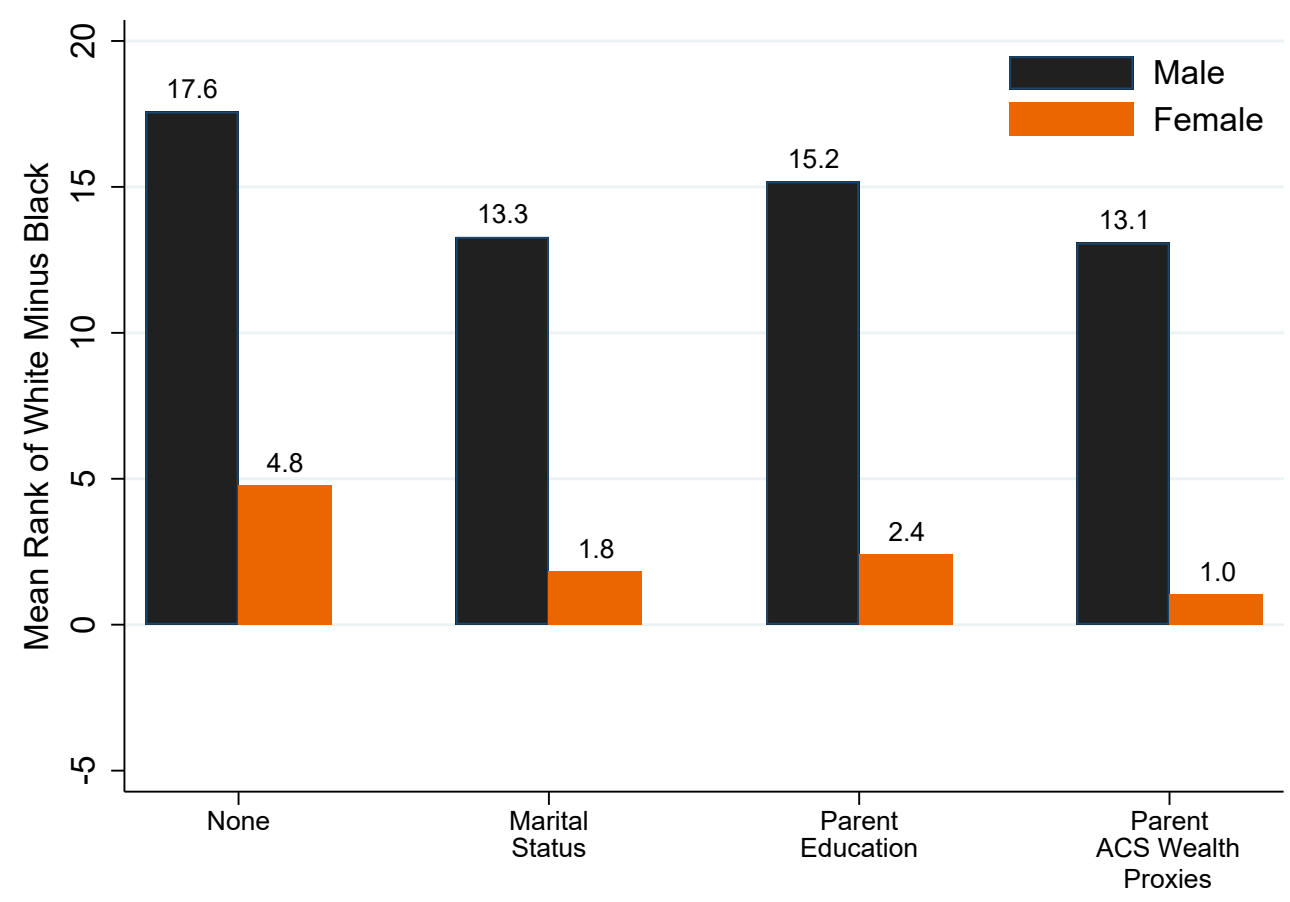

Notes: This figure shows how the black-white gap in children's individual income ranks changes as we control for family-level factors, as in Figure VIII, but without conditioning on parental income. Each bar plots an estimate from an OLS regression of children's individual income ranks on an indicator for being white and a single set of additional control variables. The first pair of bars show the unconditional black-white gap in mean individual income ranks for male and female children, respectively. The subsequent bars show how the coefficients on the race indicator change as controls are added. We use the same three groups of controls as in Figure VIII, but include only one set of controls in each regression (and do not control for parental income). See notes to Figure VIII for definitions of the control variables. 
ONLINE APPENDIX FIGURE VIII: Black-White Gaps in Test Scores for Low-Income Students, by Gender

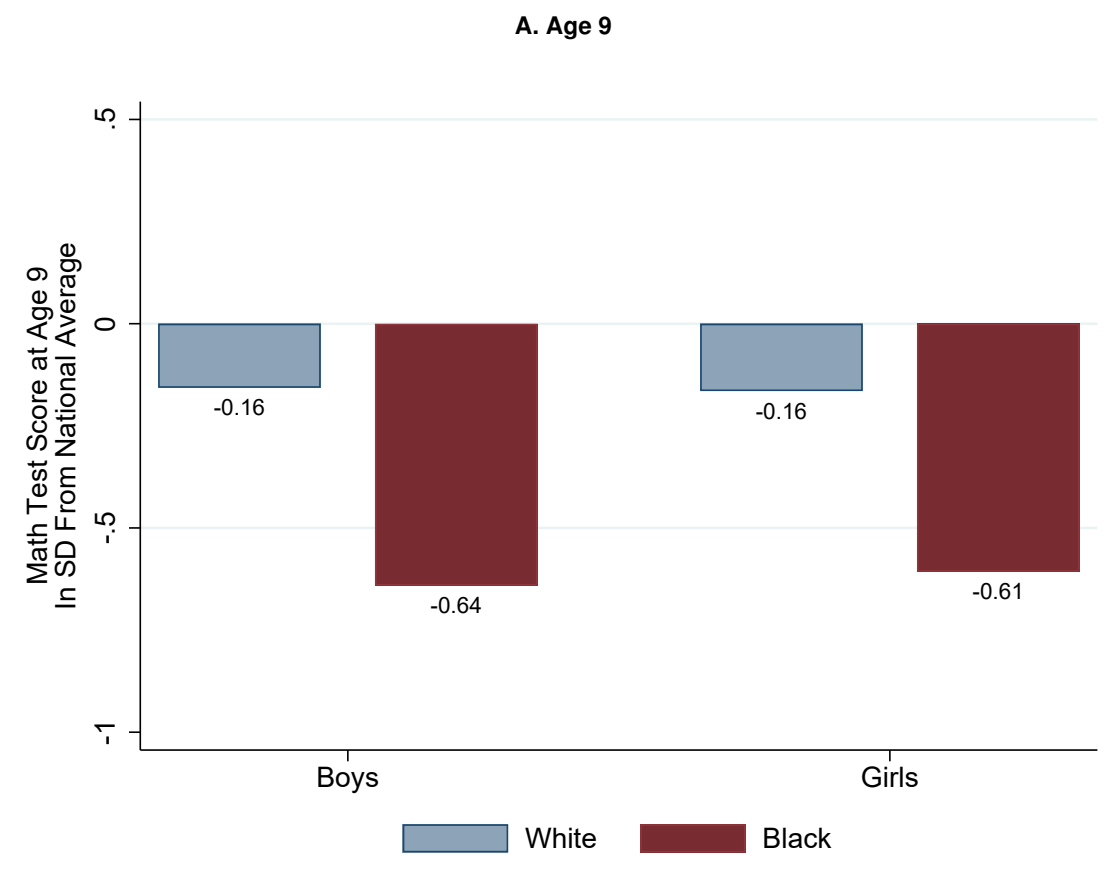

B. Age 17

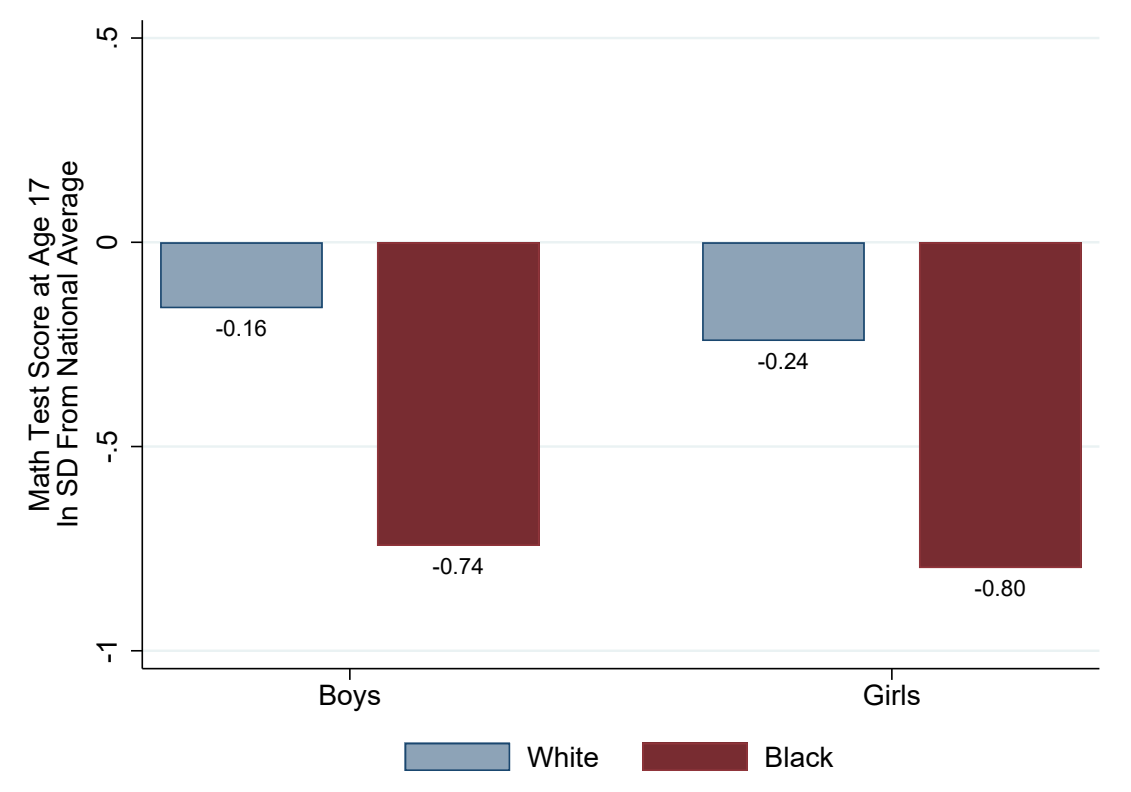

Notes: These figures plot mean math test scores from the National Assessment of Educational Progress for blacks and whites by gender in 2012. The sample consists of all children who are eligible for free or reduced price lunch programs. Panel A presents data for children at age 9, while Panel B presents data for children at age 17. The scores are scaled as standard deviations relative to the overall national mean (including children ineligible for free or reduced price lunches) among children in the same cohort. The data used to construct this figure are publicly available and can be downloaded from the Nation's Report Card. 


\section{ONLINE APPENDIX FIGURE IX: Effects of Family-Level Factors on Intergenerational Gaps}

A. Hispanic Children, Parents at 25th Percentile

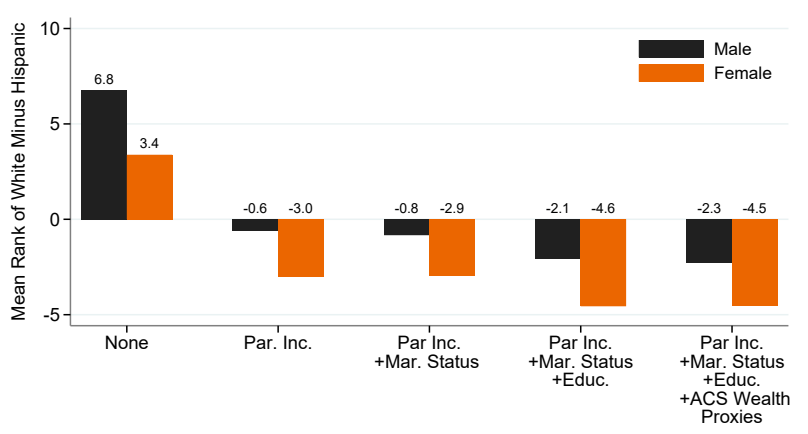

C. American Indian Children, Parents at 25th Percentile

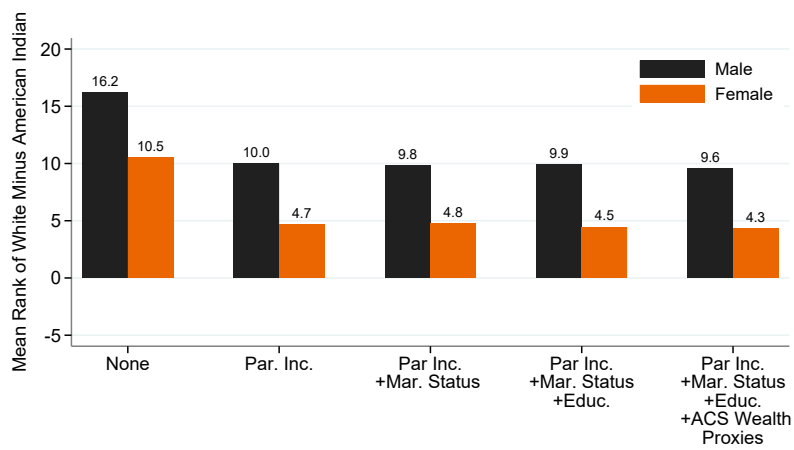

E. Asian Children Born to Native Mothers, Parents at 25th Percentile

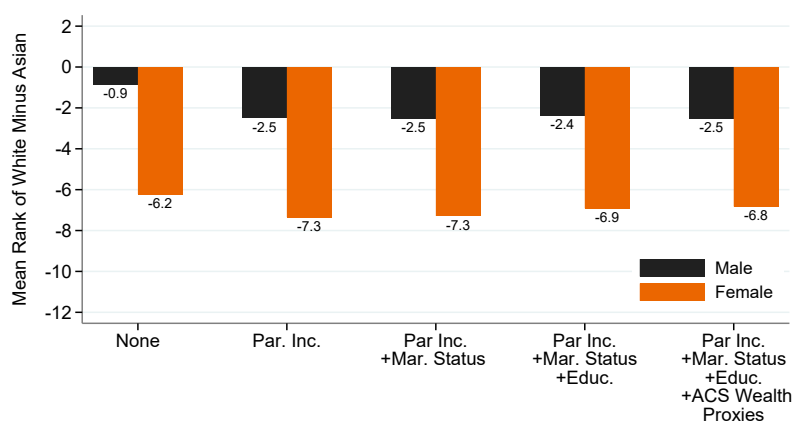

B. Hispanic Children, Parents at 75th Percentile

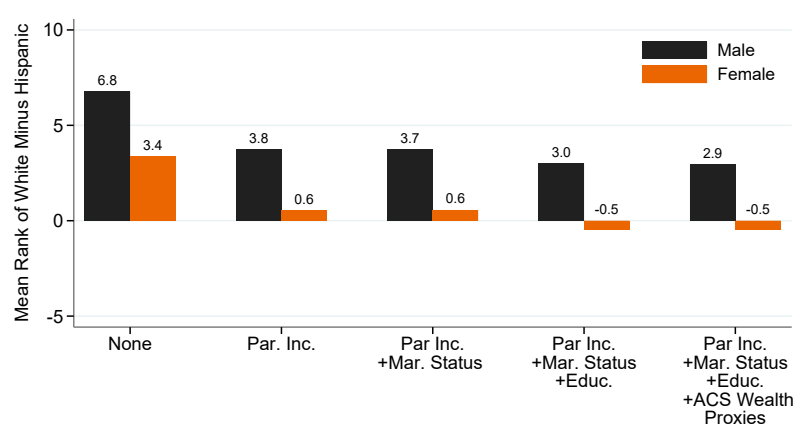

D. American Indian Children, Parents at 75th Percentile

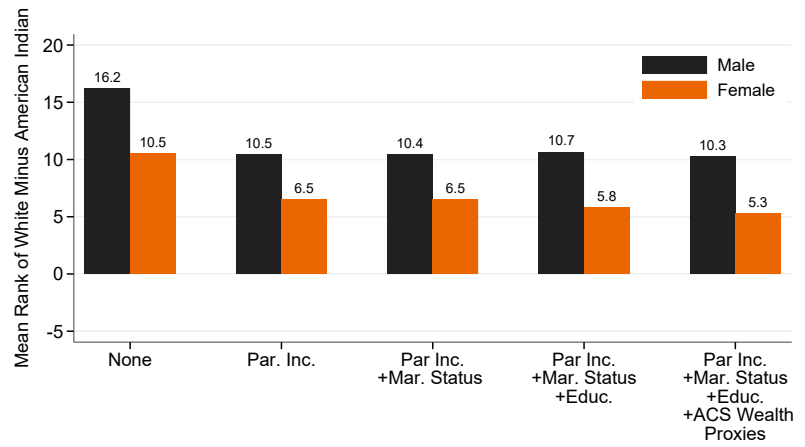

F. Asian Children Born to Native Mothers, Parents at 75th Percentile

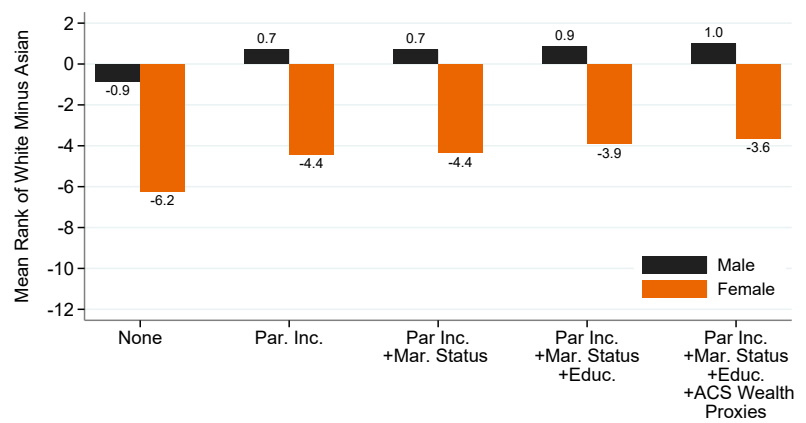

Notes: These figures replicate selected bars from Figure VIII for Hispanic children (Panels A-B), American Indian children (Panels C-D), and Asian children whose mothers were born in the U.S. (Panels E-F). All panels show gaps for the labelled group relative to whites. See notes to Figure VIII for further details. 
ONLINE APPENDIX FIGURE X: The Geography of Upward Mobility in Household Income

A. Full Population

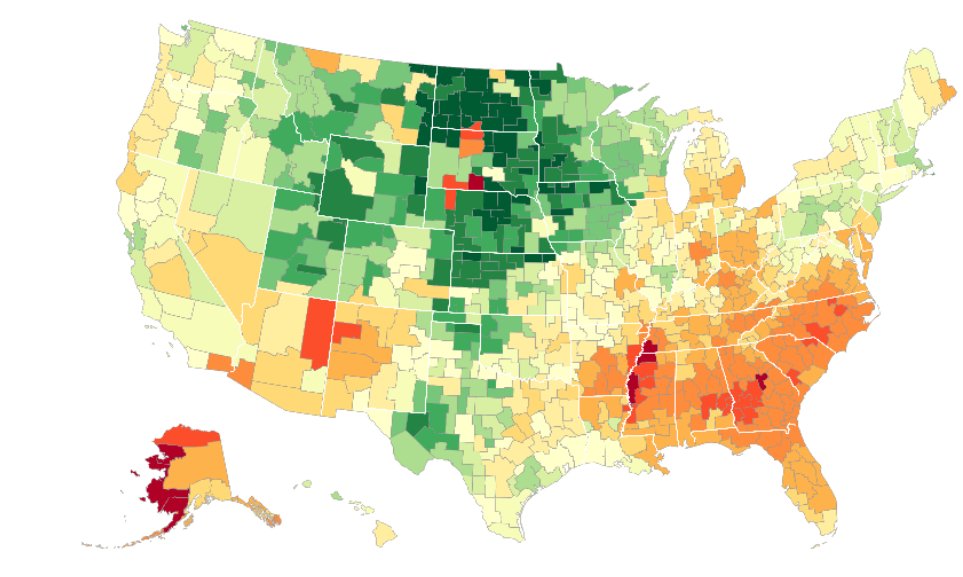

B. Whites

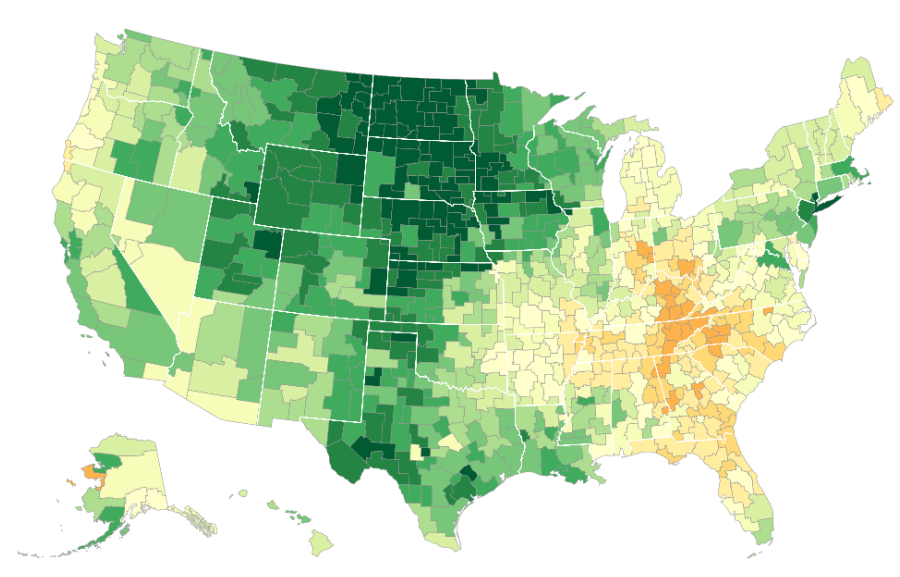

\section{Blacks}

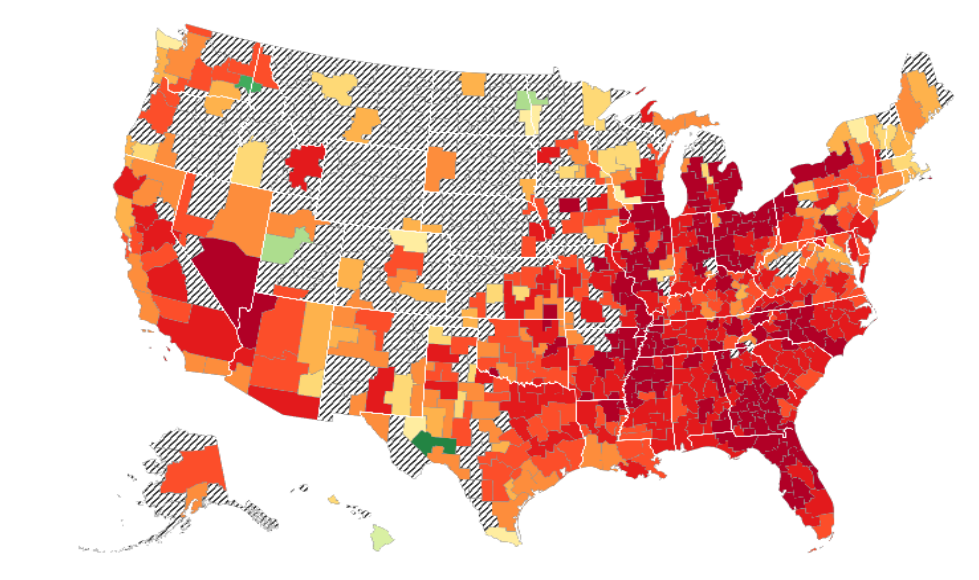

These maps must be printed in color to be interpretable.
Mean Household Income Rank

53.5 (\$45k)

50.4

48.0

46.3

44.9

43.6

42.5

41.5 (\$32k)

40.4

38.7

36.9

34.8

33.0

$31.5(\$ 21 \mathrm{k})$

Insufficient

Data

Notes: These figures replicate the results in Figure IX using household income instead of individual income when measuring children's incomes in adulthood and pooling men and women. Panel A pools all races; Panel B considers white children; and Panel C considers black children. See notes to Figure IX for details. 
ONLINE APPENDIX FIGURE XI: The Geography of Upward Mobility for Black vs. White Women

\section{A. White Females with Parents at 25th Percentile}

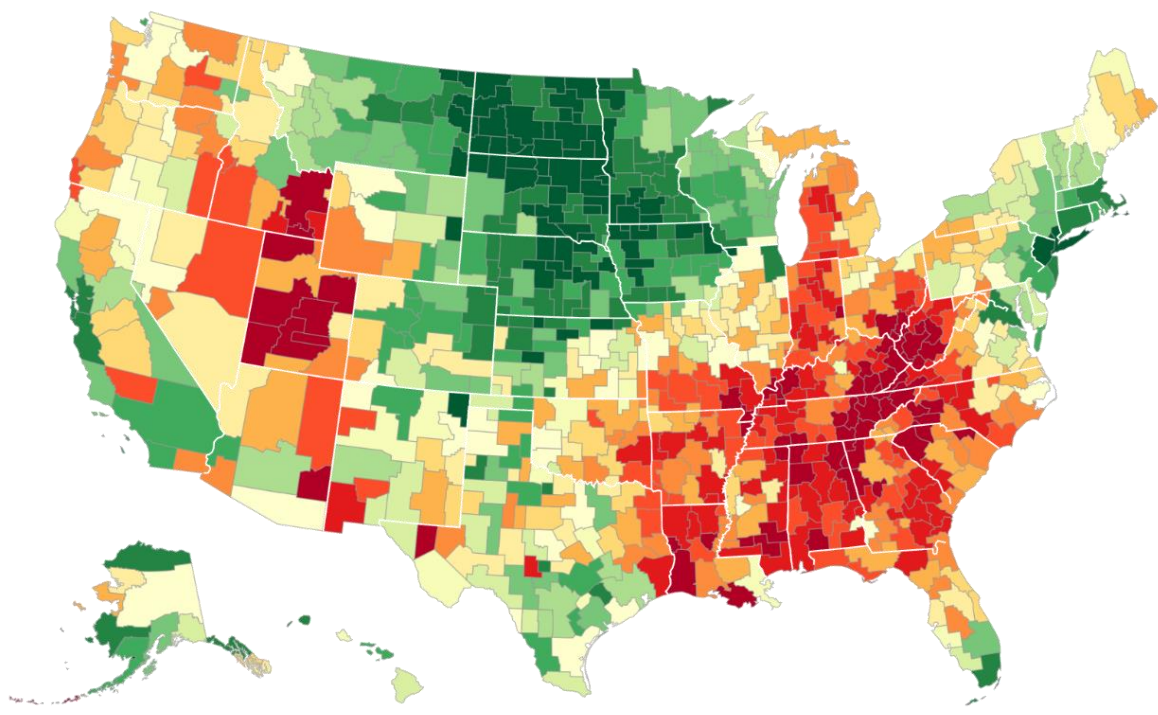

Mean Individual

Income Rank

$46.2(\$ 26 \mathrm{k})$

44.0

42.3

41.3

40.6

B. Black Females with Parents at 25th Percentile

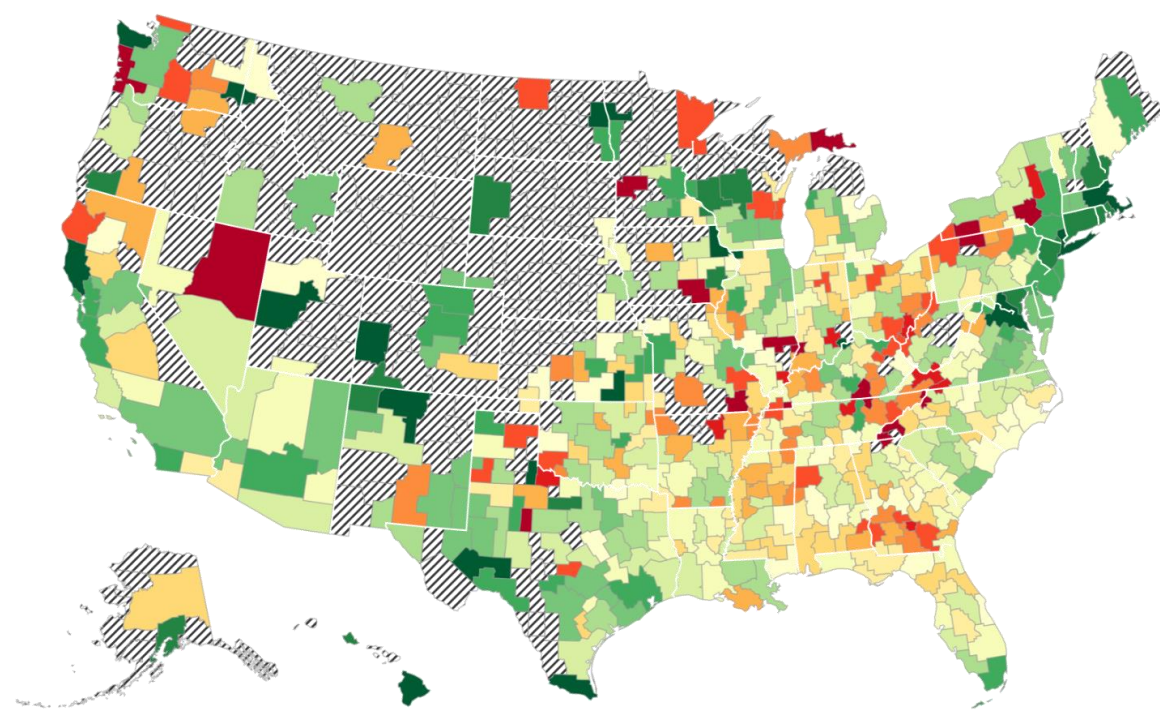

39.9

39.4

38.9 (\$20k)

38.4

37.9

37.2

36.5

35.8

$34.5(\$ 16 \mathrm{k})$

Insufficient

Data

These maps must be printed in color to be interpretable.

Notes: These figures replicate the maps in Figure IX for female children instead of male children. See notes to Figure IX for details. 
ONLINE APPENDIX FIGURE XII: The Geography of Mobility for Children with Parents at the 75th Percentile

A. White Males with Parents at 75th Percentile

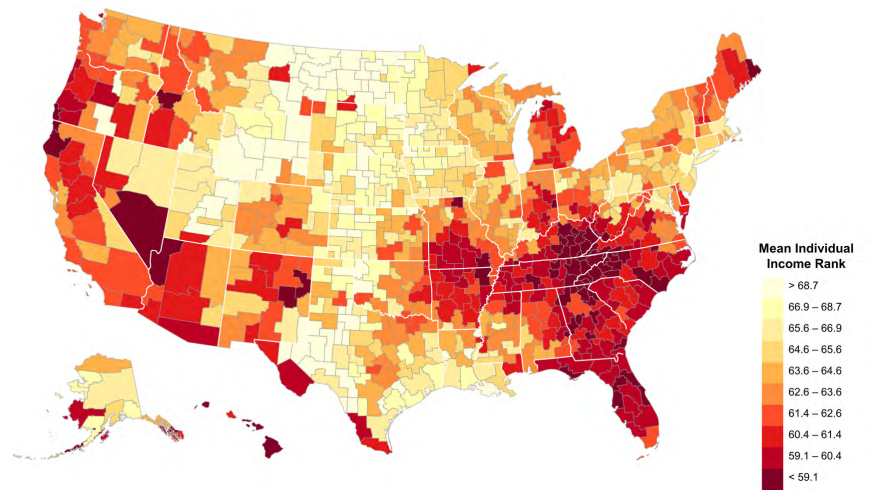

C. White Females with Parents at 75th Percentile

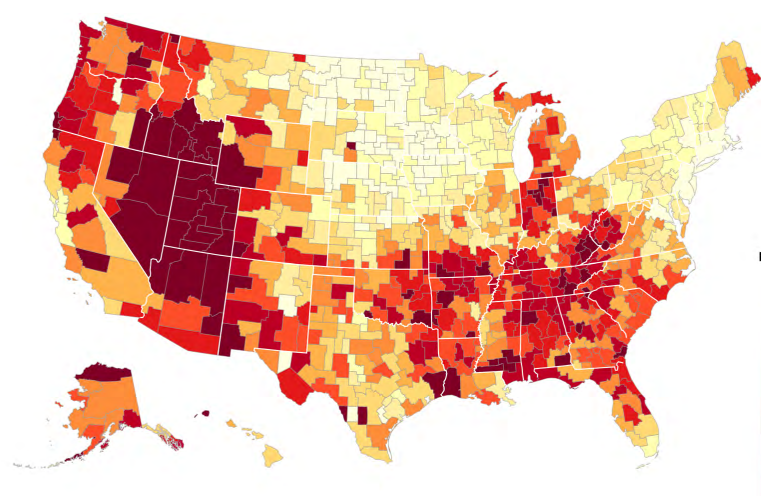

B. Black Males with Parents at 75th Percentile

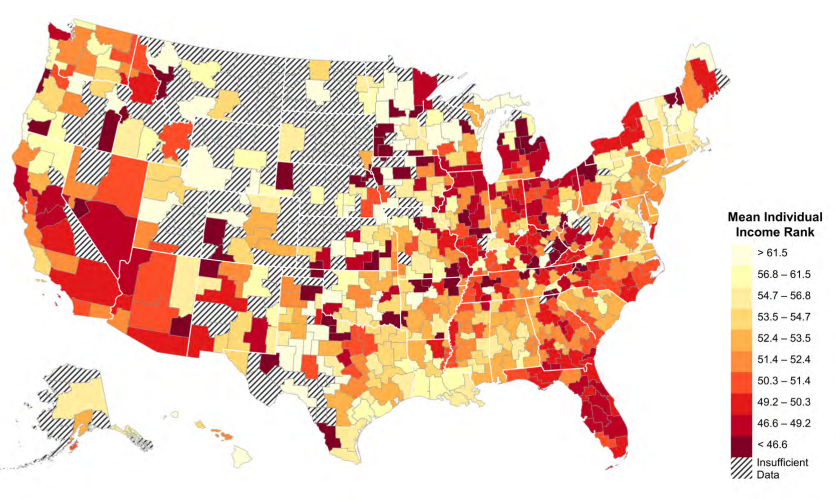

D. Black Females with Parents at 75th Percentile
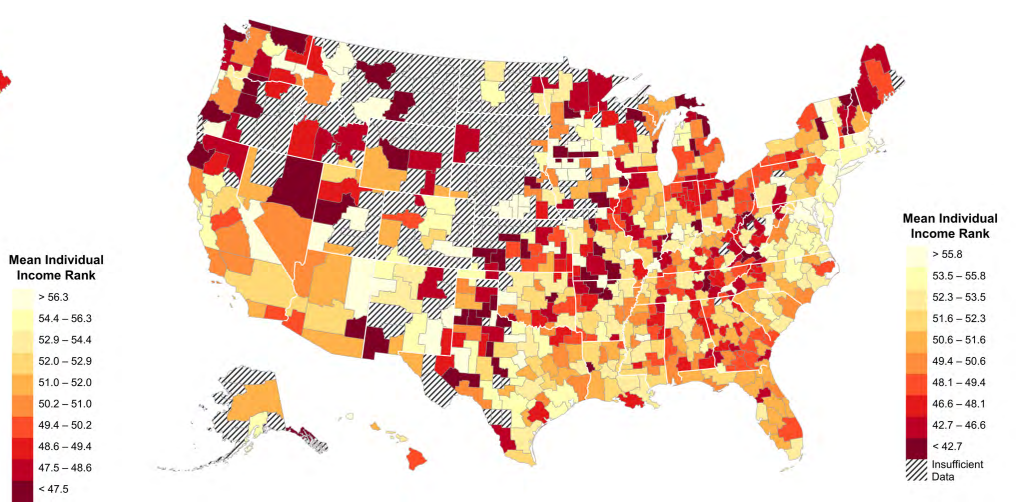

Notes: These figures replicate Figure IX and Appendix Figure X for black and white children with parents at the 75th percentile of the income distribution instead of the 25th percentile of the income distribution. For simplicity, each map is presented on a separate color scale, dividing CZs into ten (unweighted) deciles, with lighter colors representing areas with higher child incomes. See notes to Figure IX for further details on the construction of these maps. 
A. Hispanic Females with Parents at 25th Percentile

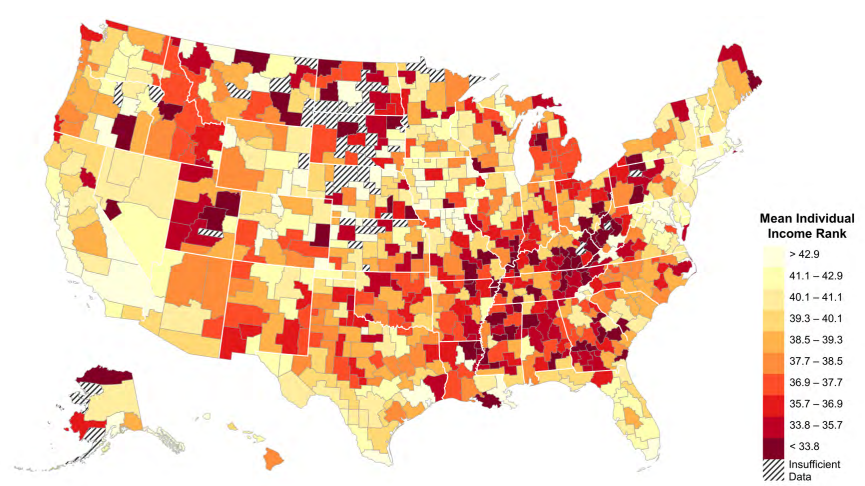

B. Hispanic Males with Parents at 25th Percentile

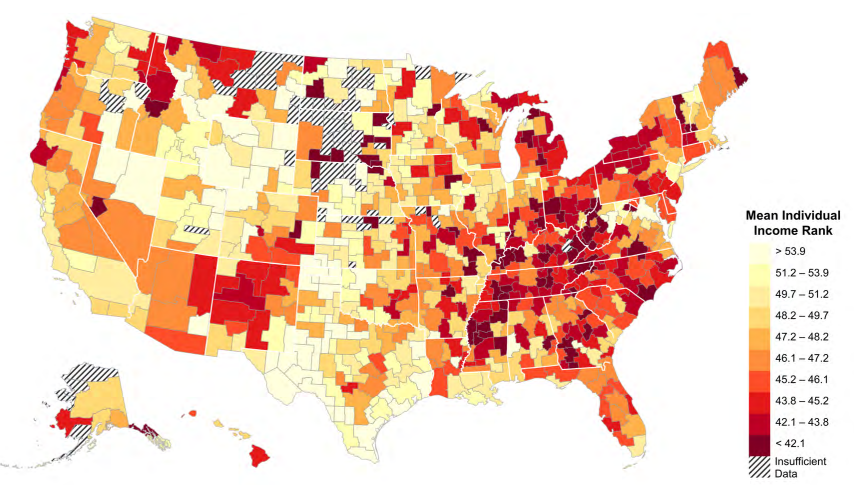

C. Hispanic Females with Parents at 75th Percentile

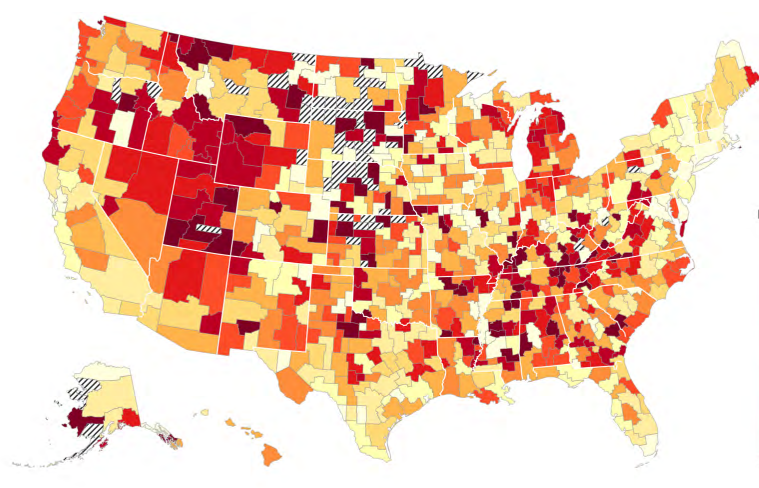

D. Hispanic Males with Parents at 75th Percentile
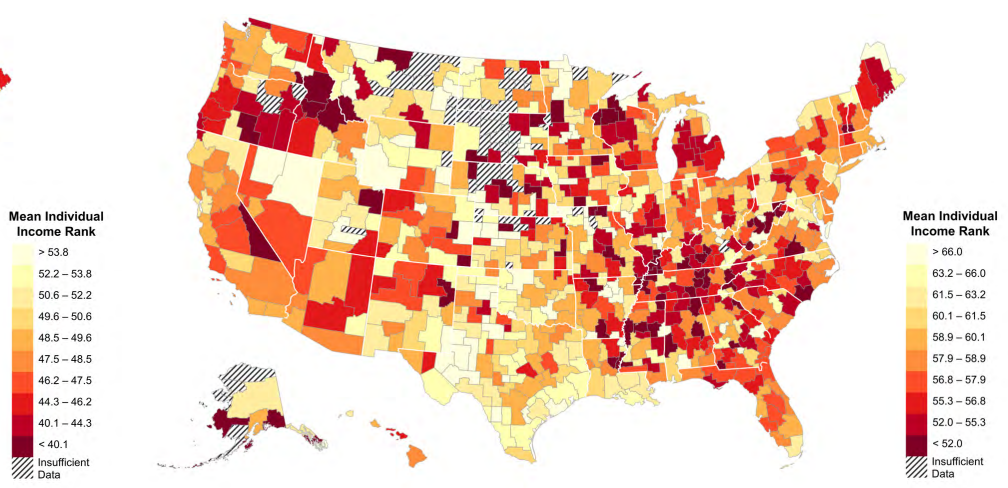

Notes: These figures reproduce the maps in Figure IX and the preceding Appendix Figures for Hispanic children. Panels A and B show the mean child individual income rank for Hispanic female and male children with parents at the 25 th percentile, respectively. Panels $\mathrm{C}$ and $\mathrm{D}$ show the same statistic for children with parents at the 75th percentile. For simplicity, each map is presented on a separate color scale, dividing CZs into ten (unweighted) deciles, with lighter colors representing areas with higher child incomes. See notes to Figure IX for further details on the construction of these maps. 


\section{ONLINE APPENDIX FIGURE XIV: Distribution of Black-White Gaps Across Tracts for Men}

A. Men with Parents at 25th Percentile

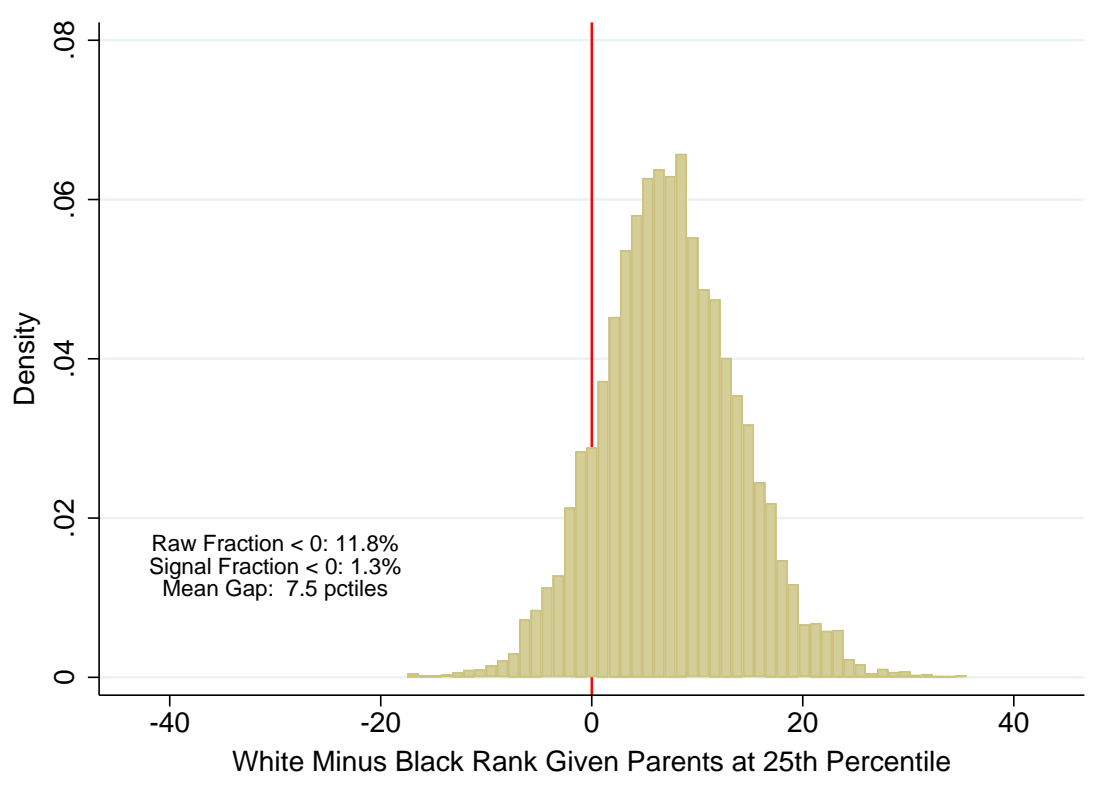

B. Men with Parents at 75th Percentile

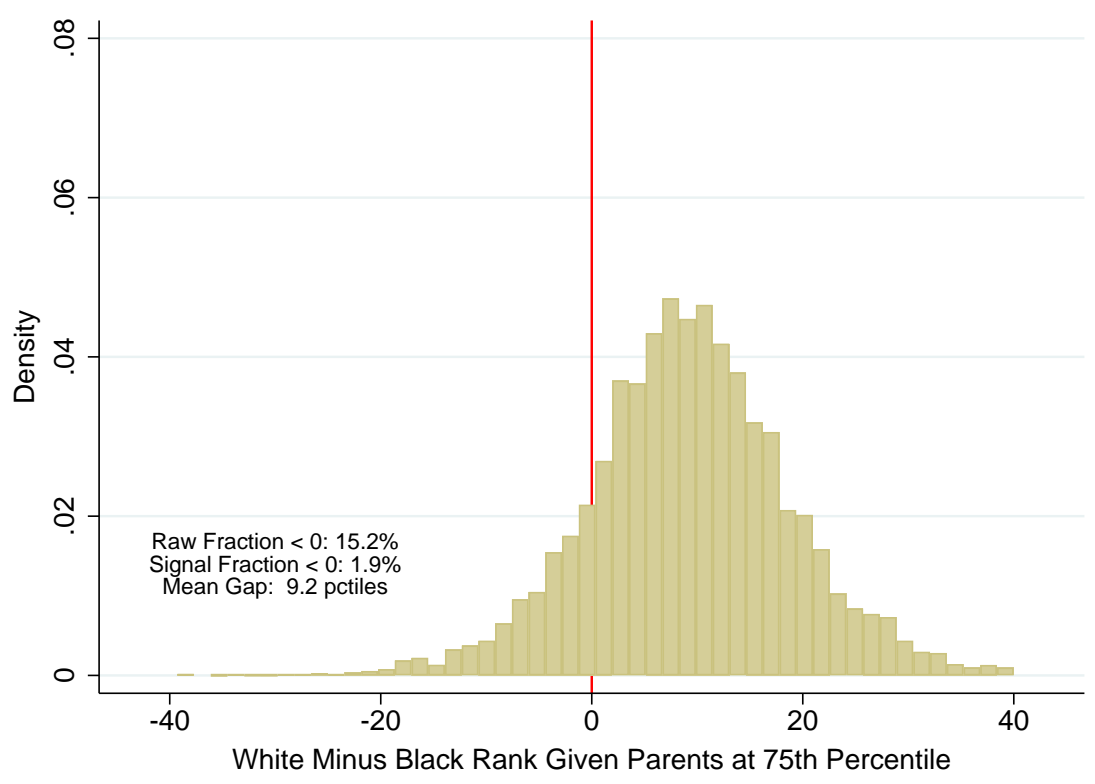

Notes: This figure plots the distribution of the black-white gap in upward mobility for men, conditional on parental income. Panel A plots the distribution of the black-white gap in upward mobility for men with parents at the 25th percentile. The distribution is weighted by the number of black male children in the tract, excluding Census tracts with fewer than 50 black or white male children. To construct upward mobility for a given race-gender group in tract $c$, we first regress children's individual income ranks on a constant and parent income rank, weighting by the number of years that each child is observed below age 23 in tract $c$. We then define upward mobility as the predicted value from this regression at the 25 th percentile of the parental income distribution. The figure also reports the mean black-white gap as well as estimates of the fraction of black males growing up in Census tracts where the predicted income rank for black males with parents at $\bar{p}=25$ is higher than that for white males. The raw estimate reports this fraction based on the empirical distribution itself (i.e., the plotted histogram), while the "signal" estimate adjusts this fraction for noise in the underlying predictions as described in the text. Panel B replicates Panel A for men with parents at the 75 th percentile. 
ONLINE APPENDIX FIGURE XV: Distribution of Black-White Gap in Individual Income Ranks for Women

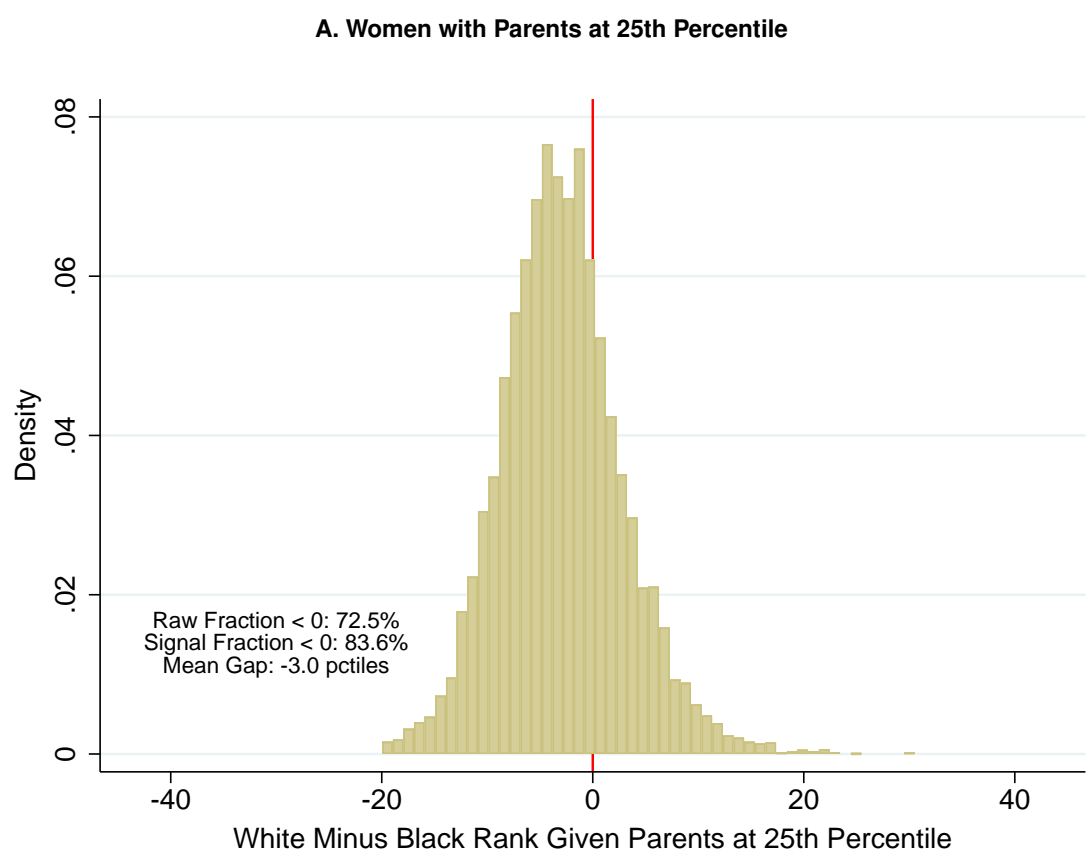

B. Women with Parents at 75th Percentile

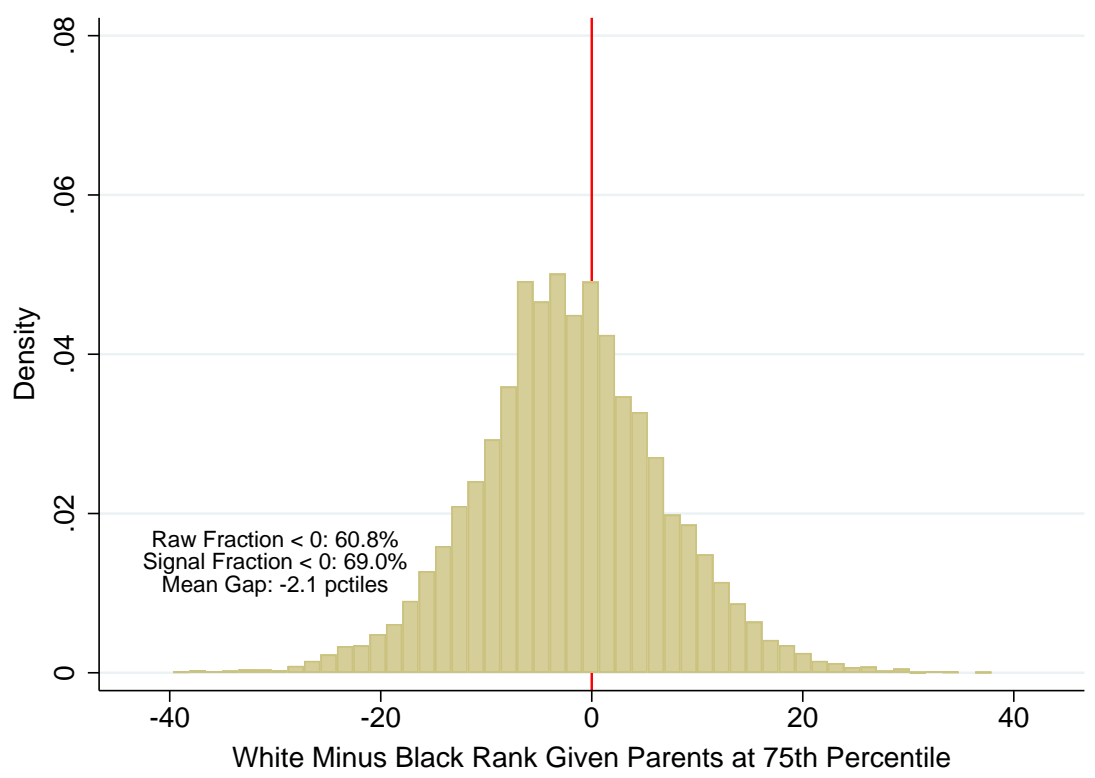

Notes: This figure replicates Online Appendix Figure XIV for females with parents at the 25th (Panel A) and 75th (Panel B) percentiles of the income distribution. See notes to Online Appendix Figure XIV for details. 
ONLINE APPENDIX FIGURE XVI: Fraction of Tracts with High Upward Mobility Rates for Black Men vs. Share above Poverty Line

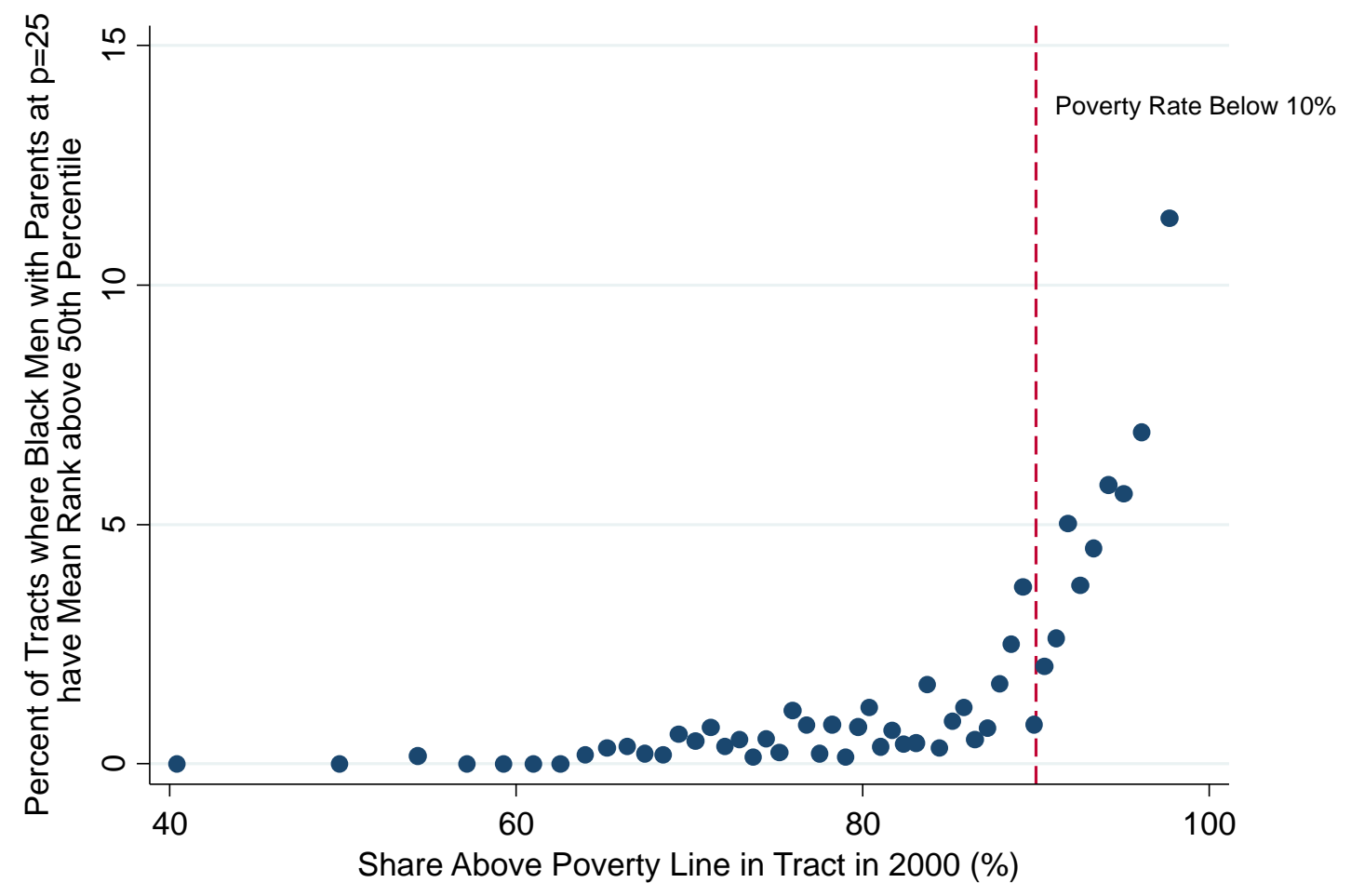

Notes: This figure presents a binned scatter plot of the fraction of Census tracts with high upward mobility rates for black men vs. the share of residents above the poverty line. A "high upward mobility" tract is defined as one in which the predicted rank of black males with parents at the 25 th percentile of the national parental income distribution is above the 50 th percentile of the national child income distribution. Predicted ranks are estimated using equation (6); see notes to Figure X for details. The sample for the figure consists of all tracts with at least 50 black men in the estimation sample. Tracts are grouped into 50 equal-sized bins, weighting by the number of black males in each tract. 